
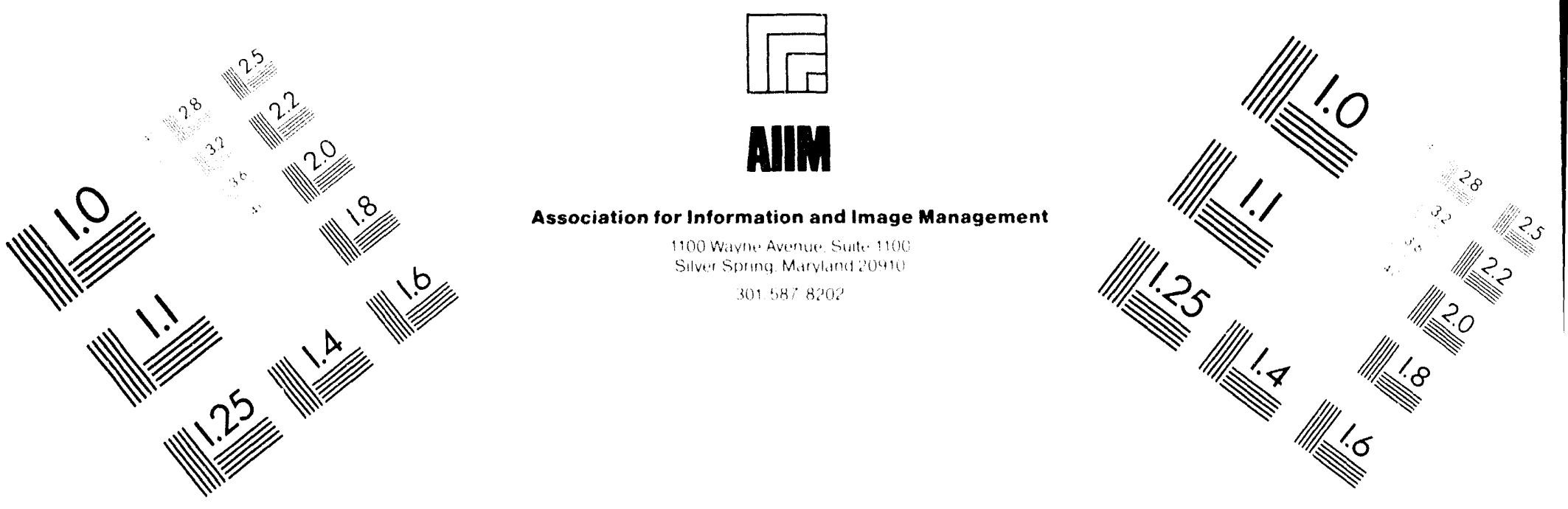

\title{
Centimeter
}

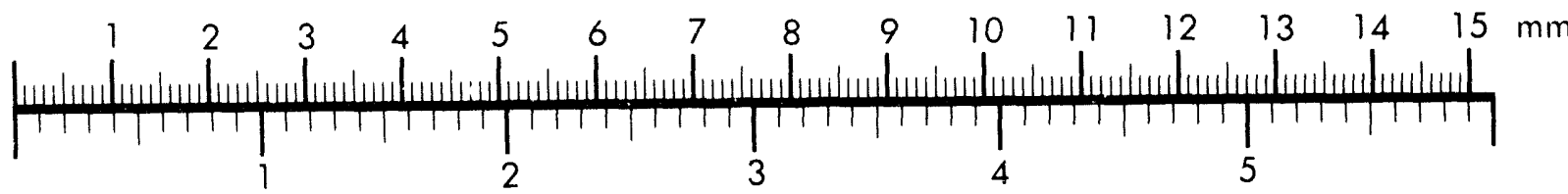

Inches
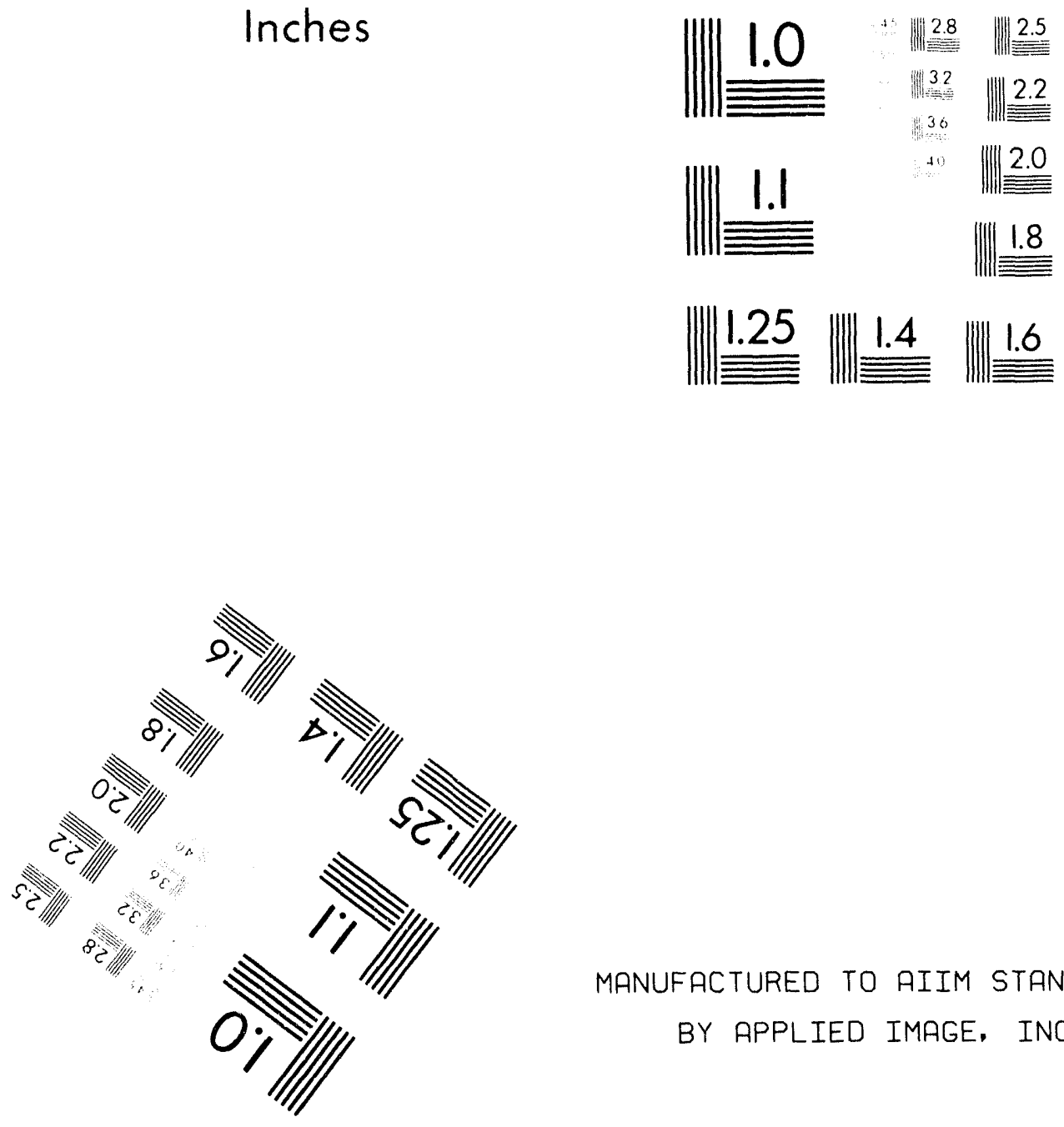

MANUFACTURED TO AIIM STANDARDS

BY APPLIED IMAGE. INC.

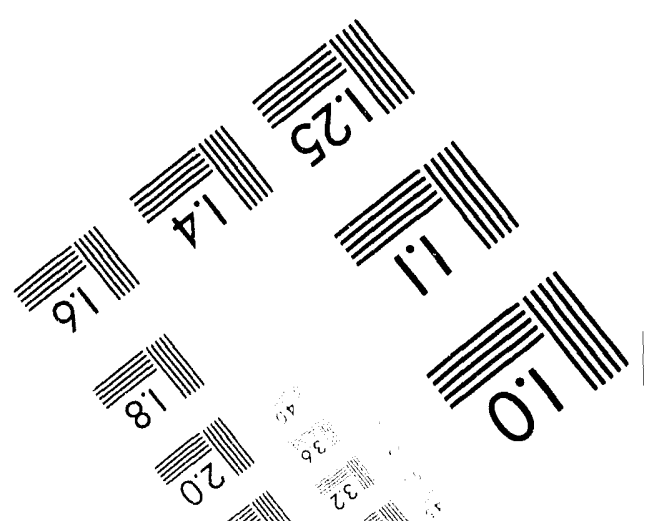



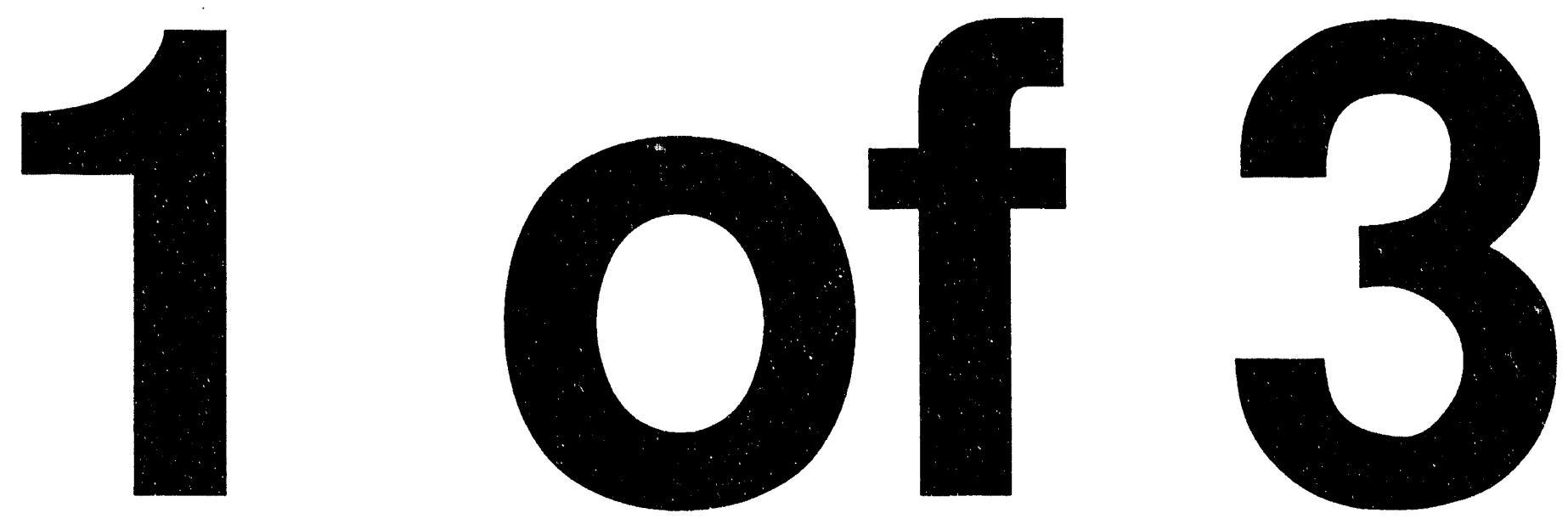


\title{
A STUDY OF THE INTERFACIAL CHEMISTRY OF PYRITE AND COAL IN FINE COAL CLEANING USING FLOTATION
}

\author{
By
}

Chengliang Jiang
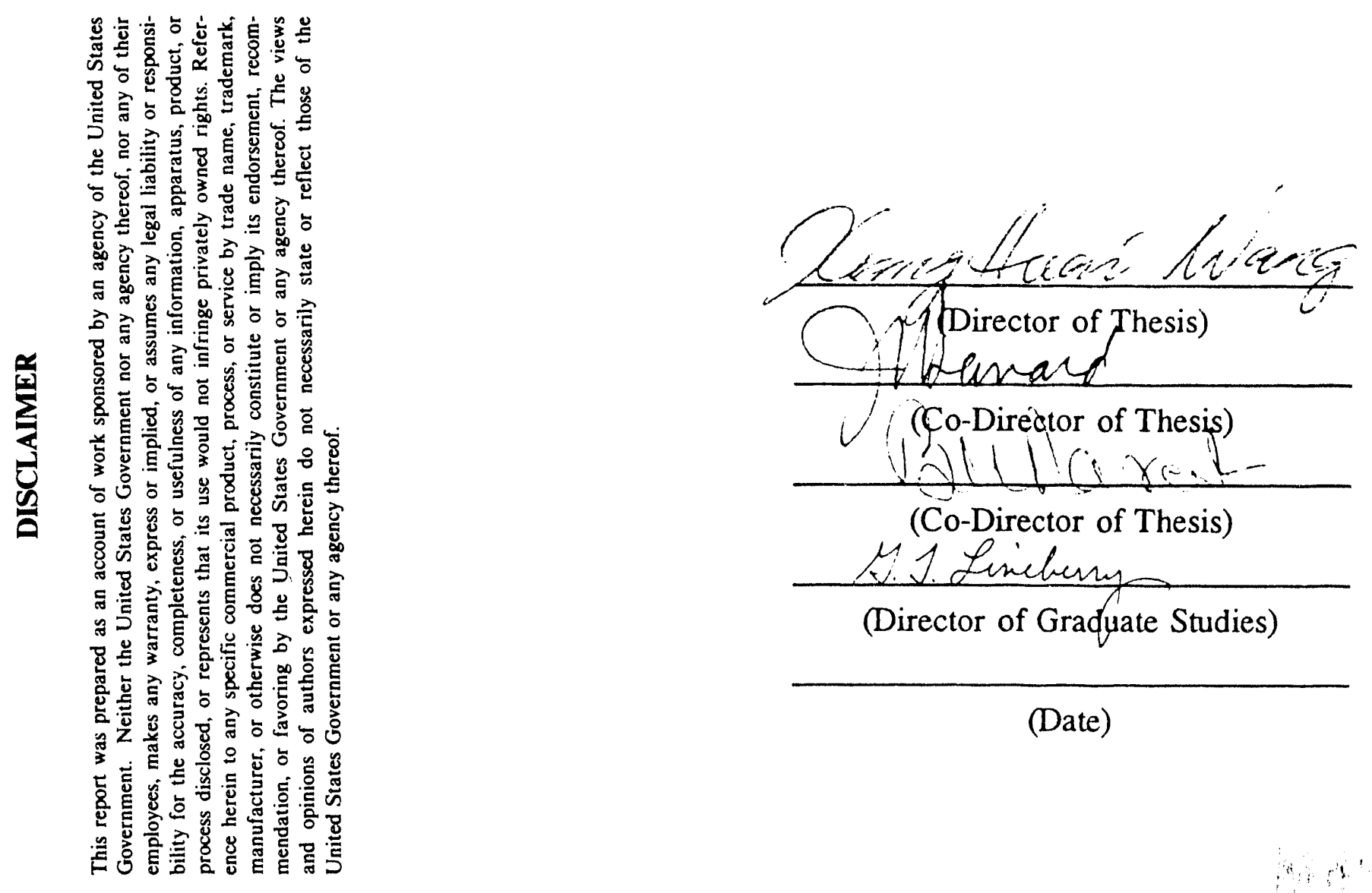

(Date) 


\section{ABSTRACT OF THESIS}

\section{A Study of the Interfacial Chemistry of Pyrite and Coal in Fine Coal Cleaning Using Flotation}

Surface oxidation, surface charge, and flotation properties have been systematically studied for coal, coal-pyrite and ore-pyrite. Electrochemical studies show that coal-pyrite exhibits much higher and more complex surface oxidation than ore-pyrite and its oxidation rate depends strongly on the carbon/coal content. Flotation studies indicate that pyrites have no self-induced floatability. Fuel oil significantly improves the floatability of coal and induces considerable flotation for coal-pyrite due to the hydrophobic interaction of fuel oil with the carbon/coal inclusions on the pyrite surface. Xanthate is a good collector for ore-pyrite but a poor collector for coal and coal-pyrite. The results from thermodynamic calculations, flotation and zeta potential measurements show that iron ions greatly affect the flotation of pyrite with xanthate and fuel oil. Various organic and inorganic chemicals have been examined for depressing coal-pyrite. It was found, for the first time, that sodium pyrophosphate is an effective depressant for coal-pyrite. Solution chemistry shows that pyrophosphate reacts with iron ions to form stable iron pyrophosphate complexes. Using pyrophosphate, the complete separation of pyrite from coal can be realized over a wide $\mathrm{pH}$ range at relatively low dosage.

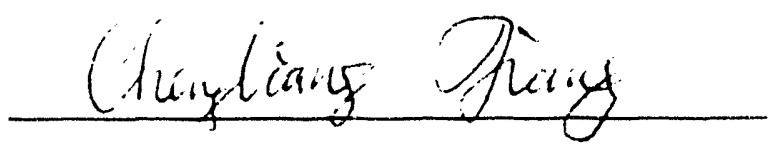

(Author's name)

$$
10 / 15 / 93
$$

(Date) 


\section{RULES FOR THE USE OF THESES}

Unpublished theses submitted for the Master's and Doctor's degrees and deposited in the University of Kentucky Library are as a rule open for inspection, but are to be used only with due regard to the rights of the authors. Bibliographical references may be noted, but quotations or summaries of parts may be published only with the permission of the author, and with the usual scholarly acknowledgements.

Extensive copying or publication of the thesis in whole or in part requires also the consent of the Dean of The Graduate School of the University of Kentucky.

A library which borrows this thesis for use by its patrons is expected to secure the signature of each user.

Name and Address

Date 
THESIS

Chengliang Jiang

The Graduate School

University of Kentucky

1993 


\section{A STUDY OF THE INTERFACIAL CHEMISTRY OF PYRITE AND COAL IN FINE COAL CLEANING USING FLOTATION}

\section{THESIS}

A thesis submitted in partial fulfillment of the requirements for the degree of Master of Science in Mining Engineering at The University of Kentucky

\section{By}

Chengliang Jiang

Lexington, Kentucky

Director: Dr. Xiang Huai Wang

Assistant Research Professor of Mining Engineering

Lexington, Kentucky 


\section{MASTER'S THESIS RELEASE}

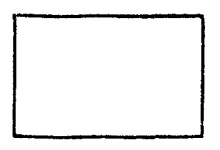

I authorize the University of Kentucky Libraries to reproduce this thesis in whole or in part for purpose of research.

I do not authorize the University of Kentucky Libraries to reproduce this thesis in whole or in part for purpose of research.

Signed:

Date: 


\section{ACKNOWLEDGEMENTS}

I would like to express my sincere appreciation to my advisor, Dr. Xiang-Huai Wang, for his guidance, valuable advice and constant encouragement throughout the course of this research.

Thanks are due to Prof. Joseph W. Leonard for his interest, advice and useful suggestions as well as to Dr. B.K. Parekh for his assistance, advice and many helpful discussions in regard to this work.

Thanks are also due to other members of my committee, Dr. G.T. Lineberry, Dr. R.J. Sweigard and Dr. P.J. Reucroft for their helpful suggestions and criticisms, and to the Department of Mining Engineering and the United States Department of Energy for the financial support.

I would like to acknowledge Dr. John G. Groppo. Jr. for his kind support and help during the experiments. My sincere thanks are extended to other members at the Center for Applied Energy Research.

The kind help from my fellow graduate students and staff at the Department 
of Mining Engineering is greatly appreciated.

Finally, I express my wholehearted and deepest appreciation to my wife, Xiaoli Liu for her love, sacrifice, encouragement and understanding through this period of graduate study. 


\section{TABLE OF CONTENTS}

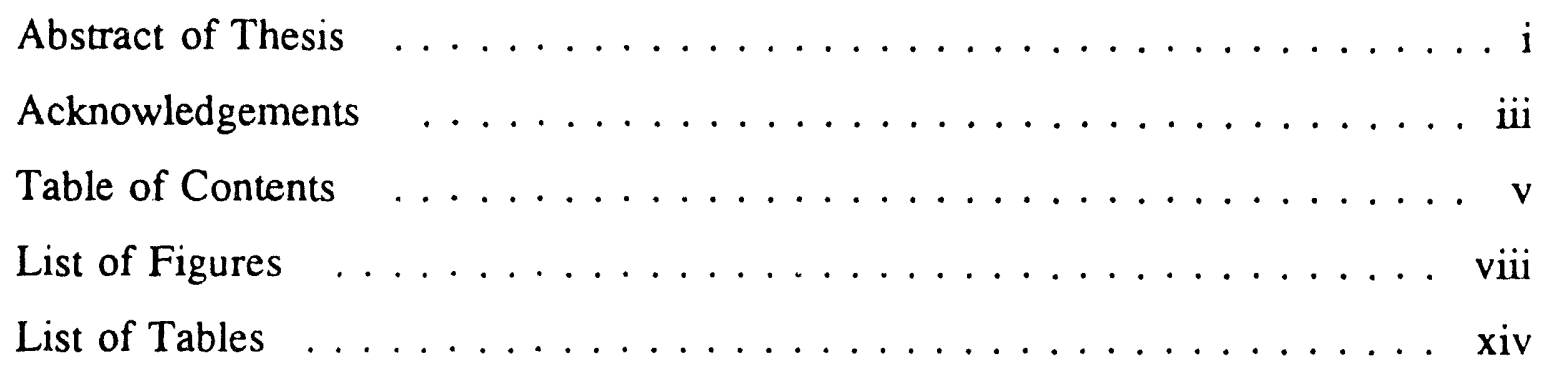

CHAPTER 1 INTRODUCTION $\ldots \ldots \ldots \ldots \ldots \ldots \ldots \ldots$

1.1 Objective and Scope of the Research ............. 5

1.2 Thesis Outline .................... 6

CHAPTER 2 BACKGROUND AND RELATED RESEARCH $\ldots \ldots \ldots$

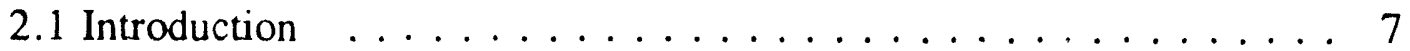

2.2 Fundamental Concepts of Electrochemistry . . . . . . . . 8

2.3 Electrical Properties of Surface . . . . . . . . . . . . . . 21

2.4 Surface Properties of Pyrite and Coal . . . . . . . . . . . 26

2.4.1 Surface Oxidation of Pyrite ............. 26

2.4.2 Hydrophobicity and Floatability of Pyrite and Coal . . . . 29

2.5 Froth Flotation . . . . . . . . . . . . . . 36

2.5.1 Direct Flotation . . . . . . . . . . 37

2.5.2 Reverse Flotation ... . . . . . . . . . . 40

2.5.3 Pyrite Flotation with Xanthate ........... 41

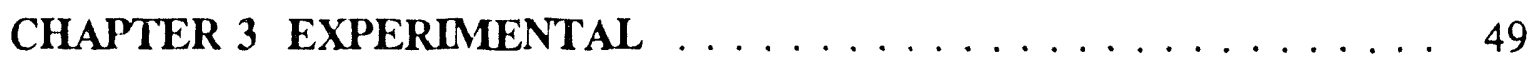

3.1 Materials and Reagents ... . . . . . . . . . . . . . . . 49 
3.2 Techniques and Procedures $\ldots \ldots \ldots \ldots \ldots \ldots \ldots \ldots$

3.2 .1 Flotation $\ldots \ldots \ldots \ldots \ldots \ldots \ldots \ldots \ldots \ldots$

3.2.2 Zeta-potential Measurements . . . . . . . . . . 54

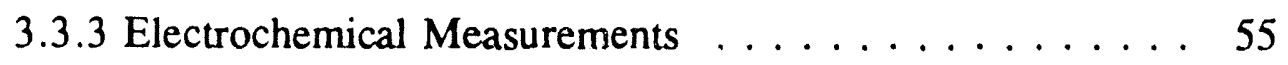

CHAPTER 4 RESULTS AND DISCUSSIONS $\ldots \ldots \ldots \ldots \ldots \ldots$

4.1 Self-Induced Flotation of Coal and Pyrites . . . . . . . . . 57

4.1.1 Effect of Ultrasonic Treatment on Self-Induced Flotation . 60

4.1.2 Effect of Acid Washing on Surface Charge . . . . . . . 62

4.2 Oil-Induced Flotation of Coal and Pyrites . . . . . . . 71

4.3 Flotation of Coal and Pyrites with Xanthate . . . . . . 85

4.3.1 Effect of Ultrasonic Treatment on Flotation with Xanthate 88

4.3.2 Effect of Iron Ions on Pyrite Flotation with Xanthate . . 92

4.3.3 Effect of Iron Ions and Xanthate on Surface Charge . . . 100

4.3.4 Thermodynamic Calculations on Pyrite Flotation

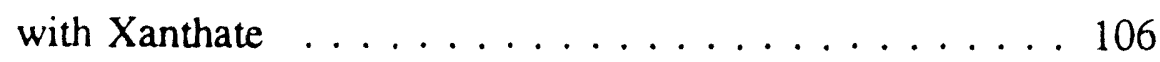

4.4 Pyrite Depressants in Coal Flotation . . . . . . . . . . 113

4.4.1 Organic Pyrite Depressants . . . . . . . . . . . 114

4.4.2 Inorganic Pyrite Depressants . . . . . . . . . . . . 115

4.5 Electrochemical Study of Surface Oxidation Pyrites . . . . . . . 130

4.5.1 Pyrite Oxidation in Acidic to Neutral Solutions . . . . . . 132

4.5.2 Pyrite Oxidation in Alkaline Solutions . . . . . . . . 140

CHAPTER 5 CONCLUSIONS AND RECOMMENDATIONS . . . . . . 150

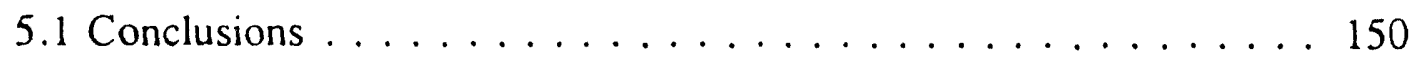

5.2 Recommendations . . . . . . . . . . . . . . 154 
REFERENCES

APPENDIX $\ldots \ldots \ldots \ldots \ldots \ldots \ldots \ldots \ldots \ldots \ldots$

ARTICLES/PRESENTATIONS . . . . . . . . . . . . . . . . 179

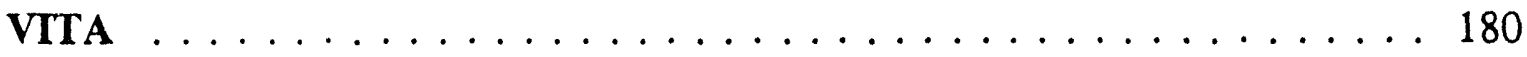




\section{LIST OF FIGURES}

Figure 2.1 I-E and corresponding logI-E characteristics for an irreversible electron transfer reaction $\ldots \ldots \ldots \ldots \ldots \ldots \ldots \ldots$

Figure 2.2 Variation of potential with time and current with potential in linear sweep voltammetry . . . . . . . . . . . . 19

Figure 2.3 Variation of potential with time and current with potential in cyclic

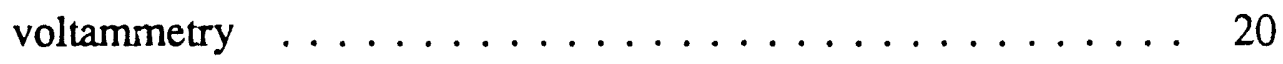

Figure 2.4 Schematic representation of the electrical double layer according to Stern's model . . . . . . . . . . . . . . . . . . . . . . . 23

Figure 2.5 Flotation recovery of pyrite as a function of $\mathrm{pH}$ in the presence of

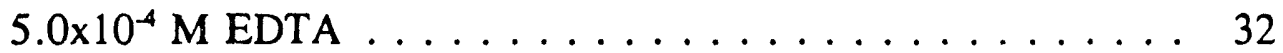

Figure 2.6 Flotation rate of pyrite at different EDTA concentrations . . . 33

Figure 2.7 Contact angle of coal-pyrite as a function of contact time under

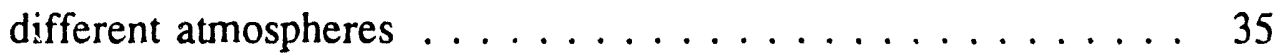

Figure 2.8 Recovery of pyrite as a function of flotation $\mathrm{pH}$ with various additions

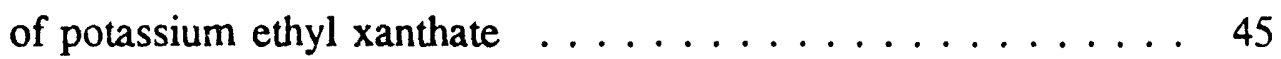

Figure 2.9 Recovery of pyrite as a function of flotation $\mathrm{pH}$ with $1.3 \times 10^{-5} \mathrm{M}$ diethyl dixanthogen .................. 46

Figure 3.1 Schematic representation of microflotation cell $\ldots \ldots \ldots 53$

Figure 4.1 Floatabilities of coal for different particle sizes as a function of solution $\mathrm{pH}$ in the presence of MIBC $\ldots \ldots \ldots \ldots \ldots$

Figure 4.2 Flotation recovery as a function of solution $\mathrm{pH}$ for coal, coal- and orepyrite in the presence of MIBC after surface cleaning by ultrasonication $\ldots \ldots \ldots \ldots \ldots \ldots \ldots \ldots \ldots \ldots$ 
Figure 4.3 The zeta potential of ore-pyrite as a function of solution $\mathrm{pH}$ with and without acid washing .................. 64

Figure 4.4 The zeta potential of ore-pyrite as a function of solution $\mathrm{pH}$ in the absence and presence of ferrous and ferric ions . . . . . . . 65

Figure 4.5 The zeta potential of coal-pyrite as a function of solution $\mathrm{pH}$ with and without acid washing .................. 67

Figure 4.6 The zeta potential of coal as a function of solution $\mathrm{pH}$ with and without

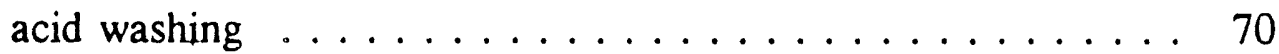

Figure 4.7 Flotation recovery of coal as a function of solution $\mathrm{pH}$ and particle size in the presence of fuel oil as collector . . . . . . . . . . . 72

Figure 4.8 Flotation recovery of coal-pyrite as a function of solution $\mathrm{pH}$ and particle size in the presence of fuel oil as collector . . . . . . 73

Figure 4.9 Flotation recovery of ore-pyrite as a function of solution $\mathrm{pH}$ and particle size in the presence of fuel oil as collector . . . . . . 74

Figure 4.10 Effect of particle size on the floatability of coal- and ore-pyrite in the presence of fuel oil as collector . . . . . . . . . . . 76

Figure 4.11 Comparison of flotation recovery of fine coal, coal- and ore-pyrite as a function of solution $\mathrm{pH}$ in the presence of fuel oil . . . . . . 78

Figure 4.12 The bulk flotation recovery of coal and coal-pyrite mixture as a function of coal/pyrite ratio in the presence of fuel oil . . . . 79

Figure 4.13 Comparison of flotation recovery of coarse coal, coal- and ore-pyrite as a function of solution $\mathrm{pH}$ in the presence of fuel oil . . . . 82

Figure 4.14 Flotation recovery as a function of solution $\mathrm{pH}$ for coal, coal- and orepyrite in the presence of fuel oil after ultrasonic treatment . . . 83

Figure 4.15 Flotation recovery of ore-pyrite as a function of solution $\mathrm{pH}$ and particle size in the presence of ethyl xanthate as collector . . . 86 
Figure 4.16 Flotation recovery of coal-pyrite as a function of solution $\mathrm{pH}$ and particle size in the presence of ethyl xanthate as collector . . . 87

Figure 4.17 Flotation recovery of coal as a function of solution $\mathrm{pH}$ and particle size in the presence of ethyl xanthate as collector . . . . . . . . 89

Figure 4.18 Comparison of flotation recovery of coal, coal- and ore-pyrite as a function of solution $\mathrm{pH}$ in the presence of ethyl xanthate as collector .......................... 90

Figure 4.19 Comparison of flotation recovery of coal, coal- and ore-pyrite as a function of $\mathrm{pH}$ in the presence of ethyl xanthate as collector after ultrasonic treatment ................... . . 91

Figure 4.20 Effect of ferric ions and reagent addition order on the floatability of ore-pyrite as a function of solution $\mathrm{pH}$ using ethyl xanthate as

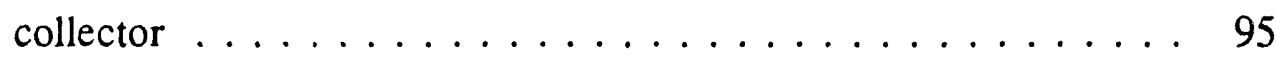

Figure 4.21 Effect of ferrous ions and reagent addition order on the floatability of ore-pyrite as a function of solution $\mathrm{pH}$ using ethyl xanthate as

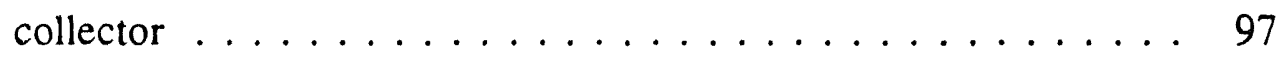

Figure 4.22 The effect of ferrous ion concentration on the flotation behavior of orepyrite in the presence of ethyl xanthate as collector . . . . . 998

Figure 4.23 The zeta potential of ore-pyrite as a function of solution $\mathrm{pH}$ in the absence and presence of ethyl xanthate ........... . . 101

Figure 4.24 The zeta potential of coal-pyrite as a function of solution $\mathrm{pH}$ in the absence and presence of ethyl xanthate ........... 102

Figure 4.25 The zeta potential of coal as a function of solution $\mathrm{pH}$ in the absence and presence of ethyl xanthate $\ldots \ldots \ldots 103$

Figure 4.26 Effect of ferric ions on the zeta potential of ore-pyrite as a function of solution $\mathrm{pH}$ in the absence and presence of ethyl xanthate . . . 105

Figure 4.27 Effect of ferrous ions on the zeta potential of ore-pyrite as a function 
of solution $\mathrm{pH}$ in the absence and presence of ethyl xanthate . . 107

Figure 4.28 $\log ($ Concentration)-pH distribution diagram for iron-ethyl xanthate system at $\mathrm{pe}=3$ for total concentration of $3.3 \times 10^{-4} \mathrm{M}$ xanthate and $2 \times 10^{-3} \mathrm{M}$ iron ........................ 110

Figure 4.29 $\log ($ Concentration)-pH distribution diagram for iron-ethyl xanthate system at pe $=3$ for total concentration of $3.3 \times 10^{-4} \mathrm{M}$ xanthate and $1 \times 10^{-2} \mathrm{M}$ iron . . . . . . . . . . . . . 111

Figure 4.30 Effect of sodium oxalate on the flotation separation of coal and coalpyrite in the presence of fuel oil ............. 116

Figure 4.31 Effect of sodium silicate on the flotation separation of coal and coalpyrite in the presence of fuel oil . . . . . . . . . 117

Figure 4.32 Effect of sodium phosphate on the flotation separation of coal and coalpyrite in the presence of fuel oil . . . . . . . . . . . 119

Figure 4.33 Effect of sodium pyrophosphate on the flotation separation of coal and coal-pyrite in the presence of fuel oil . . . . . . . . 121

Figure 4.34 Flotation recovery of coal and coal-pyrite as a function of solution $\mathrm{pH}$ in the absence and presence of sodium pyrophosphate using fuel oil as collector ......................... 122

Figure 4.35 Log(Concentration)-pH distribution diagram of the $\mathrm{Fe}(\mathrm{III})$-phosphate system for main species at total concentration of $1 \times 10^{-4} \mathrm{M} \mathrm{Fe}(\mathrm{III})$ and $1 \times 10^{-4} \mathrm{M}$ phosphate . . . . . . . . . . . . 125

Figure 4.36 Log(Concentration)-pH distribution diagram of the $\mathrm{Fe}(\mathrm{III})$-phosphate system for main species at total concentration of $1 \times 10^{-4} \mathrm{M} \mathrm{Fe}$ (III) and $1 \times 10^{-3} \mathrm{M}$ phosphate ................... 126

Figure 4.37 Log(Concentration)-pH distribution diagram of the $\mathrm{Fe}(\mathrm{III})$ pyrophosphate system for main species at total concentration of $1 \times 10^{-4}$ $\mathrm{M} \mathrm{Fe}(\mathrm{III})$ and $1 \times 10^{-4} \mathrm{M}$ pyrophosphate . . . . . . . 128 
Figure 4.38 $\log ($ Concentration)-pH distribution diagram of the $\mathrm{Fe}(\mathrm{III})$ pyrophosphate system for main species at total concentration of $1 \times 10^{-4}$ M Fe(III) and $2 \times 10^{-4}$ M pyrophosphate . . . . . . . . . . . 129

Figure 4.39 Cyclic voltammograms of the ore-pyrite (PUPY) electrode under stationary and rotation conditions at $\mathrm{pH}=5.6 \ldots \ldots \ldots 133$

Figure 4.40 Cyclic voltammograms of the purer coal-pyrite (KYPY1) electrode under stationary and rotation conditions at $\mathrm{pH}=5.6 \ldots \ldots 137$

Figure 4.41 Cyclic voltammograms of the moderately coal/carbon-contaminated coal-pyrite (KYPY2) electrode under stationary and rotation conditions at $\mathrm{pH}=5.6 \ldots \ldots \ldots \ldots \ldots \ldots \ldots$

Figure 4.42 Cyclic voltammograms of the highly coal/carbon-contaminated coalpyrite (KYPY) electrode under stationary and rotation conditions at $\mathrm{pH}=5.6 \ldots \ldots \ldots \ldots \ldots$

Figure 4.43 Cyclic voltammograms of the ore-pyrite (PUPY) electrode under stationary and rotation conditions at $\mathrm{pH}=11 \ldots \ldots \ldots$. . . . 142

Figure 4.44 Linear sweep voltammograms of the ore-pyrite (PUPY) at different rotation speed at $\mathrm{pH}=10 \ldots \ldots \ldots \ldots \ldots$

Figure 4.45 Limiting current density of peak (I) as a function of the square root of rotation speed for ore-pyrite (PUPY) electrode at $\mathrm{pH}=10 \ldots 144$

Figure 4.46 Cyclic voltammograms of the purer coal-pyrite (KYPY1) electrode under stationary and rotation conditions at $\mathrm{pH}=11 \ldots \ldots \ldots$

Figure 4.47 Cyclic voltammograms of the moderately coal/carbon-contaminated coal-pyrite (KYPY2) electrode under stationary and rotation conditions

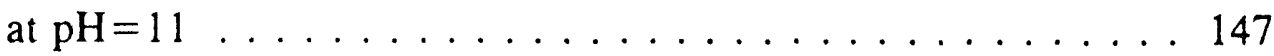

Figure 4.48 Cyclic voltammograms of the highly coal/carbon-contaminated coalpyrite (KYPY) electrode under stationary and rotation conditions at $\mathrm{pH}=11 \ldots \ldots \ldots \ldots \ldots \ldots \ldots \ldots$ 


\section{LIST OF TABLES}

Table 3.1 Analysis results of Kentucky No.9 coal . . . . . . . . . 50

Table 3.2 Chemical analysis results of pyrite samples used in the study . . 50

Table 4.1 Complexation constants of phosphates with metal ions . . . . . 124 


\section{CHAPTER 1}

\section{INTRODUCTION}

Coal is one of the most important energy resources in the United States. More than half of the national energy input for electric power generation comes from coal. With the decline of oil resources, coal will play a more dominant role in providing for future energy supply. Thus, the need to produce clean coal will continue to increase.

However, the high sulfur content of many coals imposes severe limitations on their effective utilization, since the sulfur oxide gases resulting from the combustion of coal can cause serious environmental problems such as acid rain. The 1990 Clean Air Act has strict standards on the sulfur dioxide emissions to the atmosphere, and poses an immense challenge to the coal industry. It requires that by the year 1995 , sulfur dioxide emission must be reduced to $2.5 \mathrm{lb} / \mathrm{MM} 3$ tu at large power plants, and to $1.2 \mathrm{lb} / \mathrm{MMBtu}$ at all the power plants by the year 2000 . In order to meet these new standards, the most popular options are installing scrubbers and switching to low sulfur coal. Since installing scrubbers is very costly, switching to low sulfur coals is 
generally preferred. Therefore, the increased demand for low sulfur coal in the future will motivate coal mines to increase the production of compliance coal using low cost pre-combustion cleaning technologies.

Sulfur in coal exists either in the inorganic form, which is mainly through the inclusions of pyrite, or in the organic form mainly through mercaptans and thiophenes, which is covalently bonded into the coal structure. Advanced coal cleaning processes are intended to both increase utilization and to help solve the sulfur dioxide emission problem. Sulfur in coal can be removed by chemical, biological and physical coal cleaning methods. Chemical coal cleaning methods effectively remove most of the ash and inorganic sulfur and part of the organic sulfur. Although this method seems promising, it is only in the early stage of laboratory development and the operating cost of the process is very high. Biological coal cleaning techniques are mainly limited to the bioleaching of the inorganic sulfur and some of the organic sulfur. The slow rate of sulfur extraction by bacterial oxidation and the treatment of the wastes generated during the process make the cost of the biological methods prohibitively high. In most of the U.S. high-sulfur coals, roughly half of the total sulfur is due to pyritic sulfur (Yoon, 1991). These coals can be cleaned to meet the sulfur dioxide emission control standards by the complete removal of the pyrite sulfur. Since the pyrite is present as discrete inclusions, it is amenable to remove the pyrite particles from the coal by advanced physical separation techniques, such as 
flotation, oil agglomeration, gravity and electrostatic separation. Physical separation is less expensive than chemical techniques, and has shown the potential for producing super-clean coal.

Physical coal cleaning techniques require that the feed coal is ground to a fine size where the pyrite is sufficiently liberated from the coal. However, most of the pyrite is so finely disseminated in coal that ultra-fine grinding is needed. Such fine pyrite particles cannot be effectively removed from coal by conventional physical separation methods. The most effective processes for separation of very fine particles are those based on differences in surface chemistry. Froth flotation is the only commonly used method based on surface chemistry to remove pyritic sulfur from coals finer than -200 mesh $(-74 \mu \mathrm{m})$ (Aplan and Arnold, 1991). It is particularly applicable to coal, as coal particles are naturally hydrophobic and therefore readily attach to air bubbles. However, conventional flotation is insufficiently selective to prevent flotation of the fine pyrite along with the coal. Although many effective methods have been developed for pyrite rejection from other sulfide and oxide minerals in ore flotation, attempts to transfer such technologies to coal flotation have not been satisfactory. For instance, it is shown that coal-pyrite is much more difficult to depress than ore-pyrite, and good ore-pyrite depressants usually do not effectively depress coal-pyrite. 
The reasons for the difficulties in rejecting coal-pyrite from coal are extremely complex and have not been well studied. Coal-pyrite differs in many aspects from ore-pyrite. In fact, the flotation properties of coal-pyrite vary greatly among different coal seams and even within the same coal seam. In-situ coal-pyrite basically exists in the form of porous grains, granular masses, plant cell imprint fillings and framboids, and as such is remarkably different from crystalline ore-pyrite. Due to the particular geological conditions of coal formation, in-situ coal-pyrite usually contains considerable amounts of carbon and organic materials. Such differences in particle morphology cause coal-pyrite to have a much higher surface area, solubility and reactivity than ore-pyrite. Therefore, coal-pyrite shows distinct differences in surface and flotation properties from ore-pyrite.

Surface properties, including oxidation, dissolution, and adsorption of various chemicals, determine the surface hydrophobicity and flotation behavior of pyrite. Although much work has been conducted on the flotation and surface chemistry of ore-pyrite, the corresponding research on coal-pyrite is unremarkable. Therefore, extensive studies on the flotation and surface properties on coal-pyrite are urgently needed. It is also very important to compare the flotation and surface chemistry of pyrites from coal and ore sources. Such studies will help identify the causes and possible solutions of coal-pyrite rejection problems. 


\subsection{Objective and Scope of the Research}

The objective of the present research work is to study the fundamental surface and flotation properties of coal, coal-pyrite and ore-pyrite by means of a number of techniques, including electrochemistry, microflotation, and zeta-potential measurement.

The scope of this research work includes the investigations of the surface oxidation behavior of pyrites from ore and coal sources by using electrochemical voltammetry techniques. The floatabilities of coal, coal-pyrite and ore-pyrite have been systematically examined by microflotation tests under various kinds of conditions, such as collector type, particle size, solution $\mathrm{pH}$, surface cleaning, effect of metal ions, etc. A detailed study of the effect of ferrous and ferric ions on the flotation of pyrites has been made. Different kinds of pyrite depressants have been investigated to improve the selectivity of coal flotation. Zeta-potential experiments have also been were conducted to study the surface electrical properties in order to elucidate the different flotation behavior of coal and pyrites. 


\subsection{Thesis Outline}

Chapter 2 of this thesis is directed at reviewing the fundamental aspects of surface chemistry, flotation behavior of ore-pyrite, coal-pyrite and coal. Chapter 3 describes in detail the materials, research facilities/equipment, procedures and data analysis techniques used in the study. Chapter 4 is organized to discuss the results obtained from the electrochemical, flotation, and zeta potential measurements. A new and effective depressant for pyrite has been found, and the mechanism underlying the new depressant was also studied in terms of solution chemistry. The interaction of pyrite with xanthate has been systematically characterized. Chapter 5 presents conclusions derived from this research work, and gives recommendations which may be used as a guide for future studies. It hopes that the present work in this study will not only contribute to a better understanding to the fundamental interfacial chemistry of pyrite and coal in flotation, but also help develop new technology for coal desulfurization. 


\section{CHAPTER 2}

\section{BACKGROUND AND RELATED RESEARCH}

\subsection{Introduction}

Coal preparation is the process that removes the associated impurities, such as ash and sulfur, from coal. Fine coal cleaning has grown in importance due to the increased production of coal fines by current mining method, the uncertainty over other energy sources, and strict environmental regulations. The removal of pyritic sulfur is a major problem in fine coal cleaning. Flotation is the most important technique for removing pyritic sulfur from coal.

Coal flotation is a physical separation method based on differences in the surface properties of coal and associated impurities. However, due to the ambivalent hydrophobic and hydrophilic properties of pyrite, effective removal of pyritic sulfur from coal has been difficult, especially when the particle size becomes very fine. Many surface factors such as oxidation, electrical properties, hydrophobicity, etc. can affect the flotation of pyrite and coal. 
In this chapter, the fundamental aspects of the surface properties and the principle of related measurement methods will be discussed. The surface oxidation, surface hydrophobicity, and flotation of pyrite and coal will be studied along with a brief review of related literature.

\subsection{Fundamental Concepts of Electrochemistry}

Many kinds of electrochemical reactions occur in the flotation system of sulfide minerals. These reactions may involve sulfide minerals, as well as dissolved oxygen and flotation reagents, etc. Pyrite is the most noble sulfide mineral and the electrochemical behavior of pyrite significantly affects its surface properties and interactions with other minerals and reagents. In this section, the principles of electrochemistry and the commonly used techniques will be briefly discussed.

\subsubsection{Electrochemical Cell}

The most common method to study the surface electrochemical properties of sulfide minerals is to make the mineral crystal into an electrode, which is generally called the working electrode. The potential of the working electrode is applied against a reference electrode. Theoretically, the reference electrode is a standard hydrogen electrode (SHE), the potential of which is set at zero for all temperatures. Practically, 
a saturated calomel electrode (SCE) is the most commonly used reference electrode due to its working stability and reliability. SCE potential is correlated with the SHE potential by the following relationship:

$$
E_{S C E}=E_{S H E}-245(m V)
$$

If there is no current flow through the electrode, the measured potential is called the rest potential or mixed potential of the mineral. When a current passes through the electrode, electrochemical reactions occur on the electrode surface. In such a case, a third electrode is introduced as a counter electrode. Current is controlled to flow only between the working and counter electrode while no current should pass through the reference electrode. The potential of the mineral electrode is still measured with respect to the reference electrode. Such a three electrode system has been widely used to study the electrochemical behavior involving sulfide minerals. There are two main electrode reactions, i.e. electron transfer and mass transport, which are discussed briefly as follows.

\subsubsection{Electron Transfer Reaction}

An electrode reaction is a heterogeneous chemical process involving the transfer of electrons to or from the surface of a metal or a semiconductor. The reaction can be an anodic process whereby a species is oxidized by the loss of 
electrons to the electrode, e.g.

$$
2 \mathrm{H}_{2} \mathrm{O} \rightarrow \mathrm{O}_{2}+4 \mathrm{H}^{+}+4 e
$$

The current density, I, for an anodic process is a positive quantity by convention. Alternatively, the reaction can be a cathodic reaction in which a species is reduced by the gain of electrons from the electrode, e.g.

$$
2 \mathrm{H}_{2} \mathrm{O}+2 e \rightarrow \mathrm{H}_{2}+2 \mathrm{OH}^{-}
$$

The current density for a cathodic process is a negative quantity. The current through the external circuit, $i$, is related to current density by $i=A I$, here $A$ is the electrode surface area.

The basic electrochemical principles can be examplified by considering the following redox process which occurs on an inert metal electrode:

$$
O+n e=R
$$

where $\mathrm{O}$ and $\mathrm{R}$ are two species in one redox couple and $\mathrm{e}$ is an electron. Equation (2.4) is composed of one cathodic process to the right direction (forward) and one anodic process to the left direction (backward). When no current flows through an electrochemical cell, the potential of the working electrode will eventually reach a steady state value indicating that the cell is in equilibrium. The potential of the working electrode is given by the Nernst equation (Bard and Faulkner, 1980): 


$$
E=E^{o}+\frac{R T}{n F} \ln \frac{C_{O}^{s}}{C_{R}^{s}}
$$

where the equilibrium potential, E, is related to the standard potential of the redox couple $O / R, E^{\circ}$, and the surface concentrations of $O$ and $R, C_{O}{ }^{2}$ and $C_{R}{ }^{2} \cdot n$ is the number of electrons transferred and $\mathrm{F}$ is the Faraday constant. $\mathrm{R}$ and $\mathrm{T}$ are the gas constant and absolute temperature, respectively. Clearly $E^{\circ}$ is the particular equilibrium potential when the surface concentration of $\mathrm{O}$ and $\mathrm{R}$ are equal.

If the potential of the working electrode, $E$, is made more negative or positive than the equilibrium potential, $E^{\circ}$, the equilibrium must be reestablished when the surface concentration of $\mathrm{O}$ and $\mathrm{R}$ have taken up new values demanded by the Nernst equation (2.5), at the applied potential. Thus, a current will flow through the electrode-solution surface. In fact, this overall current is determined by both cathodic and anodic processes in equation (2.4). The overall current will be considered negative for a cathodic on which equation (2.4) goes from left to right, upon which a reduction reaction takes place. Otherwise, an oxidation reaction takes place from right to left. The overall current density is described by the Butler-Volmer equation:

$$
I=I_{0}\left[\exp \left(\frac{\alpha_{A} n F}{R T} \eta\right)-\exp \left(-\frac{\alpha_{C} n F}{R T} \eta\right)\right]
$$

where $\alpha_{A}$ and $\alpha_{C}$ are known as the transfer coefficients for the anodic and cathodic 
reactions, respectively. Generally, $\alpha_{\mathrm{A}}+\alpha_{\mathrm{C}}=1$. $\mathrm{I}_{\mathrm{o}}$ is the called exchange current density which is the current density of cathodic or anodic process at equilibrium. $\eta$ is defined as the overpotential which is the deviation of the potential from the equilibrium value, i.e. $\eta=E-E^{\circ}$. Equation (2.6) is regarded as the fundamental equation of electrode kinetics, and it shows the way in which current density varies with overpotential, exchange current density and the transfer coefficients.

Two limiting forms of the Butler-Volmer equation of experimental interest are concerned with the current response of the system at both low and high overpotentials (Kissinger and Heineman, 1984). At high overpotentials, one of the terms in equation (2.6) can be ignored. For example, the anodic current density can be given by

$$
\log I=\log I_{0}+\frac{\alpha_{A} n F}{2.3 R T} \eta
$$

At low overpotential, equation (2.6) may be approximately linealized:

$$
I=I_{o} \frac{n F}{R T} \eta
$$

Equation (2.7) is known as Tafel equation and is frequently used to determine the exchange current density and charge transfer coefficients. It is also very common to use Tafel plot to obtain the number of electrons transferred for reactions with known transfer coefficients. 


\subsubsection{Mass Transport Reactions}

The mass transport of electrode processes is determined by Fick's first and second laws, which has been abundantly described in literature and will not be discussed here. The concept of three types of mass transport in common electrochemical systems is briefly discussed as follows:

(a) Diffusion. Diffusion is the movement of a species down a concentration gradient, and it occurs whenever there is a chemical change at an electrode surface. An electrode reaction converts starting material $(\mathrm{O})$ to product $(\mathrm{R})$. Therefore, close to the electrode surface there is always a boundary layer in which the concentration of $\mathrm{O}$ and $\mathrm{R}$ are a function of distance from the electrode surface. The concentration of $\mathrm{O}$ is lower at the surface than in the bulk, and hence $\mathrm{O}$ will diffuse towards the electrode. The opposite is the case for $\mathbf{R}$.

(b) Migration. Migration is the movement of a charged species due to a potential gradient. In an electrochemical cell system, the current of electrons through the external circuit must be balanced by the passage of ions through the solution between the electrodes. The forces leading to migration are purely electrostatic, and hence the charge can be carried by any ions in the solution. In the laboratory, an excess of an inert electrolyte is added to the solution, and carries most of the charge. Therefore, 
the electroactive species is seldom transported by migration.

(c) Convection. Convection is the movement of a species due to mechanical forces. Convection can be eliminated to a large extent. However, in practice it is very common to stir or agitate the electrolyte solution to obtain important information on electrode reactions.

There are two common types of experiments in studies on the mechanism and kinetics of electrode reactions; (i) using an unstirred solution (i.e. in stationary voltammetry) (ii) using a fo, $\mathrm{m}$ of forced convection (i.e. the rotating disc electrode voltammetry technique).

\subsubsection{The Interaction of Electron Transfer and Mass Transport}

In the experiment, current $\mathrm{I}$ is measured as a function of applied potential $\mathrm{E}$. The current may be determined by the rate of electron transfer or by mass transport through the solution. In understanding the I vs $\mathrm{E}$ behavior of an electrode reaction, the reversibility of the reaction is a very important concept. A typical electrode reaction process can be described by two steps: 


$$
\begin{gathered}
O_{b u l k}+O_{\text {electrode }} \\
O_{\text {electrode }}+e=R_{\text {electrode }}
\end{gathered}
$$

where $\mathrm{kf}$ and $\mathrm{kb}$ are rate constants of forward and backward reactions in equation (2.10), respectively. For this electrode process, two types of behavior can be observed depending on the relative rates of the two steps. If both $\mathrm{kf}$ and $\mathrm{kb}$ are large, the rate of the reactions (2.10) will be fast compared to (2.9), and step (2.10) occurs to be in equilibrium. In this case, the surface concentration of $O$ and $R$ can be calculated using Nernst equation (2.5), such electrode reactions are called reversible. Conversely, if $\mathrm{kf}$ and $\mathrm{kb}$ are not both large, (2.10) cannot remain equilibrium. This process is termed irreversible.

Figure 2.1 shows I-E and corresponding logI-E curves for a typical irreversible electrode reaction. As can be seen, there are three distinct regions in the Figure. (a) The pure electron transfer controlled region occurs when the current density is very low. The extent of the resulting chemical change at the electrode surface is small, and hence the surface concentration of $\mathrm{O}$ and $\mathrm{R}$ are not significantly different from the bulk concentrations. The current is solely determined by the rate of electron transfer and better represented on linear logI-E plots. (b) The other limiting situation, mass transport controlled region, corresponds to high overpotential where electron transfer is so fast that mass transport is the sole rate-determining step and depends on 


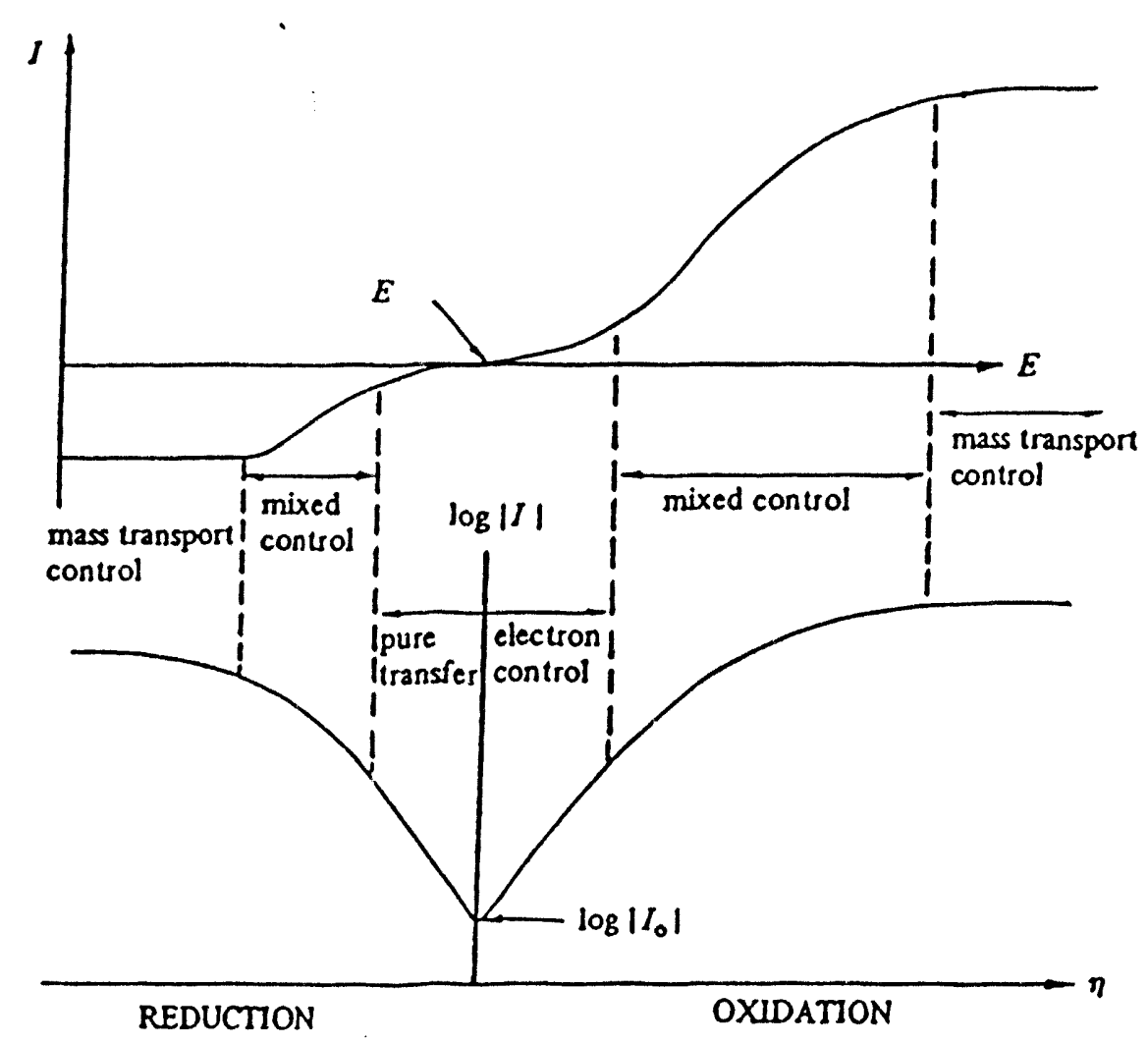

Figure 2.1 I-E and corresponding logI-E characteristics for an irreversible electron transfer reaction [from Bard and Faulkner, 1980] 
conditions of experimentation. Under steady state conditions the cell current is determined by the rate of diffusion of the reacting species, i.e., the species undergoes electron transfer as soon as it reaches the electrode surface. Therefore, the current is independent of overpotential, but is very sensitive to any changes in stirring or agitation of solution. (c) The mixed controlled region corresponds to the intermediate sizuation where there is mixed control of the current by electron transfer and mass transport. The logI-E plot is curved.

\subsubsection{Voltammetry}

Although there have been signifi:ant developments in the electrochemical methods in the past decades, two voltammetric techniques, linear sweep voltammetry or stationary electrode voltammetry (SEV) and cyclic voltammetry (CV), are among the most effective electrochemical methods available for the mechanistic studies of redox system involving sulfide minerals (Woods, 1971; Chander and Fuerstenau, 1974; Woods, 1988). SEV and CV can be performed with both stationary and rotating electrodes. These techniques are very useful for conducting preliminary studies of the oxidation and reduction reactions of sulfides. The potential at which a current peak is observed can be viewed as a characteristic of the species undergoing electrochemical reaction. From the shape of the peak current of I-E curve, a detailed reaction mechanism can be obtained. 
In linear sweep voltammetry, the potential of the working electrode is scanned linearly from an initial value to a given value at a constant scan rate $\nu$ (Volts/s). The potential changes as a triangular wave with respect to time in cyclic voltammetry. Since time is a common variable with respect to the potential and current, it usually plot the current as a function of potential in the form of a voltammogram. The potential as a function of time and the current through the electrode measured as a function of potential for the two kinds of voltammetry are schematically shown in Figures 2.2 and 2.3. By varying the potential limit in the voltammogram, the nature of reactions in various potential ranges can be determined.

Two important parameters in linear sweep voltammetry and cyclic voltamemtry are the peak potential and the peak current, which are the potential and current at the characteristic voltammogram peak. For a reversible system, the peak current is defined by the Randles-Sevcik equation (Kissinger and Heineman, 1984)

$$
i_{p}=K \times n^{3 / 2} C_{b} v^{1 / 2}
$$

Where $\mathrm{K}$ is a constant, $\mathrm{n}$ is the number of electron transferred, and $\nu$ is the scan rate $(\mathrm{V} / \mathrm{s}) . \mathrm{C}_{\mathrm{b}}$ is the concentration of the reaction species in the bulk solution. The peak potential is defined for a reduction reaction by

$$
E_{P}=E^{o^{\prime}}-0.029 / n
$$

$\mathrm{E}^{\mathrm{O}}$ is the formal electrode potential of the $\mathrm{O}$ and $\mathrm{R}$ couple corrected to the reference 


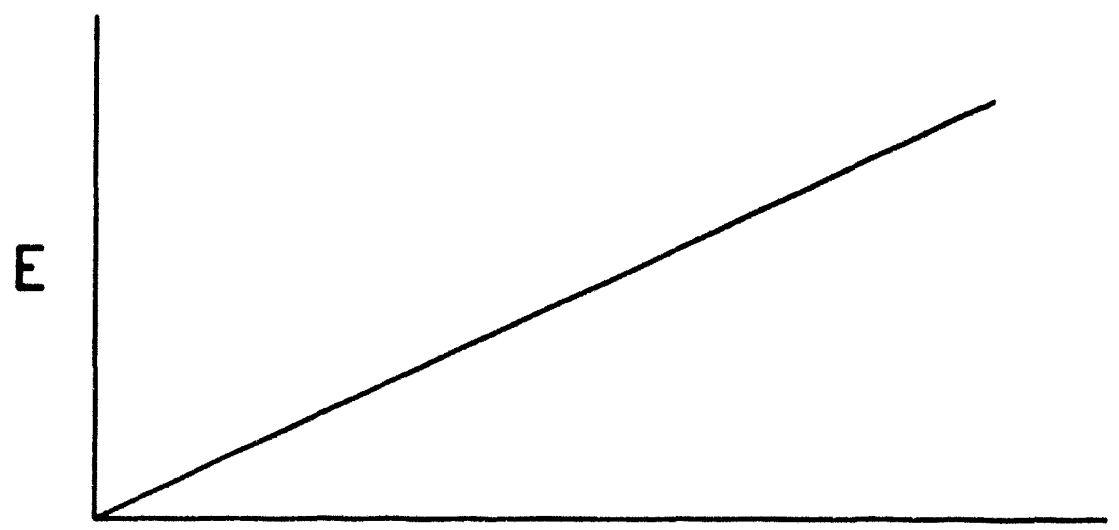

Time

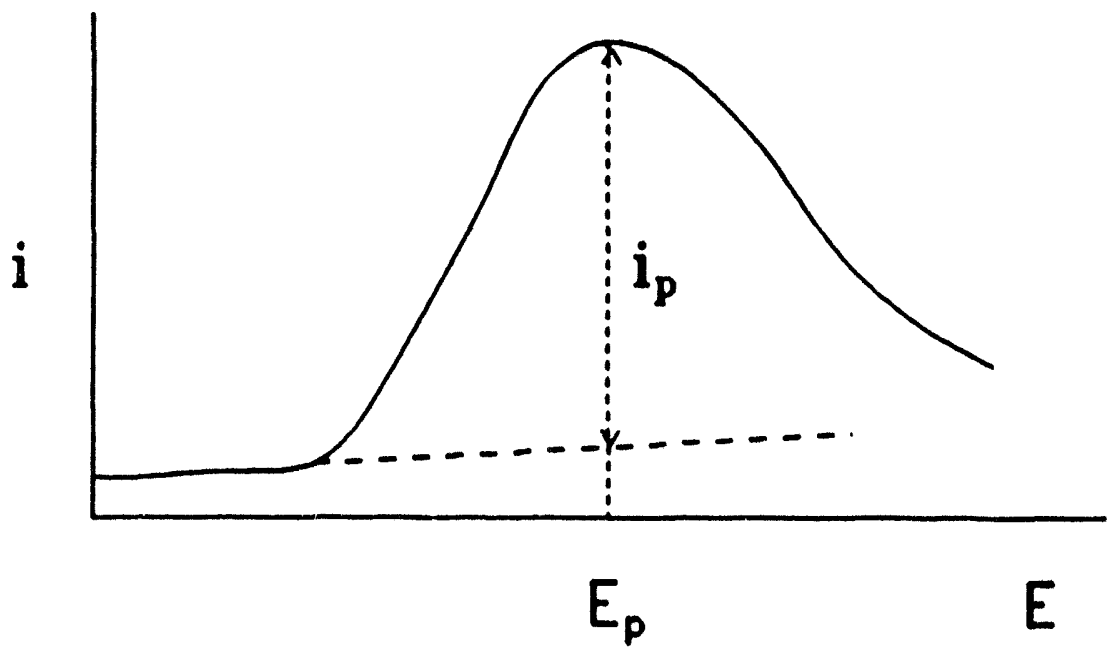

Figure 2.2 Variation of potential with time and current with potential in linear sweep voltammetry. 

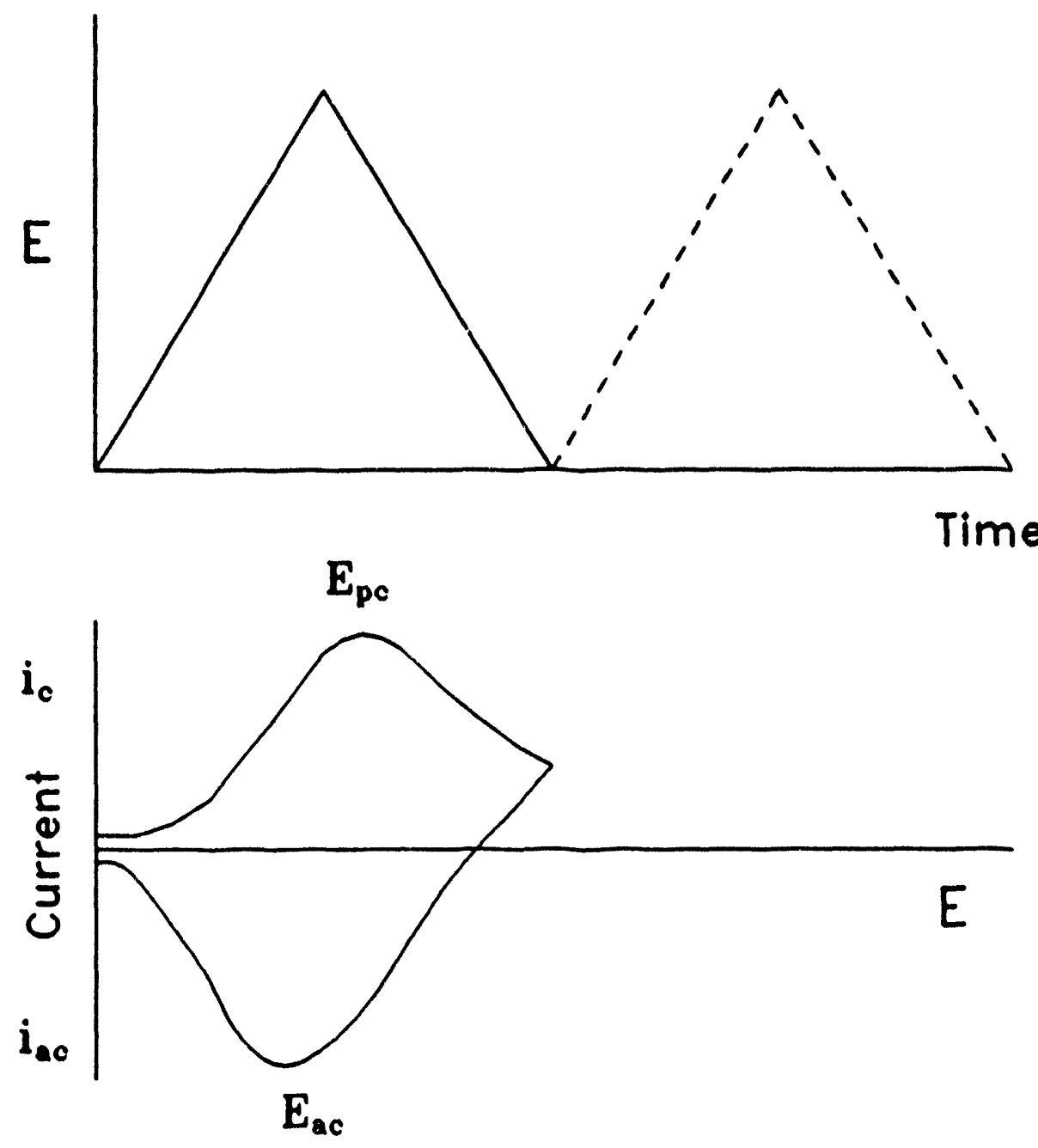

Figure 2.3 Variation of potential with time and current with potential in cyclic voltammetry. 
electrode. According to equation (2.11), $i_{\mathrm{p}}$ is proportional to $\nu^{1 / 2}$ and a plot of $i_{\mathrm{p}} v \mathrm{vs}$ $\nu^{1 / 2}$ should be a straight line for a reversible system. In contrast, the plot of peak current against scan rate is a curve for an irreversible system. The peak potential indicated in (2.12) is invariant with the scan rate for a reversible system, but for an irreversible system it is no longer independent of scan rate. Therefore, the effect of scan rates can be used to determine the degree of reversibility of the redox reactions.

In rotating disk electrode voltammetry, the electrode is rotated at a strictly controlled and measurable angular velocity, and potential control is exercised at the electrode-solution interface according to the desired experimental scheme. Rotating disc is a powerful tool to study the homogeneous and heterogeneous electrochemical reactions in electrochemistry (Thirsk and Harrison, 1972). For example, By examining the effect of rotating the electrode, it is possible to distinguish between reactions of soluble reactants/products and the reactions of insoluble species.

\subsection{Electrical Properties of Surface}

When a solid is in contact with an aqueous medium, for example, during wet grinding and flotation, it becomes charged at the surface. The surface charge can be caused by many factors, such as lattice imperfections at the solid surface, hydrolysis of the surface ions, and adsorption of ions from solution. The charged surface will 
attract the ions of opposite charge in the solution, which is called counter ion, to the solid surface, forming an electrical double layer at the solid/liquid surface. Various models have been created to describe the spacial distribution of charges at the surface. The simplest case was proposed by Helmholtz (1879), who treated the total excess of electric charges on solid surface as surface charges, with the counter ion charges in the solution as if they are forming a charged parallel plate along the surface through electrostatic forces. Guoy (1910) and Chapman (1913) proposed that the charges in the solution are exposed to the forces of thermal motion, and there exists a balance between electrostatic and thermal forces. This is known as diffusion layer model. Stern (1924) combined the above two models and divided the region near the surface into two parts, the first consisting of a layer of ions specially adsorbed at the surface called the Stern layer, and the second consisting of a diffusion layer. Ions adsorbed in the Stern layer are subject to electrostatic and specific adsorption. The closest distance of approach of the counter ions is the thickness of electrical double layer, $\delta$. The schematic representation of the Stern model is shown in Figure 2.4.

The potential $\psi$ at any distance from the surface is defined as the work required to bring an elementary charge from infinity to this distance. Potentialdetermining ions are the species of ions that determine the interfacial potential difference. The potential at the solid/liquid interface is termed the surface potential, $\psi_{0}$, which can be calculated by Nernst equation 


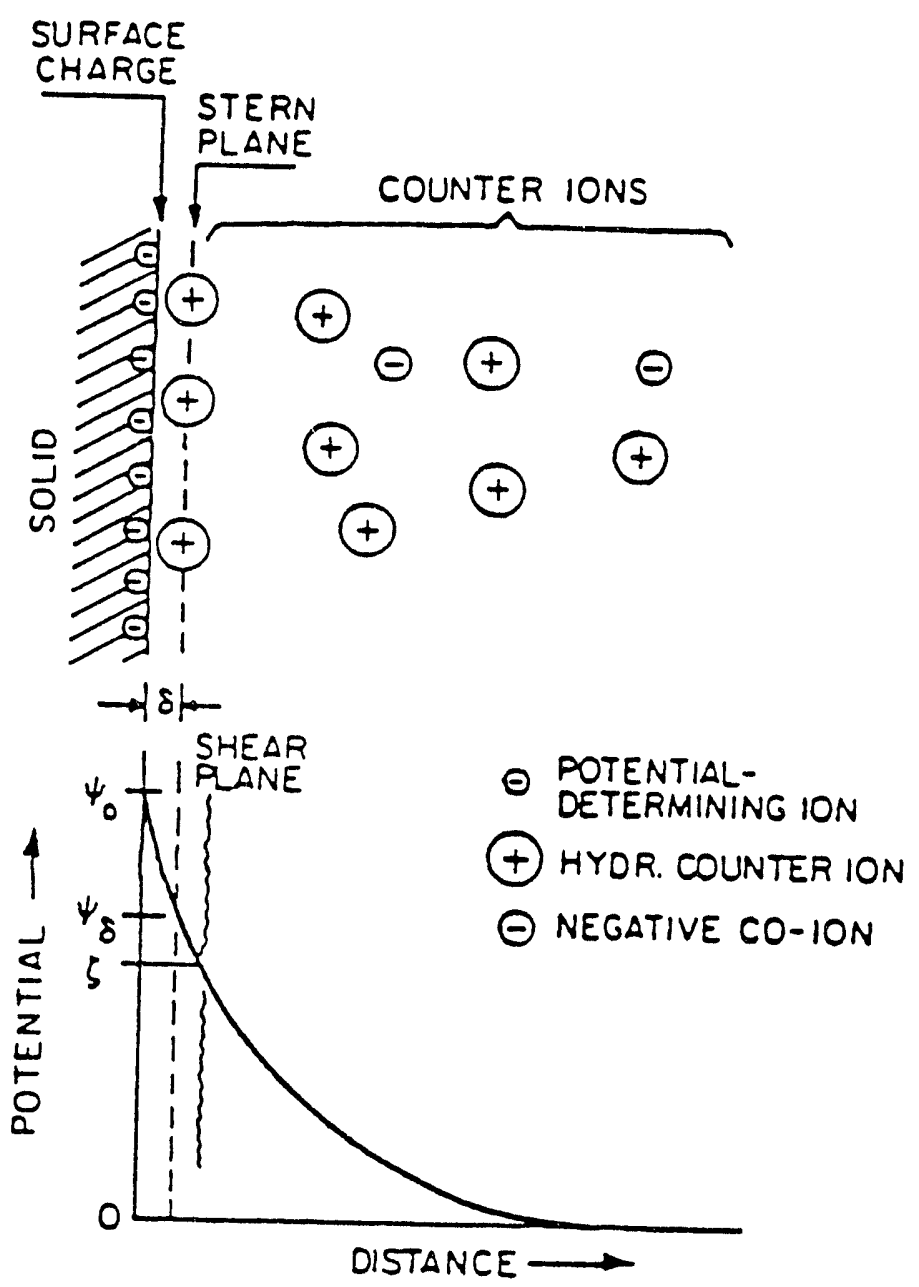

Figure 2.4 Schematic representation of the electrical double layer according to Stern's model. 


$$
\psi_{\mathrm{o}}=\frac{R T}{n F} \ln \frac{\{C\}}{\left\{C_{0}\right\}}
$$

where $\{C\}$ is the activity of the potential-determining ions. The $\left\{C_{o}\right\}$ is the activity at which the surface potential is zero, and the negative logarithm of $\left\{C_{0}\right\}$ is called point of zero charge $(\mathrm{PZC})$. For oxide minerals with $\mathrm{H}^{+}$and $\mathrm{OH}^{-}$as potentialdetermining ions, the surface potential is (Stumm, 1981)

$$
\psi_{0}=\frac{2.3 R T}{n F}\left(p H_{P Z C}-p H\right)
$$

where $\mathrm{pH}_{\mathrm{pzc}}$ is the $\mathrm{pH}$ of zero point of charge. Although the experimental observation with most oxide minerals is not accordant with equation $(2.14), \mathrm{H}^{+}$and $\mathrm{OH}^{-}$ nevertheless have a significant influence on the surface charges.

As the solid and adhered liquid move along the shear plane where fluid slips relative to a stationary solution, the difference in the potential at the shear plane and the potential in the bulk solution is referred to as the electrokinetic potential or zeta potential, $\zeta$. There are four basic types of electrokinetic phenomena, namely, electrophoresis, streaming potential, electro-osmosis and sedimentation potential. Electrophoresis is the most commonly used method for zeta-potential measurements. With this method, an electric field is applied to cause the movement of the charged particle toward one of the electrodes relative to a stationary electrolyte solution. Smoluchowski (1903) derived the basic equation for the calculation of zeta potential 
in the case of electrophoresis

$$
\zeta=\frac{4 \pi L}{\epsilon E} \eta v
$$

Where $\mathrm{E}$ is the applied potential, $\mathrm{L}$ is the distance between electrodes, $\nu$ is the velocity of the electrophoretic particle, $\eta$ is the viscosity of liquid, $\epsilon$ is the dielectric constant of the electrolyte bulk solution. The value of $\mathrm{pH}$ at which a particle shows no electrophoretic mobility or zeta potential becomes zero is defined as the isoelectric point (IEP). If there is no specific adsorption of ions on the solid surface, the PZC and IEP are assumed to be the same (Parks, 1970).

Both PZC and IEP are important parameters in determining the surface properties of minerals. When the cationic or anionic collectors are used to float minerals through electrostatic forces, PZC or IEP can be viewed as a criteria for adsorption of collector and flotation of minerals. If $\mathrm{pH}>\mathrm{pH}_{\mathrm{pzc}}$, the surface of minerals becomes negatively charged, and cationic collectors adsorb on surface resulting in flotation. Similarly, If $\mathrm{pH}<\mathrm{pH}_{\mathrm{pzc}}$, the surface is positively charged, anionic collectors interact with the positively charged surface leading to flotation. The electrokinetic phenomena of minerals in flotation has been widely used to delineate the interaction mechanism of reagents and minerals. The studies on the surface charge properties have lead to the development of new separation method for pyrite and arsenopyrite (Kydros et al., 1993). 


\subsection{Surface Properties of Pyrite and Coal}

\subsubsection{Surface Oxidation of Pyrite}

The surface oxidation of pyrite in an aqueous solution has been extensively studied due to its importance in many applications, such as the flotation separation of pyrite from sulfide ores and coals, the generation of acid in mine water, the leaching of gold-bearing pyrite, etc. Since pyrite is the most electrochemically noble and yet readily oxidized sulfide mineral, interactions between pyrite and other minerals in flotation pulp can strongly influence floatability of other minerals and separation selectivity. For instance, the metal ions originating from oxidation of minerals were found to adhere to mineral surface as hydroxides, these metal hydroxide coatings are hydrophilic and can reduce, or, totally depress the flotation (Ralston, 1991). In coal flotation, oxidation properties of the associated pyrite can inevitably influence the interaction of coal with reagents. Therefore, the study of oxidation properties of pyrite is of great importance.

There have been several reviews published on the surface oxidation of pyrite (Hiskey et al, 1982; Lowson, 1982). Most of the studies demonstrated that the surface oxidation of pyrite involves a series of steps. Pyrite oxidation may occur through formation of several intermediate ions such as ferrous, ferric, thiosulfate, sulfite, 
dithionate and dithionite; and solid products like elemental sulfur, ferrous and ferric hydroxides etc. In addition, the nature of the oxidation process depends on other factors such as solution $\mathrm{pH}$, temperature, crystal defect and pulp potential. It is generally agreed that the overall oxidation of pyrite in an aqueous solution can be described by the following reactions (Biegler and Swift, 1979; Hamilton and Woods, 1981; Ramprakash et al, 1991):

In acid solutions, elemental sulfur is formed on the surface.

$$
\mathrm{FeS}_{2} \rightarrow \mathrm{Fe}^{2+}+2 \mathrm{~S}^{0}+2 e
$$

At higher overpotential, sulfate is formed.

$$
\mathrm{FeS}_{2}+8 \mathrm{H}_{2} \mathrm{O}-\mathrm{Fe}^{3+}+2 \mathrm{SO}_{4}^{2-}+16 \mathrm{H}^{+}+15 e
$$

In alkaline solution, ferric hydroxides is precipitated on the surface.

$$
\mathrm{FeS}_{2}+3 \mathrm{H}_{2} \mathrm{O} \rightarrow \mathrm{Fe}(\mathrm{OH})_{3}+\mathrm{S}^{\circ}+3 \mathrm{H}^{+}+3 e
$$

At high overpotential, sulfur is oxidized to sulfate.

$$
\mathrm{FeS}_{2}+11 \mathrm{H}_{2} \mathrm{O}-\mathrm{Fe}(\mathrm{OH})_{3}+2 \mathrm{SO}_{4}^{2-}+19 \mathrm{H}^{+}+15 e
$$

However, there is no general agreement regarding the detailed reaction mechanism. There are two major problems which are still debatable. For instance, whether elemental sulfur is an intermediate during the formation of sulfate and which component, iron or sulfur, is oxidized preferentially. 
The studies by Hamilton and Woods (1981) indicated that elemental sulfur is the major product of pyrite oxidation in acidic solutions and the formation of sulfate takes places with elemental sulfur as a intermediate. However, Biegler and Swift (1979) concluded that elemental sulfur is not a intermediate in the formation of sulfate.

The other more controversial problem is on the incongruity of the oxidation process of iron and sulfur in pyrite. Two alternative mechanisms have been postulated to describe the incongruent oxidation: (a) Preferential release and oxidation of the iron species: In this mechanism, the oxidation of pyrite begins at the iron atoms. Iron oxidizes preferentially and migrates from the pyrite surface into the solution or precipitates on the surface as hydroxides, leaving a reacted layer of sulfur. This concept was previously proposed by Sato (1960) and supported by recent studies (Peters, 1984; Buckley et al, 1985, 1988; Chander and Briceno, 1987; Briceno and Chander, 1988). (b) Preferential release of sulfur species: In this mechanism, the sulfur in pyrite is first oxidized and released from the surface. The reacted layer is occupied by an iron hydroxide precipitation layer (Conway et al, 1980; Goldhaber, 1983).

Wang (1989) and Ahlberg et al (1990) studied the surface oxidation of several ore-pyrites in acidic and alkaline solutions. They found that in alkaline solutions and 
for all sie samples tested, the initial oxidation of pyrite produces a hydrophobic sulfur- rich surface together with hydrophilic iron hydroxide precipitation. The iron hydroxide layers were thicker if the electrode polishing was performed in air rather than in a nitrogen atmosphere. In acid solution, it was found that the oxidation of pyrite is weak and independent of the solution pH. Ramprakash et al (1991) conducted electrochemical studies to examine the development of iron oxide film on pyrite, they found that the ferrous hydroxide oxides exist on a fresh pyrite surface. However, after short exposure to the air the surface layer oxidized to ferric hydroxides.

\subsubsection{Hydrophobicity and Floatability of Pyrite and Coal}

The native floatability and hydrophobicity of sulfide minerals is very important both fundamentally and practically. In fact, collectorless flotation of sulfide from crushed and ground ores has been commercially used. It is important to distinguish between native floatability and self-induced floatability. Minerals such as molybdenite, orpiment, realgar and stibnite are easily floated without the use of collectors, and are regarded to have native floatability (or hydrophobicity). The basis for native floatability depends on the assumption that sulfide lattice ions are expected to be weakly hydrated and do not react strongly with water. A number of studies showed that sulfide minerals can be floated under mild to modest oxidizing conditions in the absence of collector. The new term, self-induced floatability, was created to describe 
the floatability of sulfide minerals in the absence of any hydrophobicizing chemicals and to distinguish the native floatability of minerals as well as other chemical induced flotation. Coal-pyrite may float without a sulfhydryl collector which is normally needed to float ore pyrite (Yancey and Taylor, 1935), it was interpreted to be due to the self-induced floatability by surface oxidation (Breceno and Chander, 1988).

Gaudin (1932) studied the native floatability of sulfides and considered that surfaces formed by the rupture of Van Der Waals bonds are naturally hydrophobic. It has been shown that the floatability of many sulfide minerals is dependent upon the slight oxidation of the mineral surface. Guy and Trahar (1985) studied the collectorless flotation of sulfide minerals. They found that at moderate oxidizing environment, the sulfide minerals displays a self-induced floatability to a different extent. For instance, chalcopyrite is highly floatable and pyrite is only slightly floatable. Flotation behavior can be controlled by manipulation of the pulp potential.

Hayes and coworkers (1987) summarized that sulfide minerals which are amenable to collectorless flotation oxidize through a continuum of metal-deficient sulfides of decreasing metal content to elemental sulfur. However, Fuerstenau and Sabacky (1981) reported that the common base sulfides are all naturally floatable in a virtually oxygen-free environment. The reasons for the discrepancies are complicated and not clear. However, possible reasons should be the differences in the 
surface state of minerals, such as the degree of oxidation, surface defect, surface roughness etc. The variation of the surface state of sulfide minerals can be changed not only by chemicals in the solution but also by the preparation conditions (Somasundaran and Lin, 1972). Studies demonstrated that the surface roughness and defect can strongly affect the floatability of sulfide minerals (Oliver et al, 1980; Harris and Richter, 1985).

Wang and Forssberg (1990) studied the native and EDTA-induced floatability of pyrite and a number of other sulfides. They found that the freshly ground pyrites are hydrophilic and nonfloatable. They have shown that this is due to the formation of iron hydroxide layers in pyrite during grinding. However, the addition of a low concentration of EDTA can increase the surface hydrophobicity of pyrite and induce a good flotation. It was shown that the flotation of pyrite in EDTA solutions is strongly dependent on the $\mathrm{pH}$ and EDTA concentrations as shown in Figure 2.5 and 2.6. Their studies demonstrated that the hydrophilic iron hydroxide layers is removed by EDTA from the pyrite surface exposing a sulfur-rich surface to water.

The collectorless flotation of sulfide minerals treated with sodium sulfide has been studied by a number of investigators (Yoon, 1981; Luttrell and Yoon, 1984; Trahar, 1984). The major role of sodium sulfide was believed to remove hydrophilic oxidation products of pyrite. The elemental sulfur on the surface was mainly 


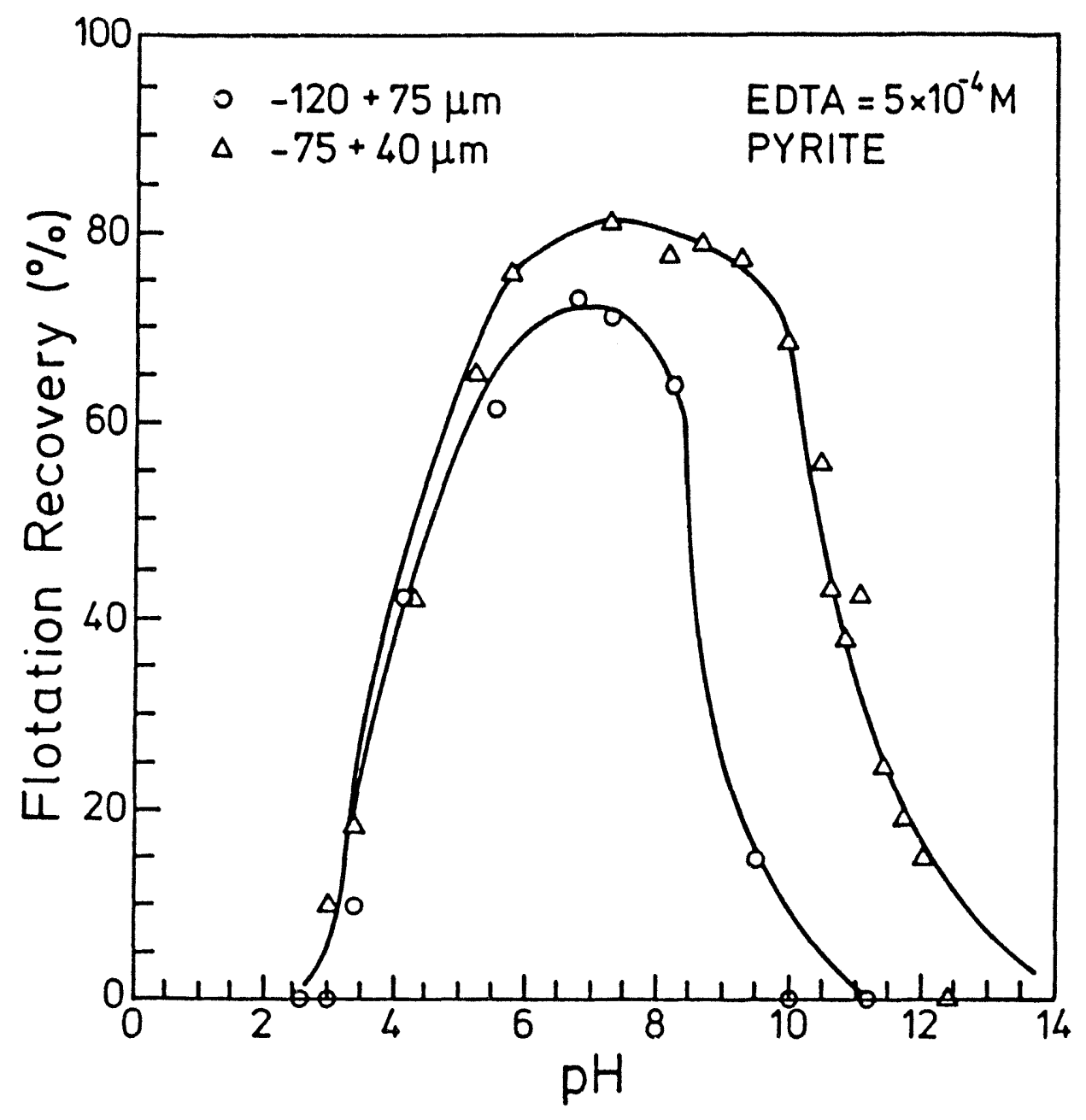

Figure 2.5 Flotation recovery of pyrite as a function of $\mathrm{pH}$ in the presence of $5 \times 10^{-4} \mathrm{M}$ EDTA [from Wang and Forssberg, 1990]. 


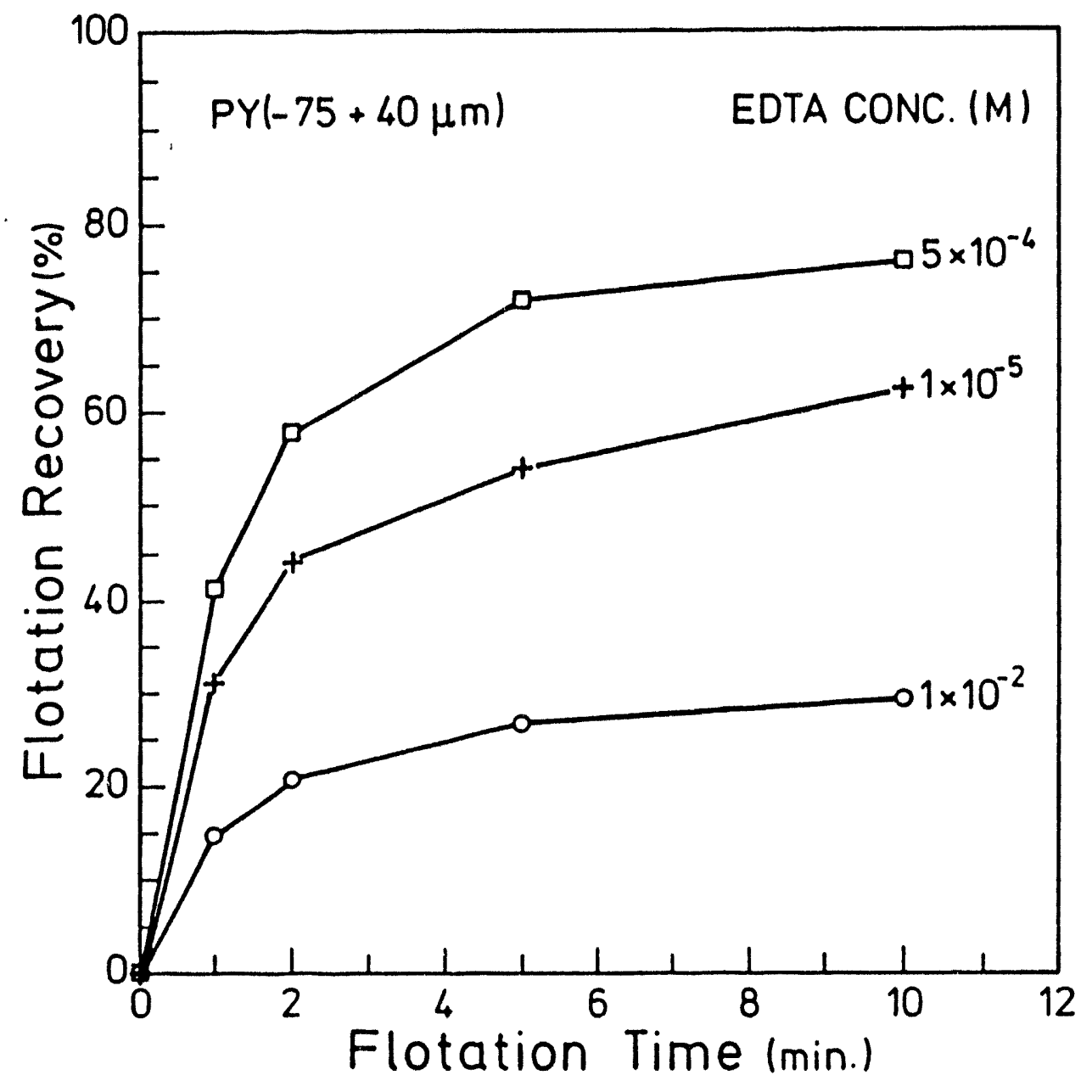

Figure 2.6 Flotation rate of pyrite at different EDTA concentrations [from Wang and Forssberg, 1990]. 
responsible for the hydrophobicity of pyrite. The X-ray photoelectron spectroscopic study by McCarron and co-workers (1990) indicated that after treatment with sodium sulfide solution in the presence of oxygen, the pyrite surface becomes more sulfurenriched at moderate sodium sulfide concentration than at high concentration.

Aging increases the hydrophobicity of coal-pyrite and affects its rejection properties from coal. Parekh et al (1989) reported that the rejection of pyrite was more efficient for freshly ground coals. They found that the amount of pyritic sulfur rejected form Kentucky No.9 coal decreases with increasing aging time after grinding. Similar results was reported by the Stoessner and Zowardzki (1987), without using any pyrite depressants the flotation of fresh coal produced a clean coal with extremely low suifui content. These results suggested that the surface hydrophobicity of the coal-pyrite increases after aging. The contact angle studies conducted on coal pyrite showed that atmospheric environment can greatly affects the hydrophobicity of coal pyrite (Wang et al., 1992) as shown in Figure 2.7. The results indicated that the moderate exposure of pyrite in an oxygen atmosphere significantly increases its hydrophobicity.

Coal is usually referred to as a naturally hydrophobic and floatable mineral (Leja, 1982). However, snce coal is not a chemically uniform substance, its natural hydrophobicity and flcatability can vary with many factors such as geological origins, 


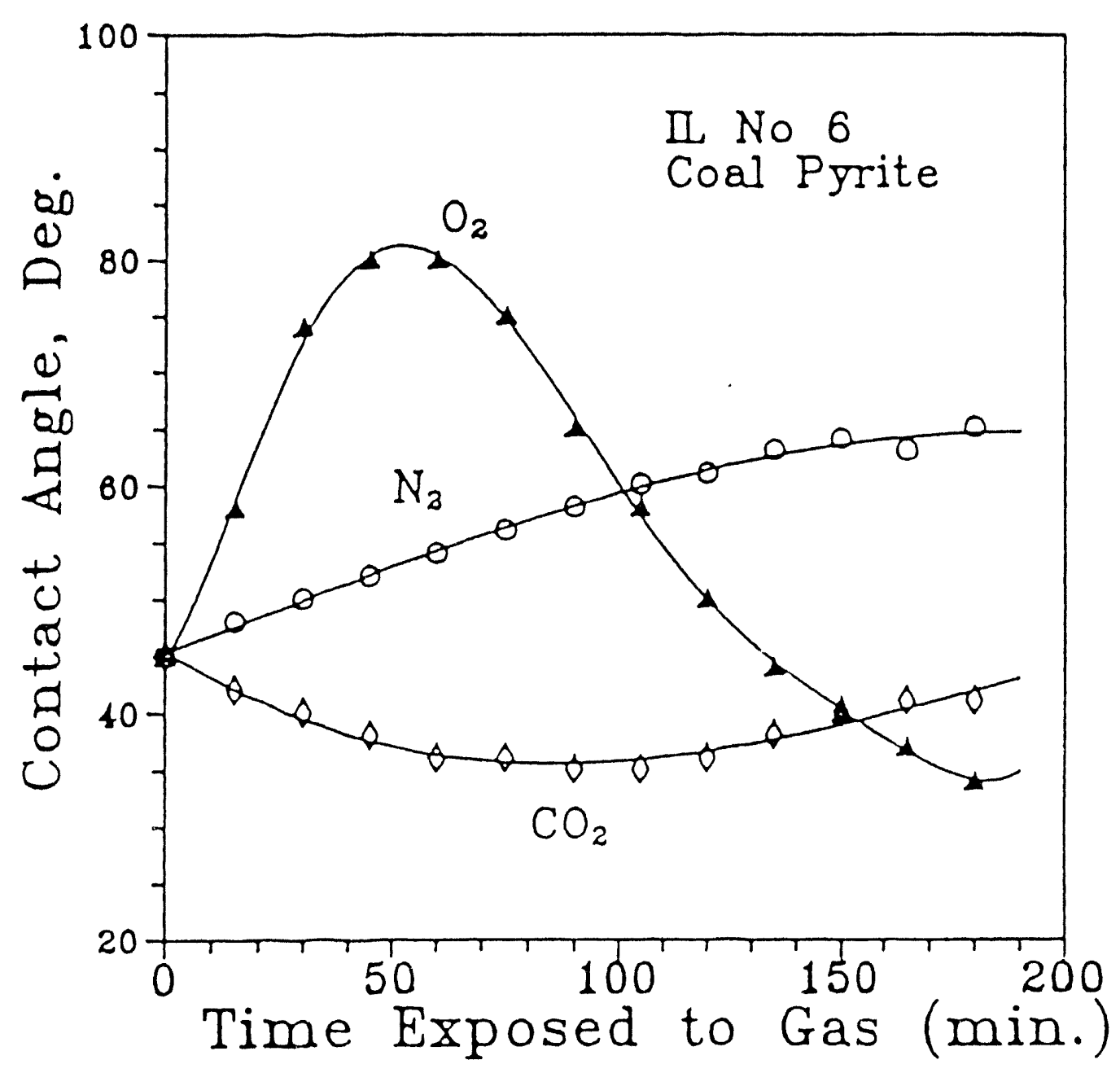

Figure 2.7 Contact angle of coal-pyrite as a function of time under different atmospheres [from Wang et al, 1992]. 
rank, petrographic compositions and the degree of oxidation. Gayle et al (1962) reported that surface oxidation greatly influences coal flotation in the absence of a collector. For the bituminous coals, the effect of surface oxidation is a function of rank. The hydrophobicity and floatability of high rank coal are slightly affected by moderate oxidation, but greatly decreased for the low rank coal. They proposed that the detrimental effect of oxidation on coal is due to the formation of surface functional groups like carboxylic oxygen, humic acids, iron hydroxides, and water soluble organic compounds. However, it has been shown that there is considerable variations in the floatability of coals from different regions, coals of different mines in the same region, and also of coals of different seams of the same mine (Hower et al., 1986). This suggests that the flotation of coal depend strongly on the coal feed.

\subsection{Froth Flotation}

To achieve efficient reduction of pyritic sulfur, fine grinding is needed to liberate finely disseminated pyrite from coal. Froth flotation is the most commonly used method for cleaning fine coals. The removal of pyritic sulfur in coal flotation can be realized by two common ways

a) floating coal and depressing pyrite (Direct flotation)

b) floating pyrite and depressing coal (Reverse flotation) 


\subsubsection{Direct Flotation}

Although coal is naturally floatable due to its hydrophobic surface properties, many factors such as oxidation, particle size, slime coating can cause a decrease in floatability (Rao, 1988; Aplan and Arnold, 1986). Theoretically, high rank coals need no reagents for their flotation. However, a collector with a frother is usually employed to make even these highly hydrophobic coal more floatable. These practices can also increase the flotation rate of coal, form a stable froth, float coarse particle and improve low rank coal flotation. The widely used collectors for coal are nonpolar oils such as fuel oil or diesel oil. MIBC, methyl isobutyl carbinol, is a major coal flotation frother. Of the above options for the removal of pyritic sulfur, the depression of pyrite by a depressant is the simplest because the natural hydrophobic properties of coal contribute to the direct flotation.

The flotation of pyrite in ore can be effectively depressed by many inorganic and organic chemica's. A number of extensive reviews have been published on these subjects (Ball and Richsrd, 1976; Chander, 1987). However, the experience in the depression of ore-pyrite can not be directly transferred to coal pyrite. It has been shown that the rejection of pyrite from coal is much more difficult than from ore. Nevertheless, some recent work has been done to develop effective reagents in depressing coal-pyrite. 
Different types of pyrite depressants can be used in coal flotation. Aplan and Arnold (1991) categorized the coal-pyrite depressant system as alkalis, oxidizing agents, reducing agents, inorganic/organic compounds, and dispersing agents etc. The work by Yancey and Taylor (1935) showed that sodium cyanide, aminophenol and pyrogallic acid are good depressants of pyrite. Zimmerman (1948) found that lime and moderately $\mathrm{pH}$ control had a depressing effect on pyrite. A high solution $\mathrm{pH}$ is detrimental to the flotation of coal. Miller (1964) found that sodium sulfite is effective depressant for coal-pyrite especially when used together with potassium permangnate. Perry and Aplan (1985) recommended a high amylose-containing starch as a good depressant for pyrites. It was observed that the adsorption behavior of the compound on ore-pyrite differs from that on coal-pyrite. Choudhry and Aplan (1992) evaluated a series of inorganic depressants during coal flotation. It was observed that the mixture of $\mathrm{CaO}$ and $\mathrm{K}_{2} \mathrm{Cr}_{2} \mathrm{O}_{7}$ gave a superior depression effect for pyrite when oxidizing/reducing agents were used alone or combined with inorganic ions. The impact of the dispersing agents on pyrite depression was also examined. The dispersing agents is used to disperse the particles in pulp and to decrease the entrainment of pyrite by coal. The common inorganic dispersants, sodium silicate and hexametaphosphate were shown to be more selective than organic dispersants. Other dispersants used in coal flotation include aerosols, quebracholgnin and polymeric sulfonate, etc. These organic reagents should be carefully used to get appropriate separation results, because an excess dosage can also depress the flotation of coal. 
The oxidation products of pyrite was believed to have a certain depression effect on the flotation of pyrite. Yancey and Taylor (1935) found the oxidation products, ferrous an ferric sulfates, to be good pyrite depressants. Similar results with the use of ferric chloride was reported by Plouf (1980). Choulhry and Aplan (1992) studied the effect of the leaching solution of oxidized pyrite on the flotation of coalpyrite, the results indicated that it was not a very effective depressant. The difference in the results was explained to be due to the nature of the pyrite, its oxidation conditions, or the concentration of oxidation products in the solution. Firth and Nicol (1984) studied the effect of pyrite oxidation products on the flotation of coal. It was observed that the presence of iron(II) and iron(III) had little effect on the flotation of clean coal in the presence of a hydrocarbon collector, but in the absence of a collector flotation was depressed.

A method of separating coal and pyrite based on the difference in the rate of flotation of coal and pyrite was suggested by Aplan (1977). The rate of recovery of a floatable bituminous coal can be ten times faster than the rate of recovery of pyrite under mild conditions. Therefore, by employing such conditions and a shorter residence time, much of the coal can be recovered before the slower floating pyrite appears in the froth. However, an oily collector and more rigorous conditions can increase the rate of flotation of pyrite more than that of coal and result in a poorer separation. 


\subsubsection{Reverse Flotation}

Although a number of potential flotation depressants have been suggested for coal-pyrite, little if any use has been made of such depressants in industrial coal preparation plants (Miller and Deurbrouck, 1982). Most of the recent studies has been devoted to the improved machines and processed such as column flotation for the fine coal cleaning (Mishra and Harries, 1988; Parekh et al, 1989). Pyrite depressants have not proven very effective in the direct flotation of coal. However, the ineffectiveness of such depressants may have been due in part to incomplete liberation of pyrite. Since the flotation of pyrite is difficult to suppress, an interesting alternative is the reverse flotation of coal.

Two-stage reverse flotation of pyrite from coal was developed and being tested in a pilot plant as a possible process for improved removal of pyritic sulfur (Baker and Miller 1971; Baker et al, 1973; Miller, 1975). In this method, the coal is floated during the first stage. In this stage, most of the coal is collected as froth, whereas some of the coarse pyrite and much of the ash-minerals are rejected. The second stage involves flotation of pyrite remaining in the coal froth of first stage by using xanthate as a collector of pyrite, and an organic colloid depressant, such as dextrin as depressant of coal. 
Pyrite is readily floatable with several types of collectors such as xanthate, dithiophosphates, fatty acids, etc. The xanthate type is the most important and effective collector used for ore-pyrite flotation. However, it has been shown that coalsource pyrite is much less floatable with xanthate than ore-pyrite. Long chain xanthate like amyl xanthate is used to ensure high coal-pyrite recovery. Miller (1975) showed that as much as $0.5-1.0 \mathrm{lb} / \mathrm{t}$ of amyl xanthate is required for the favorable flotation of coal-pyrite. Chernosky and Lyon (1972) compared the flotation and adsorption nature of ore and coal-pyrite, it was found that the adsorption of xanthate on ore and coal-pyrite follows the same general trends, but the coal-pyrite has much higher adsorption capacity than ore-pyrite. Specially, nearly all of the xanthate added can be adsorbed by coal-pyrite. Research has shown that there is a wide variability in coalpyrite flotation by xanthate, which is strongly dependent on the source (Chen and Aplan, 1991). It was observed that ten to one thousands times more xanthate collector may be required to float coal-pyrites than ore-pyrites.

\subsubsection{Pyrite Flotation with Xanthate}

Xanthate is the most important and most widely used collector in sulfide flotation. The flotation of pyrite in ore separation is usually carried out using xanthate as a collector. As mentioned in the previous section, there is an increasing interest in promoting pyrite rejection from coal by reverse flotation. However, large dosages 
of xanthate consumption is a major disadvantage in the flotation of coal source pyrite with xanthate. The reason for this is not clear, but some investigations simply attribute the ease of oxidation of coal-pyrite versus ore-pyrite (Chen and Aplan, 1991). Understanding the principle involved in pyrite flotation by xanthate will be most helpful for the improvement of the pyrite removal by reverse flotation.

Xanthates are derivatives of carbonic acid, $\mathrm{H}_{2} \mathrm{CO}_{3}$, in which two oxygens have been replaced by sulfur and one hydrogen by an alkyl group. The general formula of xanthate acid is ROCSSH. Where R denotes alkyl group. Xanthate is generally used in the form of its sodium or potassium salts. A number of xanthate derived species depending on certain conditions may be present in the pulp of flotation process (Leja, 1982), which include xanthate ions, ROCSS (X), xanthatic acid, ROCSSH (HX), dixanthogen, ROCSS-SSCOR $\left(\mathrm{X}_{2}\right)$, monothiocarbonate ion ROCOS', perxanthate, etc. The mechanisms of adsorption of xanthate on pyrite have been extensively studied. It was generally accepted that the sole species of xanthate responsible for pyrite flotation is dixanthogen, independent of solution and pyrite surface conditions (Fuerstenau et al, 1968; Majima and Takeda, 1968; Allison et al, 1972; Ball and Richard, 1976; Finkelstein and Poling, 1977; Woods, 1988; Fuerstenau et al, 1990). This conclusion was based on the results of spectroscopic, flotation, zeta-potential and electrochemical studies. The proposed mechanism can be described as follows (Ball and Richard, 1976): 
Dixanthogen forms by anodic oxidation of xanthate ion on the pyrite surface coupled with cathodic reduction of the adsorbed oxygen

$$
\begin{gathered}
2 \mathrm{X}^{-}=\mathrm{X}_{2}(\text { surface })+2 e \\
\frac{1}{2} \mathrm{O}_{2}(\mathrm{ads})+\mathrm{H}_{2} \mathrm{O}+2 e=\mathrm{X}_{2}+2 \mathrm{OH}^{-}
\end{gathered}
$$

Since pyrite is an electronic conductor, an electron transfer reaction occurs through the pyrite as a catalyst. The overall reaction is

$$
2 \mathrm{X}^{-}+\frac{1}{2} \mathrm{O}_{2}(\mathrm{ads})+\mathrm{H}_{2} \mathrm{O}=\mathrm{X}_{2}+2 \mathrm{OH}^{-}
$$

These reactions are believed to be possible up to $\mathrm{pH}=11$. Above $\mathrm{pH}=11$ dixanthogen is decomposed to xanthate ion.

However, the above proposed mechanisms can not explain a number of phenomena observed in the pyrite flotation system by xanthate. For instance, the complete or partial depression of pyrite was observed in the neutral $\mathrm{pH}$ range; the zeta-potential of pyrite became negative below $\mathrm{pH}_{\mathrm{PzC}}$ in the presence of xanthate.

Fuerstenau et al (1968) studied the effect of solution $\mathrm{pH}$ and different xanthate concentration on the flotation recovery of pyrite as shown in Figures 2.8 and 2.9. The flotation recovery curve $\mathrm{vs} \mathrm{pH}$ is characterized by two humps and one intermediate 
depression region. When low concentrations of xanthates are used, in spite of the nature of xanthate species added, xanthate (Figure 2.8) or dixanthogen (Figure 2.9), a high or complete recovery hump in the acidic region, a partial recovery hump under mildly alkaline solution, and an intermediate depression or low recovery region in neutral $\mathrm{pH}$ range were observed. At high xanthate concentration, the depression in the neutral $\mathrm{pH}$ range is recovered. However, they could not explain the intermediate depression and simply concluded that dixanthogen adsorption is primarily responsible for the flotation of pyrite. Later, based on the work of Sheikh (1972) on Mossbauer spectroscopy of iron xanthate, Leja (1982) suggested that ferric xanthate, $\mathrm{FeX}_{3}$, may be responsible for the improved recoveries in acidic solutions and $\mathrm{Fe}(\mathrm{OH}) \mathrm{X}_{2}$ may be the cause of low recovery under mildly alkaline $\mathrm{pH}$. He also suggested that the depression in neutral $\mathrm{pH}$ range may be associated with the formation of $\mathrm{Fe}(\mathrm{OH})^{+} \mathrm{X}$ complex which eliminates the adsorption of particular hydrophobic xanthate species on pyrite surface.

In addition, zeta-potential measurements demonstrated that the surface charge of pyrite is reversed in the presence of xanthate, and the higher the xanthate concentration, the more negative the zeta-potential becomes (Fuerstenau, et al, 1981; Fuerstenau and Mishra, 1981; Fuerstenau, et al, 1990). Obviously, the flotation results obtained by these investigators were contradictory to their zeta-potential measurement. If only dixanthogen is adsorbed, its adsorption should have no effect 


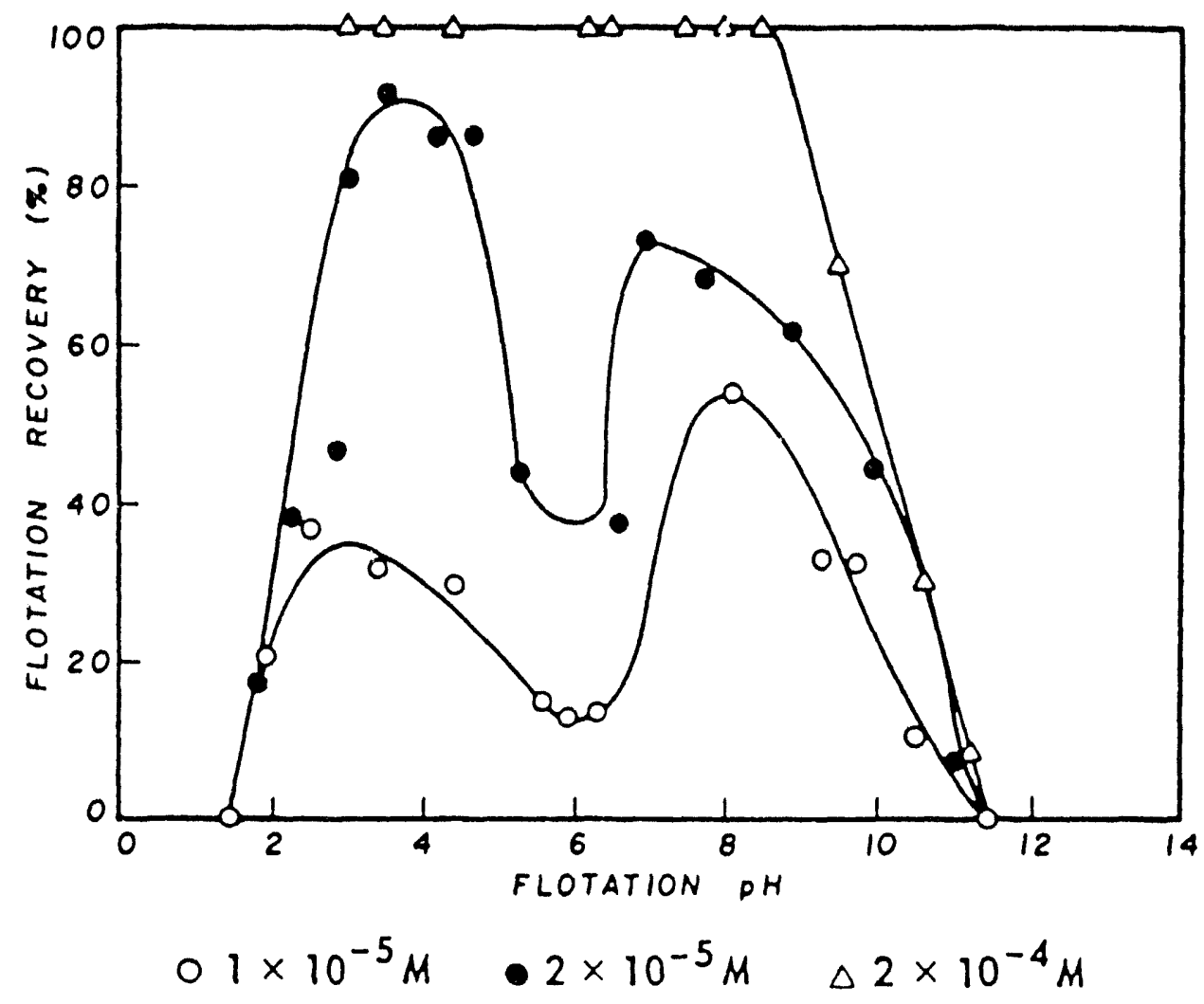

Figure 2.8 Recovery of pyrite as a function of flotation $\mathrm{pH}$ with various additions of potassium ethyl xanthate [from Fuerstenau et al., 1968] 


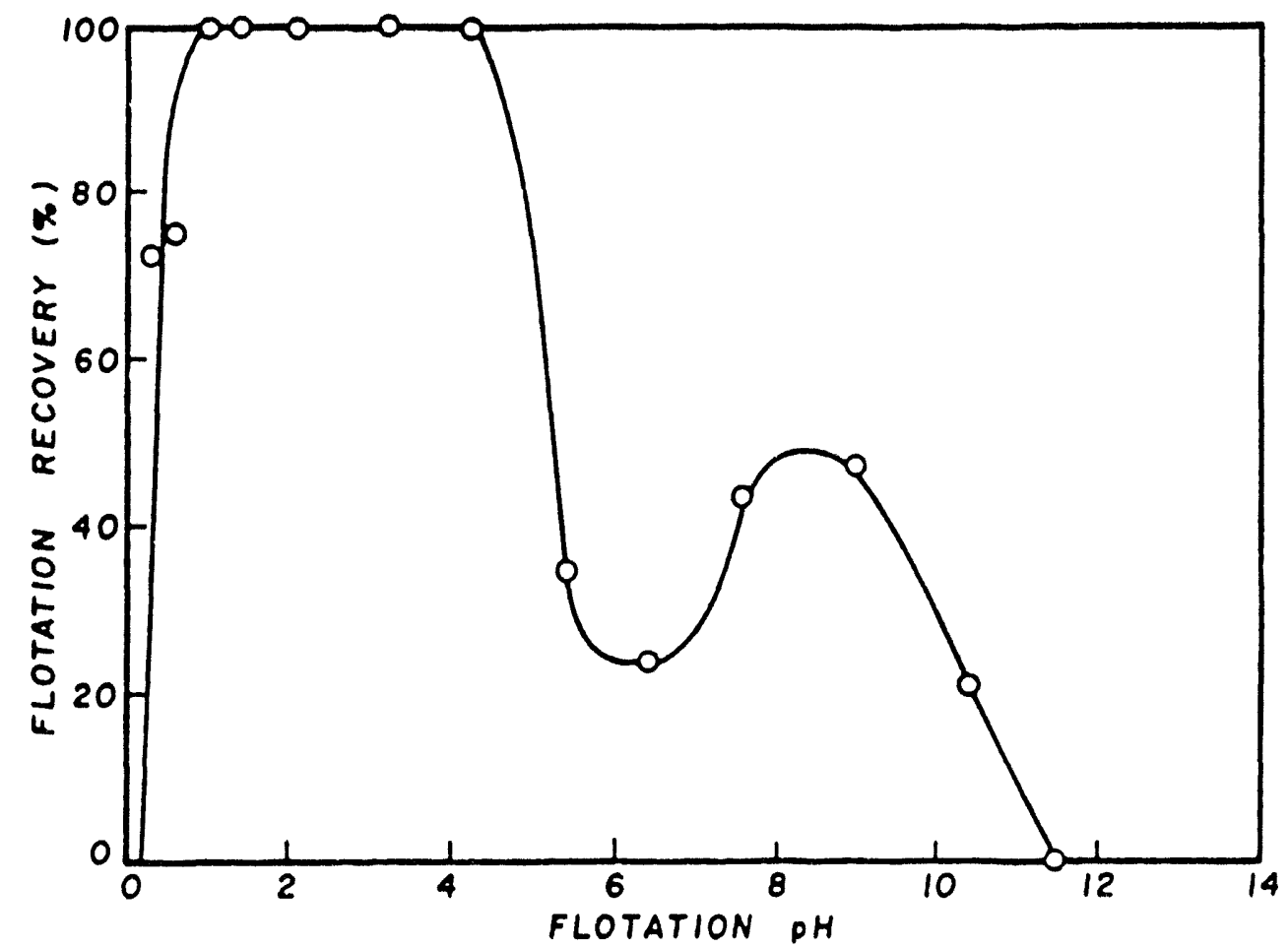

Figure 2.9 Recovery of pyrite as a function of flotation $\mathrm{pH}$ with $1.3 \times 10^{-5} \mathrm{M}$ diethyl dixanthogen [from Fuerstenau et al., 1968] 
on the zeta-potential of the pyrite surface since dixanthogen, ROCSS-SSCOR, is an electrically neutral dimer.

These results suggested that there are some other reactions taking place on the pyrite surface and species other than dixanthogen have been formed or adsorbed on the pyrite surface. Therefore, the conclusion given by the previous investigators was too vague, the real mechanism may be much more complex. Recently, extensive and convincing studies using a number of techniques have been conducted to delineate the principles underlying pyrite flotation with xanthate (Wang, 1989; Wang et al., 1989a; Wang and Forssberg, 1991). They found that a number of ferric xanthate compounds can be formed under the conditions of pyrite flotation and that these compounds play a very important role. The adsorption of xanthate in the acidic $\mathrm{pH}$ region is due to the chemisorption of xanthate ions and dixanthogen, and the formation of surface or bulk ferric xanthate at the high concentration of iron ions. In the alkaline $\mathrm{pH}$ region, the adsorption of xanthate is due to the physical adsorption of aqueous dixanthogen and xanthate ions. In both cases, good flotation can be expected. On the basis of electrochemical studies and thermodynamic calculations, they found that the formation of a surface and /or bulk ferric dihydroxo xanthate, $\mathrm{Fe}(\mathrm{OH})_{2} \mathrm{X}$, is the primary cause of the intermediate depression of pyrite in the neutral $\mathrm{pH}$ range. This is because ferric dihydroxo xanthates are only slightly hydrophobic and may cause depression of pyrite at low xanthate concentrations. At high xanthate concentrations, dixanthogen 
is co-adsorbed and complete flotation is still possible. The above conclusion was successfully adopted by other investigators to study the interaction of ethyl xanthate with pyrite (Fornasiero and Ralston, 1992).

As discussed above, it should be pointed out that the oxidation products like ferric ions was obviously involved in the reaction of xanthate adsorption on pyrite surfaces. It can be expected that the adsorption of xanthate is strongly related to the oxidation of pyrite surface, depending on the solution conditions. It is known that coal-pyrite differs significantly from ore-pyrite in oxidation behavior, so studying the role of oxidation products of pyrite such as iron ions in the flotation of pyrite is very helpful for understanding the principles of coal-pyrite flotation with xanthate. 


\section{CHAPTER 3}

\section{EXPERIMENTAL}

\subsection{Materials and Reagents}

Coal and pyrite samples have been utilized in the study. Pyrites from coal and ore sources were used in order to compare their different physicochemical properties. The ore-pyrite samples from Peru (PUPY) were obtained from Wards Natural Science Establishment Inc., Rochester, New York. The coal and coal-pyrite (KYPY) samples were collected from the Kentucky No.9 coal seam. Chemical analysis results of the coal and pyrite samples are given in Tables 3.1 and 3.2, respectively. The ore-pyrite sample was of high purity and no further cleaning was necessary. The coal-pyrite sample was in the form of lumps with visibly attached coal particles. The coal-pyrite was first crushed with a hammer and the coal particles were removed manually. Only the slabs having no visible coal contamination were used for the experiments. However, the fine coal/carbon substances were uniformly disseminated in the coalpyrite crystals and could not be removed manually. Large crystals of pyrite were selected for preparing electrodes for electrochemical studies. The selected samples of 
Table 3.1 Analysis results of Kentucky No.9 coal

\begin{tabular}{|l|c|}
\hline Analysis & Dry basis (Wt\%) \\
\hline Volatile Matter & 39.1 \\
\hline Fixed Carbon & 48.93 \\
\hline Ash & 11.97 \\
\hline Total Sulfur & 5.70 \\
\hline Pyritic Sulfur & 2.97 \\
\hline Organic Sulfur & 2.66 \\
\hline Sulfate Sulfur & 0.08 \\
\hline
\end{tabular}

Table 3.2 Chemical analysis results of pyrite samples used in the study

\begin{tabular}{|l|ccccccccc|}
\hline \multirow{2}{*}{ Pyrite } & \multicolumn{10}{|c|}{ Element (\%) } \\
\cline { 2 - 10 } & $\mathrm{Fe}$ & $\mathrm{S}$ & $\mathrm{C}$ & $\mathrm{Ca}$ & $\mathrm{SiO}_{2}$ & $\mathrm{MgO}^{\prime}$ & $\mathrm{Al}_{2} \mathrm{O}_{3}$ & $\mathrm{Cu}$ & $\mathrm{Pb}$ \\
\hline PUPY & 42.0 & 49.6 & $<0.1$ & 0.03 & $<.01$ & $\mathrm{~N}$ & $\mathrm{~N}$ & 2.67 & 0.12 \\
\hline KYPY & 30.0 & 39.0 & 4.33 & 6.60 & 2.08 & 0.91 & 0.55 & 0.02 & $<.01$ \\
\hline
\end{tabular}

Note: $\mathrm{N}$ denotes non-detective. 
coal and pyrite were first crushed to 20 mesh by jaw and roll crusher, and ground to 100 mesh with a laboratory pulverizer. The ground samples were dry screened to obtain different size fractions: For the pyrites, $-45 \mu \mathrm{m},-74+45 \mu \mathrm{m},-100+74 \mu \mathrm{m}$ and $150+100 \mu \mathrm{m}$ particle size fractions were prepared. For the coal, $-74 \mu \mathrm{m}$ and $150+100 \mu \mathrm{m}$ size fractions were obtained. The $-45 \mu \mathrm{m}$ fraction of pyrites and $-74 \mu \mathrm{m}$ fraction of coal were used for zeta potential measurements. The prepared samples were kept in a refrigerator to minimize surface oxidation. Detailed description of the sample treatment in some of the experiments will be given in Chapter 4 .

Reagents used in microflotation include fuel oil, potassium ethyl xanthate of analytical grade (American Cyanamid Co.), and methyl isobutyl carbinol (MIBC) (Shell Oil Co.). Sodium hydroxide, nitric acid, potassium nitrate, sodium silicate, sodium metaphosphate, sodium phosphate, sodium pyrophosphate, disodium ethylenediamine tetraacetic acid (EDTA), thiophene carboxylic acid $\left(\mathrm{C}_{5} \mathrm{H}_{4} \mathrm{O}_{2} \mathrm{~S}\right)$, and thiosalicylic acid $\left(\mathrm{HSC}_{6} \mathrm{H}_{4} \mathrm{CO}_{2} \mathrm{H}\right)$ and sodium oxalate $(\mathrm{NaOOCCOONa})$ were obtained form Aldrich Chemical; tartaric acid ((CHOHCOOH $\left.)_{2}\right)$ from Allied Chemical; percholic acid, ferrous sulfate and ferric sulfate from Fisher Scientific Co. and potassium perchlorate from Germany. All the chemicals were of analytical grade. Distilled and deionized water was used throughout the experiment. All the $\mathrm{pH}$ adjustments were made with sodium hydroxide or nitric acid. 


\subsection{Techniques and Procedures}

\subsubsection{Flotation}

The purpose of the flotation tests was to study the flotation behavior of coal, coal-pyrite and ore-pyrite under different conditions. The flotation experiments were carried out in a glass microflotation cell with a $2 \mathrm{~cm}$ diameter and $20 \mathrm{~cm}$ height. The system, which is schematically shown in Figure 3.1, consists of the flotation cell, air supply, flowmeter, pressure regulator and a magnetic stirrer. Nitrogen gas was used in all flotation tests at the flow rate of $5 \mathrm{ml} / \mathrm{min}$. The basic procedures are described as follows. One gram of the prepared pyrite/coal sample was first conditioned in a beaker with $60 \mathrm{ml}$ of distilled and deionized water for 2 minutes at the desired $\mathrm{pH}$. It was observed that, for coal-pyrite, when the desired slurry $\mathrm{pH}$ was far from the natural $\mathrm{pH}$, it was difficult to stabilize the solution $\mathrm{pH}$. In such cases, the conditioning time was allowed to exceed 2 minutes in order to reach the steady-state $\mathrm{pH}$ value by adding extra acid or base. The collector, fuel oil or ethyl xanthate, was added and conditioned for $2 \mathrm{~min}$, unless stated elsewhere. MIBC was then added and the slurry was allowed to further conditioning for $1 \mathrm{~min}$. The slurry was immediately transferred into the micro-flotation cell, and the total flotation slurry volume was adjusted to 100 $\mathrm{ml}$ with water. The $\mathrm{pH}$ of the water used during transference of slurry and flotation was kept the same as that used during conditioning periods to avoid the $\mathrm{pH}$ change 


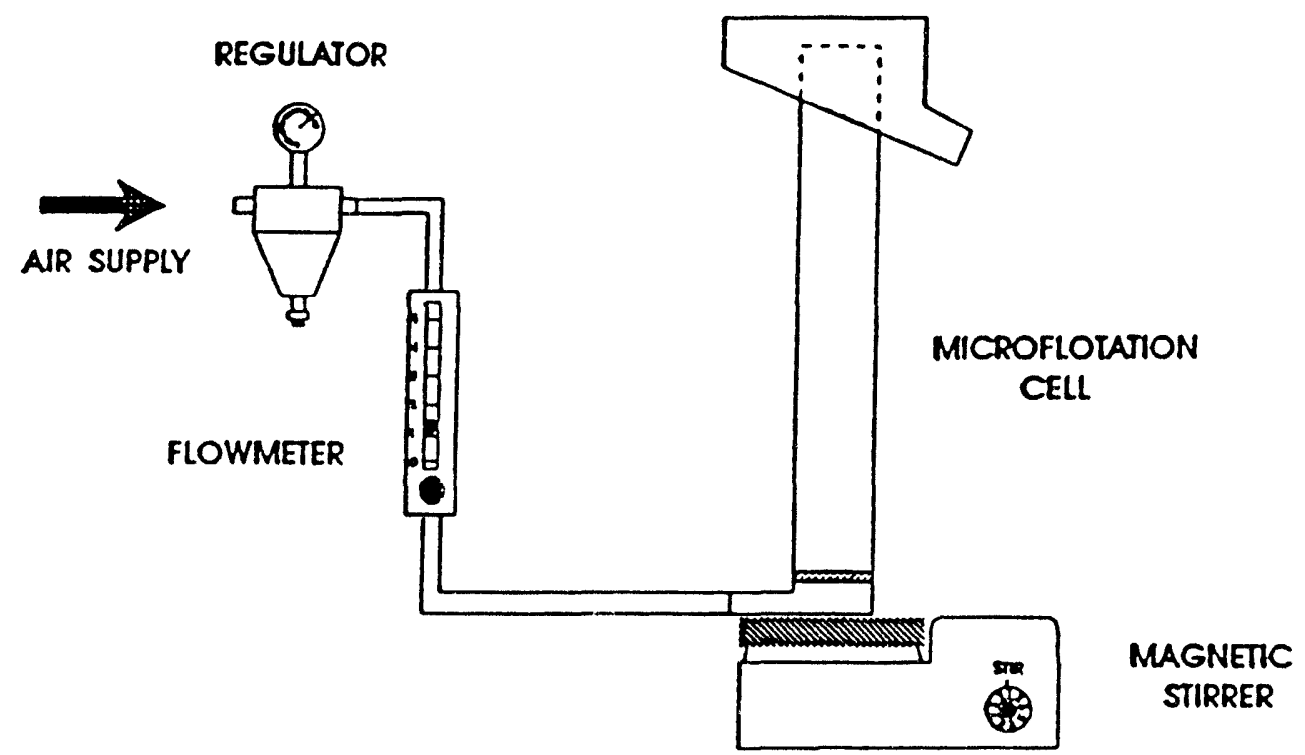

Figure 3.1 Schematic representation of microflotation cell 
due to dilution. A 0.5 min conditioning time was carried out prior to aeration. Froth was then collected for $3 \mathrm{~min}$. After flotation, froth and tailing were filtered, dried and weighed, the froth weight fraction was calculated as recovery. The $\mathrm{pH}$ of the tailing solution in the flotation cell was measured and taken as the flotation $\mathrm{pH}$.

\subsubsection{Zeta Potential Measurements}

The surface electrical properties were investigated by measuring the zeta potentials. Zeta-potential measurements were conducted in a Zeta-Meter Model 3.0 system. These measurements were used to identify the surface electrical charges of the particles. Before each measurement, one gram of $-45 \mu \mathrm{m}$ pyrite or $-74 \mu \mathrm{m}$ coal samples was prepared by wet grinding in a mortar and pestle manually to obtain fresh surfaces. The ground samples were transferred to a beaker containing $100 \mathrm{ml}$ of $10^{-2}$ $\mathrm{M} \mathrm{KNO}_{3}$ solution and conditioned at the selected $\mathrm{pH}$ for 5 minutes. Portion of the suspension was then transferred to the electrophoretic mobility cell and the zeta potential was determined. Ten measurements were made, and the average value are reported here. After measurement, the $\mathrm{pH}$ of the suspension was measured again. The reported $\mathrm{pH}$ was the average $\mathrm{pH}$ value before and after measurement. The detailed procedures for the surface cleaning of the samples with acid washing and the addition of different chemicals are described in Chapter 4. 


\subsubsection{Electrochemical Measurements}

Cyclic voltammetry measurements were performed with a standard threeelectrode system. A pyrite electrode is the working electrode. The counter electrode is a platinum electrode. The potentials were measured against a saturated calomel electrode (SCE). The system consists of an EG\&G Princeton Applied Research (PAR) Model 273 potentiostat/galvanostat, and a PAR Model 660 rotating-disc electrode apparatus. The system, including data acquisition, is operated by a 386 IBM computer. All the measurements were performed using modified Headstart Creative Software. The rotating-disc electrode (RDE) technique enables one to study the effect of rotating the electrode on the reaction process occurring at the electrode surface, and therefore to distinguish the solution species from the solid species involved in the reactions. The EG\&G Princeton Applied Research manufactured RDE system has several drawbacks. Therefore, the RDE has been modified such that only the upper portion keeps tight contact with the electrochemical cell lid. The cell is thus sealed from the atmosphere. Unless otherwise stated, all the electrochemical experiments in this study were performed in $0.1 \mathrm{M}$, potassium perchlorate $\left(\mathrm{KCIO}_{4}\right)$ solution. The solution was purged with high purity nitrogen gas for at least 60 minutes before the experiments were started. A nitrogen gas flow was maintained above the solution surface during the experiments to prevent the return of oxygen/air to the system. 
The pyrite electrodes were prepared from massive natural specimen. The slabs were cut to cubic samples and attached to a brass rods using a conducting carbon glue. The electrodes were molded in epoxy resin, exposing only one face to the electrolyte solution. Before each measurement, the electrode was polished with 400 grit SiC polishing paper in air with distilled and deionized (DD) water and rinsed with DD water. The polished electrode was immediately put into the electrochemical cell. The measured geometric surface areas were used for calculating the current density. All the $\mathrm{pH}$ adjustment were made with perchloric acid and sodium hydroxide and no complexing buffer was used in the experiment. 


\section{CHAPTER 4}

\section{RESULTS AND DISCUSSIONS}

\subsection{Self-Induced Flotation of Coal and Pyrites}

The self-induced flotation of Kentucky No.9 coal in the presence of $50 \mathrm{mg} / 1$ MIBC as a function of $\mathrm{pH}$ for different particle sizes is presented in Figure 4.1. Of the various particle sizes studied, only the size fraction of $-74 \mu \mathrm{m}$ coal shows moderate flotation in acidic media in the absence of a collector. Maximum recovery is found to be about $55 \%$ in the acidic $\mathrm{pH}$ range (below $\mathrm{pH}$ 6). Above $\mathrm{pH} 6$, the recovery decreases drastically with increasing $\mathrm{pH}$. The flotation ceases at about $\mathrm{pH} 10$. However, for coarse size fractions $(-150+100 \mu \mathrm{m})$, the presence of $50 \mathrm{mg} / \mathrm{l} \mathrm{MIBC}$ does not induce coal flotation.

The results indicate that the self-induced floatability of coal depends strongly on the particle size. It is known that flotation is determined by many factors. Besides the surface hydrophobicity which determines the thermodynamics of flotation, the particle size controls the kinetics of flotation (Crawford and Ralston, 1988). The 


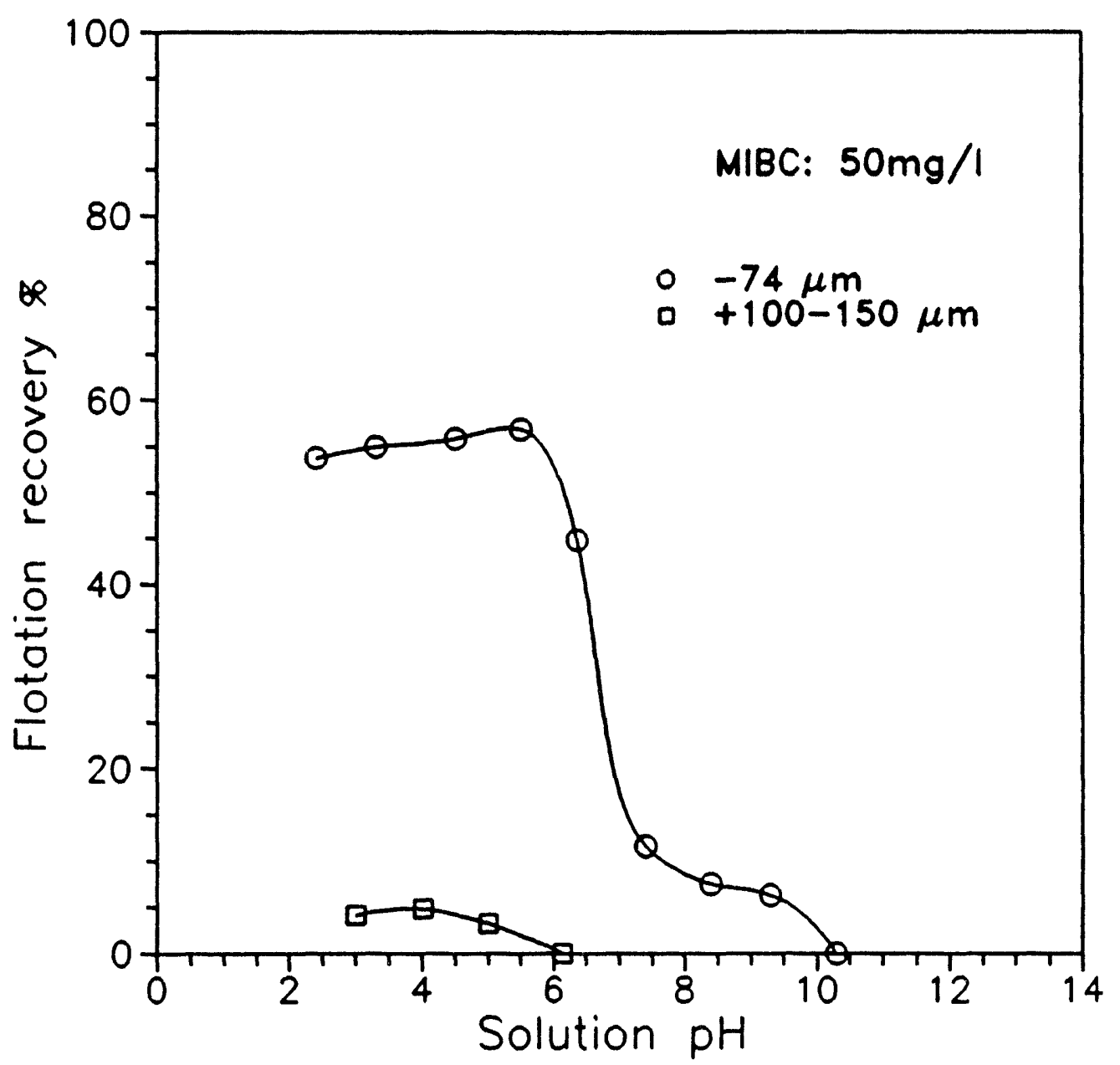

Figure 4.1 Floatability of Kentucky No.9 coal of different particle sizes as a function of solution $\mathrm{pH}$ in the presence of MIBC. 
moderate flotation of fine coal $(-74 \mu \mathrm{m})$ would be attributed to the natural surface hydrophobicity of coal. The lack of floatability of the coarse coal particles $(-150+100$ $\mu \mathrm{m})$ is probably due to the greater probability of detachment from the bubbles in the flotation cell (Trahar, 1981).

In contrast to coal, in the absence of a collector, it was found that coal-pyrite and ore-pyrite of all size fractions exhibit no flotation in the whole $\mathrm{pH}$ range. This indicates that the surfaces of the coal- and ore-pyrite are hydrophilic. It should be pointed out that the self-induced flotation of pyrite depends on the relative amount and distribution of the hydrophobic and hydrophilic species at the surface. The hydrophobic species were considered to be sulfur-rich iron sulfide or elemental sulfur, whereas the hydrophilic species were considered to be iron hydroxides. The relative amount of these species is determined by the rate of oxidation, degree of oxidation and the solution chemical composition. Although the exact nature of the distribution and composition of surface oxidation products on the pyrite surface is not clear, it is considered that the iron hydroxide is precipitated on the outer most layer, thus rendering the pyrite surfaces hydrophilic (Ramprakash et al, 1991; Smart, 1991).

The hydrophilic iron hydroxide layer present on the pyrite surface can be removed by reacting with complexing agents such as EDTA (Wang and Forssberg 1990; Pang and Chander, 1992) or by ultrasonic pretreatment (Raichur, 1992), a 
hydrophobic surface due to the presence of a sulfur rich layer can be exposed resulting in the self-induced flotation of pyrite.

\subsubsection{Effect of Ultrasonic Treatment on Self-Induced Flotation}

One gram of pyrite or coal sample was placed in a beaker with $100 \mathrm{ml}$ distilled water and ultrasonically treated for 2 minutes. The solution was then discarded and the sample rinsed with water. Ultrasonic treatment continued for another 2 minutes following the same procedure. The treated sample was immediately used for the flotation experiments.

In Figure 4.2, the flotation recovery of coal, coal-pyrite and ore-pyrite as a function of $\mathrm{pH}$ in the presence of $100 \mathrm{mg} / \mathrm{l} \mathrm{MIBC}$ after ultrasonic pretreatment is presented. Compared with untreated coal (Figure 4.1), it can be seen that ultrasonic treatment significantly increases the floatability of coal $(-150+100 \mu \mathrm{m})$ in both acidic and alkaline solutions. In the neutral solution of about $\mathrm{pH} 6$ treated coal remains poorly floatable. It should be noted that for the same particle size, the untreated coal shows negligible flotation. It indicates that apart from the particle size, coal flotation also depends on the surface oxidation state and the chemical conditions of solution.

The floatability of ore-pyrite increases, similar to that of coal after ultrasonic 


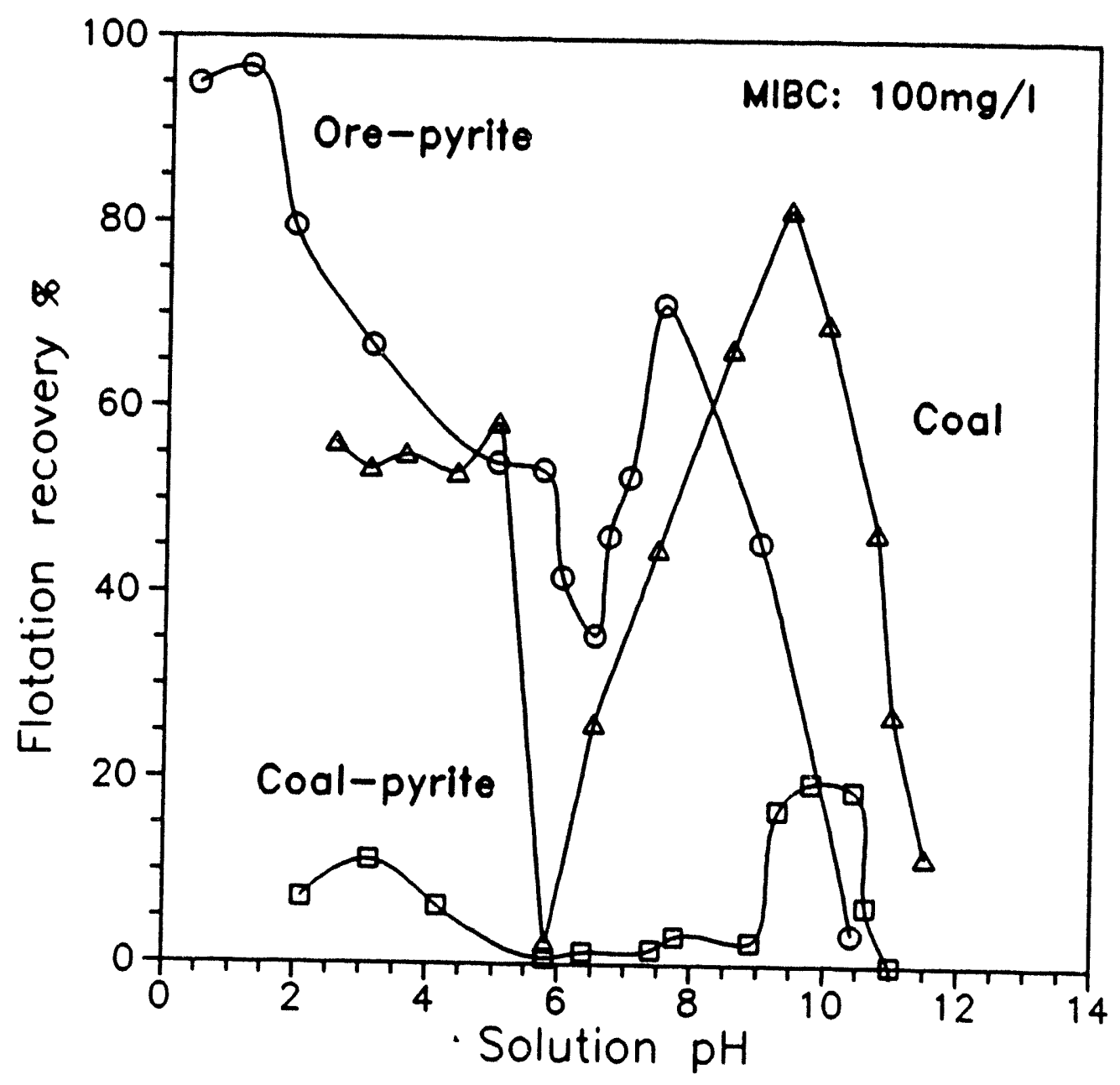

Figure 4.2 Flotation recovery as a function of solution $\mathrm{pH}$ for coal, coal- and ore-pyrite in the presence of MIBC after surface cleaning by ultrasonication. Particle size: coal $-150+100 \mu \mathrm{m}$; coal-pyrite and ore-pyrite $-74+45 \mu \mathrm{m}$. 
treatment. The ore-pyrite shows good flotation up to $\mathrm{pH} 10$. In acidic solution below $\mathrm{pH} 2$, ore-pyrite becomes completely floatable indicating that its surface is highly hydrophobic. Unlike ore-pyrite, the floatability of coal-pyrite treated ultrasonically is extremely low and no significant increase is noted. These results demonstrate that the hydrophilic iron hydroxide layer on the ore-pyrite is thin and can be readily removed by mechanical cleaning methods such as ultrasonic treatment. As will seen later in Section 4.5, electrochemical studies have shown that coal-pyrite exhibits a high degree of oxidation and such oxidation products adhere strongly to the surface. A much thicker iron hydroxide layer is formed on the coal-pyrite surface compared to the ore-pyrite surface. Surface cleaning with ultrasonication cannot readily remove these hydrophilic species. Thus, the surface remains coated with iron hydroxide, and no substantial exposure of the sulfur rich layer on the coal-pyrite surface is available after mechanical treatment.

\subsubsection{Effect of Acid Washing on Surface Charge}

Acid washing of coal or pyrite sample was carried out with dilute nitric acid solution of $\mathrm{pH} 2$ for 10 minutes. The sample was then thoroughly washed with distilled water and re-ground for zeta potential measurements.

At the solid-aqueous solution interface encountered in sulfide mineral flotation, 
an electrical double layer is established. Surface oxidation, ion adsorption and bubble interaction, etc., all take place in this double layer. Because pyrite is susceptible to oxidation, the pyrite-solution interface will therefore reflect the nature of the various species produced by oxidation and their effect on surface properties.

Figure 4.3 shows the zeta potential of ore-pyrite as a function of $\mathrm{pH}$ before and after acid washing. It can be seen that the $\mathrm{PZC}$ of ore-pyrite is $\mathrm{pH} 7.4$ without acid washing and decreased to $\mathrm{pH} 3.5$ after acid washing. The result is in agreement with previous studies (Fuerstenau and Mishra, 1981; Fuerstenau et al, 1990), where the $\mathrm{PZC}$ of pyrite was reported to be $\mathrm{pH}=3.5$ in a deoxygenated solution and was changed to $\mathrm{pH} 7$ in the presence of oxygen. On the other hand, it has been shown by Wang and Forssberg (1990) that the presence of a complexing agent, like EDTA, leads to iron dissolution from the pyrite surface, followed by a shift of PZC to lower $\mathrm{pH}$ values. Similar to other surface cleaning methods, the decrease of PZC with acid washing can be attributed to the removal of the metal hydroxide and the exposure of negatively charged sulfur rich layer on the pyrite surface. Therefore, when using ultrasonic treatment for surface cleaning, the increased surface hydrophobicity can greatly enhance the flotation of ore-pyrite.

The effect of ferric and ferrous ion additions on the zeta potential of ore-pyrite is shown in Figure 4.4. In the presence of ferric ions, the zeta potential behavior of 


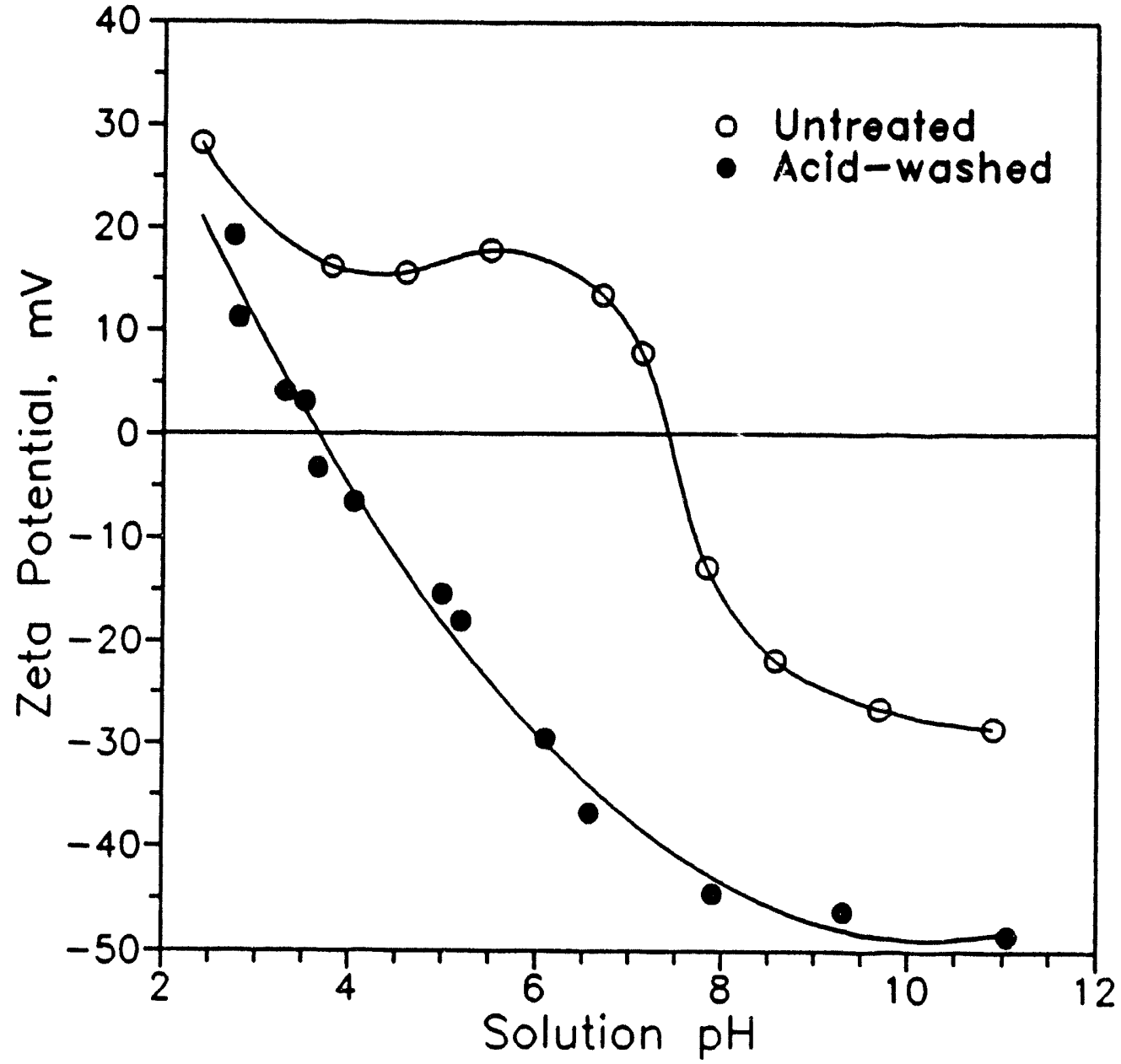

Figure 4.3 The zeta potential of ore-pyrite as a function of solution $\mathrm{pH}$ with and without acid washing. 


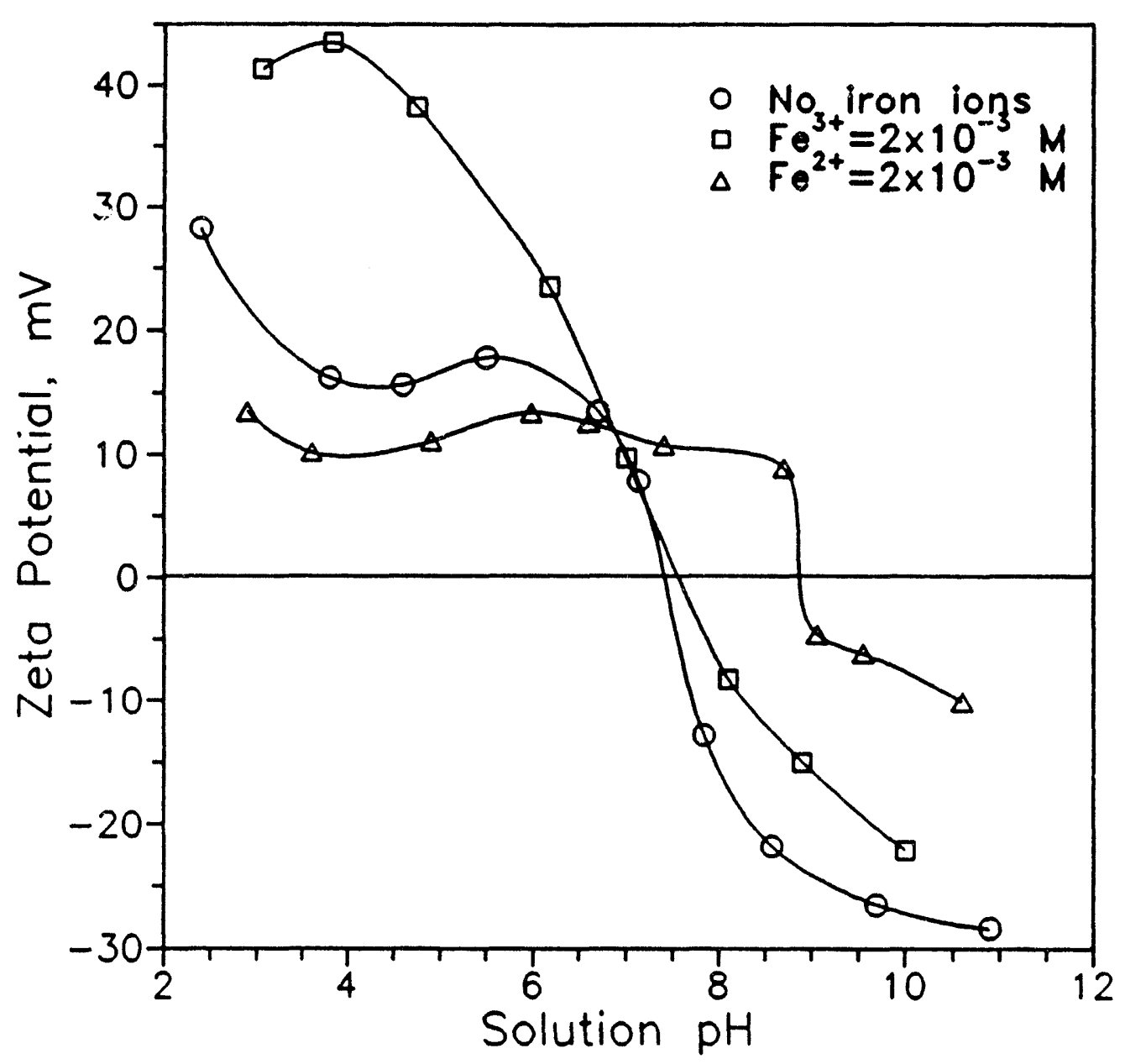

Figure 4.4 The zeta potential of ore-pyrite as a function of solution $\mathrm{pH}$ in the presence of ferrous and ferric ions. 
ore-pyrite follows a similar trend to that in the absence of ferric ions, and in both cases, the PZC's are nearly the same at around $\mathrm{pH} 7.5$, except that the surface becomes more positively charged below $\mathrm{pH} 7.5$. Unlike ferric ions, the addition of ferrous ions increases the $\mathrm{PZC}$ of ore-pyrite from $\mathrm{pH} 7.5$ to $\mathrm{pH} 9$. It should be noted that in the presence of ferrous ions, the magnitude of the zeta potential of ore-pyrite is apparently lowered. It is obvious from Figure 4.4 that the surface electrical properties of ore-pyrite are principally determined by the presence of ferric ions. The electrokinetic behavior of ore-pyrite can be explained by the oxidation of the pyrite surfaces. Except for the ferric hydroxide produced by oxidation, the hydroxylated cationic species, $\mathrm{FeOH}^{2+}, \mathrm{Fe}(\mathrm{OH})^{+}$, and $\mathrm{Fe}_{2}(\mathrm{OH})_{2}{ }^{4+}$, also exist in solution (see Figure A-1 in Appendix). These positively charged ions may adsorb onto the surface as a result of electrostatic interaction with the negatively charged sulfur rich layer at the pyrite surface. Following the precipitation of iron hydroxide on pyrite, the surface is postulated to acquire the electrokinetic features of the iron hydroxide. Hence, the $\mathrm{PZC}$ should shift to a higher $\mathrm{pH}$ value with an increase in the concentration of ferric ions, produced either by pyrite oxidation or added. It has been shown that even a modest degree of oxidation will produce a pyrite surface which behaves like iron oxide (Fornasiero and Ralston, 1992), which was reported to have a PZC at a pH of around 7 (Fuerstenau et al, 1988).

Figure 4.5 presents the zeta potential of coal-pyrite with and without acid 


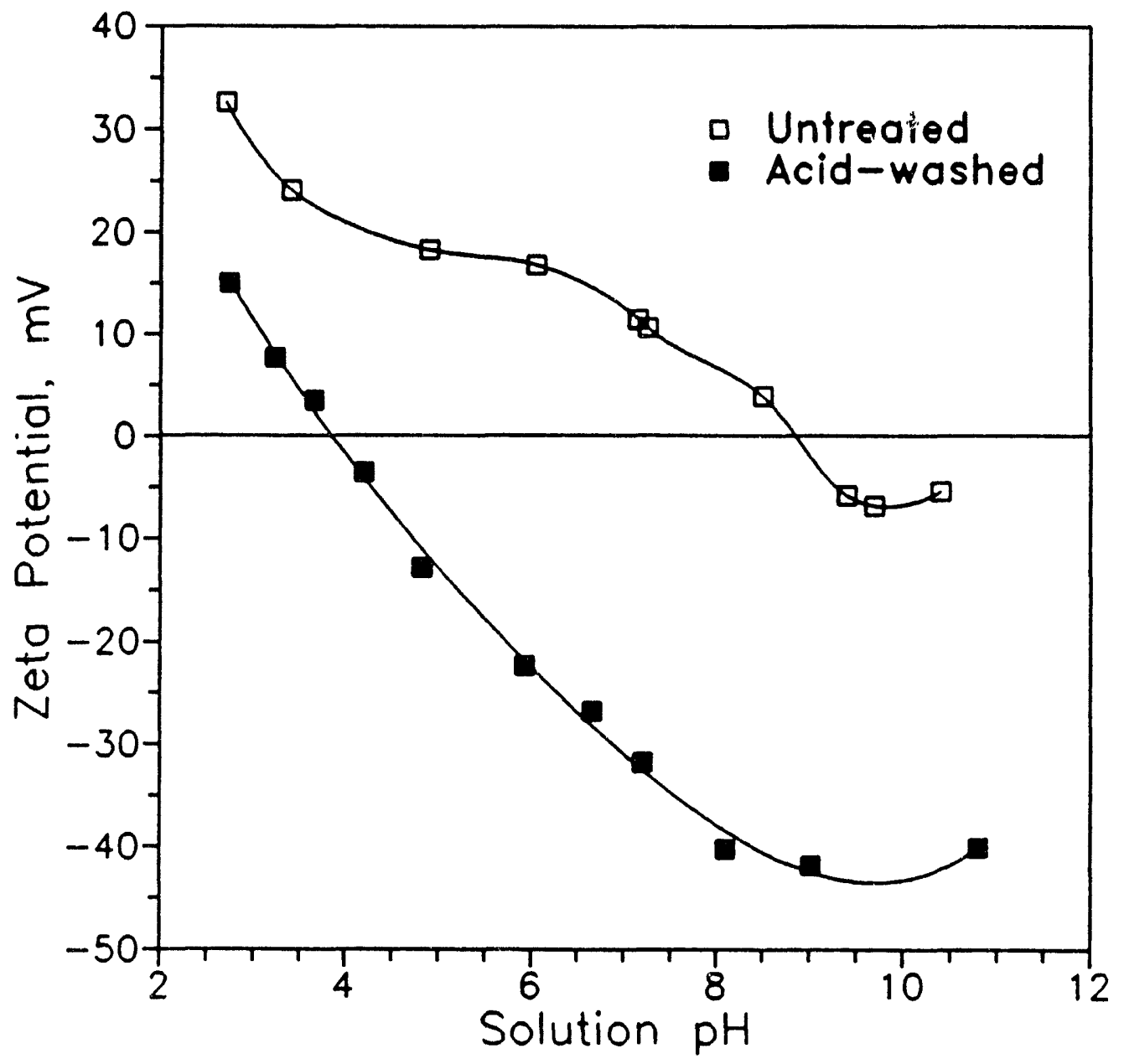

Figure 4.5 The zeta potential of coal-pyrite as a function of solution $\mathrm{pH}$ with and without acid washing. 
washing. Without acid washing, the coal-pyrite particles are positively charged below $\mathrm{pH} 8.7$. It can be seen that the electrokinetic behavior of coal-pyrite is analogous to that of ore-pyrite in the presence of ferrous ions. As shown in Figure 4.4, the same $\mathrm{PZC}$ at $\mathrm{pH} 8.7$ was observed. It demonstrates that the surface charge of coal-pyrite may be in part controlled by the ferrous ions. After acid washing, similar to orepyrite, the PZC of coal-pyrite is decreased to $\mathrm{pH} 3.5$. This shows that the surface oxidation product was effectively removed by acid and the surface of coal-pyrite becomes sulfur-rich thus behaving like that of acid-washed ore-pyrite.

Mechanical surface cleaning like ultrasonic treatment significantly increases the hydrophobicity of ore-pyrite compared to coal-pyrite. The reasons why coal-pyrite remain less unaffected may be caused by the formation of a thicker iron hydroxide layer on the coal-pyrite. When subjected to mechanical cleaning, the iron hydroxide layers may be removed but quickly re-deposited on the surface due to high solution concentration. While in the case of acid-washing, the iron-hydroxides are dissolved at very low $\mathrm{pH}$ value (ca. $\mathrm{pH} 2$ ), then little re-deposition onto surface takes place. This infers that acid possesses a stronger cleaning ability than mechanical cleaning. A thin oxidation layer on ore-pyrite can be removed with both treatment methods due to the lower concentration of oxidation product on the ore-pyrite surface. The sulfurrich layer is responsible for the decrease of PZC's of both coal-pyrite and ore-pyrite after acid washing. 
The electrokinetic behavior of coal with or without acid washing is presented in Figure 4.6. After acid washing, the coal was positively charged below pH5.3 and negatively charged above pH5.3. The results are like those obtained by Campbell and Sun (1970) who reported the PZC of bituminous coal to be $\mathrm{pH} 4.8$. Without acid washing, the PZC of coal reaches $\mathrm{pH} 7.5$, a same value as that of ore-pyrite (Figure 4.3). It can be expected that apart from the surface oxidation of coal, the iron ions contaminating coal may affect the surface electrical properties. Baker and Miller (1971) reported a PZC for coal to be $\mathrm{pH} 5$, and in the presence of small amount of ferric ion the PZC was increased to $\mathrm{pH} 7.5$. Thus, at $\mathrm{pH}$ values below 7.5 when no acid washing was performed, it is possible for iron(III) or iron(II) precipitate to adsorb onto the coal surface and render the surface positively charged. Since coal can yield a good flotation performance by ultrasonic treatment, and since coal shows a decreased PZC after acid washing, the iron hydroxides produced by the oxidation of small amount of pyrite in coal samples are loosely precipitated on coal surface and can be readily removed.

From the above zeta potential measurements, it is evident that the iron hydroxides produced by pyrite oxidation play an important role in the surface properties of pyrites and coal. The hydrophilic iron hydroxides on surfaces not only affect the affinity of pyrites to air bubbles, but also reduce the attachment of coal particles to air bubbles when the particle size is large. 


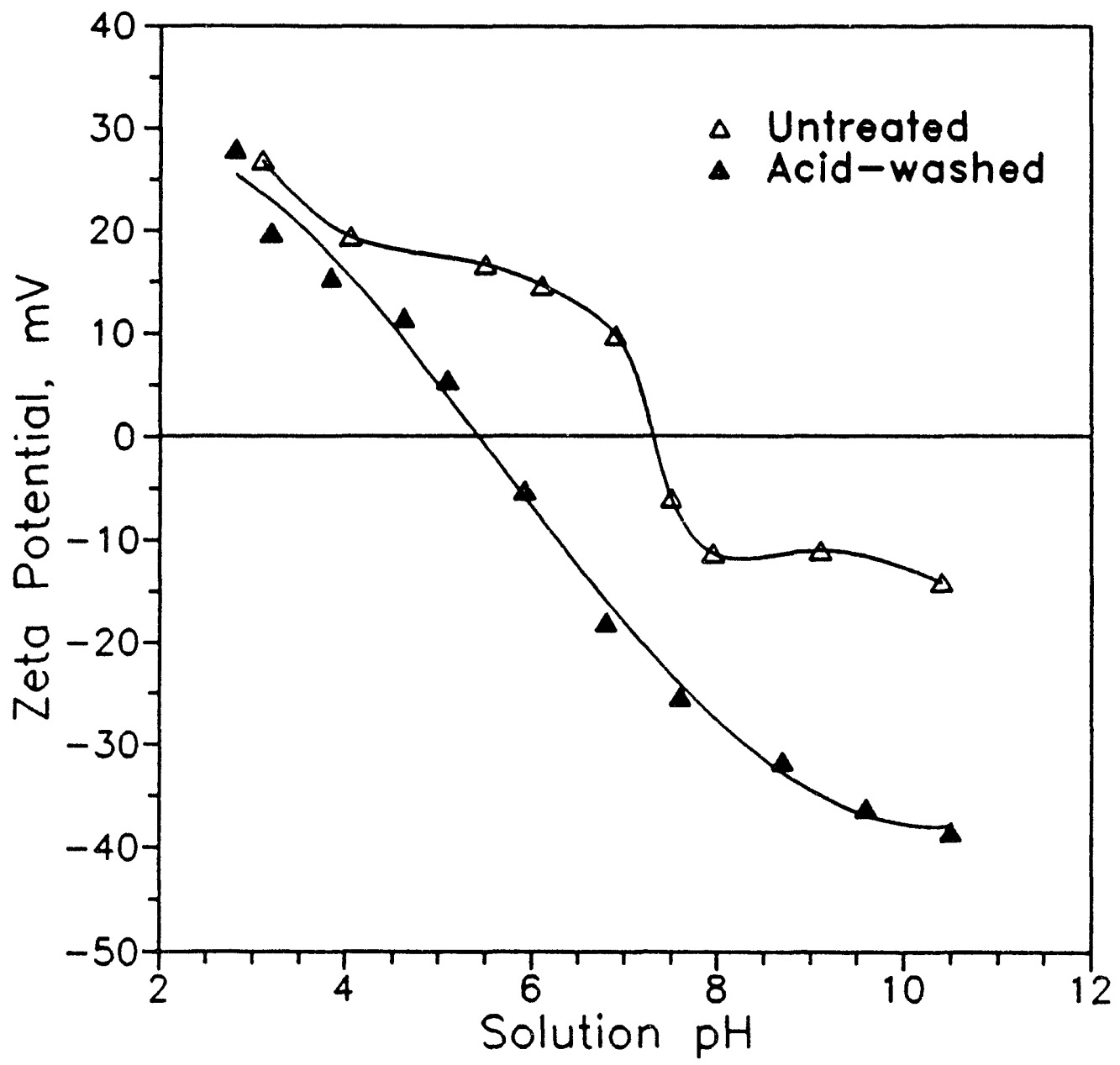

Figure 4.6 The zeta potential of coal as a function of solution $\mathrm{pH}$ with and without acid washing. 


\subsection{Oil-Induced Flotation of Coal and Pyrites}

Nonpolar oily organic compounds such as fuel oil have been widely used as collectors in coal flotation to improve the hydrophobicity of the coal surface. It is generally assumed that the oily collectors are adsorbed only on coal particle surfaces. Some investigators concluded that coal-pyrite is recovered in the coal froth predominantly by entrainment; and as such has no hydrophobic character (Kawatra and Eisele, 1988). However, no convincing evidence has been provided. These conclusions were usually made on the basis of one or two $\mathrm{pH}$ and particle size levels. Since the floatability of pyrite is strongly $\mathrm{pH}$ and particle size dependent, to understand the causes of the undesirable recovery of pyritic sulfur in coal froth, it is desirable to systematically examine the effects of oily collectors on the floatability of coal and pyrites for different particle sizes over a wide $\mathrm{pH}$ range.

The floatabilities of coal, coal-pyrite and ore-pyrite as a function of $\mathrm{pH}$ in the presence of fuel oil are presented in Figures 4.7-4.9, respectively. It can be seen from Figure 4.7 that except for the fine size coal $(-74 \mu \mathrm{m})$, no flotation has been observed for the coal-pyrite and ore-pyrite in the absence of fuel oil. When $50 \mathrm{mg} / \mathrm{l}$ fuel oil was added, coal shows good flotation properties up to $\mathrm{pH} 10.5$. Even at a $\mathrm{pH} 12$, recoveries of the two different sizes of coal are still $65 \%$ and $75 \%$, respectively. Hence, as expected, the floatabilities of the coal was considerably improved by the 


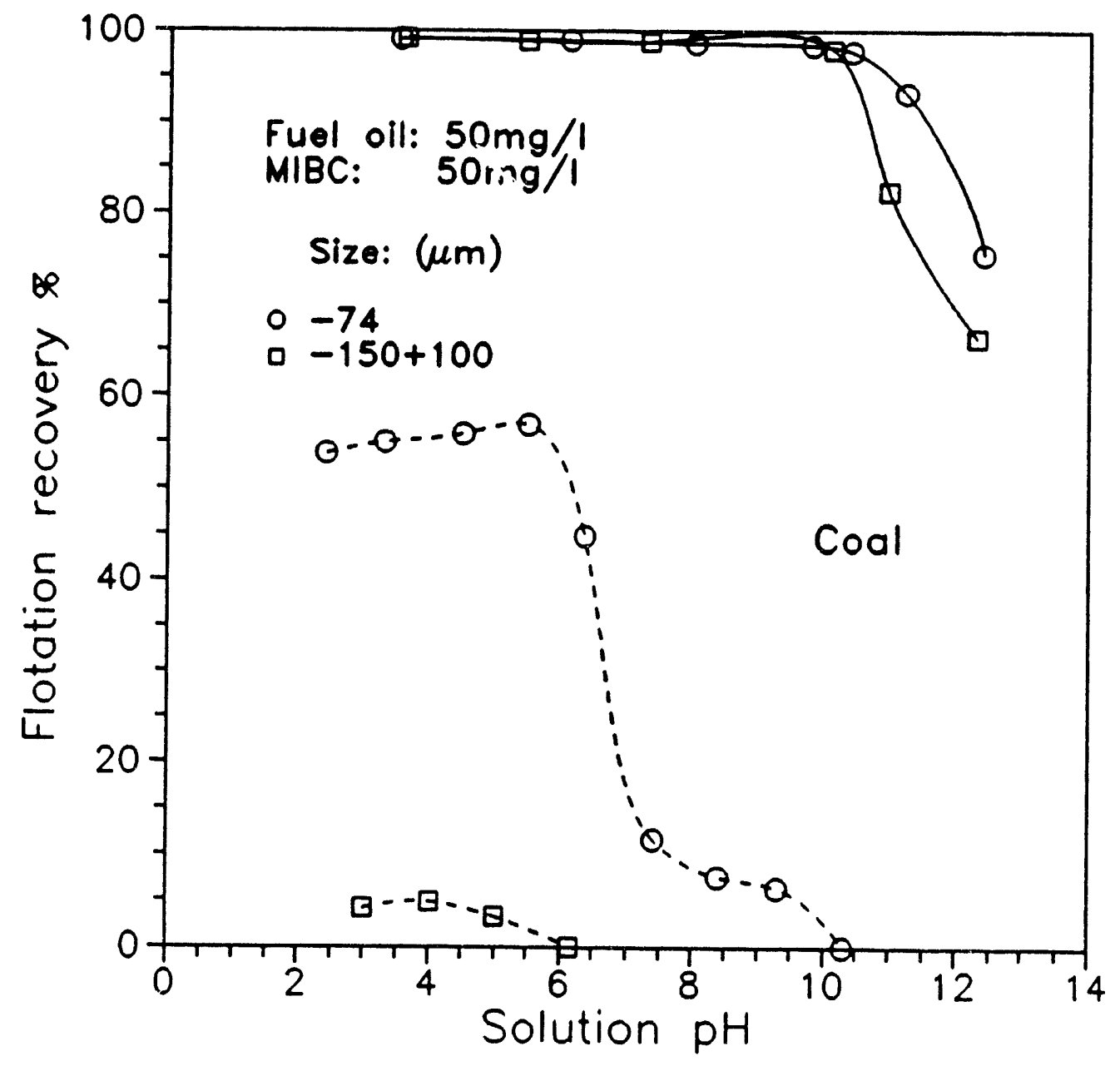

Figure 4.7 Flotation recovery of coal as a function of solution $\mathrm{pH}$ and particle size in the presence of fuel oil as collector. Dashed lines show the floatabilities of coal in the absence of fuel oil as shown in Figure 4.1. 


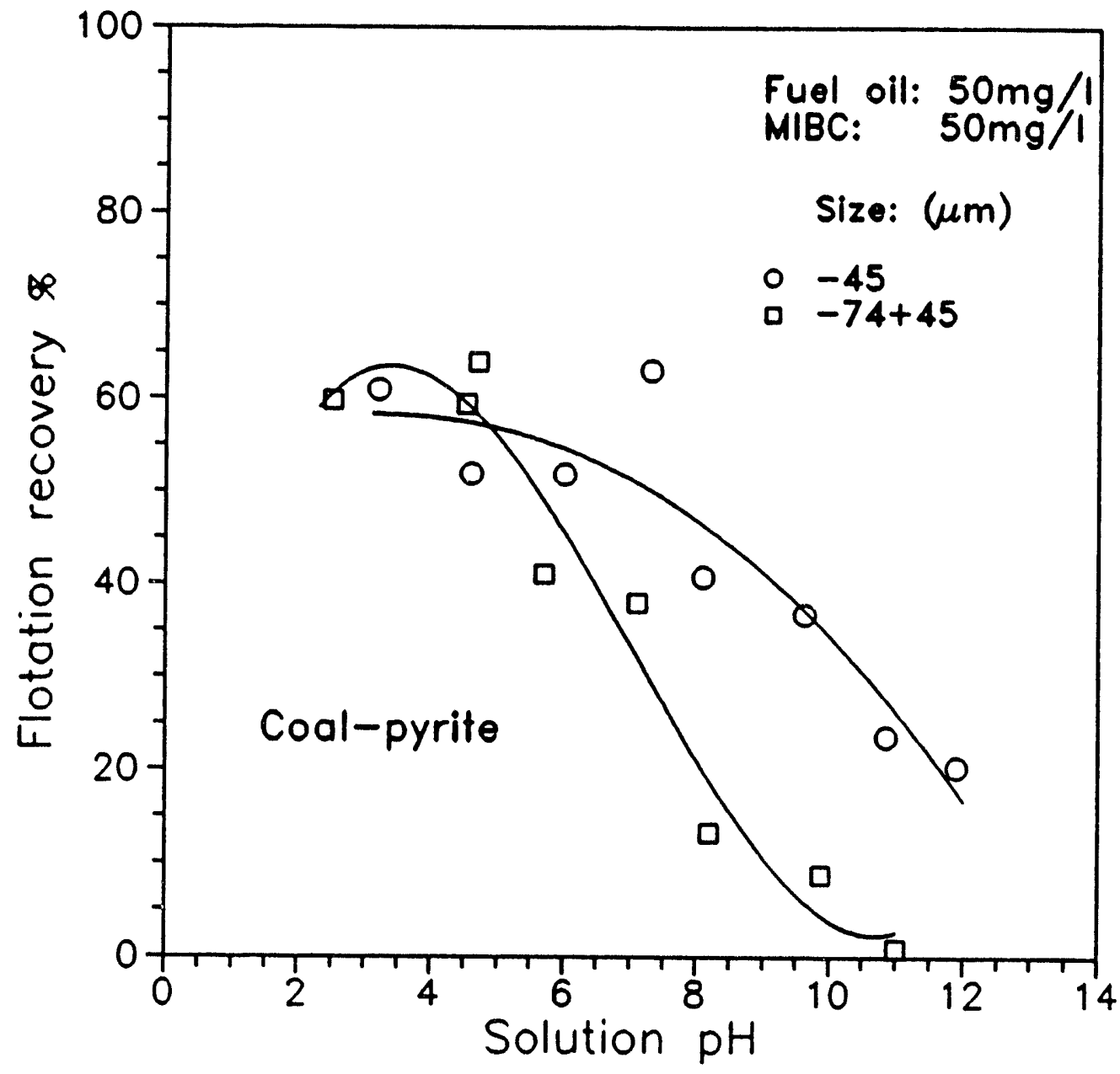

Figure 4.8 Flotation recovery of coal-pyrite as a function of solution $\mathrm{pH}$ and particle size in the presence of fuel oil as collector. 


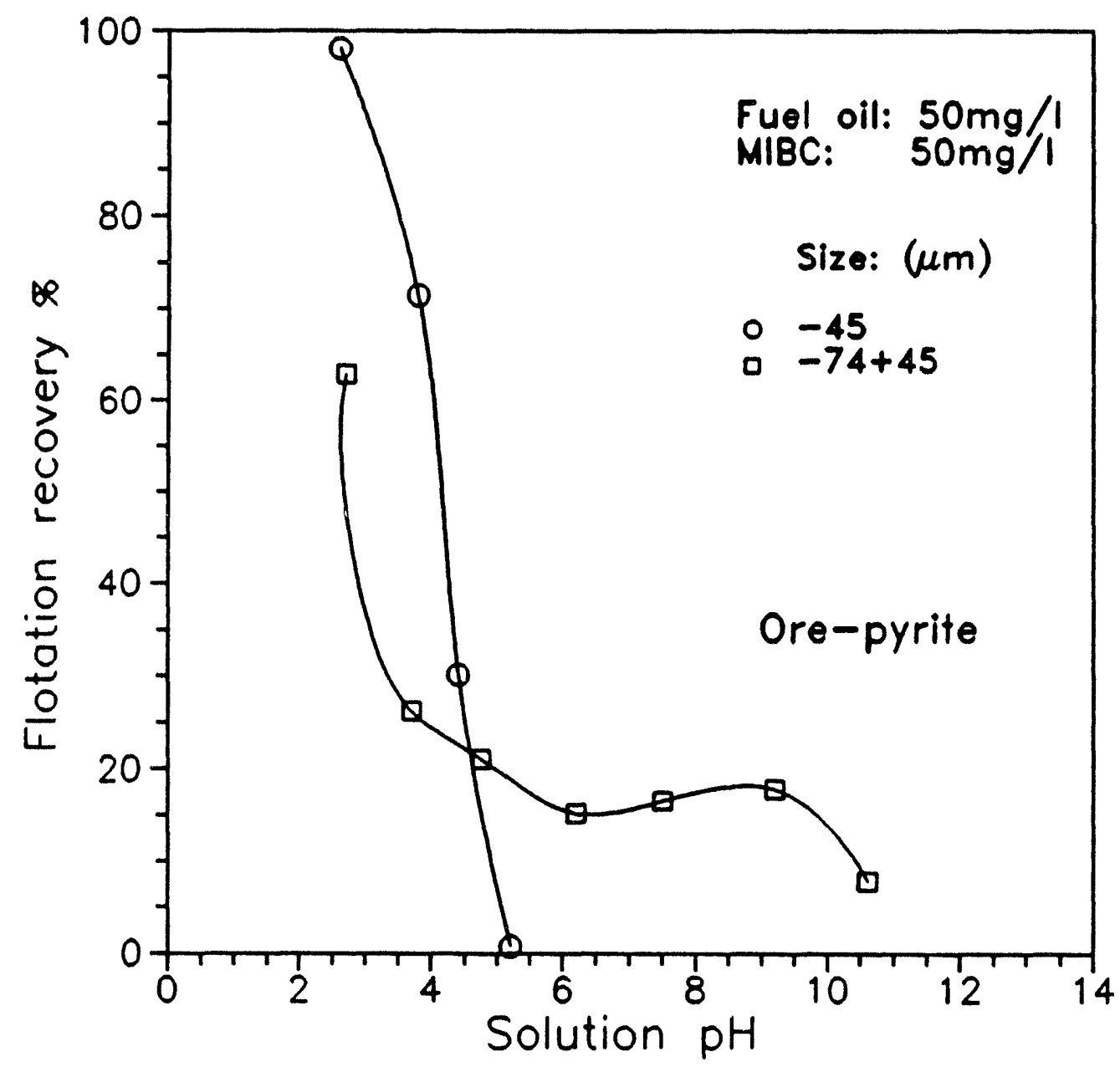

Figure 4.9 Flotation recovery of ore-pyrite as a function of solution $\mathrm{pH}$ and particle size in the presence of fuel oil as collector. 
presence of fuel oil.

The presence of fuel oil also induces considerable flotation for coal-pyrite, particularly for the fine particle sizes as shown in Figure 4.8. The floatabilities of coal-pyrite are relatively high in the acidic range and decrease as $\mathrm{pH}$ increases. It is interesting to note that the finer size fraction $(-45 \mu \mathrm{m})$ of the coal-pyrite shows higher flotation in alkaline solutions than the coarser size fraction $(-75+45 \mu \mathrm{m})$. Even up to $\mathrm{pH} 12,20 \%$ recovery of the coal-pyrite of size $-45 \mu \mathrm{m}$ can still be observed, while flotation has ceased for the coarse size $(-74+45 \mu \mathrm{m})$ at $\mathrm{pH} 10$. Further studies indicate that the flotation of the coal-pyrite increases with increasing concentration of fuel oil. For the ore-pyrite, both coarse and fine size fractions display a moderate flotation in acidic solution, as can be seen from Figure 4.9. However, in the neutral and alkaline solutions, no flotation can be observed for fine size ore-pyrite $(-45 \mu \mathrm{m})$. The coarse size fraction $(-74+45 \mu \mathrm{m})$ of ore-pyrite shows a flotation plateau of about $15 \%$ recovery. Thus, the finer size fraction of the ore-pyrite is less floatable than the coarser size fraction. This is contrary to that of the coal-pyrite.

Figure 4.10 shows the effect of particle sizes on the floatabilities of coal-pyrite and ore-pyrite in the presence of fuel oil at pH6-7. The effect of particle sizes on the floatabilities of pyrites from coal and ore sources follows different pattern. For the coal-pyrite, the finer the particle size, the higher the floatability; while, for ore-pyrite, 


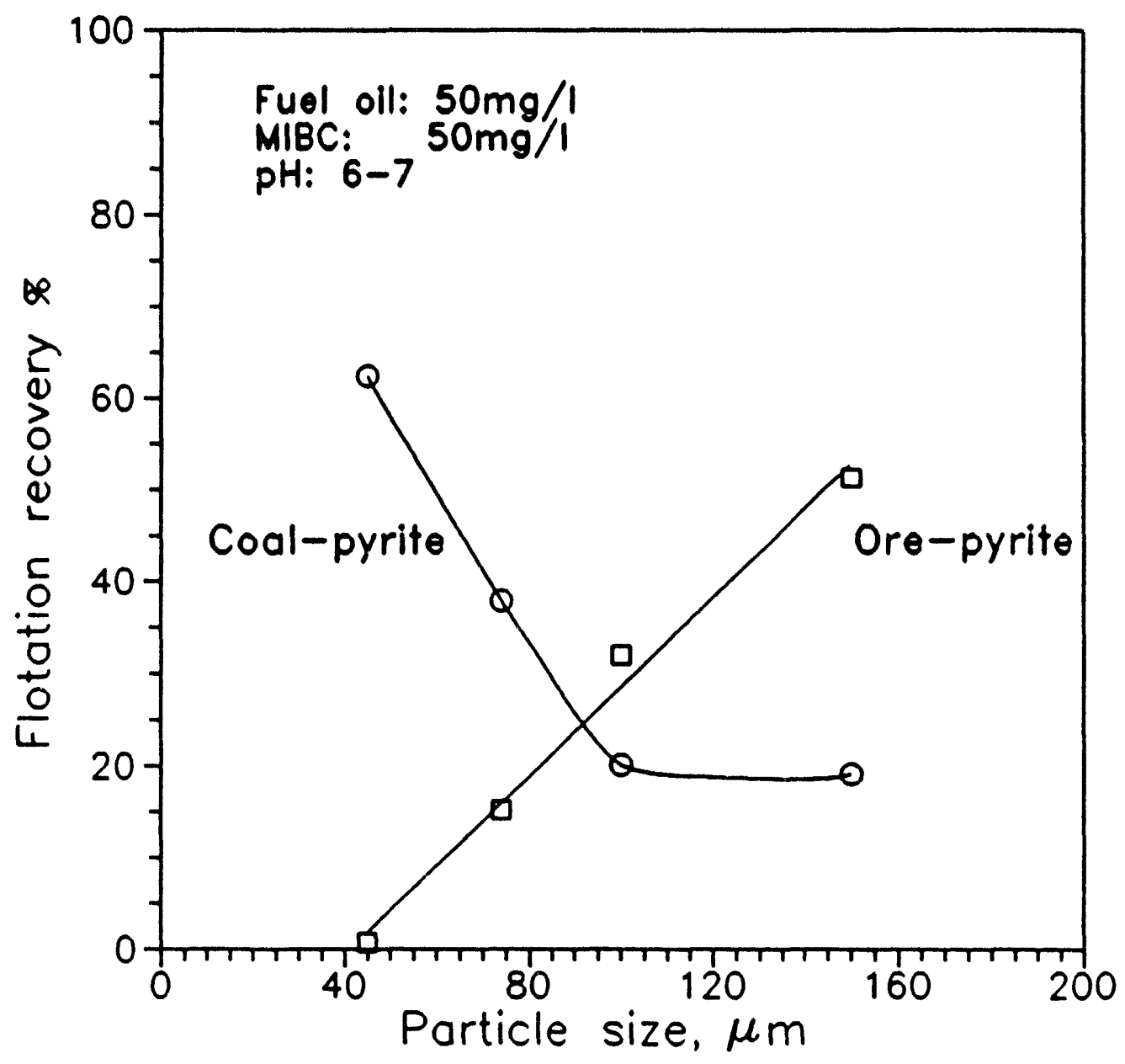

Figure 4.10 Effect of particle size on the floatability of coal- and ore-pyrite in the presence of fuel oil as collector. 
the floatability increases with increasing particle size. When the particle size is below $45 \mu \mathrm{m}$, the coal-pyrite reaches a recovery above $60 \%$, but ore-pyrite shows no flotation at all. The results demonstrate that fine coal-pyrite has high affinity for fuel oil.

Figure 4.11 compares the floatabilities of fine coal, coal-pyrite and ore-pyrite as a function of $\mathrm{pH}$ in the presence of fuel oil. It clearly shows that in the presence of fuel oil coal displays complete flotation, ore-pyrite has no floatability above pH5, while coal-pyrite lies in the middle. It is worthwhile noting that coal-pyrite and coal show considerable similarity in their flotation characteristics. These results indicate that fuel oil adsorbs not only on the coal surface but also on the coal-pyrite surface, rendering the surfaces hydrophobic, and thereby reducing the selectivity of flotation separation.

The bulk flotation recovery of coal and coal-pyrite mixtures as a function of the coal/pyrite ratio is shown in Figure 4.12. It should be noted that for pure coalpyrite and pure coal, the flotation recoveries at pH6-7 are $41 \%$ and $98 \%$, respectively. The theoretical bulk recovery curve was calculated by the weight average of the corresponding floatabilities of coal and coal-pyrite. It is evident that the experimental results of the bulk recovery of coal and coal-pyrite is almost same as that of the theoretical prediction. Minor deviation occurs only when the coal/pyrite 


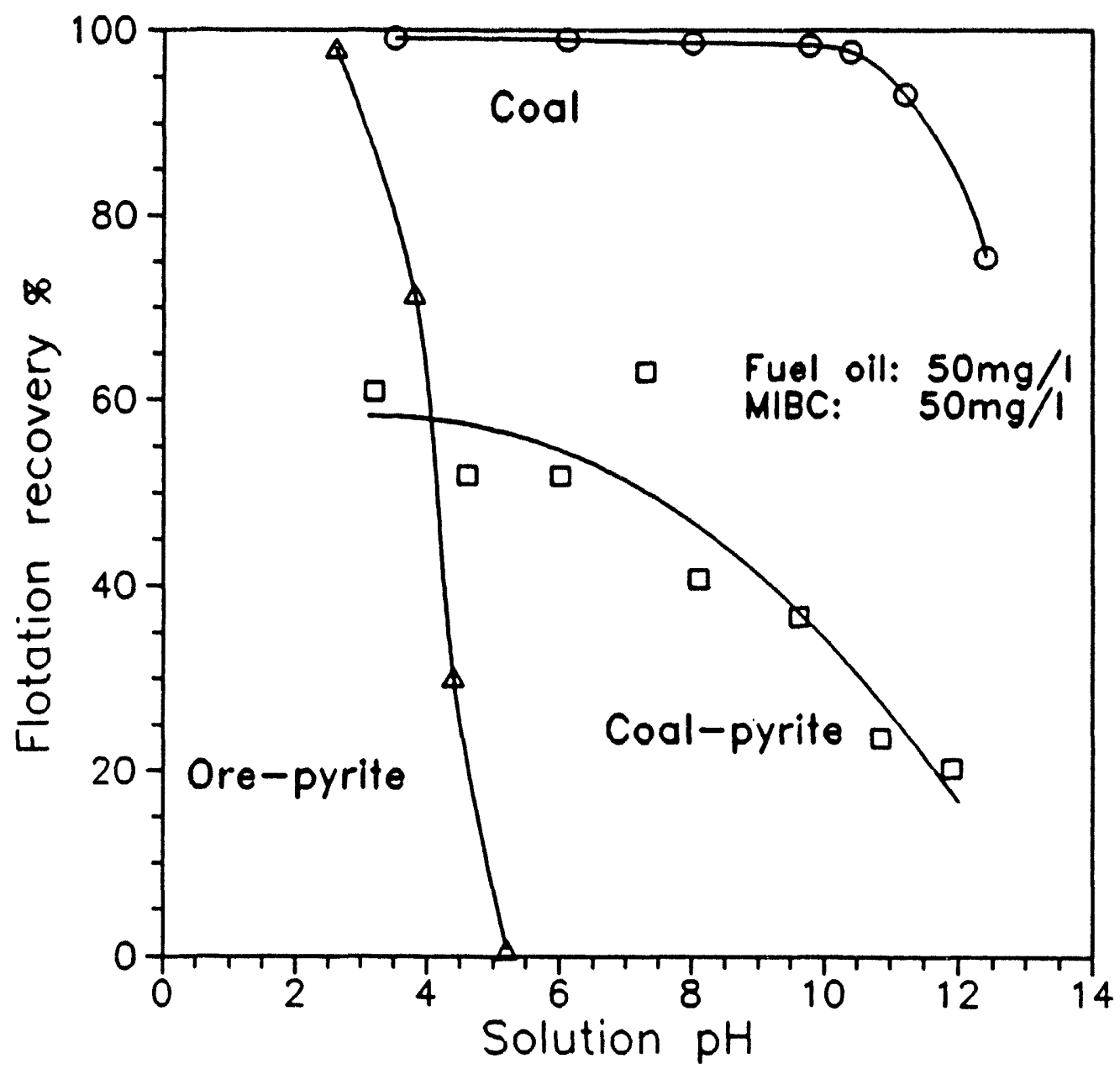

Figure 4.11 Comparison of flotation recovery of fine coal, coal- and orepyrite as a function of solution $\mathrm{pH}$ in the presence of fuel oil. Coal: $-74 \mu \mathrm{m}$; coal- and ore-pyrite: $-45 \mu \mathrm{m}$. 

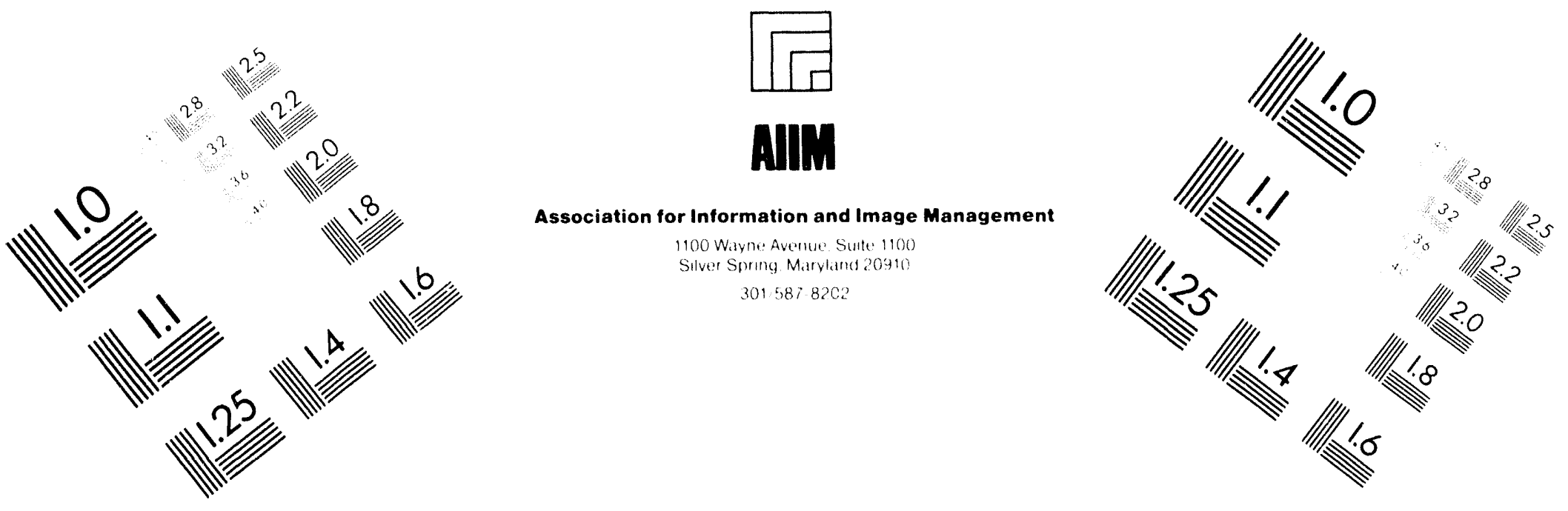

Centimeter

$\left.\right|_{\mid} ^{1}$ Inches
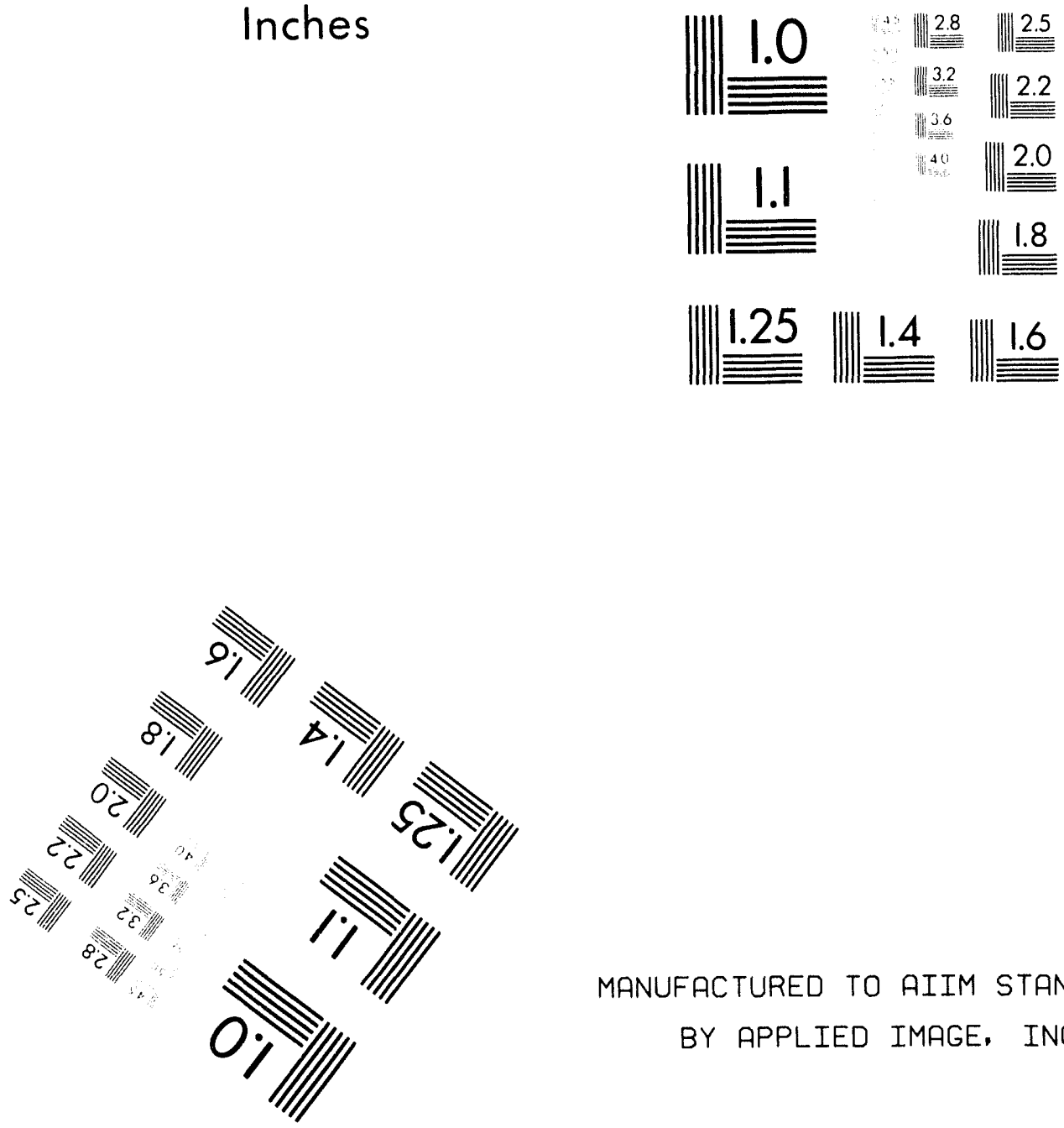

MANUFACTURED TO AIIM STANDARDS

BY APPLIED IMAGE. INC.

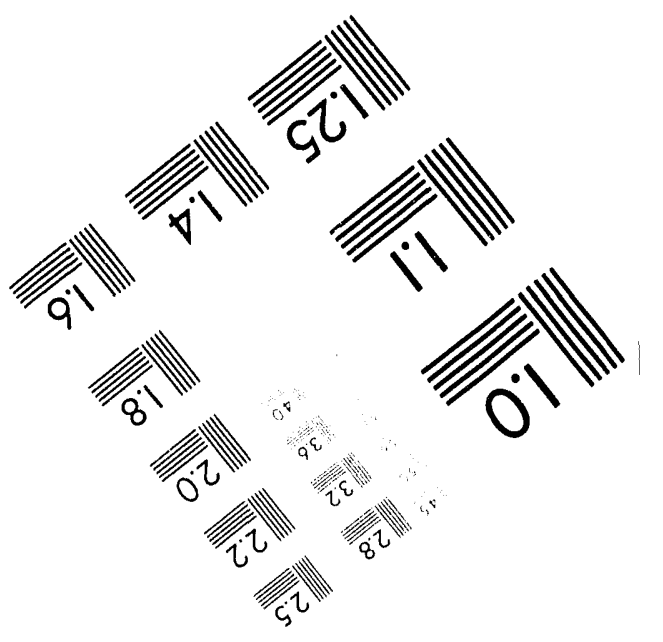



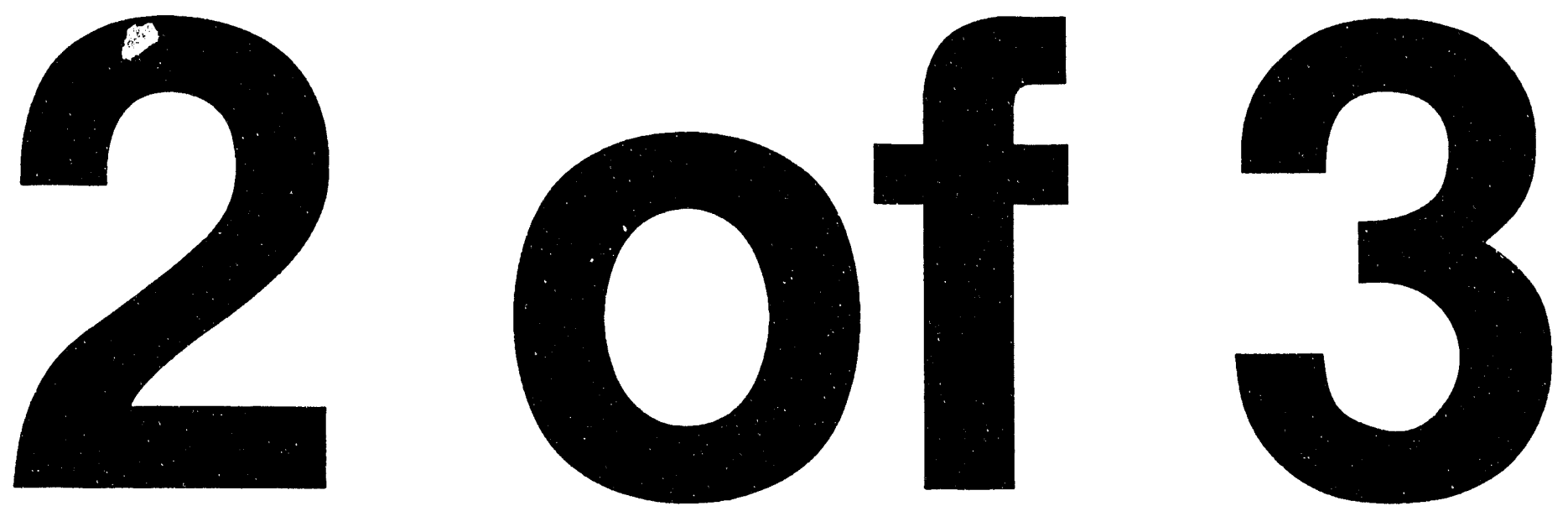


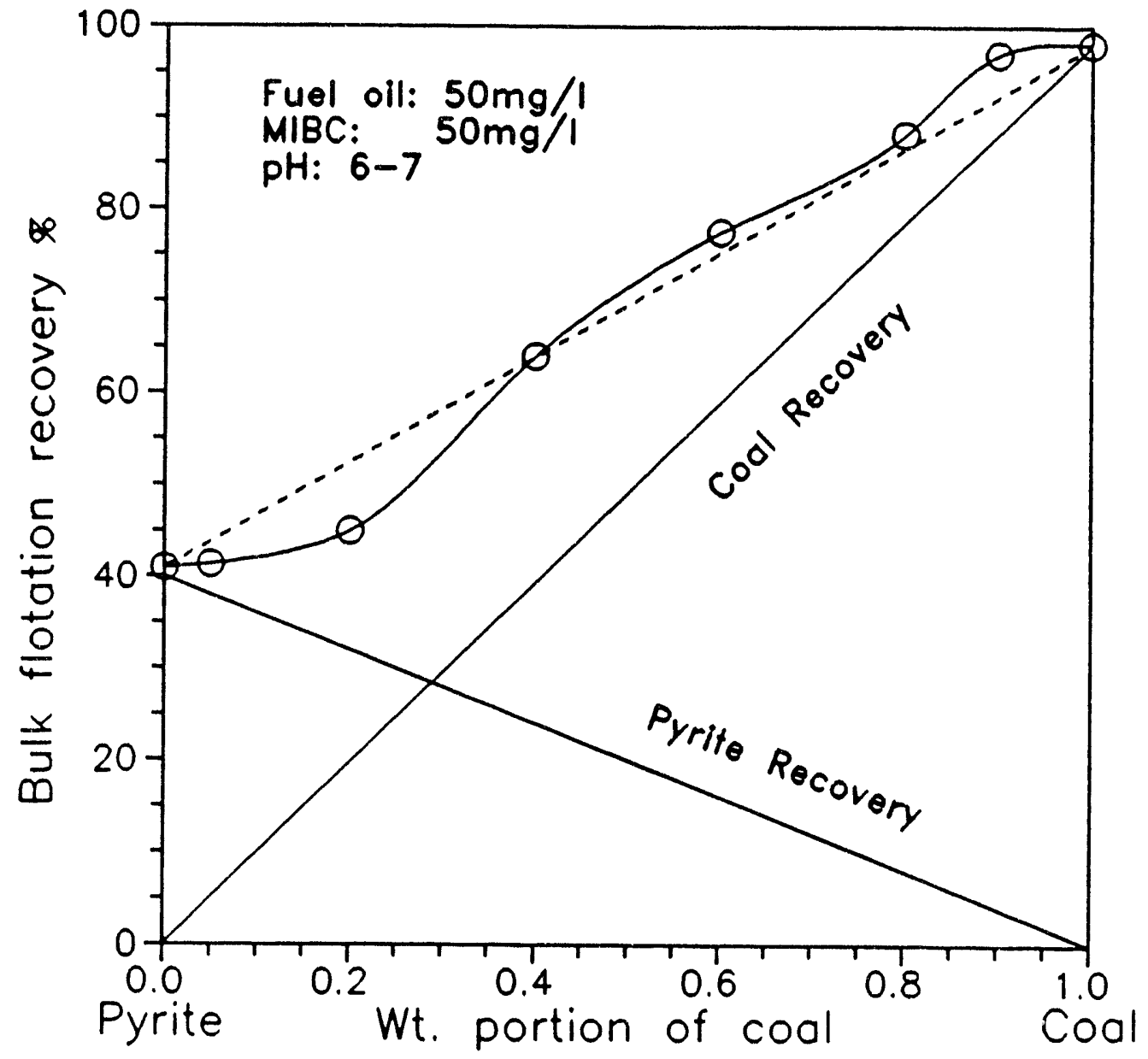

Figure 4.12 The bulk flotation recovery of coal and coal-pyrite mixture as a function of coal/pyrite ratio in the presence of fuel oil. 
ratio is close to zero and one. This indicates that the bulk flotation recovery of the mixtures is mainly a sum of the individual recovery of the coal and coal-pyrite. The results also show that the entrapment effect of coal on pyrite in coal flotation is not very significant and the undesirable recovery of pyritic sulfur in the coal concentrate is due to the inherent floatability of coal-pyrite.

As shown in the above studies, the flotation behavior of coal- and ore-pyrite in the presence of fuel oil differs remarkably. The causes of the differences are complex. However, the principal difference in the chemical composition between the pyrites from coal and ore sources is their carbon content. The chemical analysis results given in Table 3.2 of Chapter 3 shows that the impurities contained in orepyrite are mainly heavy metals. The $\mathrm{S} / \mathrm{Fe}$ ratio of ore-pyrite is close to 2 , the theoretical stoichiometric value. However, coal-pyrite contains high carbon $(4.33 \%)$ and calcium content, and the ratio of $\mathrm{S}$ to $\mathrm{Fe}$ is 2.26 . The compositional deviation of coal-pyrite from the theoretical value and the existence or incursions of carbonaceous material might have resulted in great differences from ore-pyrite in the crystalline, morphology, and surface properties. The results from the cyclic voltammetric studies have demonstrated that coal-pyrite is more reactive than ore-pyrite. Besides the oxidation of coal-pyrite itself, the presence of organic coal compounds at the surface of coal-pyrite may also be susceptible to the electrochemical reaction. The surface of the coal-pyrite possesses more characteristics of coal/carbon than pyrite itself. Hence, 
the surface hydrophobicity of the coal-pyrite in the presence of fuel oil can be mainly determined by the coating of coal/carbon on the surface.

The oil-induced floatability of coal-pyrite by the addition of fuel oil may be due to the adsorption of nonpolar fuel oil with the carbon/coal area on the surface. Since in the presence of fuel oil, the flotation behavior of coal-pyrites is extremely analogous to that of coal as shown in Figure 4.11. The area covered by coal/carbon on the coal-pyrite surface may change with the particle size. Fine size coal-pyrite may have a larger surface area and expose more hydrophobic carbon/coal sites than coarse size particles. Therefore, in the presence of fuel oil, as the particle size decreases, the floatability of coal-pyrite significantly increases. Unlike coal-pyrite, the ore-pyrite has no carbon/coal substances on its surface. Furthermore, the surface is covered by the hydrophilic iron hydroxide layers. Therefore, in the presence of fuel oil, fine size orepyrite shows no flotation at all in neutral and alkaline solutions. The moderate flotation with fuel oil for coarse sizes of ore-pyrite may be ascribed to the hydrophobic adsorption of oil with the sulfur formed by the moderate oxidation of pyrite.

In Figures 4.13 and 4.14 , the flotation results of coarse size samples in the presence of fuel oil before and after ultrasonic treatment are presented, respectively. With or without ultrasonic treatment, coal showed no big change in flotation. It 


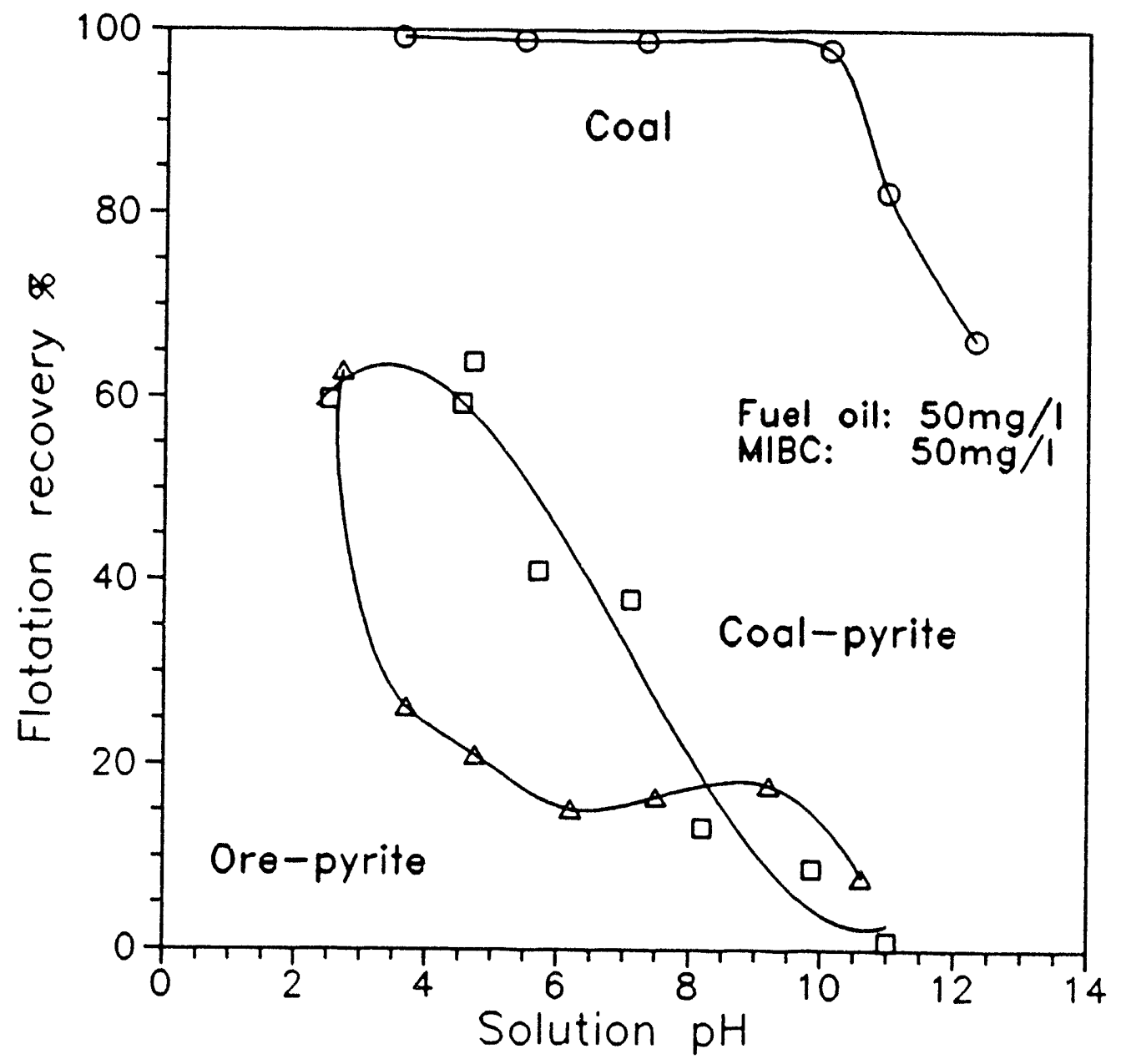

Figure 4.13 Comparison of flotation recovery of coarse coal, coal- and orepyrite as a function of solution $\mathrm{pH}$ in the presence of fuel oil. Coal: $-150+100 \mu \mathrm{m}$; coal- and ore-pyrite: $-74+45 \mu \mathrm{m}$. 


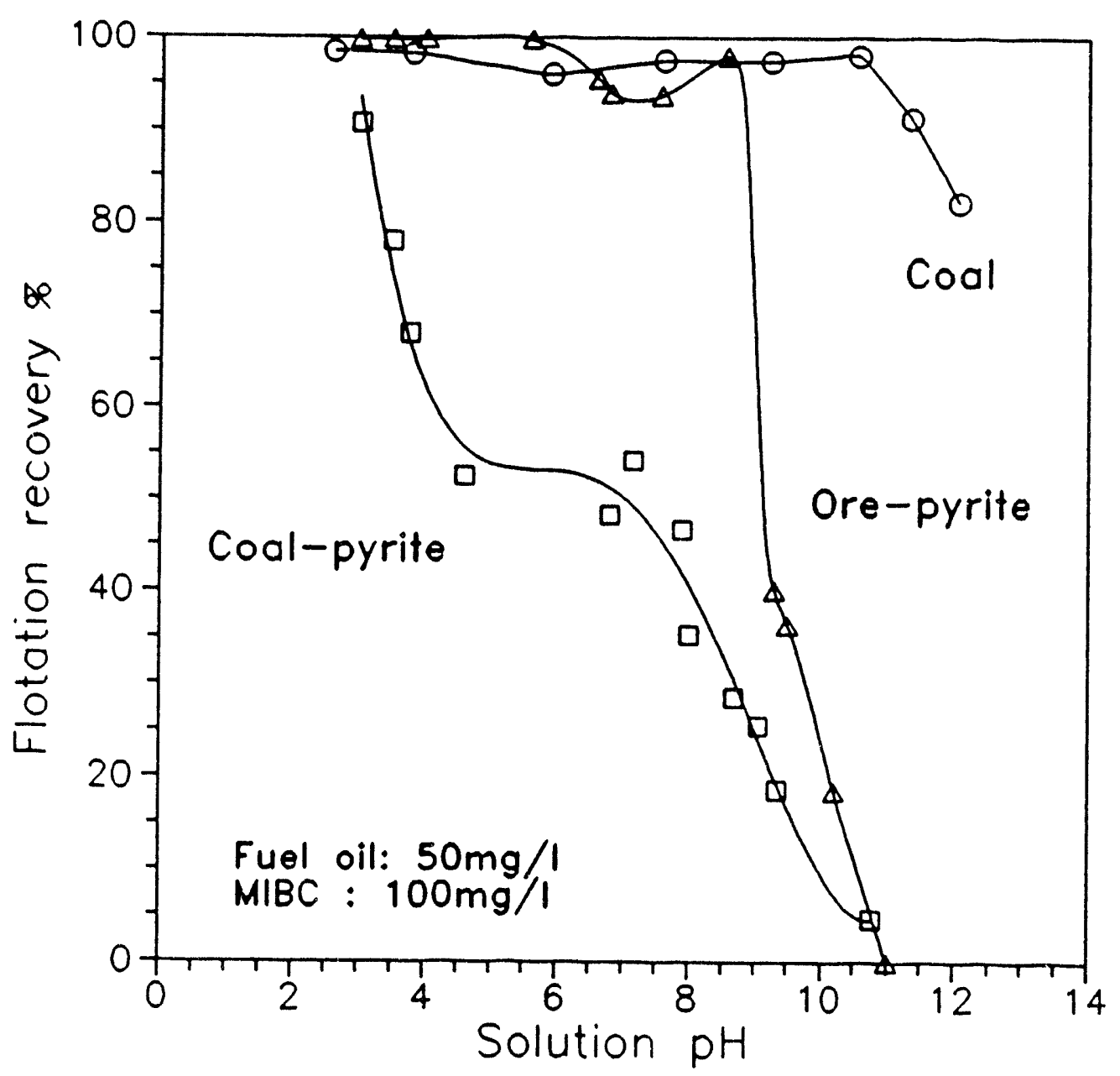

Figure 4.14 Flotation recovery as a function of solution $\mathrm{pH}$ for coal, coal- and ore-pyrite in the presence of fuel oil after ultrasonic treatment. Coal: $-150+100 \mu \mathrm{m}$; coal- and ore-pyrite: $-74+45 \mu \mathrm{m}$. 
indicates that in the presence of an oily collector the oxidation of the coal surface has a negligible effect on floatability. However, after surface cleaning with ultrasonication the floatability of ore-pyrite was significantly increased, indeed, the flotation recovery reached over $90 \%$ below $\mathrm{pH} 9$. It shows that ultrasonic treatment can easily remove the hydrophilic iron hydroxide layers on ore-pyrite. The increased floatability is due to the strong hydrophobic interaction of the exposed sulfur rich layer with the nonpolar collector, fuel oil. Except for the pH ranges below 4, coal-pyrite did not show significant increases in floatability in the presence of fuel oil. Since the oxidation products formed on coal-pyrites are strongly attached to the surface, ultrasonic treatment cannot remove these iron hydroxides easily. Therefore, surface hydrophobicity did not change much. However, as shown in the previous section, acid washing method can clean the surface. Hence, the increase of floatability below pH4 is probably due to the acid cleaning effect on the surface.

The flotation results suggest that there are two main reasons for the difficulty of pyritic sulfur removal from coal using nonpolar oil as a collector: one is the oilinduced floatability of coal-pyrite due to the coating of carbon/coal on its surface; the other is the formation of hydrophobic sulfur rich pyrite surface layers due to the moderate surface oxidation. The flotation results of coal and coal-pyrite mixture (Figure 4.12) indicate that the entrapment or entrainment effect of coal froth on coalpyrite is negligible, the pyritic sulfur recovery in coal froth results from its own 
floatability. Therefore, fuel oil used in coal flotation can be adsorbed non-selectively on both coal and coal-pyrite surfaces. This increases the difficulty in rejecting pyrite from coal by flotation.

\subsection{Flotation of Coal and Pyrites with Xanthate}

Figure 4.15 shows the flotation of various size ore-pyrites as a function of $\mathrm{pH}$ in the presence of $50 \mathrm{mg} / \mathrm{l}$ ethyl xanthate. It can be seen that for all the particle sizes studied, ore-pyrite reveals complete flotation in the acidic solution below pH6. However, above $\mathrm{pH} 6$, flotation depends strongly on the solution $\mathrm{pH}$ and particle size. The coarser particle fraction $(-100+74 \mu \mathrm{m})$ floats completely up to $\mathrm{pH} 11$. Flotation of fine ore-pyrite particles $(-45 \mu \mathrm{m})$ decreases sharply at $\mathrm{pH} 6$, ultimately becomes zero in the alkaline solutions. The intermediate size fraction $(-74+45 \mu \mathrm{m})$ reveals partial flotation in the neutral $\mathrm{pH}$ range, which is in good agreement with previous studies (Fuerstenau et al, 1968; Ball and Richard, 1976). The flotation behavior of coal-pyrite differs considerably from that of ore-pyrite. As shown in Figure 4.16, the floatability of coal-pyrite is almost independent of particle size but strongly dependent on solution pH. All the coal-pyrite size fractions tested display good flotation below pH6. However, at around $\mathrm{pH} 6$, the recoveries of the coal-pyrite decrease drastically. In the alkaline solution above $\mathrm{pH} 6$, little flotation can be observed for coarse size fractions $(-150+100 \mu \mathrm{m}$ and $-100+74 \mu \mathrm{m})$ and almost no flotation is obtained for fine size 


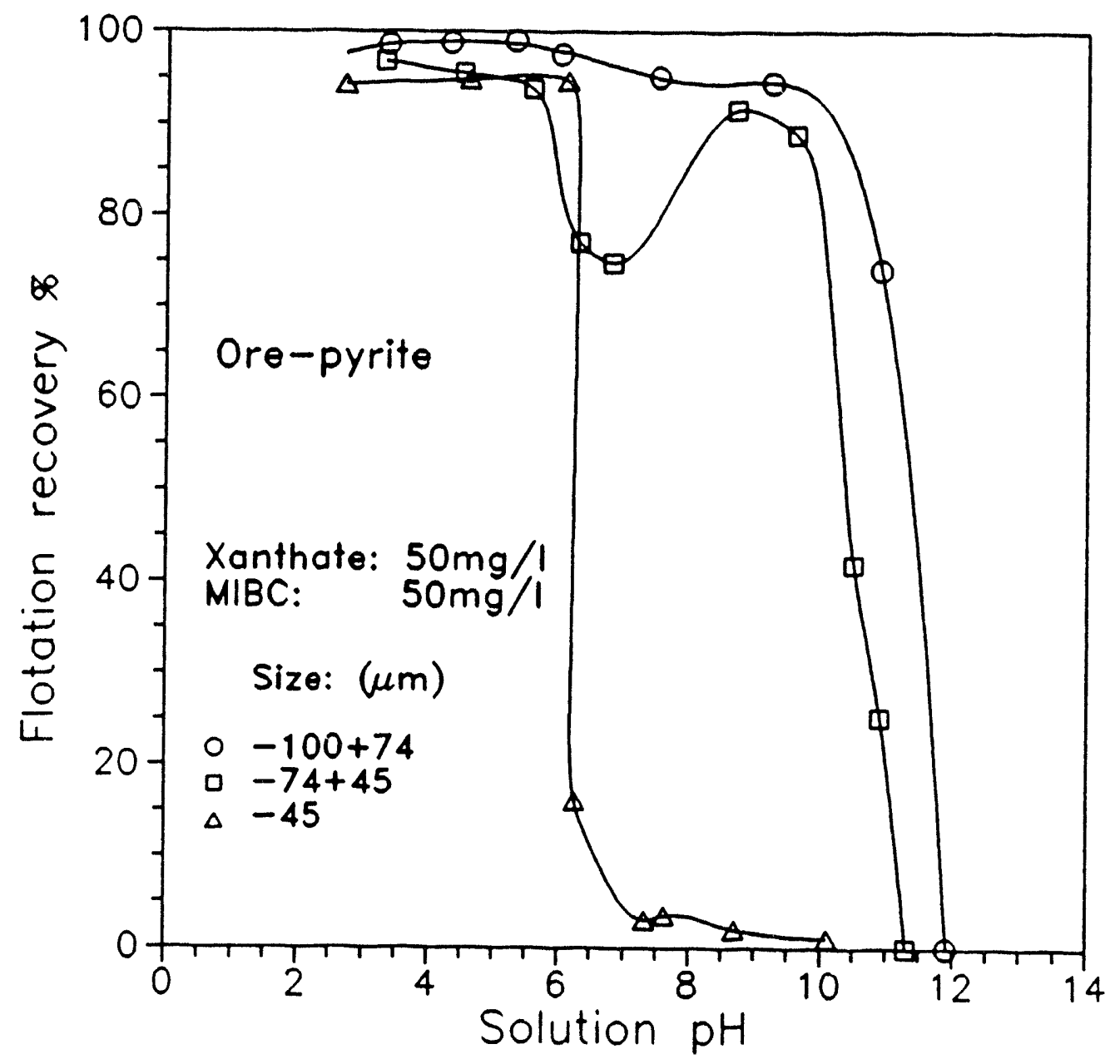

Figure 4.15 Flotation recovery of ore-pyrite as a function of solution $\mathrm{pH}$ and particle size in the presence of ethyl xanthate as collector. 


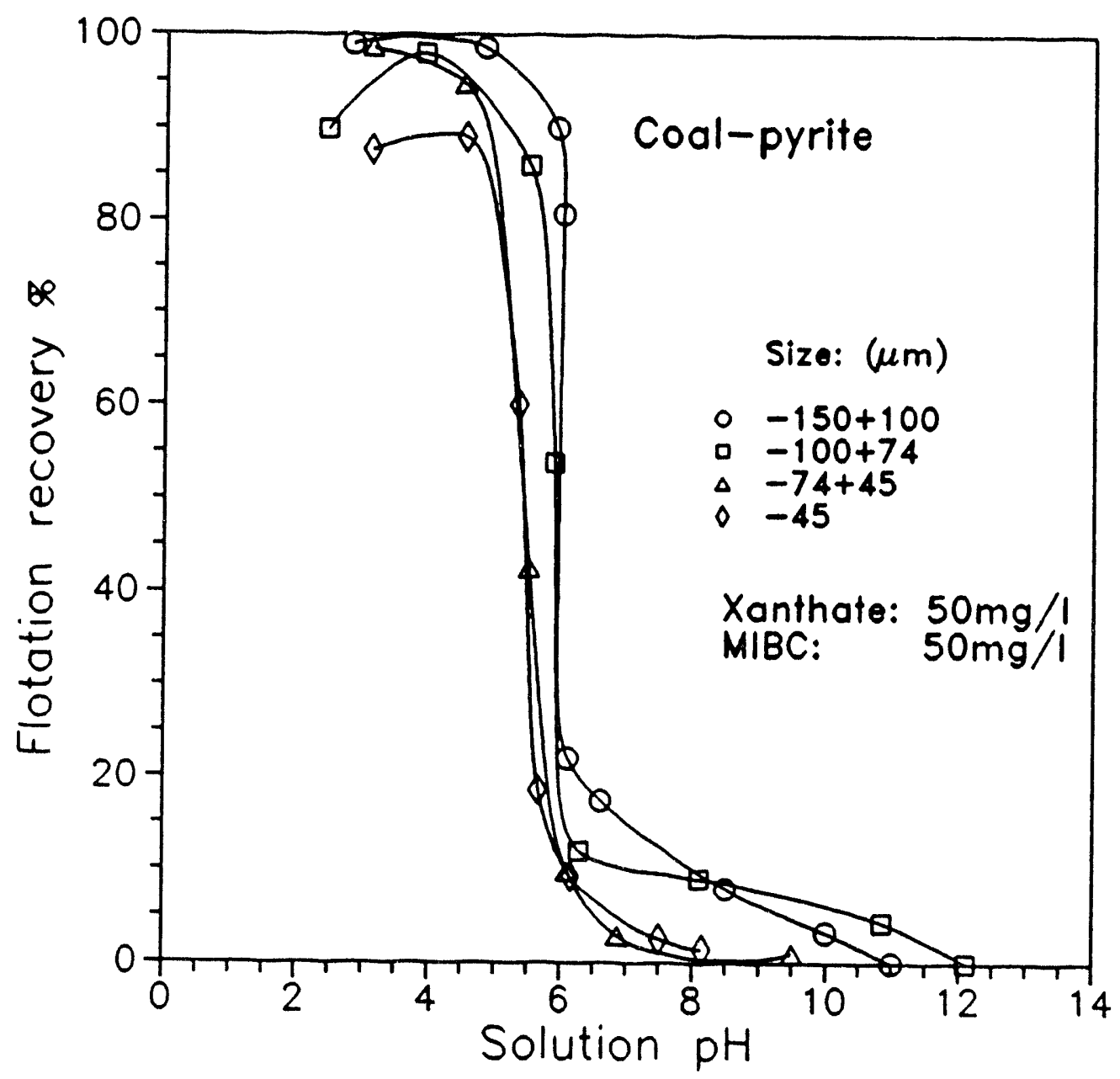

Figure 4.16 Flotation recovery of coal-pyrite as a function of solution $\mathrm{pH}$ and particle size in the presence of ethyl xanthate as collector. 
fractions $(-74+45 \mu \mathrm{m}$ and $-45 \mu \mathrm{m})$. These results shows that the flotation of coal-pyrite with xanthate must be performed in the acidic solution. The results are in agreement with the results obtained by Chernosky and Lyon (1972).

Figure 4.17 presents the flotation recovery of coal vs $\mathrm{pH}$ in the presence of ethyl xanthate. Compared with the results obtained in the absence of a collector (Figure 4.1), the floatabilities of coal are improved in acidic solution, particularly for coarse size coal $(-150+100 \mu \mathrm{m})$. It can be seen that coal floats very well with xanthate in acidic solutions, but its recoveries drastically decrease at $\mathrm{pH} 6$. At $\mathrm{pH}>6$, the coarse coal $(-150+100 \mu \mathrm{m})$ is nearly nonfloatable, while fine coal $(-74 \mu \mathrm{m})$ flotation ceases at $\mathrm{pH} 11$. It can be seen that the flotation behavior of coal and coal-pyrite is very similar in the presence of xanthate.

\subsubsection{Effect of Ultrasonic Treatment on Flotation with Xanthate}

Figures 4.18 and 4.19 compare flotation recovery vs solution $\mathrm{pH}$ for coal, coal- and ore-pyrite in the presence of ethyl xanthate with and without ultrasonic treatment, respectively. It can be seen from Figure 4.18 that for the particle size tested only ore-pyrite displays good flotation in the alkaline solution, while the flotation behavior of coal and coal-pyrite is almost identical, both having the same critical pH at 6 . These results demonstrate that in the presence of xanthate collector 


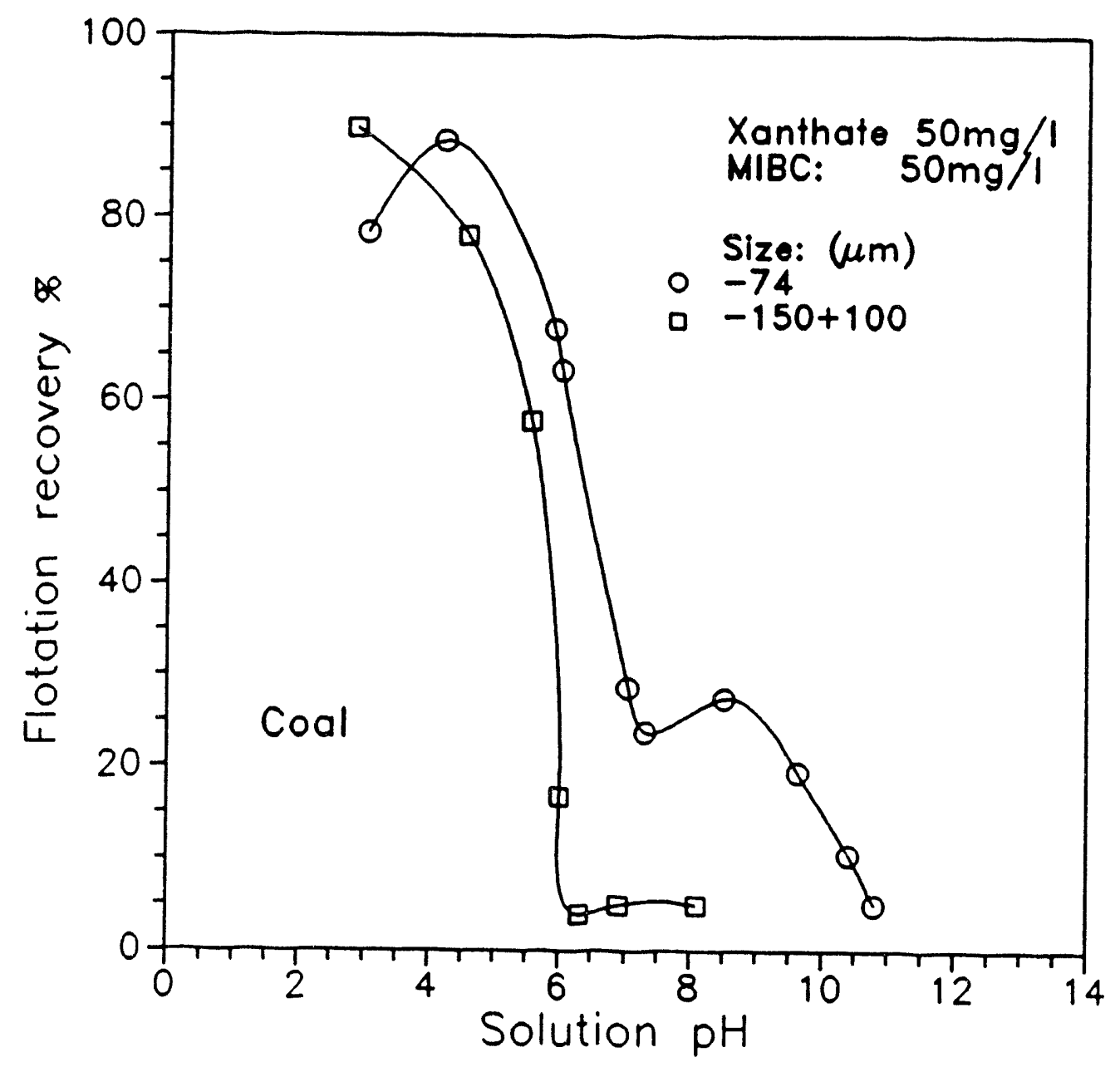

Figure 4.17 Flotation recovery of coal as a function of solution $\mathrm{pH}$ and particle size in the presence of ethyl xanthate as collector. 


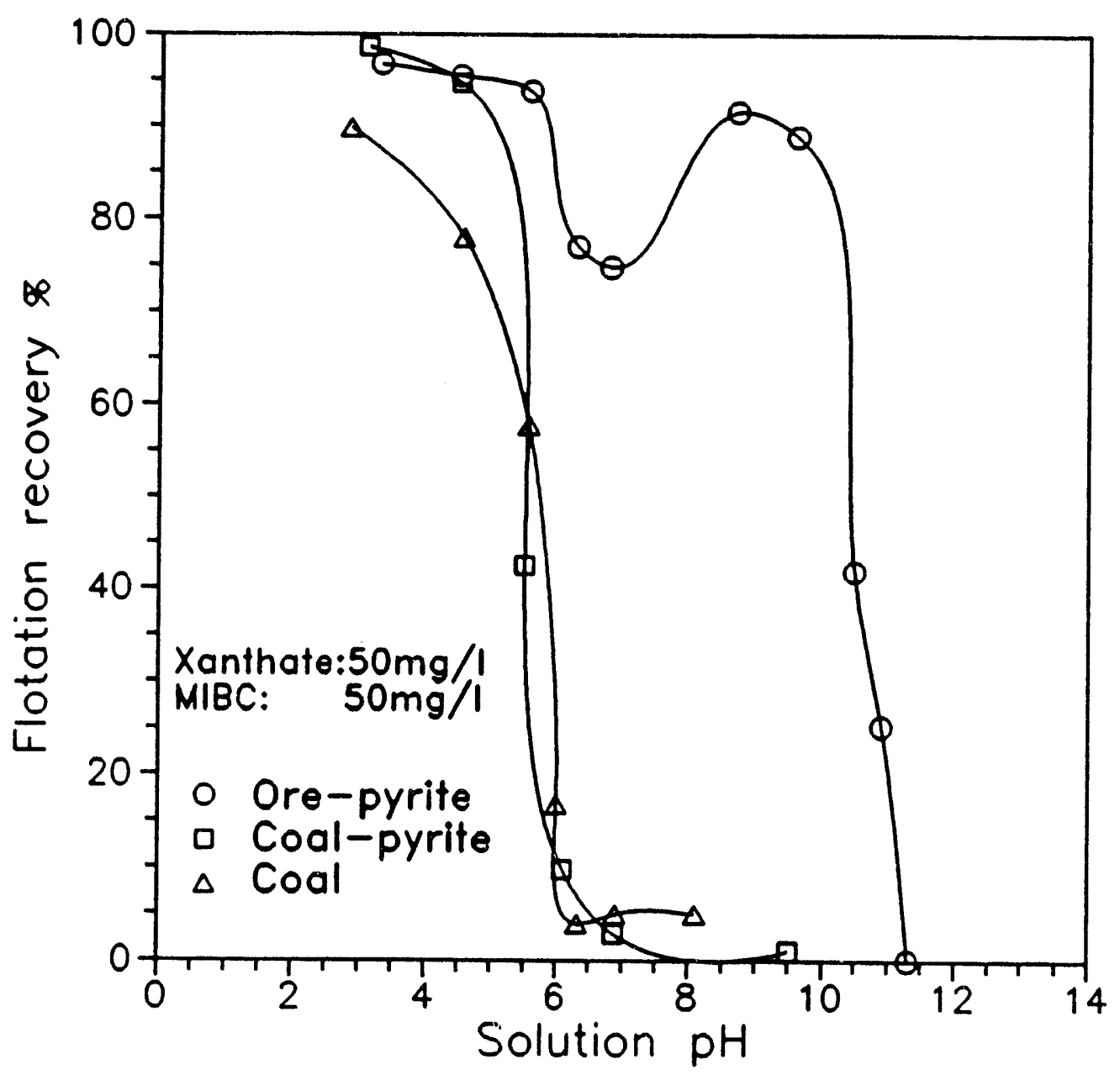

Figure 4.18 Comparison of flotation recovery of coal, coal- and ore-pyrite as a function of solution $\mathrm{pH}$ in the presence of ethyl xanthate as collector. Coal: $-150+100 \mu \mathrm{m}$; coal- and ore-pyrite: $-74+45 \mu \mathrm{m}$. 


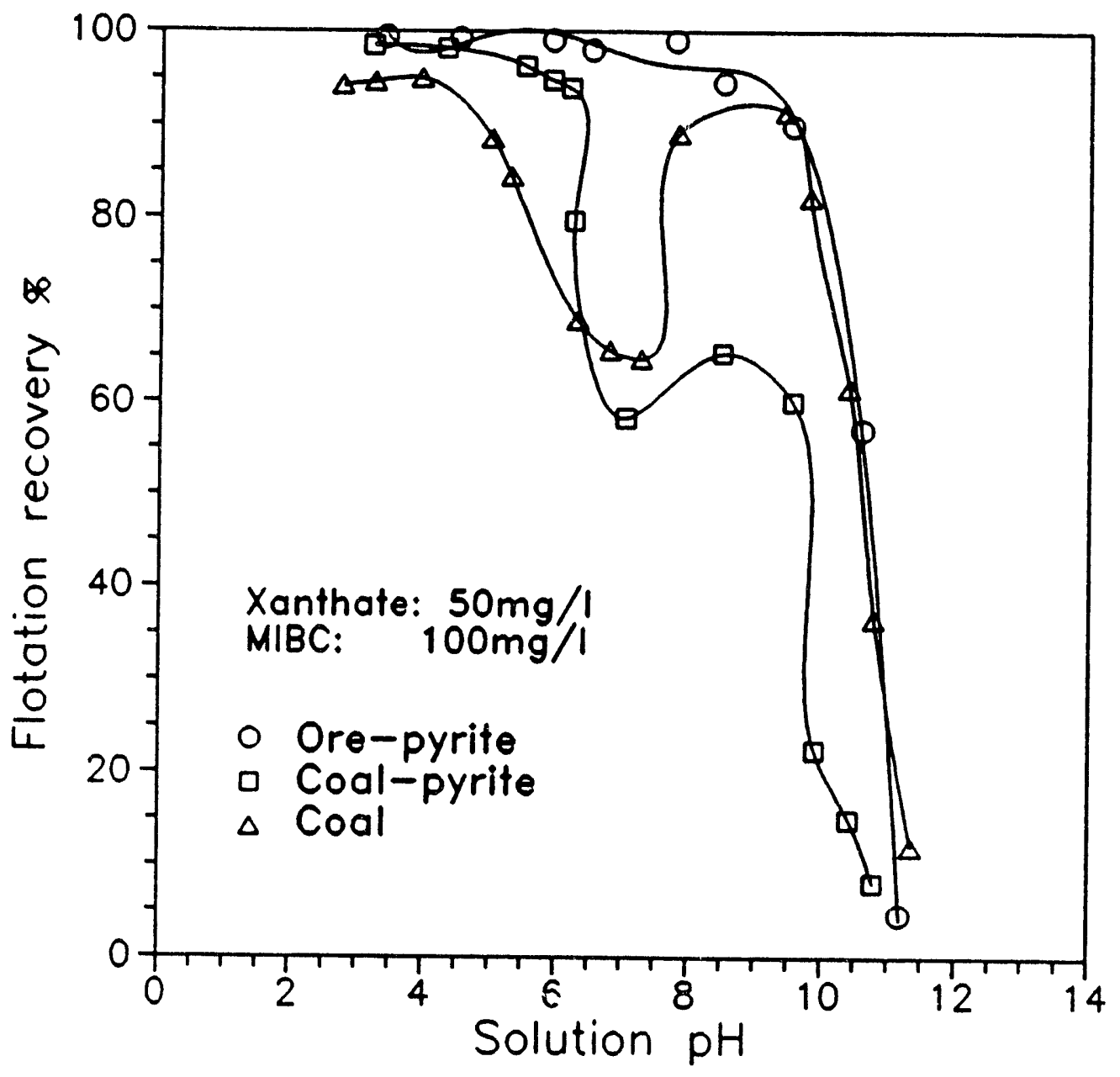

Figure 4.19 Comparison of flotation recovery of coal, coal- and ore-pyrite as a function of solution $\mathrm{pH}$ in the presence of ethyl xanthate as collector after ultrasonic treatment. Coal: $-150+100 \mu \mathrm{m}$; coal- and ore-pyrite: $-74+45 \mu \mathrm{m}$. 
coal-pyrite is less floatable than ore-pyrite, which is contrary to the previous results using fuel oil as the collector. After ultrasonic treatment (Figure 4.19), the floatabilities of coal and pyrites increase. The partial flotation in neutral $\mathrm{pH}$ for orepyrite disappears but the critical $\mathrm{pH}$ remains the same. For coal-pyrite, the floatability is increased to about $60 \%$ in the alkaline solutions of pH6-10. However, the decrease in flotation at $\mathrm{pH} 6$ can still be observed. Coal exhibits considerable flotation in the alkaline media with the same critical $\mathrm{pH}$ as ore-pyrite. However, there exists a partial flotation in neutral $\mathrm{pH}$. These results show that xanthate is an effective collector for ore-pyrite and a poor collector for coal-pyrite, particularly in alkaline solutions.

\subsubsection{Effect of Iron Ions on Pyrite Flotation with Xanthate}

The role of iron ions in the flotation of pyrite by xanthate has long been ignored. At present, a general concept is accepted that the only product of xanthate adsorption on pyrite is dixanthogen which is responsible for the flotation. However, this conclusion has been misleading in studying the mechanism of pyrite flotation with xanthate, since the basic flotation phenomena could not be explained. Recently, the flotation behavior of pyrite was satisfactorily interpreted in terms of the stability of iron-xanthate compounds (Wang et al, 1989a; Wang and Forssberg, 1991). It was found that the flotation of pyrite is strongly dependent on the presence of iron ions and solution $\mathrm{pH}$. Since pyrite is composed of ferrous disulfide and susceptible to 
oxidation, when pyrite is exposed to air and water, the following stoichiometric reactions may characterize the oxidation of pyrite (Stumm, 1982):

$$
\begin{gathered}
\mathrm{FeS}_{2}(\mathrm{~s})+\frac{7}{2} \mathrm{O}_{2}+\mathrm{H}_{2} \mathrm{O}=\mathrm{Fe}^{2+}+2 \mathrm{SO}_{4}^{2-}+2 \mathrm{H}^{+} \\
\mathrm{Fe}^{2+}+\frac{1}{4} \mathrm{O}_{2}+\mathrm{H}^{+}=\mathrm{Fe}^{3+}+\frac{1}{2} \mathrm{H}_{2} \mathrm{O} \\
\mathrm{Fe}^{3+}+3 \mathrm{H}_{2} \mathrm{O}=\mathrm{Fe}(\mathrm{OH})_{3}(\mathrm{~s})+3 \mathrm{H}^{+} \\
\mathrm{FeS}_{2}(\mathrm{~s})+14 \mathrm{Fe}^{3+}+18 \mathrm{H}_{2} \mathrm{O}=15 \mathrm{Fe}^{2+}+2 \mathrm{SO}_{4}^{2-}+16 \mathrm{H}^{+}
\end{gathered}
$$

The oxidation of the pyrite releases sulfate, dissolved ferrous iron and hydrogen ions as shown in reaction 4.1. Subsequently, the ferrous iron undergoes oxidation to ferric iron, which then hydrolyses to form insoluble iron hydroxide through reaction 4.3. In addition, ferric iron can also be reduced by pyrite itself (reaction 4.4), where pyrite is again oxidized and additional ferrous iron is formed. A reaction cycle exists from reactions 4.2 to 4.4 . Since the oxidation of pyrite can take place within a very short time of exposure to air and water, during the flotation processes, the ferrous and ferric irons are ubiquitous on the pyrite surface and in the solution, which may considerably influence the flotation behavior of pyrite by xanthate.

It was found that the sequence of reagent addition and $\mathrm{pH}$ adjustment has a very profound effects on the flotation of pyrite. Figure 4.20 compares the flotation 
results of three different cases when ferric ions are added. For this size fraction, complete flotation is observed up to $\mathrm{pH}=10$ when no ferric ions are added. In the presence of $2 \times 10^{-3} \mathrm{M} \mathrm{Fe}^{3+}$, the flotation recovery is significantly reduced. The flotation recovery vs $\mathrm{pH}$ curve shows two humps in the acidic $\mathrm{pH}$ and alkaline $\mathrm{pH}$ regions, respectively; while in the intermediate $\mathrm{pH}$ range, partial flotation is obtained, indicating that the pyrite flotation is depressed by ferric ions. The order of the reagent addition and $\mathrm{pH}$ adjustment further affects the flotation response of pyrite in the medium $\mathrm{pH}$ region. When the solution $\mathrm{pH}$ is first adjusted before xanthate addition, the depression is much more significant in the neutral $\mathrm{pH}$ range than that obtained in the reverse order (i.e, xanthate is first added before $\mathrm{pH}$ is adjusted). The partial depression in both cases due to the order of conditioning commences at about $\mathrm{pH} 6$, corresponding well with the flotation behavior for coal-pyrite and fine size ore-pyrite. This indicates that a different reaction mechanism is involved in this region. The depression of pyrite below $\mathrm{pH} 3$ was attributed by Fuerstenau et al (1968) to the decomposition of xanthic acid into disulfide and alcohol. However, in the absence of ferric iron, no depression was observed below $\mathrm{pH} 3$. The enhancement of the decomposition of xanthate by ferric iron or the formation of ferric xanthate would be more likely responsible for the depression. It can be seen that at high alkaline pH values the presence of ferric iron does not substantially affect the flotation of pyrite by xanthate, showing that the adsorption of xanthate species is dominant. 


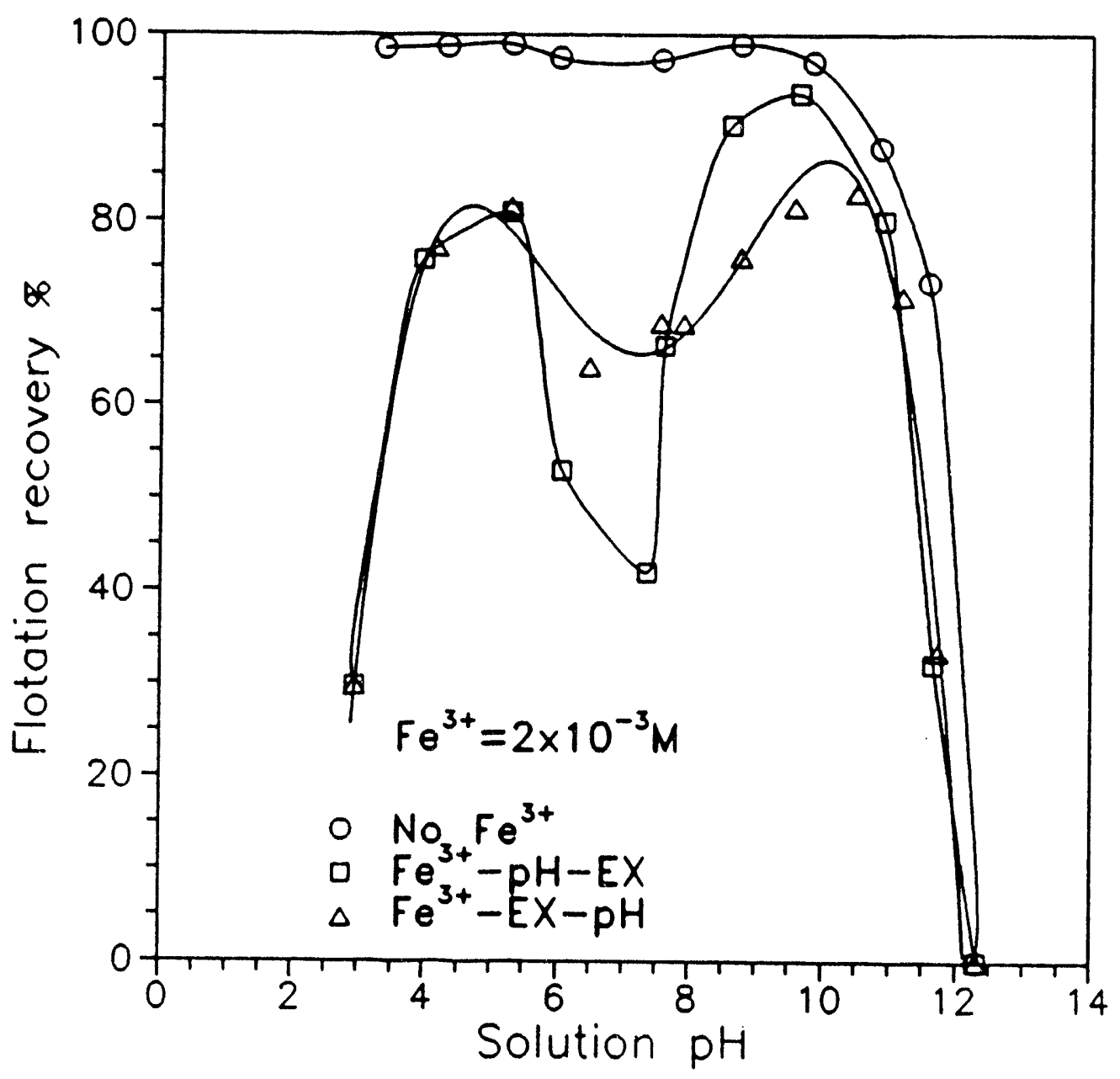

Figure 4.20 Effect of ferric ions and reagent addition order on the floatability of ore-pyrite as a function of solution $\mathrm{pH}$ using ethyl xanthate as collector. Particle size: $-150+100 \mu \mathrm{m}$. Reagent addition order: $\bigcirc$ no $\mathrm{Fe}^{3+}$ was added; $\mathrm{Fe}^{3+}$ was added first, followed by $\mathrm{pH}$ adjustment and then xanthate addition; $\triangle \mathrm{Fe}^{3+}$ was added first, followed by xanthate addition and then $\mathrm{pH}$ adjustment. 
Studies were also conducted to determine the effect of ferrous iron. In this case, the concentration of ferrous iron was also kept at $2 \times 10^{-3} \mathrm{M}$, and again, the effect of the order of reagent addition on flotation was investigated. Figure 4.21 shows the effect of ferrous iron on the flotation of pyrite. It can be seen that in the presence of ferrous iron complete flotation is obtained from $\mathrm{pH} 2$ to about $\mathrm{pH} 5$. Interestingly, partial flotation is again obtained around the neutral $\mathrm{pH}$ region, while a hump in flotation recovery is observed in the $\mathrm{pH}$ range of 9-10. Similar to the case of ferric ions, the partial flotation region is much broader when xanthate is added before $\mathrm{pH}$ adjustment than that when $\mathrm{pH}$ was first adjusted and followed by xanthate addition. Unlike ferric iron, in the acidic media below $\mathrm{pH} 6$, the presence of $2 \times 10^{-3}$ $\mathrm{M}$ ferrous iron does not deteriorate the flotation of pyrite and a complete recovery is produced. Since the solubility of ferrous xanthate is high, it indicates that in the acidic $\mathrm{pH}$ region no significant reaction between ferrous iron and xanthate occurs, or if any, the reaction must be very weak. However, the drastic decrease of floatability of pyrite at around $\mathrm{pH} 6$ obviously suggests that ferrous iron is indeed involved in the reaction with xanthate to form a weakly hydrophobic compound.

Figure 4.22 shows the effect of ferrous iron concentration on the flotation recovery $\mathrm{vs} \mathrm{pH}$ in the presence of $50 \mathrm{mg} / \mathrm{l}$ ethyl xanthate. It is interesting to see that even at very high ferrous iron concentration of $1 \times 10^{-2} \mathrm{M}$ complete flotation of pyrite remains unchanged below $\mathrm{pH} 6$, suggesting that ferrous iron has no effect on the 


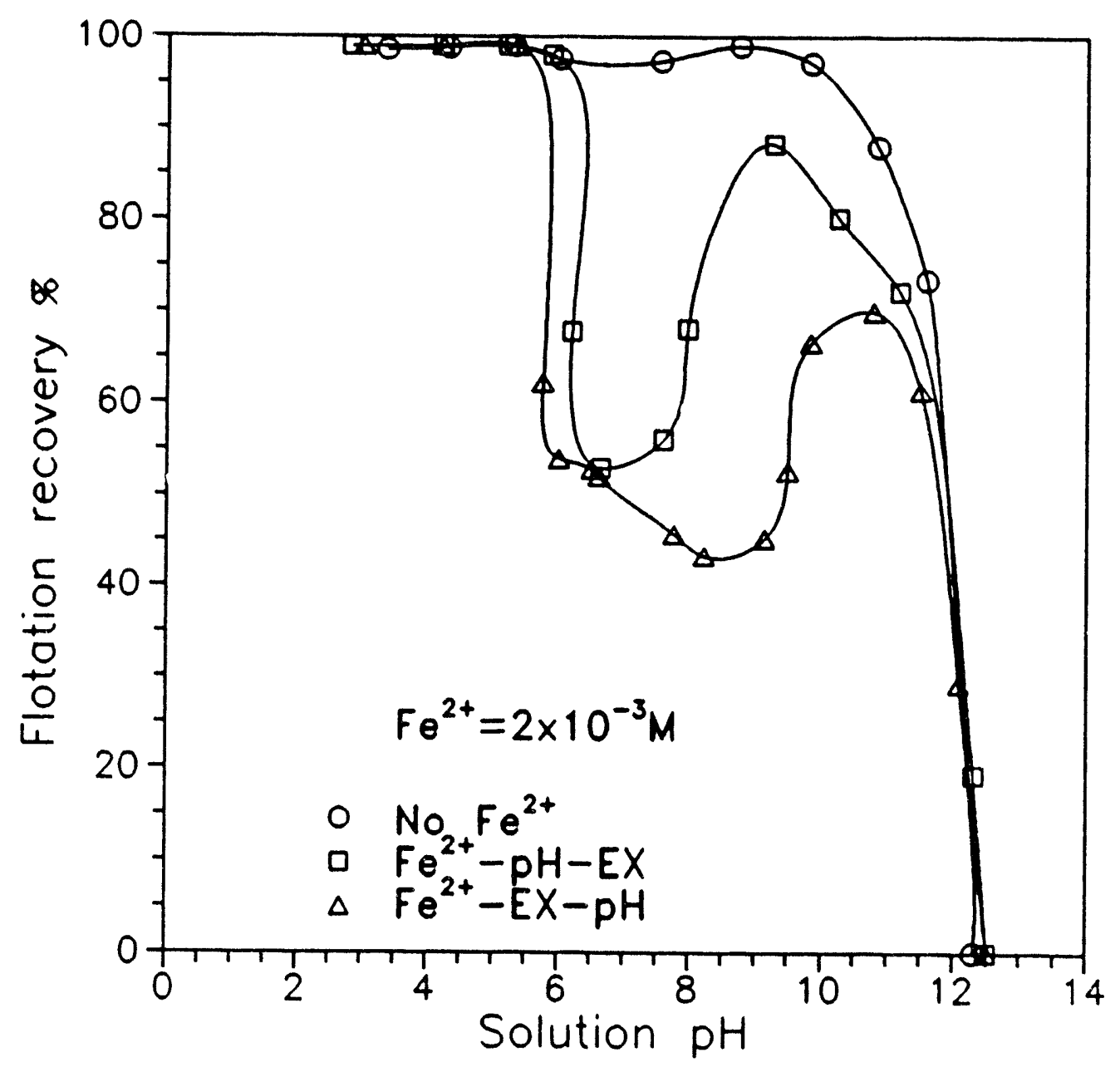

Figure 4.21 Effect of ferrous ions and reagent addition order , the floatability of ore-pyrite as a function of solution $\mathrm{pH}$ using ethyl xanthate as collector. Particle size: $-150+100 \mu \mathrm{m}$. Reagent addition order: $\bigcirc$ no $\mathrm{Fe}^{2+}$ was added; $\square \mathrm{Fe}^{2+}$ was added first, followed by $\mathrm{pH}$ adjustment and then xanthate addition; $\Delta \mathrm{Fe}^{2+}$ was added first, followed by xanthate addition and then $\mathrm{pH}$ adjustment. 


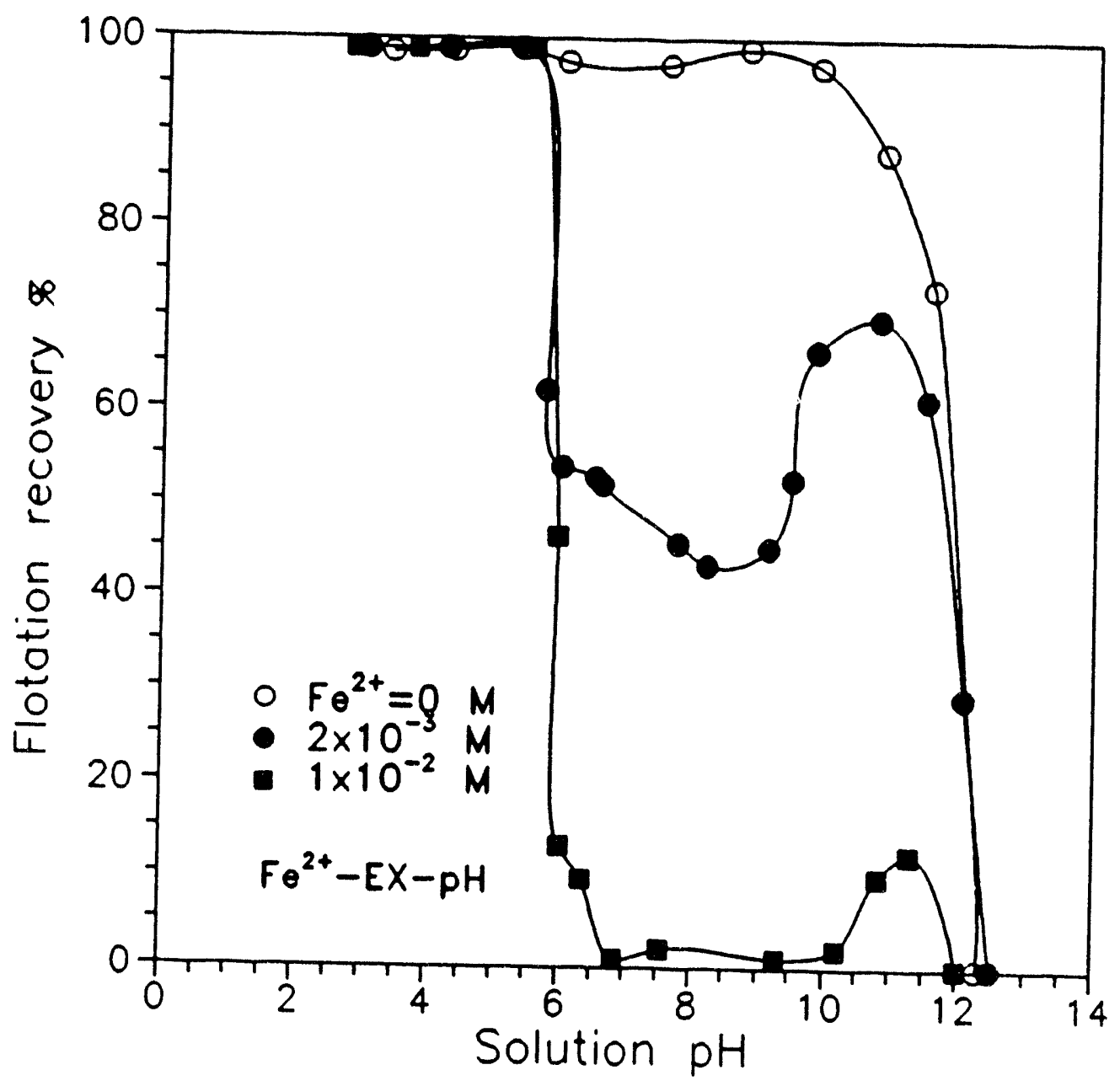

Figure 4.22 The effect of ferrous ion concentration on the flotation behavior of ore-pyrite in the presence of ethyl xanthate as collector. Particle size: $50+100 \mu \mathrm{m}$. 
adsorption of xanthate on the pyrite surface. More importantly, the facts that the flotation recovery sharply decreases at $\mathrm{pH}=6$ and that this critical $\mathrm{pH}$ is almost independent of the ferrous iron concentration as shown in Figure 4.22 suggests that the depression of ferrous iron on pyrite flotation is only effective above the critical $\mathrm{pH}$. On the other hand, as the ferrous iron concentration increases from $2 \times 10^{-3} \mathrm{M}$ to $1 \times 10^{-2} \mathrm{M}$, the intermediate $\mathrm{pH}$ range depression increases from $\mathrm{pH} 6-9$ to $\mathrm{pH} 6-10$, and the flotation recovery of pyrite is further reduced. In the presence of $1 \times 10^{-2} \mathrm{M}$ ferrous iron, pyrite is almost nonfloatable when the solution $\mathrm{pH}$ is greater than 6 , and the recovery vs pH curves becomes almost identical to the flotation curve of coal-pyrite (see Figure 4.16). This shows that the flotation of coal-pyrite with xanthate may be strongly controlled by the presence of ferrous species. Compared with the flotation curve of pyrite in the presence of $2 \times 10^{-3} \mathrm{M} \mathrm{Fe}^{2+}$, a much smaller flotation hump at around $\mathrm{pH} 11$ is still observed in the presence of $1 \times 10^{-3} \mathrm{M} \mathrm{Fe}^{2+}$. This reveals that the detrimental effect of ferrous ions on pyrite flotation with xanthate is more predominant in the neutral $\mathrm{pH}$ range than in the highly alkaline $\mathrm{pH}$ range. These results suggest that apart from ferric iron, the ferrous iron also plays an important role in influencing the adsorption of xanthate on pyrite in the intermediate depression region. 


\subsubsection{Effect of Iron Ions and Xanthate on Surface Charge}

The zeta potential of ore-pyrite as a function of $\mathrm{pH}$ was determined in the absence and presence of two different concentrations of ethyl xanthate, $3.3 \times 10^{-4} \mathrm{M}$ $(50 \mathrm{mg} / \mathrm{l})$ and $6.6 \times 10^{-4} \mathrm{M}(100 \mathrm{mg} / \mathrm{l})$. The results of these measurements are given in Figure 4.23. The PZC of pyrite in the absence of xanthate is found to be at $\mathrm{pH} 7.5$. In the presence of $3.3 \times 10^{-4} \mathrm{M}$ ethyl xanthate, the zeta potential is reversed in the $\mathrm{pH}$ range of 4.5-6. At $\mathrm{pH}>6$, there is little difference from that obtained in the absence of xanthate. This indicates that xanthate can adsorb readily onto pyrite below pH6, where the surface is positively charged. However, when ethyl xanthate is increased to $6.6 \times 10^{-4} \mathrm{M}$, the zeta potential of pyrite becomes negative in the whole $\mathrm{pH}$ range, and no PZC can be observed. Similar results have been reported previously (Cases et al., 1990). Since the magnitude of zeta potential is nearly independent of the solution $\mathrm{pH}$, it shows the xanthate species to be potential-determining ions.

Similar studies were performed with coal-pyrite and coal. Figures 4.24 and 4.25 show the electrokinetic behavior of coal-pyrite and coal as a function of $\mathrm{pH}$ in the absence and presence of $6.6 \times 10^{-4} \mathrm{M}$ ethyl xanthate, respectively. It can be seen that the addition of xanthate only slightly decreases the zeta potential values of coalpyrite below pH8 (Figure 4.24) and of coal below pH7.5 (Figure 4.25), and no great difference occurs at higher $\mathrm{pH}$, showing that the adsorption of xanthate is only 


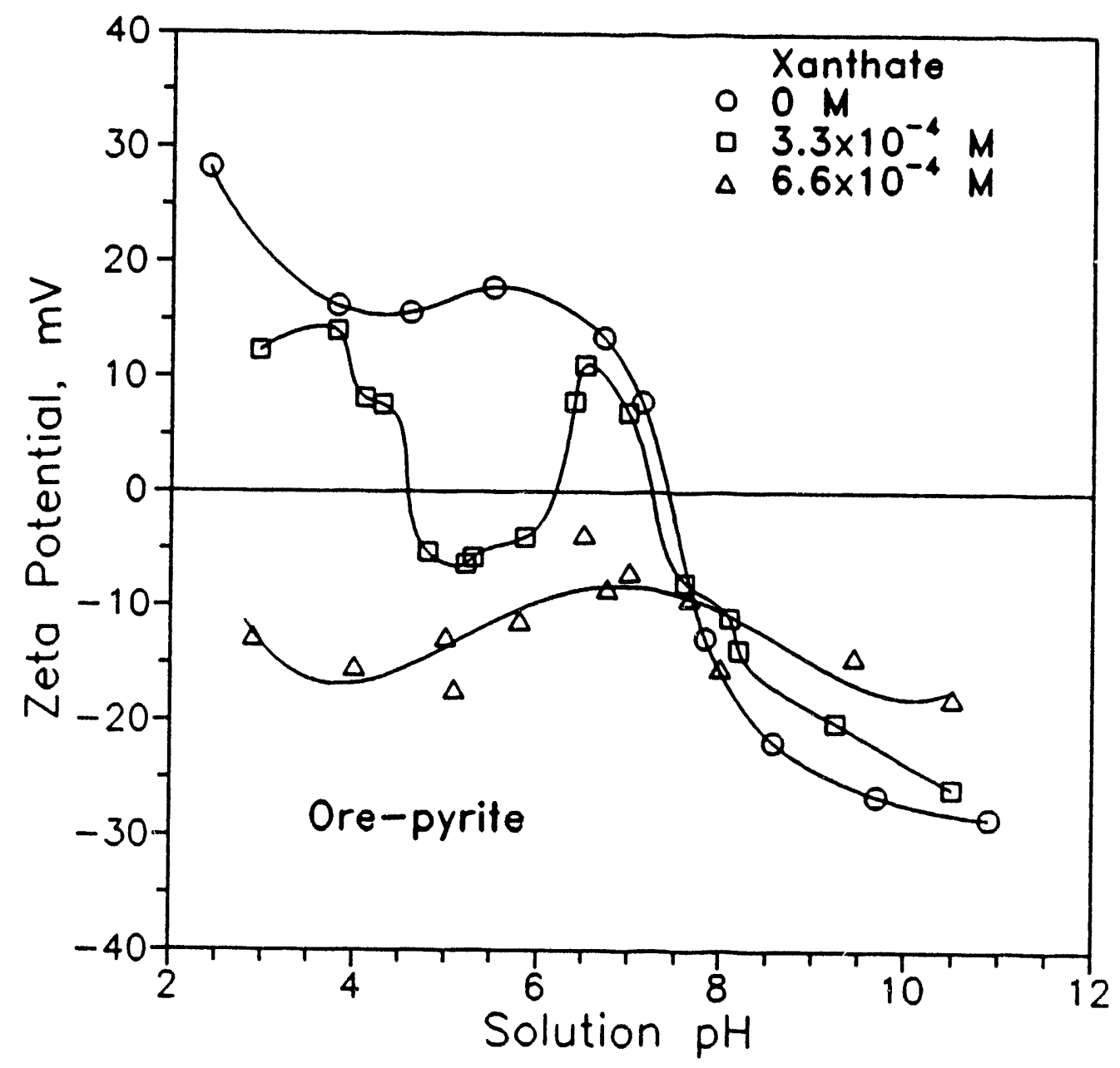

Figure 4.23 The zeta potential of ore-pyrite as a function of solution $\mathrm{pH}$ in the absence and presence of ethyl xanthate. 


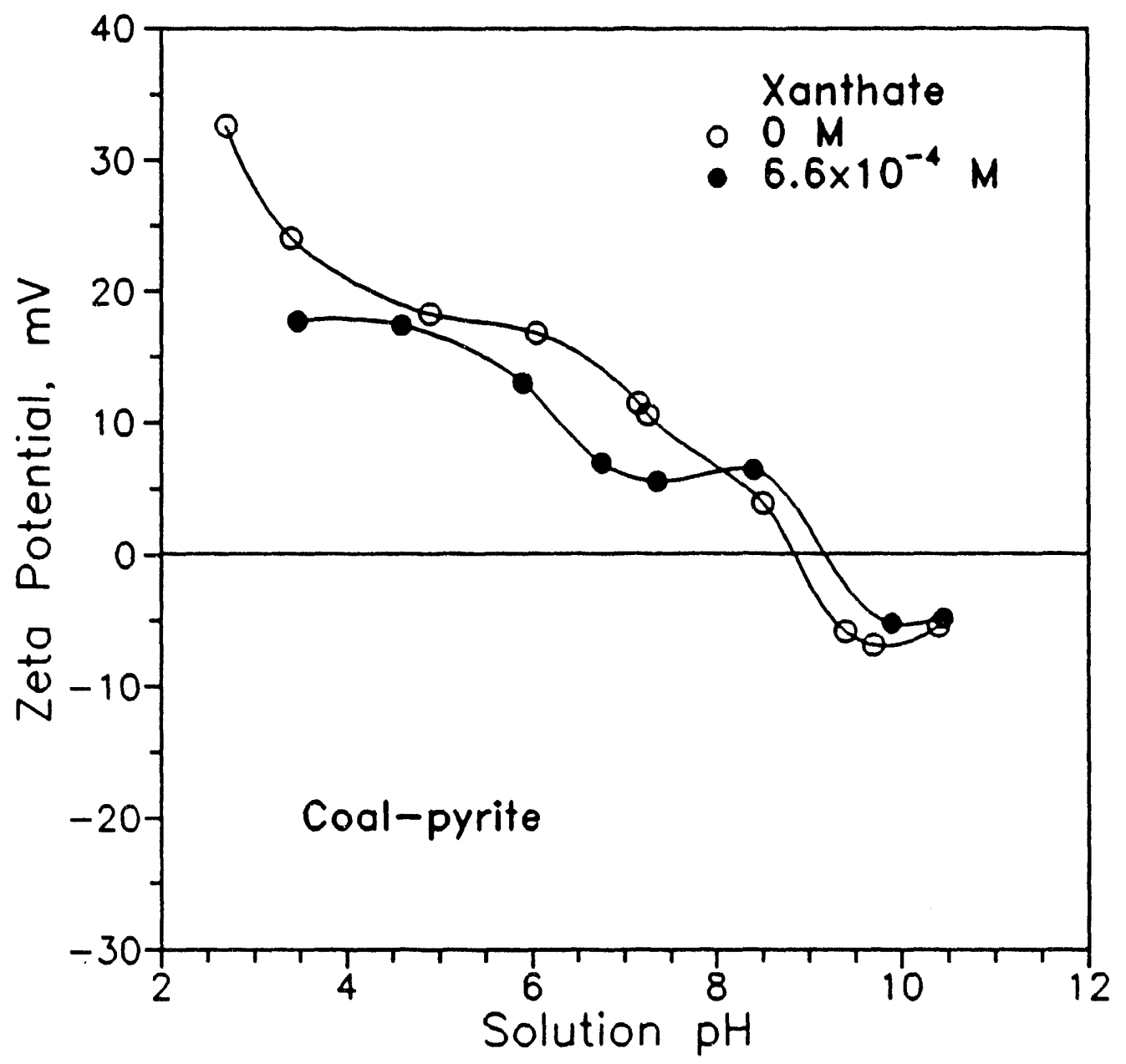

Figure 4.24 The zeta potential of coal-pyrite as a function of solution $\mathrm{pH}$ in the absence and presence of ethyl xanthate. 


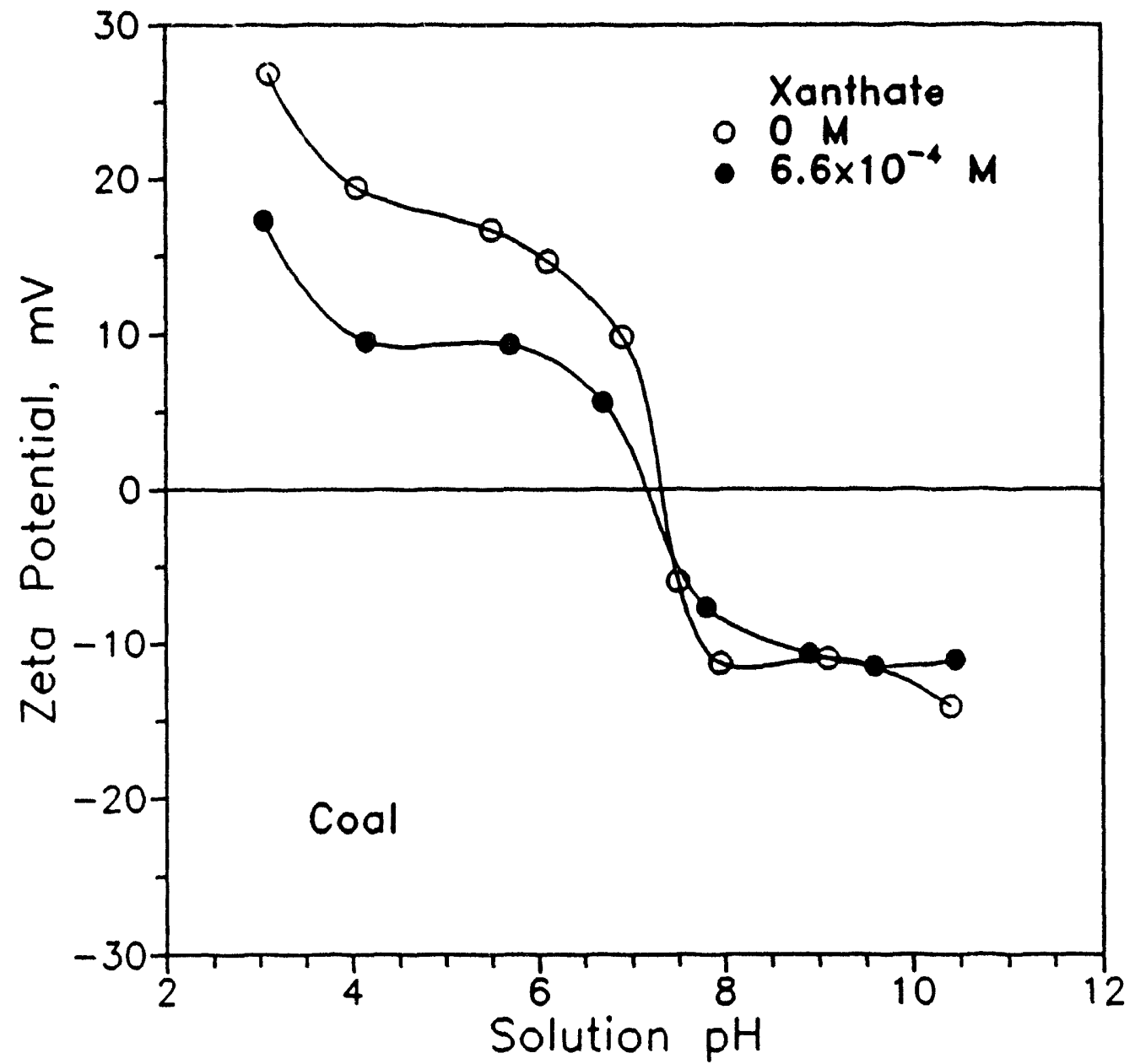

Figure 4.25 The zeta potential of coal as a function of solution $\mathrm{pH}$ in the absence and presence of ethyl xanthate. 
favored below PZC or in the acidic solutions. It should be noted that both coal-pyrite and coal floats by xanthate at an equivalent level to ore-pyrite in acidic media, and it is expected that the adsorption of xanthate on coal-pyrite and coal should also be strong. However, the change in their zeta potential value is much smaller than orepyrite. As studied earlier, the oxidation products such as ferric and ferrous irons may result in these differences.

Figure 4.26 presents the effect of ferric iron on the zeta potential of ore-pyrite as a function of $\mathrm{pH}$. It can be seen that in the presence of $2 \times 10^{-3} \mathrm{M}$ ferric iron and $6.6 \times 10^{-4} \mathrm{M}$ ethyl xanthate, the zeta potential of ore-pyrite shows less positive charge below PZC of $\mathrm{pH} 7.5$ compared with that in the presence of only ferric iron alone. At $\mathrm{pH}>7.5$, there is no big difference between the two curves. In addition, as the concentration of ferric iron decreases from $1.5 \times 10^{-3} \mathrm{M}$ to $1.0 \times 10^{-3} \mathrm{M}$, the zeta potential value at $\mathrm{pH} 2.5$ shifts from positive, $+19 \mathrm{mV}$, to negative, $-12 \mathrm{mV}$, a value corresponding well with that in the presence of only xanthate. These results show that the electrokinetic behavior of pyrite is critically controlled by the presence of ferric concentration. It also suggests that the insignificant decrease of zeta potential value of coal-pyrite and coal (Figure 4.24 and Figure 4.25) can be attributed to the presence of high concentrations of ferric iron.

The effect of ferrous irons on the electrokinetic behavior of ore-pyrite was also 


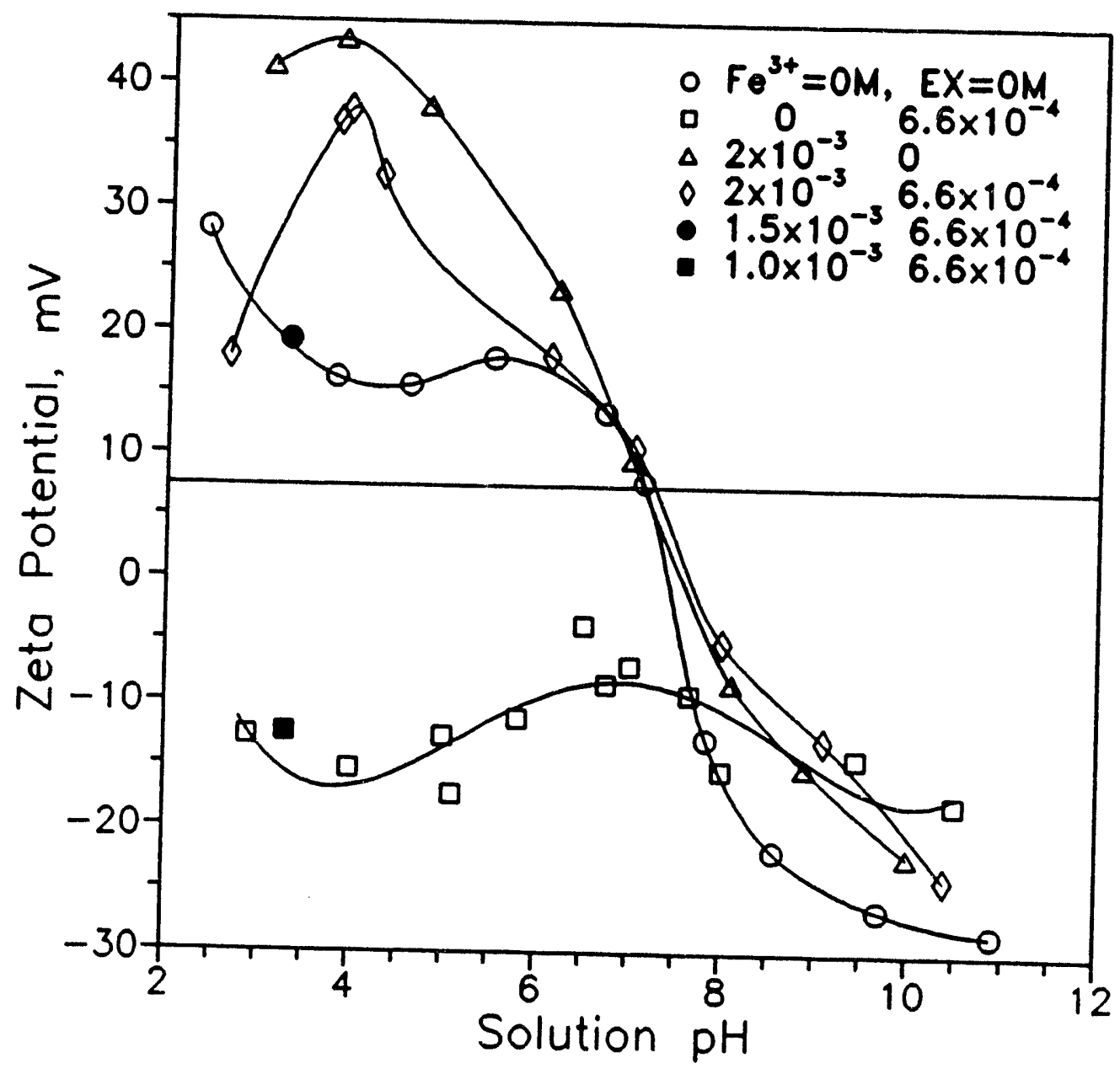

Figure 4.26 Effect of ferric ions on the zeta potential of ore-pyrite as a function of solution $\mathrm{pH}$ in the absence and presence of ethyl xanthate. 
studied as shown in Figure 4.27. In the presence of both $2 \times 10^{-3} \mathrm{M}$ ferrous iron and $6.6 \times 10^{-4} \mathrm{M}$ ethyl xanthate, apart from the $\mathrm{PZC}$ of around $\mathrm{pH} 9$ in the presence of only ferrous iron, a new surface charge reversal is also observed at $\mathrm{pH} 6$. It is obvious that different reaction mechanism were involved below and above $\mathrm{pH} 6$. At $\mathrm{pH}<6$, the zeta potential of pyrite is negative and similar to the results in the presence of only xanthate. At $\mathrm{pH}>6$, the zeta potential curve is identical to that in the presence of only ferrous iron. These results reveal that unlike ferric iron, ferrous ions do not undergo reaction with xanthate in the acidic solution $(\mathrm{pH}<6)$, the flotation of pyrite in this region is mainly due to the adsorption of xanthate. At $\mathrm{pH}>6$, the adsorption of xanthate is apparently reduced. These results are in excellent agreement with the flotation results in the presence of ferrous irons.

\subsubsection{Thermodynamic Calculations on Pyrite Flotation with Xanthate}

Pyrite is an iron-containing sulfide. The oxidation products such as ferric and ferrous irons formed on the surface play an important role in influencing the surface electrical properties and flotation of pyrite with xanthate, as has been shown above. The different flotation and surface properties of ore-pyrite and coal-pyrite may result from differerces in chemical composition and oxidation behavior. It can be expected that coal-pyrite in coal deposits could have been exposed to a more oxidizing environment than ore-pyrite. A higher degree of oxidation might have occurred even 


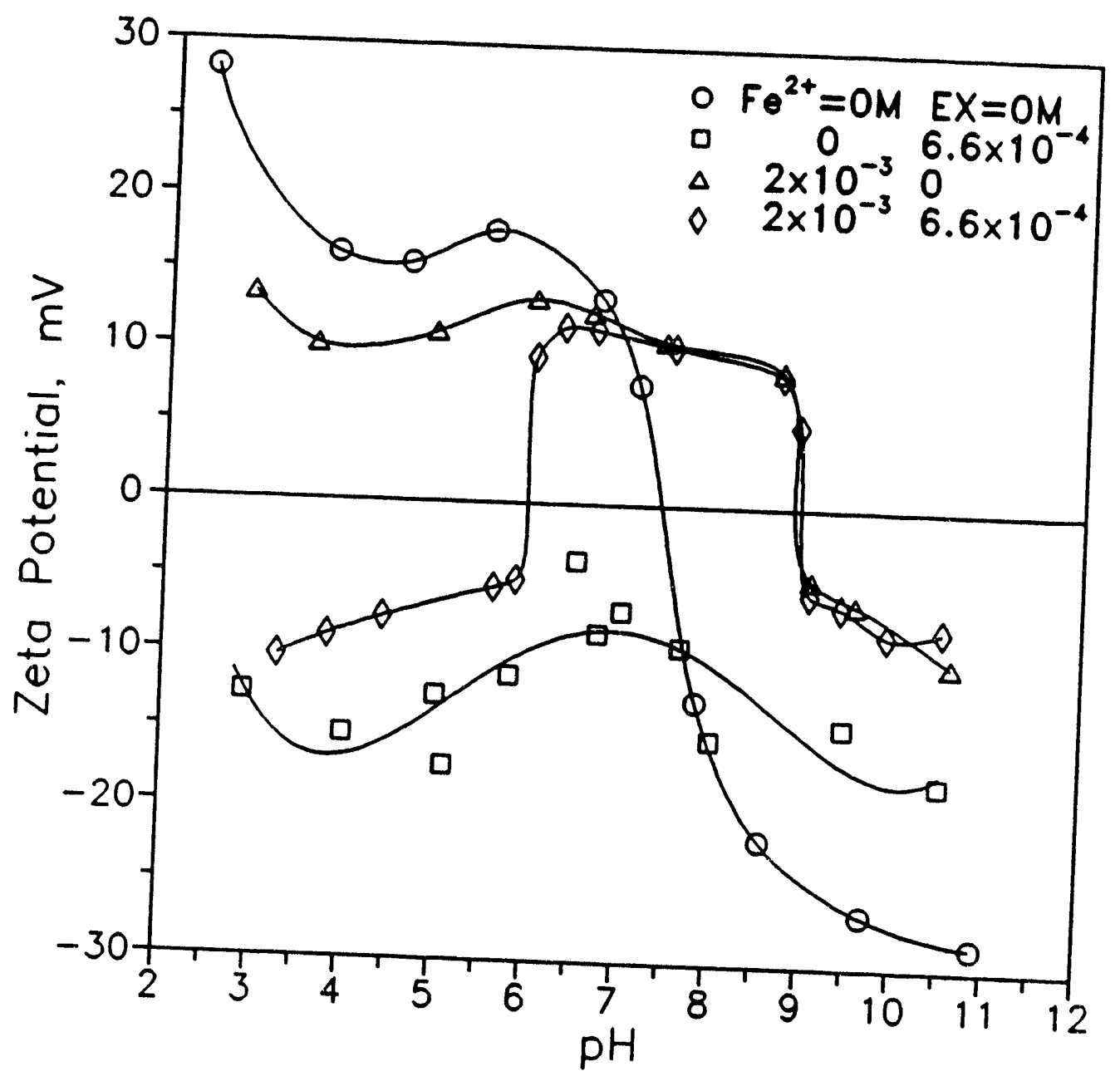

Figure 4.27 Effect of ferrous ions on the zeta potential of ore-pyrite as a function of solution $\mathrm{pH}$ in the absence and presence of ethyl xanthate. 
in the interior of the coal-pyrite, thereby producing larger quantities of ferric or ferrous iron on the surface than ore-pyrite. Lai et al (1990) and Khan et al (1992) studied the surface oxidation of pyrites by XPS, they found that the iron atoms showed a much higher oxidation state on coal-pyrite than on ore-pyrite. This is consistent with the poor floatability of coal-coal-pyrite in the presence of xanthate even with ultrasonic surface cleaning (Figure 4.19).

Sase' on the flotation and electrokinetic studies, the mechanism in the flotation of pyrite in the presence of xanthate can be explained in terms of the solution chemistry of the iron-xanthate. The thermodynamic equilibrium calculations were performed with the help of the computer program SOLGASWATER (Eriksson, 1979). The stability constants of the species considered in this study were obtained from literature (Sillen and Martel, 1964, 1970; Smith and Martel, 1976; Wang, 1989; Wang et al, 1989a), and listed in the appendix. The calculated results were presented in terms of distribution $[\log ($ concentration $)$ vs. $\mathrm{pH}]$ diagram, where $\mathrm{pe}=-\log$ (electron activity). The pe gives electron activity at equilibrium and measures the relative tendency of a solution to accept or transfer electrons. The pe is related to the redox potential E vs. SHE by the following equation:

$$
p e=\frac{F E}{2.3 R T}=\left(\frac{E(m V)}{59} \text {, at } T=298.15 K\right)
$$

where $\mathrm{R}$ is the gas constant, $\mathrm{T}$ is the absolute temperature $(\mathrm{K})$ and $\mathrm{F}$ is Faraday constant. 
Figure 4.28 and 4.29 show the $\log ($ Concentration)-pH distribution diagrams for the thermodynamic system of iron-xanthate at $p e=3$ for different iron ion concentrations. At a concentration of ethyl xanthate $3.3 \times 10^{-4} \mathrm{M}(50 \mathrm{mg} / \mathrm{l})$ and iron $2 \times 10^{-3} \mathrm{M}$, and in acidic solution, aqueous and liquid dixanthogen is the predominant species of xanthate. In the neutral $\mathrm{pH}$ range of $\mathrm{pH} 5-9$ where the stable insoluble ferric dihydroxo xanthate $\left(\mathrm{Fe}(\mathrm{OH})_{2} \mathrm{EX}(\mathrm{s})\right)$ are formed, and liquid dixanthogen completely disappears, the quantities of aqueous xanthate are relatively small, at $\mathrm{pH}>9$, xanthate ion is the main species. At a higher iron ion concentration of $1 \times 10^{-2} \mathrm{M}$, as shown in Figure 4.29, dixanthogen species disappear over the entire $\mathrm{pH}$ range. It can be seen that in acidic solution below $\mathrm{pH} 4$, the ferric xanthate, $\mathrm{Fe}(\mathrm{EX})_{3}$ is formed. Consequently, the conclusion that dixanthogen is the only species responsible for pyrite flotation is unjustified (Fuerstenau, et al, 1968; Ball and Richard, 1976; Fuerstenau and Mishra, 1981). The presence of the metal xanthate species such as ferric hydroxo-xanthate is more likely to determine the flotation behavior of pyrite in alkaline solution (Wang, 1989; Wang et al, 1989a; Wang and Forssberg, 1991; Fornasiero and Ralston, 1992).

The results obtained from the thermodynamic calculations can satisfactorily explain the flotation results of pyrite by xanthate and zeta-potential phenomena. Freshly ground coarse size $(-100+74 \mu \mathrm{m})$ ore pyrite, which has a low degree of surface oxidation, shows complete flotation over the entire $\mathrm{pH}$ range (Figure 4.8). For 


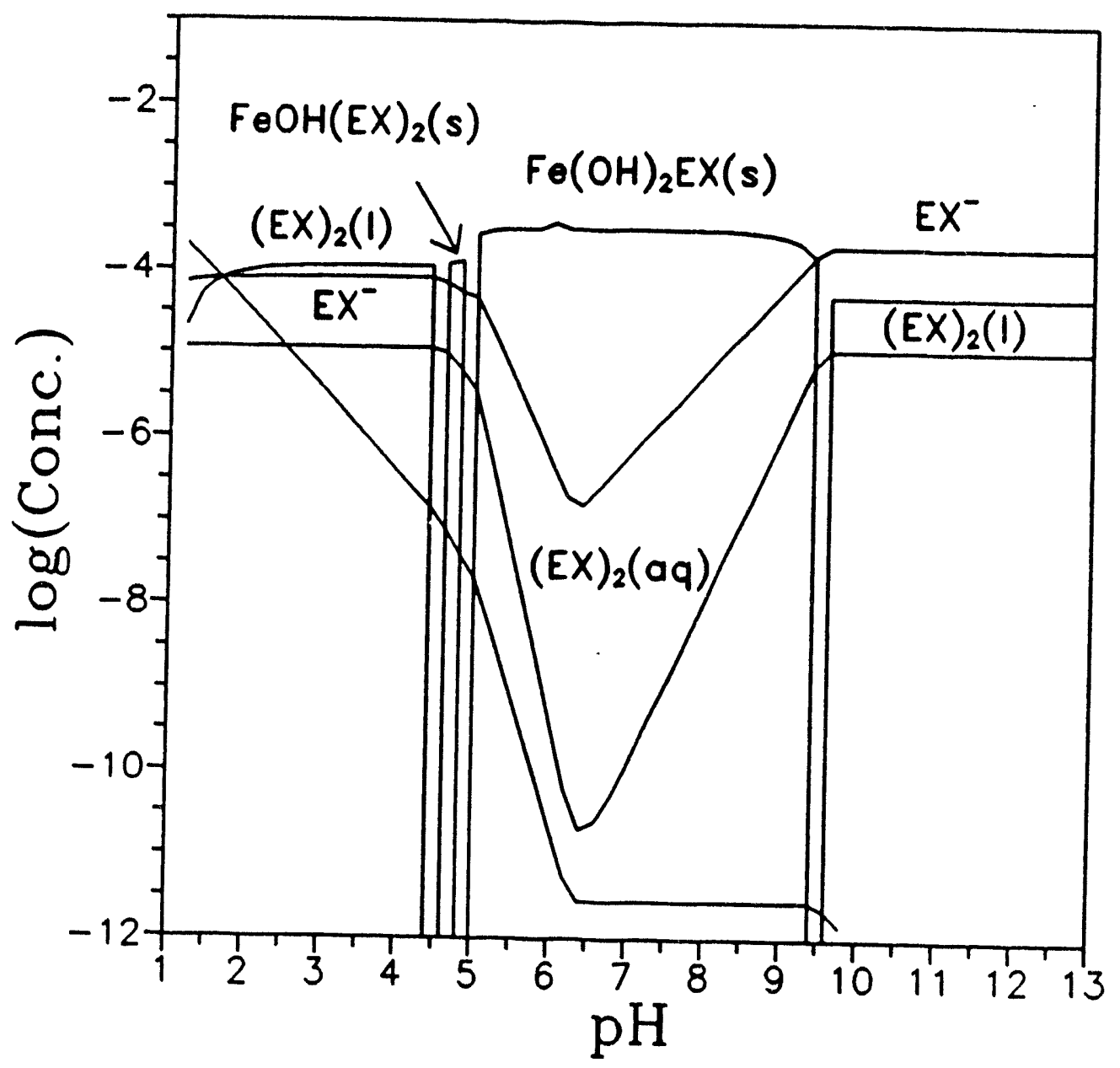

Figure 4.28 $\log$ (Concentration)-pH distribution diagram for iron-ethyl xanthate system at $\mathrm{pe}=3$ for total concentration of $3.3 \times 10^{-4} \mathrm{M}$ ethyl xanthate and $2 \times 10^{-3} \mathrm{M}$ iron. 


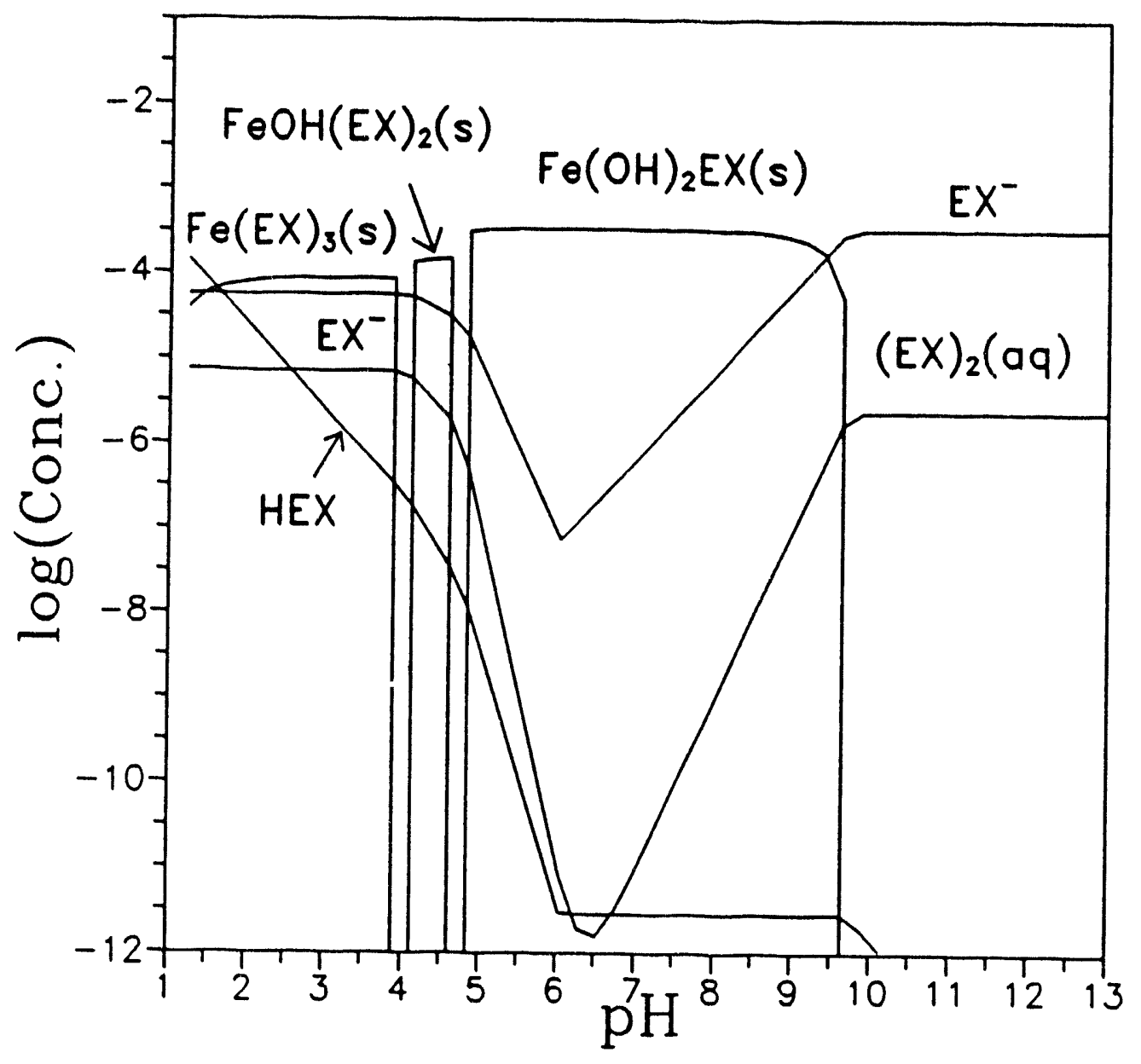

Figure 4.29 $\log ($ Cencentration)-pH distribution diagram for iron-ethyl xantahte system at $\mathrm{pe}=3$ for total concentration of $3.3 \times 10^{-4} \mathrm{M}$ ethyl xanthate and $1 \times 10^{-2} \mathrm{M}$ iron. 
the fine size fraction of ore-pyrite $(-45 \mu \mathrm{m})$, two factors need to be considered. First, it is expected that a thicker layer of surface oxidation products such as ferric or ferrous irons could have been formed on the pyrite surfaces. Hence, more ferric dihydroxo-xanthate is likely to be formed on the surface. Second, as the particle size decreases, the surface concentration of xanthate will decrease. This is effectively equivalent to a decrease in xanthate concentration for the sample particle size. Therefore, the formation of ferric dihydroxo xanthate in the solution or on the surface resulted in the poor floatability of fine ore-pyrite at $\mathrm{pH}>6$ (Figure 4.16 ), which corresponds very well with the flotation results of coarse size ore-pyrite ($150+100 \mu \mathrm{m})$ in the presence of iron ions especially for ferrous iron as shown in Figure 4.22. Since $\mathrm{Fe}(\mathrm{OH})_{2} \mathrm{EX}$ is poorly hydrophobic due to the hydroxyl groups, and as shown in Figures 4.28 and 4.29 , under these conditions, the quantities of dixanthogen and xanthate are extremely small. It is anticipated that the surface of fine ore-pyrite will remain poorly hydrophobic. The flotation behavior of coal-pyrite for different particle sizes by xanthate is extremely similar to that of fine ore-pyrite (Figures 4.15 and 4.16). The high degree oxidation of coal-pyrite produces large amounts of ferric and ferrous ions existing both on the surface and in the solution under the normal flotation conditions. It is expected that much of xanthate added will be consumed by the formation of ferric dihydroxo xanthate. This reduces the floatability of coal-pyrite. The particle size independence of coal-pyrite flotation with xanthate suggests that the oxidation of coal-pyrite surface is very severe. The sharp 
decrease in flotation recovery for coal-pyrite and fine ore-pyrite at $\mathrm{pH}$ around 6 suggests that the ferrous irons may mainly determine the flotation properties with xanthate. It is not clear which xanthate compounds are responsible for the coal flotation. The improvement of coal flotation by xanthate in acidic solution may be due to the adsorption of xanthate ions and dixanthogen on the coal surface. However, it should be noted that the coal sample contains $3 \%$ pyritic sulfur, as shown in Table 3.1. It appears that the iron ions must have been involved in the flotation process, since coal shows poor floatability of coal at $\mathrm{pH}>6$ using xanthate as a collector (Figure 4.17). The exact mechanism for coal flotation with xanthate is not very clear and further studies are needed.

\subsection{Pyrite Depressants in Coal Flotation}

Pyrite, the most common sulfide mineral, is often associated with other base sulfides such as galena, chalcopyrite and sphalerite etc. During the flotation of these ore minerals, the flotation of pyrite is readily depressed by raising the slurry $\mathrm{pH}$ or by adding lime. This prevents the formation of a hydrophobic surface on pyrite when thiol-collectors like xanthate are used. However, in coal flotation a high solution $\mathrm{pH}$, or the addition of lime also reduces the combustible recovery. Therefore, a reagent that can adsorb on pyrite and render the surface hydrophilic would be an ideal coal flotation reagents. This section describes the investigation aimed at depressing the 
floatability of coal-pyrite using various kinds of organic and inorganic depressants. In the tests, $50 \mathrm{mg} / \mathrm{l}$ fuel oil as the collector and $50 \mathrm{mg} / \mathrm{MIBC}$ as the frother were employed. The particle size of coal and coal-pyrite are $-74 \mu \mathrm{m}$ and $-45 \mu \mathrm{m}$, respectively.

\subsubsection{Organic Pyrite Depressants}

A number of organic reagents with different functional groups were studied to examine their effect in depressing pyrite. These reagents were selected on the basis of two basic properties. First, the reagent should have a functional group that has an affinity for iron ions of pyrite; and second, it should have such a structure that it will impart a hydrophilic nature to the pyrite surface if adsorbed. The reagents used in the study are listed as follows:

Sodium oxalate

Tartaric acid

Disodium ethyldiamine tetraacetic acid(EDTA)

Thiophene carboxylic acid

Thiosalicyclic acid
$\mathrm{NaOOCCOONa}$

$\mathrm{HOOC}(\mathrm{CHOH})_{2} \mathrm{COOH}$

$(\mathrm{NaOOC})_{2} \mathrm{NHNH}(\mathrm{COONa})_{2}$

$\mathrm{C}_{4} \mathrm{H}_{3} \mathrm{SCOOH}$

$\mathrm{HSC}_{4} \mathrm{H}_{4} \mathrm{COOH}$

The effect of these reagents on the flotation separation of coal and coal-pyrite 
has been studied. The flotation results demonstrate that sodium oxalate is an effective pyrite depressant as shown in Figure 4.30. As the concentration of sodium oxalate increases, the flotation of coal-pyrite is decreased without affecting the flotation recovery of coal. However, a very high concentration of $4 \times 10^{-3} \mathrm{M}$ is needed to reduce the pyrite recovery from $42 \%$ to $15 \%$, which is apparently impractical in coal flotation. Other reagents studied are ineffective in the selective depression of pyrite. The flotation results for coal and coal-pyrite using these reagents are presented in the Figures A-1 to A-4 in the appendix. It can be seen that tartaric acid does not change the flotation behavior of coal and coal-pyrite (Figure A-1). Thiophene carboxylic acid only slightly depresses the flotation of pyrite (Figure A-2). At moderate concentrations, thiosalicyclic acid results in the reduced flotation of pyrite, and simultaneously depresses coal (Figure A-3). While the addition of EDTA significantly increases the flotation recovery of coal-pyrite to an equivalent level to coal, eliminating possible separation (Figure A-4).

\subsubsection{Inorganic Pyrite Depressants}

The effects of sodium silicate and sodium metaphosphate on the separation efficiency of coal from pyrite were studied. Figure 4.31 shows the effect of sodium silicate concentration on the flotation of coal and coal-pyrite. The results show that the addition of sodium silicate is not efficient for the depression of pyrite. At a high 


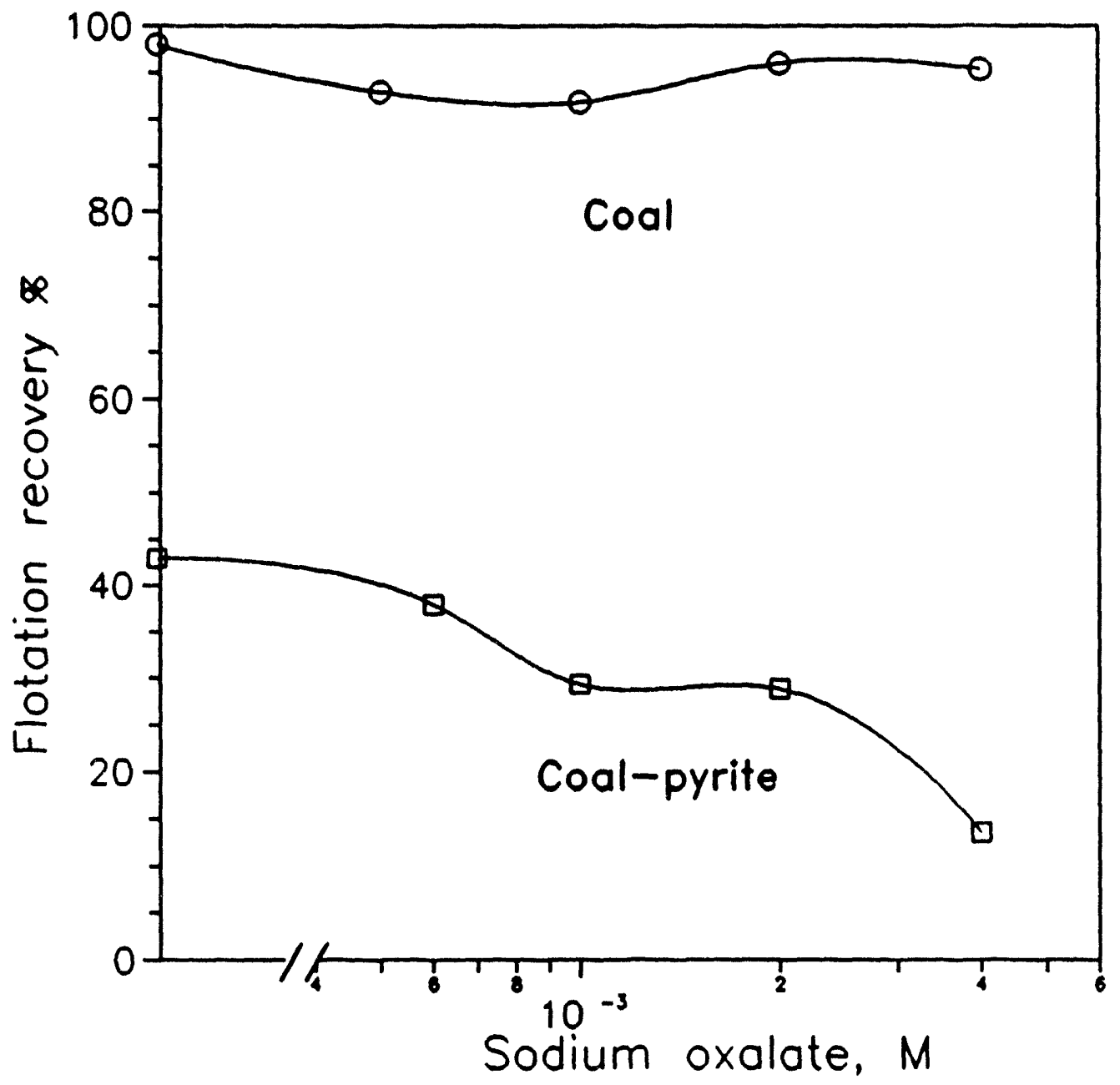

Figure 4.30 Effect of sodium oxalate on the flotation separation of coal and coal-pyrite in the presence of fuel oil. 


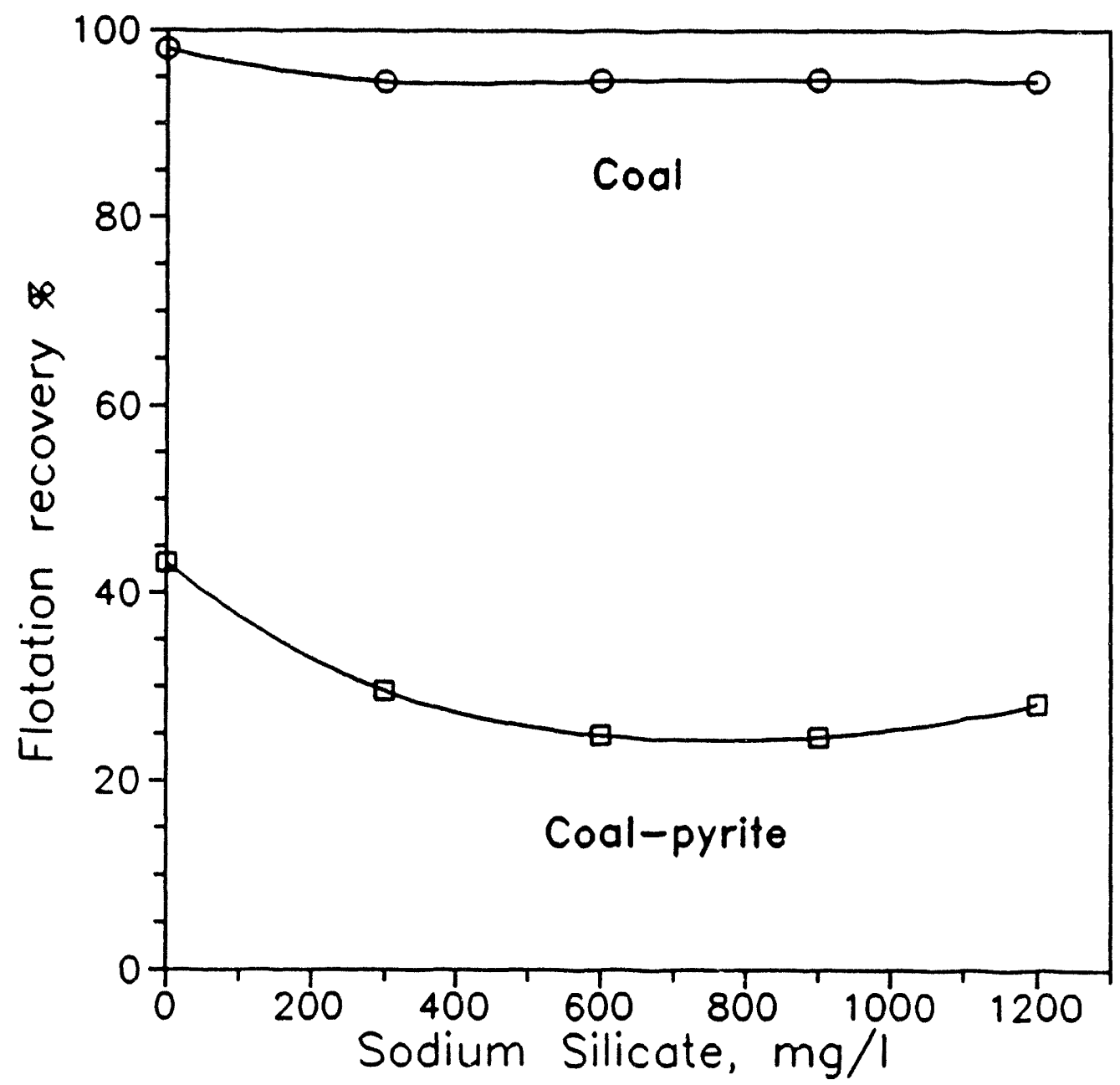

Figure 4.31 Effect of sodium silicate on the flotation separation of coal and coal-pyrite in the presence of fuel oil. 
dosage of $1200 \mathrm{mg} / \mathrm{l}$, the recovery of coal-pyrite is still above $25 \%$. Similar results are obtained for sodium metaphosphate as shown in Figure A-5 in the appendix, where the flotation of coal-pyrite is only slightly depressed. It shows that commonly used inorganic depressants cannot achieve good separation results for the tested coal and coal-pyrite sample. Further tests must be conducted to develop new effective pyrite depressants.

Although use of organic compounds may result in good depression for coalpyrite, a major drawback is their extremely high dosage requirement. Inorganic chemicals are generally hydrophilic and susceptible for the hydrolysis in aqueous solution. In this study, great efforts have been made toward finding effective inorganic compounds for pyrite depression. Since pyrite is an iron disulfide, the inorganic reagents have been selected based on their ability to react with iron ions to form stable complexes. The preliminary flotation tests showed that among a variety of reagents tested only the phosphate group compounds were found to be effective for the selective depression of coal-pyrite from coal. The results of the two kinds of phosphate depressants having the best depression effect on coal-pyrite are presented and their possible reaction mechanisms are discussed.

Figure 4.32 shows the flotation separation results of coal and coal-pyrite using sodium phosphate as depressants. It can be seen that when the concentration of 


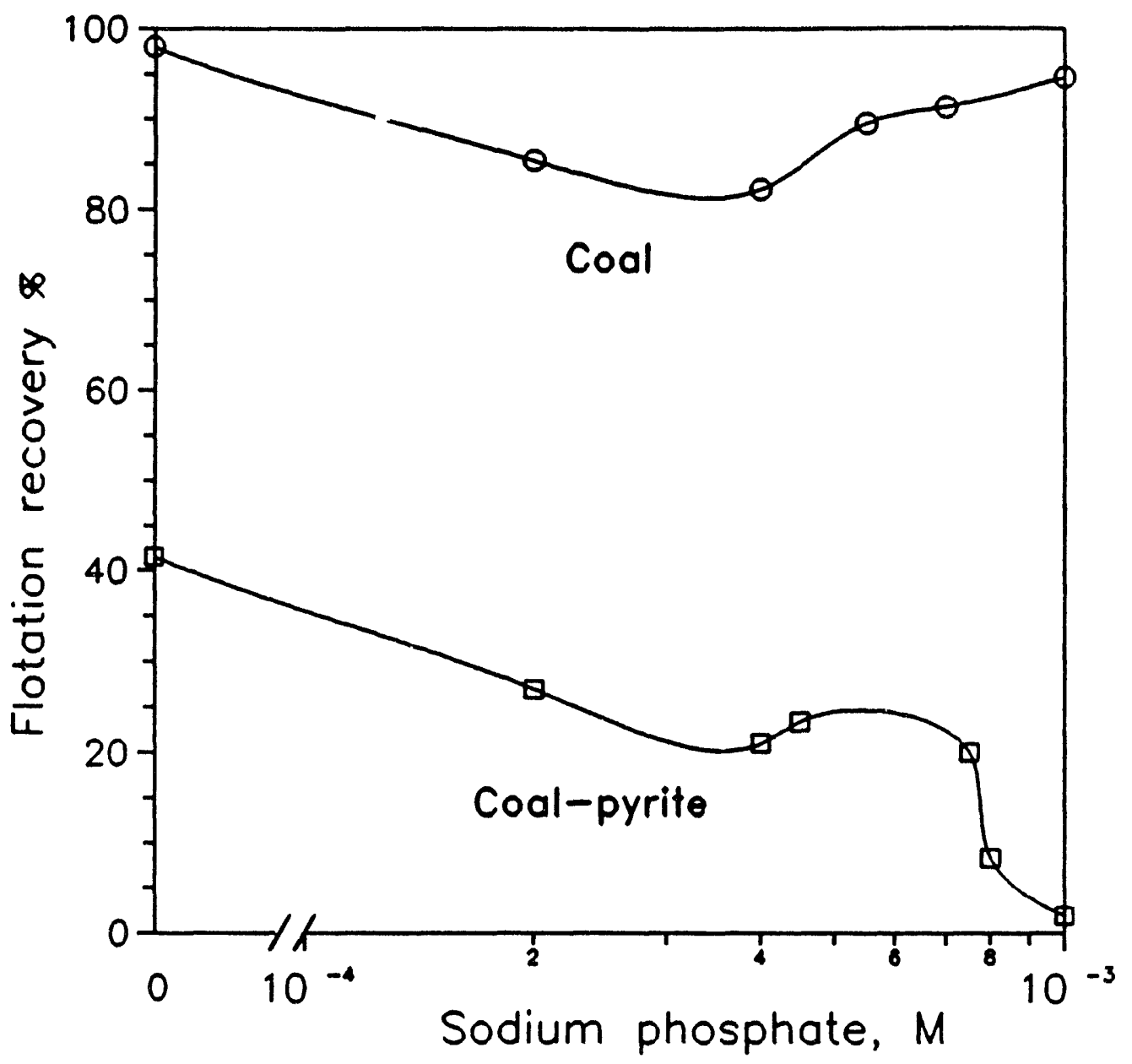

Figure 4.32 Effect of sodium phosphate on the flotation separation of coal and coal-pyrite in the presence of fuel oil. 
sodium phosphate is higher than $8 \times 10^{-4} \mathrm{M}$, effective separation of pyrite from coal are obtained. Coal-pyrite has a recovery lower than $10 \%$ while the recovery of coal reaches $90 \%$. At lower reagent concentrations, the recovery of coal-pyrite is slightly decreased and maintained between $20-27 \%$, thus efficient separation between coal and pyrite at lower reagent concentration can not be achieved. Therefore, high dosage of sodium phosphate will be needed to ensure good results. Figure 4.33 shows the effect of sodium pyrophosphate on the separation of coal and coal-pyrite. As the pyrophosphate concentration increases, the flotation recovery of coal-pyrite is strongly reduced. Even at extremely low concentration of $1 \times 10^{-4} \mathrm{M}$, the recovery of pyrite is only $10 \%$. A higher concentration is sufficient to result in the complete depression of coal-pyrite. However, in the presence of pyrophosphate, the flotation recovery of coal is kept at a level of $85 \%$ and almost independent of the pyrophosphate concentrations. This indicates that pyrophosphate is highly selective for depressing coal-pyrite and superior to sodium phosphate. Further experiments were conducted to examine the effect of sodium pyrophosphate on the flotation behavior of coal and coal-pyrite as a function of $\mathrm{pH}$. As shown in Figure 4.34 , in the presence of $2.5 \times 10^{-4}$ $\mathrm{M}$ sodium pyrophosphate, complete separation is achieved above $\mathrm{pH} 4$. Compared with the flotation curves in the absence of depressants, the depression of pyrite by pyrophosphate is effected even at a very low $\mathrm{pH}$ value of 3 , while the floatability of coal drops to a much smaller degree as the solution $\mathrm{pH}$ increases. These results show that pyrophosphate is an ideal coal-pyrite depressant over nearly the entire $\mathrm{pH}$ range, 


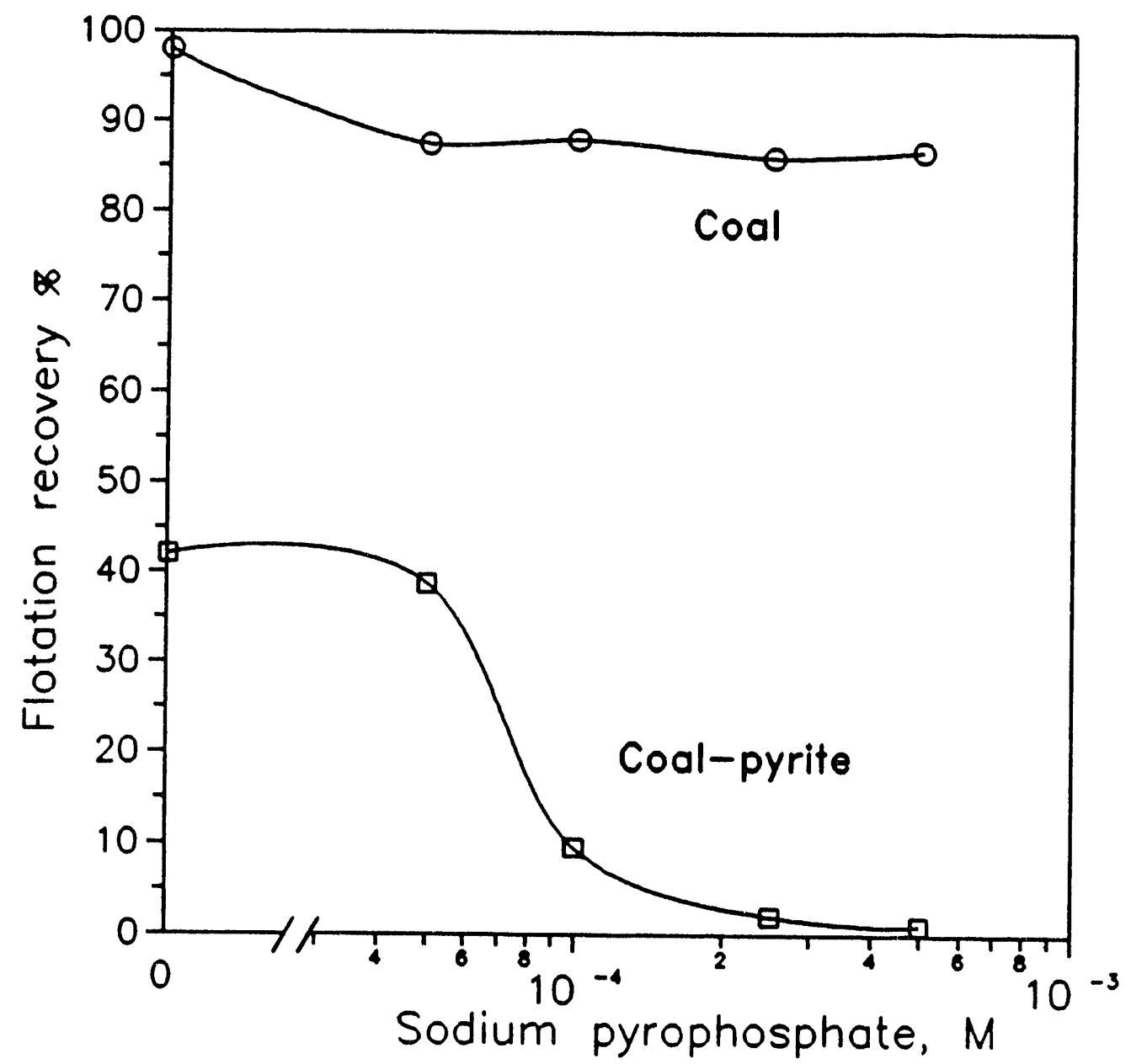

Figure 4.33 Effect of sodium pyrophosphate on the flotation separation of coal and coal-pyrite in the presence of fuel oil. 


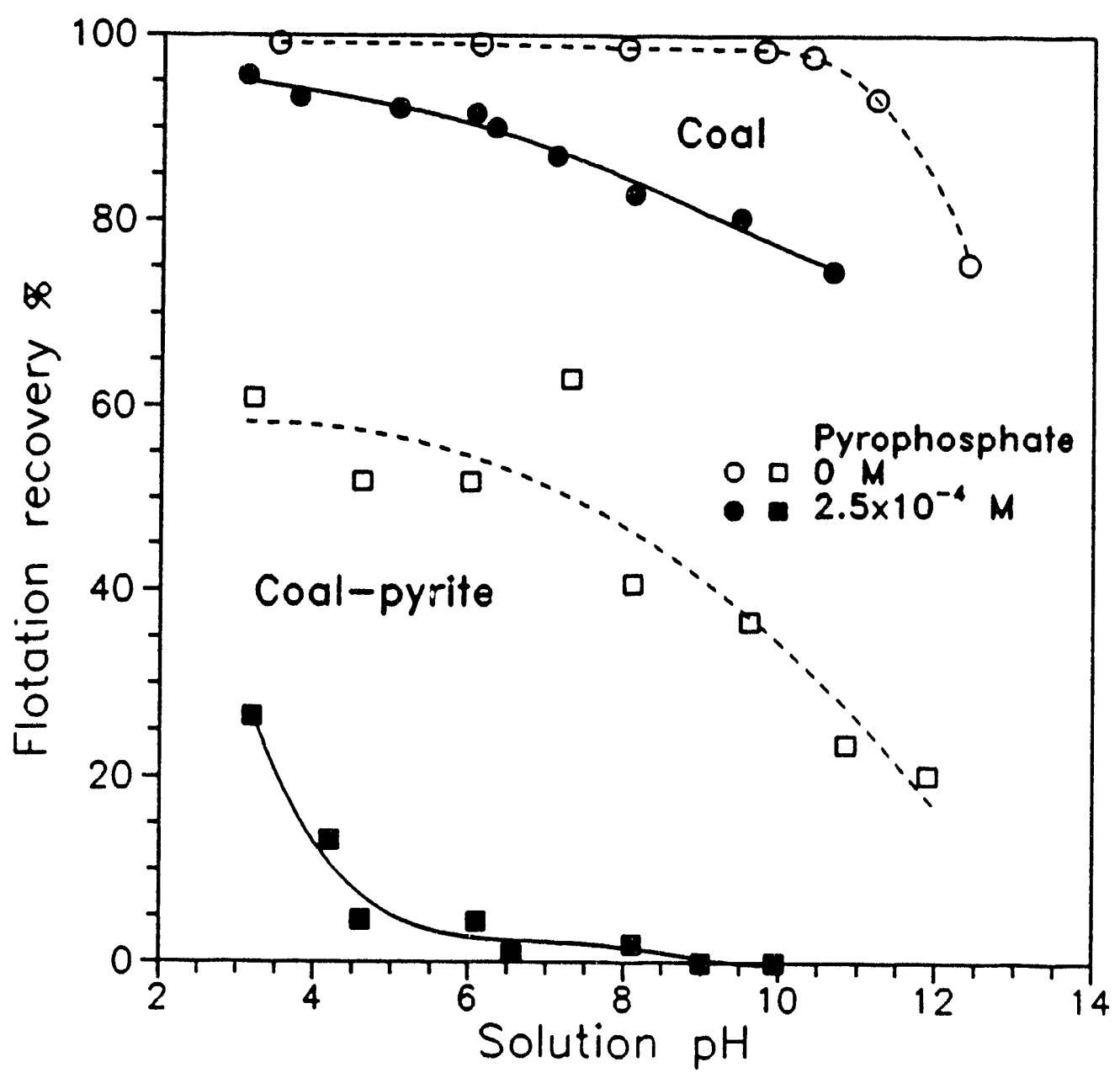

Figure 4.34 Flotation recovery of coal and coal-pyrite as a function of solution $\mathrm{pH}$ in the absence and presence of sodium pyrophosphate using fuel oil as collector. 
and separation sensitivity is not effected with variations in concentration.

It should be noted that coal-pyrite is not pure and contains mainly iron and also small quantity of other metals such as $\mathrm{Mg}$ and $\mathrm{Ca}$. In order to understand the mechanism of phosphate compounds in depressing pyrite, the solution chemistry of the phosphate systems is investigated. Phosphorus in phosphate has a formal oxidation number $\mathrm{V}$ and a coordination number 4 with the oxygen ion. The ionic form of orthophosphate can be represented as $\left[\mathrm{PO}_{4}\right]^{3}$. The polyphosphate with two or more orthophosphate ions are distinguished by two groups. One is linear-chain polyphosphates with a general formula of $\left[\mathrm{P}_{\mathrm{n}} \mathrm{O}_{3 \mathrm{n}+1}\right]^{(\mathrm{n}+2)}$ such as $\mathrm{P}_{2} \mathrm{O}_{7}{ }^{4}$ (pyrophosphate). The other is cyclic metaphosphates such as $\mathrm{P}_{6} \mathrm{O}_{18}{ }^{6}$ (hexametaphosphate). Phosphate, pyrophosphate and other polyphosphate are known to form complexes, chelates and insoluble salts with a number of metal ions. Table 4.1 presents the complexation constants of phosphates with metal ions. It can be seen that the sodium salts of these phosphates are highly soluble. Very importantly, phosphate and pyrophosphate reacts with iron ions and forms stable complexes, which may be responsible for the depression of pyrite.

The species distribution diagrams of $\mathrm{Fe}(\mathrm{III})$-water, phosphate-water and pyrophosphate-water systems as a function of $\mathrm{pH}$ are given in Figures A-6 to A-8 in the appendix, respectively. The species distribution diagrams for Fe(III)-phosphate 
Table 4.1 Complexation constants of phosphates with metal ions

\begin{tabular}{lc}
\hline Equilibrium & $-\log ($ constant $)$ \\
\hline $\mathrm{Na}^{+}+\mathrm{HPO}_{4}{ }^{2 \cdot}=\mathrm{NaHPO}_{4}{ }^{-}$ & 0.6 \\
$\mathrm{Mg}^{2+}+\mathrm{HPO}_{4}{ }^{2 \cdot}=\mathrm{MgHPO}_{4}(\mathrm{aq})$ & 2.5 \\
$\mathrm{Ca}^{2+}+\mathrm{HPO}_{4}{ }^{2 \cdot}=\mathrm{CaHPO}_{4}(\mathrm{aq})$ & 2.2 \\
$\mathrm{Fe}^{3+}+\mathrm{HPO}_{4}{ }^{2 \cdot}=\mathrm{FeHPO}_{4}{ }^{+}$ & 8.3 \\
$\mathrm{Ca}^{2+}+\mathrm{H}_{2} \mathrm{PO}_{7}{ }^{3 \cdot}=\mathrm{CaH}_{2} \mathrm{PO}_{7} \cdot$ & 2.0 \\
$\mathrm{Mg}^{2+}+\mathrm{H}_{2} \mathrm{PO}_{7}{ }^{3 \cdot}=\mathrm{MgH}_{2} \mathrm{PO}_{7}$ & 5.7 \\
$\mathrm{Na}^{+}+\mathrm{P}_{2} \mathrm{O}_{7}{ }^{4 \cdot}=\mathrm{NaP}_{2} \mathrm{O}_{7}{ }^{3 \cdot}$ & 2.2 \\
$\mathrm{Fe}^{3+}+2 \mathrm{HP}_{2} \mathrm{O}_{7}{ }^{3 \cdot}=\mathrm{Fe}\left(\mathrm{HP}_{2} \mathrm{P}_{7}\right)_{2}{ }^{3 \cdot}$ & 22 \\
\hline
\end{tabular}

and $\mathrm{Fe}(\mathrm{III})$-pyrophosphate at different concentrations of phosphates are given in Figures $4.35-4.38$, in which the total Fe(III) concentration is kept at $1 \times 10^{-4} \mathrm{M}$. The stability constants used in the calculations were extracted from literature (Sillen and Martell, 1964; Sillen and Martell, 1970; Smith and Martell, 1979; Hogfeldt, 1982) and listed in the tables A-1 to A-6 in the appendix. It can be seen from Figure 4.35 that in the presence of $1 \times 10^{-4} \mathrm{M}$ phosphate, the ferric hydroxide precipitation is most stable species in the $\mathrm{pH}$ range of 3-13. The formation of ferric phosphate complexes, 


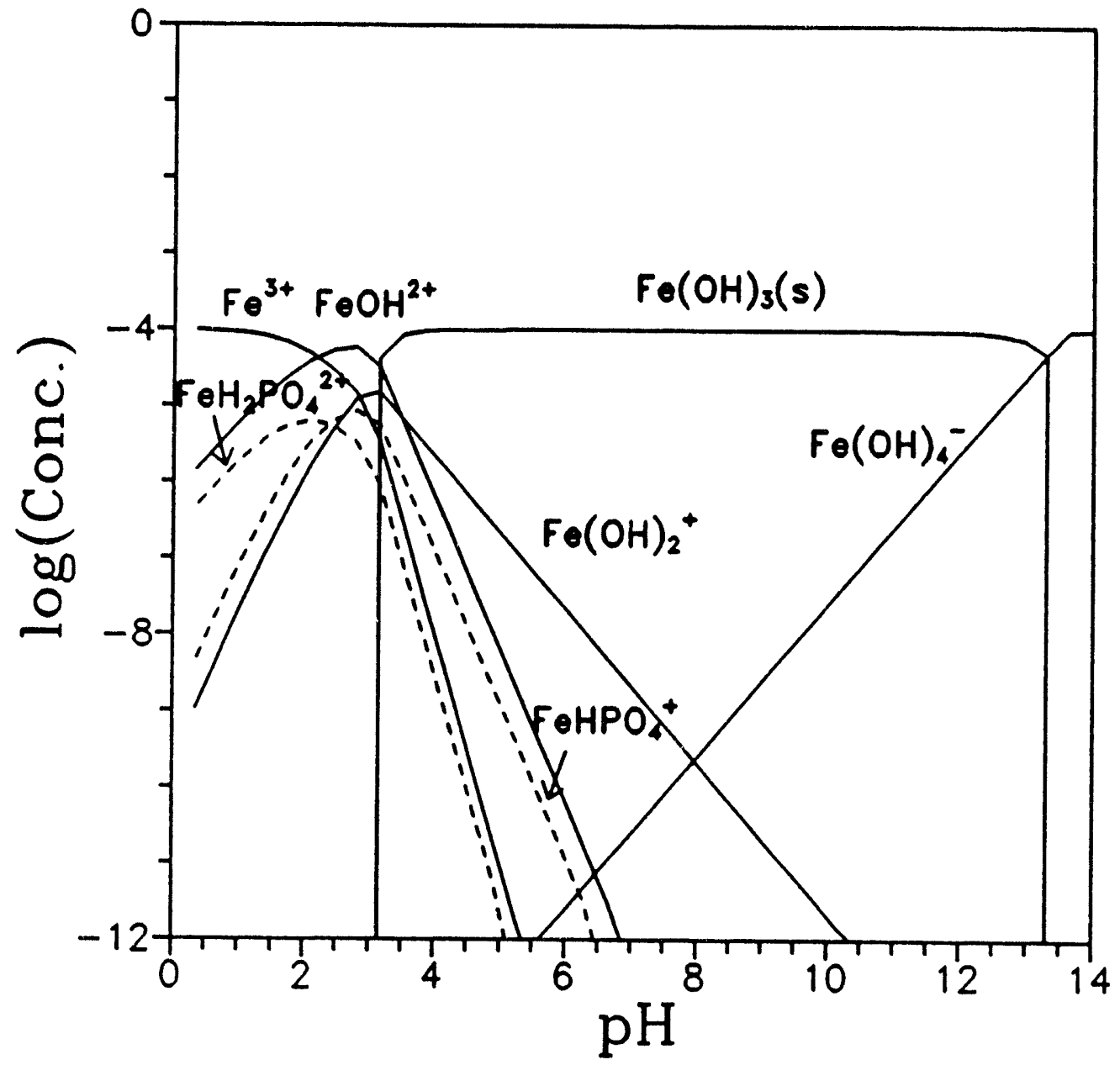

Figure 4.35 $\log$ (Concentration)-pH distribution diagram of the $\mathrm{Fe}(\mathrm{III})$ phosphate system for main species at total concentration of $1 \times 10^{-4} \mathrm{M} \mathrm{Fe}(\mathrm{III})$ and $1 \times 10^{-4} \mathrm{M}$ phosphate. 


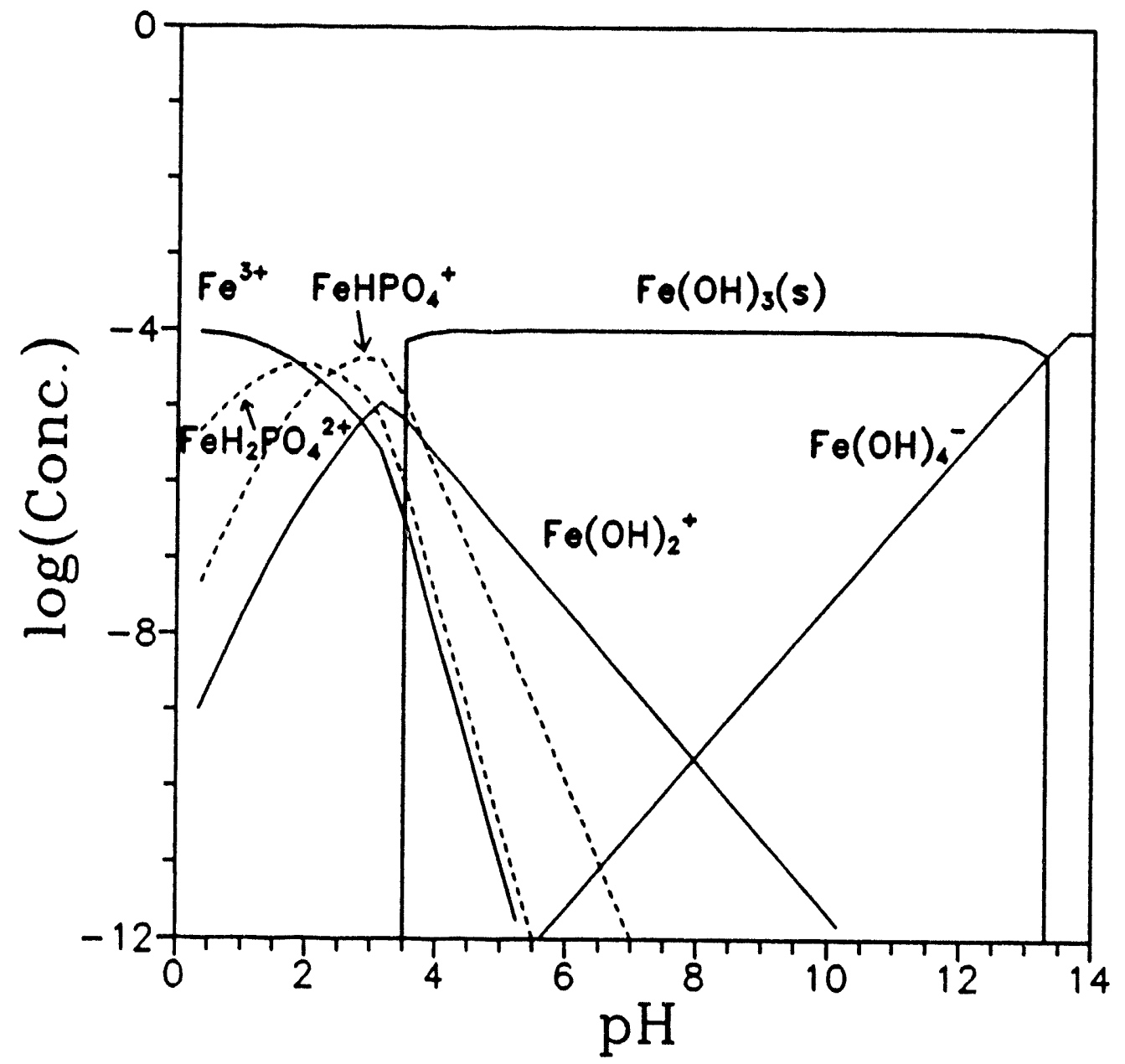

Figure 4.36 $\log ($ Concentration)-pH distribution diagram of the $\mathrm{Fe}(\mathrm{III})$ phosphate system for main species at total concentration of $1 \times 10^{-4} \mathrm{M} \mathrm{Fe}$ (III) and $1 \times 10^{-3} \mathrm{M}$ phosphate. 
$\mathrm{FeH}_{2} \mathrm{PO}_{4}{ }^{2+}$ and $\mathrm{FeHPO}_{4}{ }^{+}$, occurs in the acidic solutions with the maximum complexing ability at around $\mathrm{pH} 1-4$, without affecting the precipitation region of ferric hydroxide. By increasing the phosphate concentration to $1 \times 10^{-3} \mathrm{M}$, the distribution diagram does not change much, as shown in Figure 4.36, $\mathrm{FeH}_{2} \mathrm{PO}_{4}{ }^{2+}$ and $\mathrm{FeHPO}_{4}{ }^{+}$complexes are not formed in the alkaline solutions. This supports the flotation results where phosphate was not found to be very effective for the depression of pyrite at $\mathrm{pH} 7-8$. However, in the presence of $1 \times 10^{-4} \mathrm{M}$ pyrophosphate as shown in Figure 4.37, the formation of ferric pyrophosphate complexes occurs over a wide $\mathrm{pH}$ range. Below $\mathrm{pH} 2, \mathrm{FeH}_{3} \mathrm{P}_{2} \mathrm{O}_{7}{ }^{2+}$ and $\mathrm{FeH}_{2} \mathrm{P}_{2} \mathrm{O}_{7}{ }^{+}$are stable complexes, in the $\mathrm{pH}$ ranges of $2-8, \mathrm{Fe}\left(\mathrm{HP}_{2} \mathrm{O}_{7}\right)_{2}{ }^{3 \cdot}$ is the predominant pyrophosphate complex species, and above $\mathrm{pH} 8, \mathrm{Fe}(\mathrm{OH})_{2} \mathrm{P}_{2} \mathrm{O}_{7}{ }^{2-}$ is favored. Figure 4.38 clearly shows that in the presence of $2 \times 10^{-4} \mathrm{M}$ pyrophosphate, even ferric hydroxide is unstable. It dissolves below pH4.7 and partly dissolves at $\mathrm{pH} 4.7-8$ to form $\mathrm{Fe}\left(\mathrm{HP}_{2} \mathrm{O}_{7}\right)_{2}{ }^{3 \cdot}$. At $\mathrm{pH}$ values greater than $8, \mathrm{Fe}(\mathrm{OH})_{2} \mathrm{P}_{2} \mathrm{O}_{7}{ }^{2-}$ is formed through replacing one hydroxyl ion in the ferric hydroxide by pyrophosphate ion. It can be seen that for different concentrations of pyrophosphate the most important ferric pyrophosphate species over the entire $\mathrm{pH}$ range is $\mathrm{Fe}\left(\mathrm{HP}_{2} \mathrm{O}_{7}\right)_{2}{ }^{3}$. It is evident that due to the formation of these stable hydrophilic ferric pyrophosphate complexes on the surface, the selective depression of pyrite can be achieved. Calculation results also show that pyrophosphate is much more effective than phosphate for complexing ferric irons. Therefore, pyrophosphate is an ideal depressant in coal flotation. 


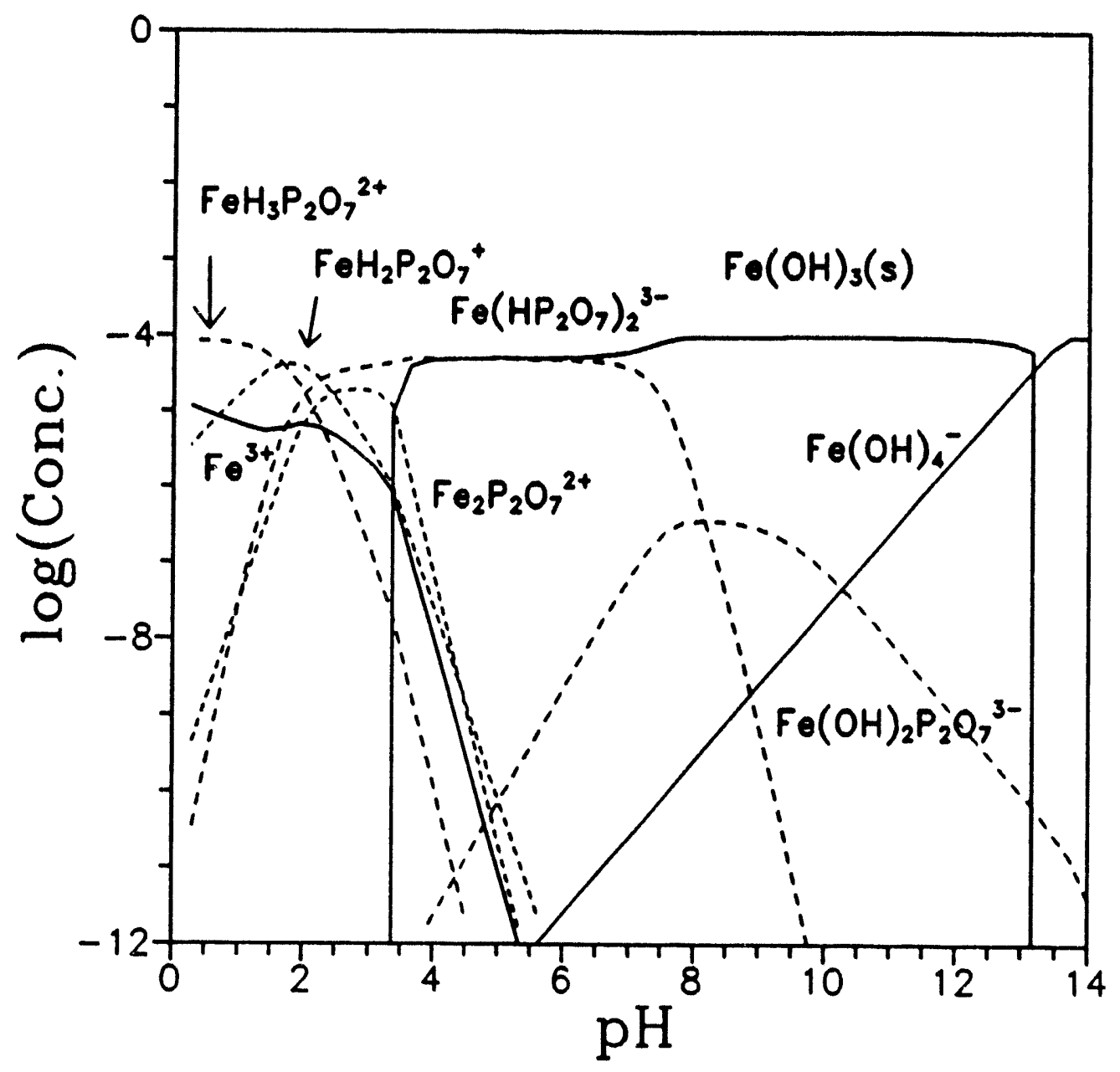

Figure 4.37 $\log$ (Concentration)-pH distribution diagram of the $\mathrm{Fe}(\mathrm{III})$ pyrophosphate system for main species at total concentration of $1 \times 10^{-4} \mathrm{M}$ $\mathrm{Fe}(\mathrm{III})$ and $1 \times 10^{-4} \mathrm{M}$ pyrophosphate. 


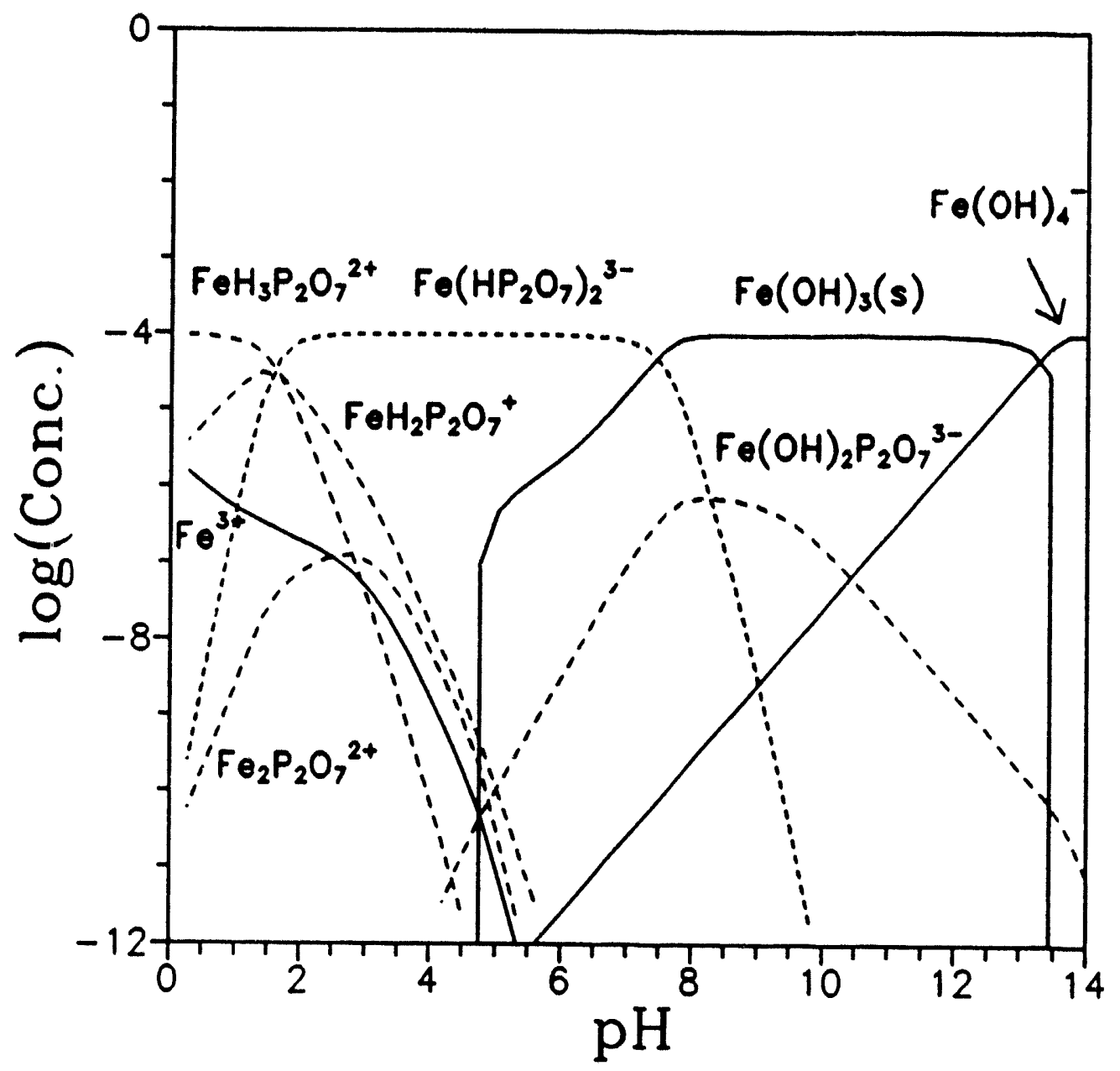

Figure 4.38 $\log ($ Concentration)-pH distribution diagram of the $\mathrm{Fe}(\mathrm{III})$ pyrophosphate system for main species at total concentration of $1 \times 10^{-4} \mathrm{M}$ Fe(III) and $2 \times 10^{-4} \mathrm{M}$ pyrophosphate. 


\subsection{Electrochemical Study of Surface Oxidation of Pyrites}

Pyrite is a good electronic conductor, its oxidation can be described in terms of electrochemical reactions. Electrochemical studies can provide both the mechanistic and kinetic information for the surface reaction of pyrite oxidation. Extensive investigations have been conducted on ore-pyrite oxidation, however, the studies on coal-pyrite were relatively more limited. To develop effective surface-based technology for the removal of pyritic sulfur from coal, the understanding of the electrochemical oxidation behavior of coal-pyrite is very important. A number of investigators have shown that coal-pyrite exhibits significantly different electrochemical behavior than ore-pyrite due to the differences in morphology, carbon inclusions and heterogeneity (Wang et al., 1992; Zhu et al., 1992; Lai et al., 1990). In this section, the electrochemical properties of ore-pyrite and coal-pyrite will be compared in order to determine how the source of pyrite affects the oxidation and flotation of coal-pyrite.

Chemically, coal-pyrite is much more heterogeneous than ore-pyrite. Besides the coal/carbon and other impurities contained in coal-pyrite, there are many other factors that can change the electrochemical reactivity of coal-pyrites, such as crystallinity and composition deviation, etc. In general, it is not feasible to examine the effects of each individual parameters on oxidation, since a minor variation in one 
of the preceding parameters will always be accompanied by a change in the others. However, as shown in the previous chapters and many previous studies (Wang et al., 1992; Raichur, 1992), the most important factor that changes the flotation behavior of coal-pyrite is the content of coal/carbon. Thus, in this study, the effects of coal content on the oxidation of pyrite have been systematically studied.

Three Kentucky No.9 coal-pyrite samples were selected. One electrode was made from the same material as used in the flotation tests (see Table 3.2 for chemical composition). The sample was carefully cut and a slab of about $5 \times 5 \mathrm{~mm}$ in crosssection was used to make the electrode. The electrode was named KYPY. The other coal-pyrite sample was a hand-picked polycrystalline pyrite from a Kentucky No.9 coal seam. The physical appearance of this sample was quite similar to that of orepyrite. It exhibited good crystal faces on one end where no coal trace could be observed, suggesting that this part of the crystal occurred in association with other minerals; while on the other half of the sample, coal traces were observed adhering tightly to the pyrite, indicating that it was associated with coal before extraction. After removing the carbon and coal particles on the surface by hand, the sample was cut into two pieces along the boundary using a diamond saw. Each piece was further cut, and two cubic specimen were acquired from the respective core part and were made into two electrodes. The electrode made from the purer part is denoted as KYPY1, while the electrode from the other part of the crystal is called KYPY2. The 
carbon content of the three electrodes decreases in the order of KYPY $>$ KYPY2 > KYPY1. The ore-pyrite electrode used in the study was prepared from a pure cubic crystal of Peru pyrite and named PUPY.

\subsubsection{Pyrite Oxidation in Acidic to Neutral Solutions}

A series of experiments on the ore-pyrite and coal-pyrite have been conducted at different solution pH's. It was found that for the same pyrite electrode, the voltammograms were very similar in the acidic to neutral $\mathrm{pH}$ ranges of $3-8.5$, i.e., and where almost independent of solution pH. Figure 4.39 shows the typical cyclic voltammograms of the stationary and rotating ore-pyrite (PUPY) electrode at pH5.6. The initial sweeps were started at the open-circuit potentials in the positive-going direction. It can be seen that several anodic and cathodic peaks were observed at the stationary electrode. When the potential sweep is first in the positive direction, a large anodic current rise (I) occurs at about $500 \mathrm{mV}$ vs SCE. The current density increases with increasing potential. This peak has been attributed to the oxidation of pyrite to form iron ions, elemental sulfur and sulfates. The overall process can be described by the reaction (Peters and Majima, 1968; Meyer, 1979):

$$
\begin{gathered}
\mathrm{FeS}_{2}+8 \mathrm{H}_{2} \mathrm{O}-\mathrm{Fe}^{3+}+2 \mathrm{SO}_{4}^{2-}+16 \mathrm{H}^{+}+15 e \\
\mathrm{FeS}_{2}-\mathrm{Fe}^{3+}+2 \mathrm{~S}^{\circ}+3 e
\end{gathered}
$$




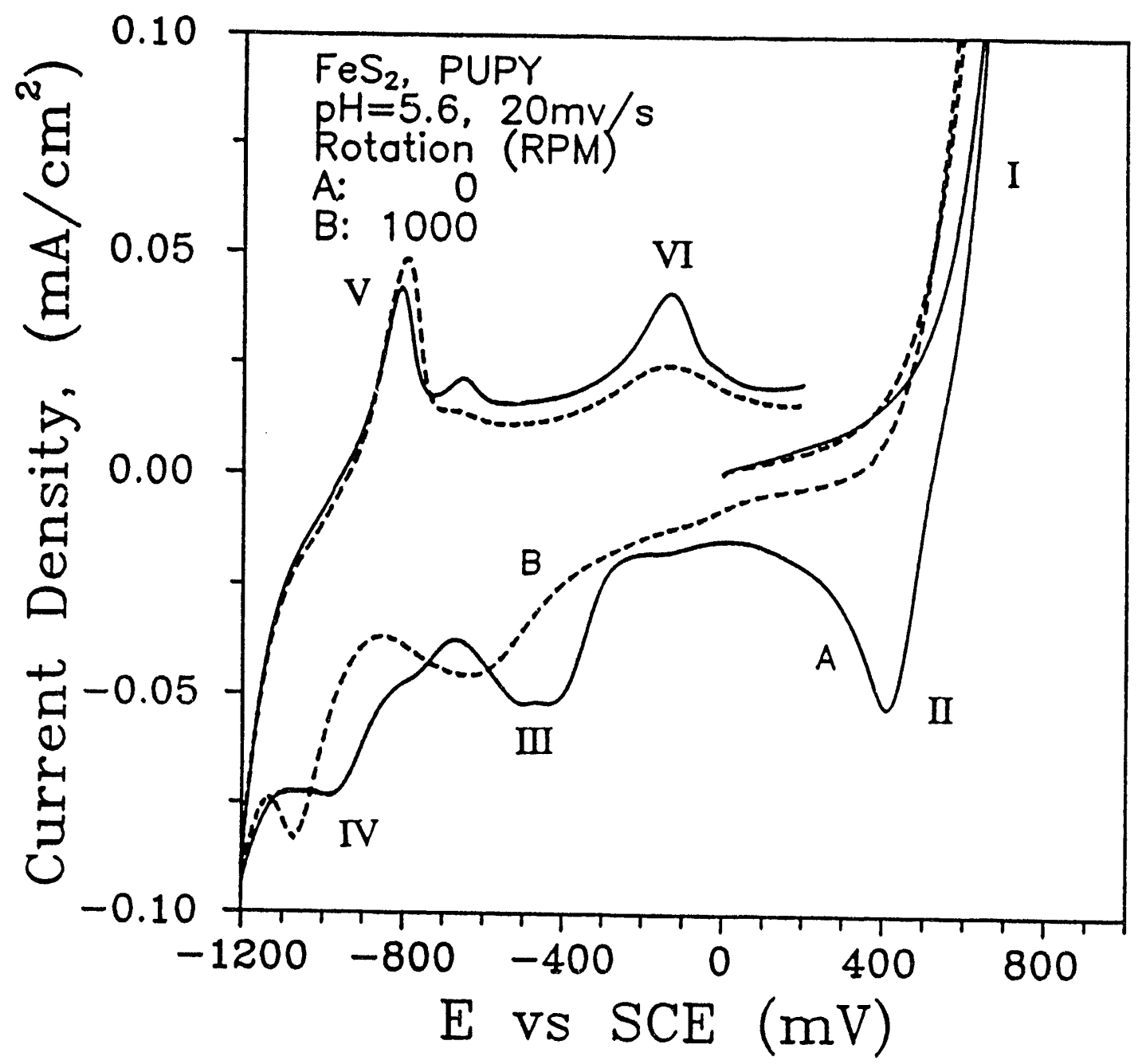

Figure 4.39 Cyclic voltammograms of the ore-pyrite (PUPY) electrode under stationary and rotation conditions at $\mathrm{pH}=5.6$. 
Such reactions were based on the thermodynamics. However, the real processes are much more complex, our results indicate that the overall reaction can be written as:

$$
\begin{aligned}
& \mathrm{FeS}_{2}+4 x \mathrm{H}_{2} \mathrm{O} \rightarrow y \mathrm{Fe}^{3+}+(1-y) \mathrm{Fe}^{2+}+(2-x) \mathrm{S}^{0} \\
&+x \mathrm{SO}_{4}^{2-}+8 x \mathrm{H}^{+}+(6 x+2 y+1) e \\
& \text { where } 0 \leq x \leq 2 ; 0 \leq y \leq 1
\end{aligned}
$$

The actual oxidation products will be determined by the oxidation potential. For example, at lower potentials, only $\mathrm{Fe}^{2+}$ is produced, while at potentials above 600 $\mathrm{mV}$ vs SCE, $\mathrm{Fe}^{3+}$ is produced. This can be clearly seen from the cyclic voltammograms. According to the above reactions, pyrite oxidation produces high concentrations of hydrogen ions where the surface is much more acidic than the bulk solution. It can be expected that the iron species produced on the pyrite surface during oxidation will be soluble and remain in the vicinity of the electrode. If the species is reducible, the reduction can be observed on the return scan. As shown in figure 4.39, a sharp reduction peak (II) appears at about $400 \mathrm{mV}$ on the return scan. Further studies showed that this reduction peak was characterized by the following features:

(1) the peak appears only when the foregoing potential sweep has an upper limit above $600 \mathrm{mV}$ vs SCE;

(2) the peak disappears on the rotating electrode;

(3) the peak current increases with increasing potential limit;

(4) the peak potential is nearly independent of the potential limit of the preceding 
positive-going sweep;

(5) the peak potential and current are independent of the bulk solution $\mathrm{pH}$ (pH3-8.5);

(6) the peak current increases with increasing the ferric ion concentration in solution and the peak potential matches with the reduction of ferric to ferrous ions.

These results demonstrate that this peak (II) results from the reduction of ferric iron to ferrous iron on pyrite surface:

$$
\mathrm{Fe}^{3+}+\mathrm{e}-\mathrm{Fe}^{2+}
$$

The rotation dependence of peak (II) suggests that the oxidation products of orepyrite, iron species and sulfates, are soluble. When the potential is further lowered, a broader reduction peak (III) is formed at about $-400 \mathrm{mV}$, which may be attributed to the reactions:

$$
\begin{aligned}
& \mathrm{Fe}^{2+}+\mathrm{S}^{0}+2 e-\mathrm{FeS} \\
& \mathrm{S}^{0}+\mathrm{H}^{+}+2 e-H S^{-}
\end{aligned}
$$

The peak (IV) at the more negative potential of $-1000 \mathrm{mV}$ shows that both pyrite and iron (II) can be reduced, forming elemental iron on electrode surface (Ahlberg et al., 1990):

$$
\mathrm{Fe}^{2+}+2 e \rightarrow \mathrm{Fe}^{\mathrm{o}}
$$


On the second positive-going scan, the peak (V) appears, which is identified as being due to the oxidation of iron:

$$
\mathrm{Fe}^{\mathrm{O}}+2 \mathrm{H}_{2} \mathrm{O}-\mathrm{Fe}(\mathrm{OH})_{2}(\mathrm{~s})+2 \mathrm{H}^{+}+2 e
$$

With the further increase in potential, an anodic peak (VI) occurs at about -200 $\mathrm{mV}$. This peak is rotation dependent. The current density decreases at the rotating electrode. The reaction involved in this peak is the reverse of reactions 4.10 and 4.11 , leading to the formation of elemental sulfur.

Similar studies were also conducted for coal-pyrite. Figures $4.40-4.42$ present the cyclic voltammograms of KYPY1, KYPY2 and KYPY coal-pyrite electrodes at $\mathrm{pH} 5.6$, respectively. It can be clearly noticed that the voltammetric behavior of the three electrodes are quite different. Under both stationary and rotating conditions, the cyclic voltammograms of KYPY1 closely resemble that of the ore-pyrite (PUPY) electrode as shown in Figure 4.40. The reduction peak at $400 \mathrm{mV}$ with respect to the reduction of ferric to ferrous ion and the oxidation peak at $-200 \mathrm{mV}$ relating to the formation of sulfur were also observed. However, for KYPY2 electrode (Figure 4.41) the voltammogram shows little rotation dependence and differs remarkably from those obtained on KYPY1 and PUPY. No well-shaped redox peaks can be observed. As shown in Figure 4.42 , the cyclic voltammograms of the KYPY electrode are extremely smooth and similar to that of KYPY2 but nearly rotation independent. It 


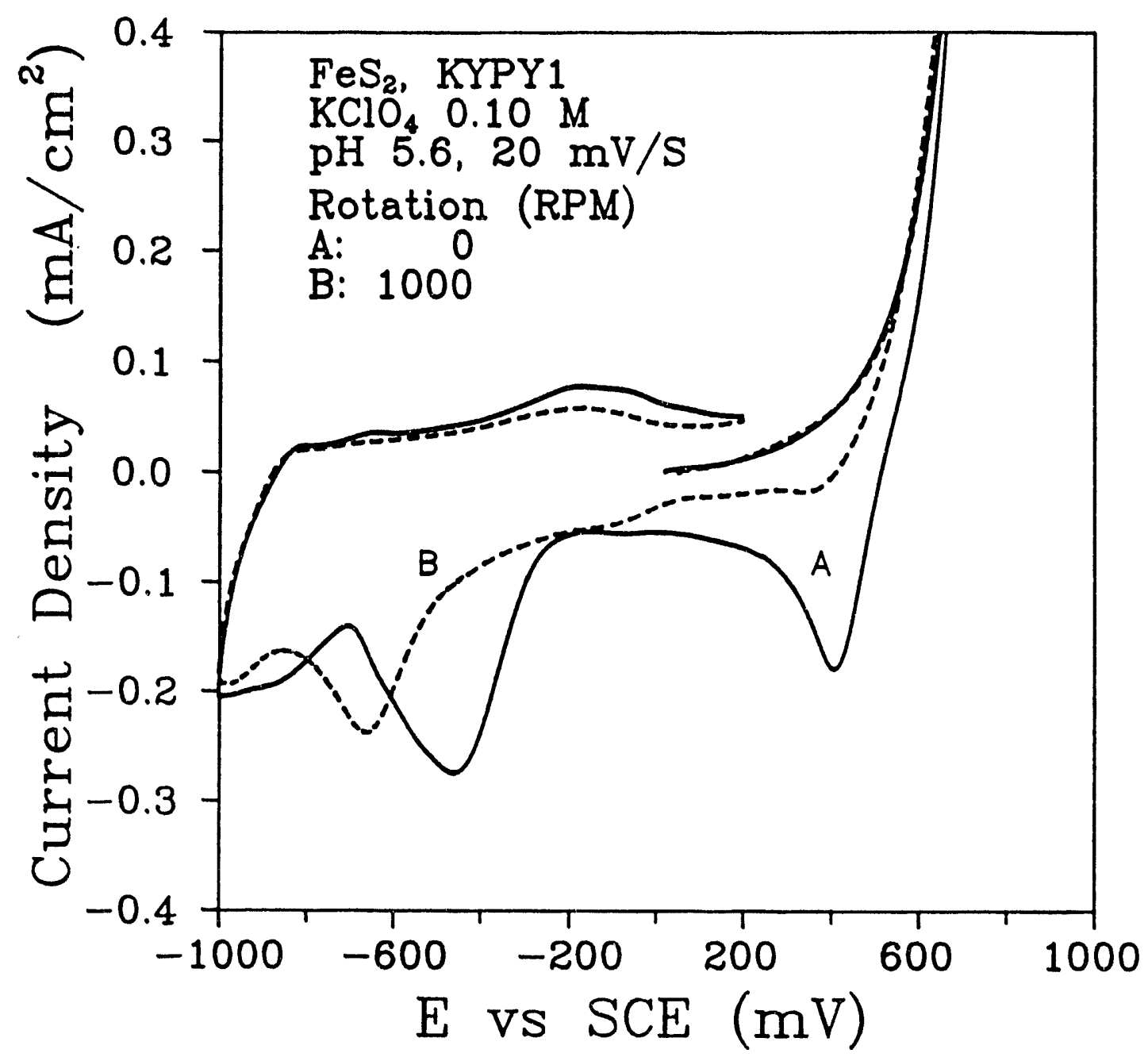

Figure 4.40 Cyclic voltammograms of the purer coal-pyrite (KYPY1) electrode under stationary and rotation conditions at $\mathrm{pH}=5.6$. 


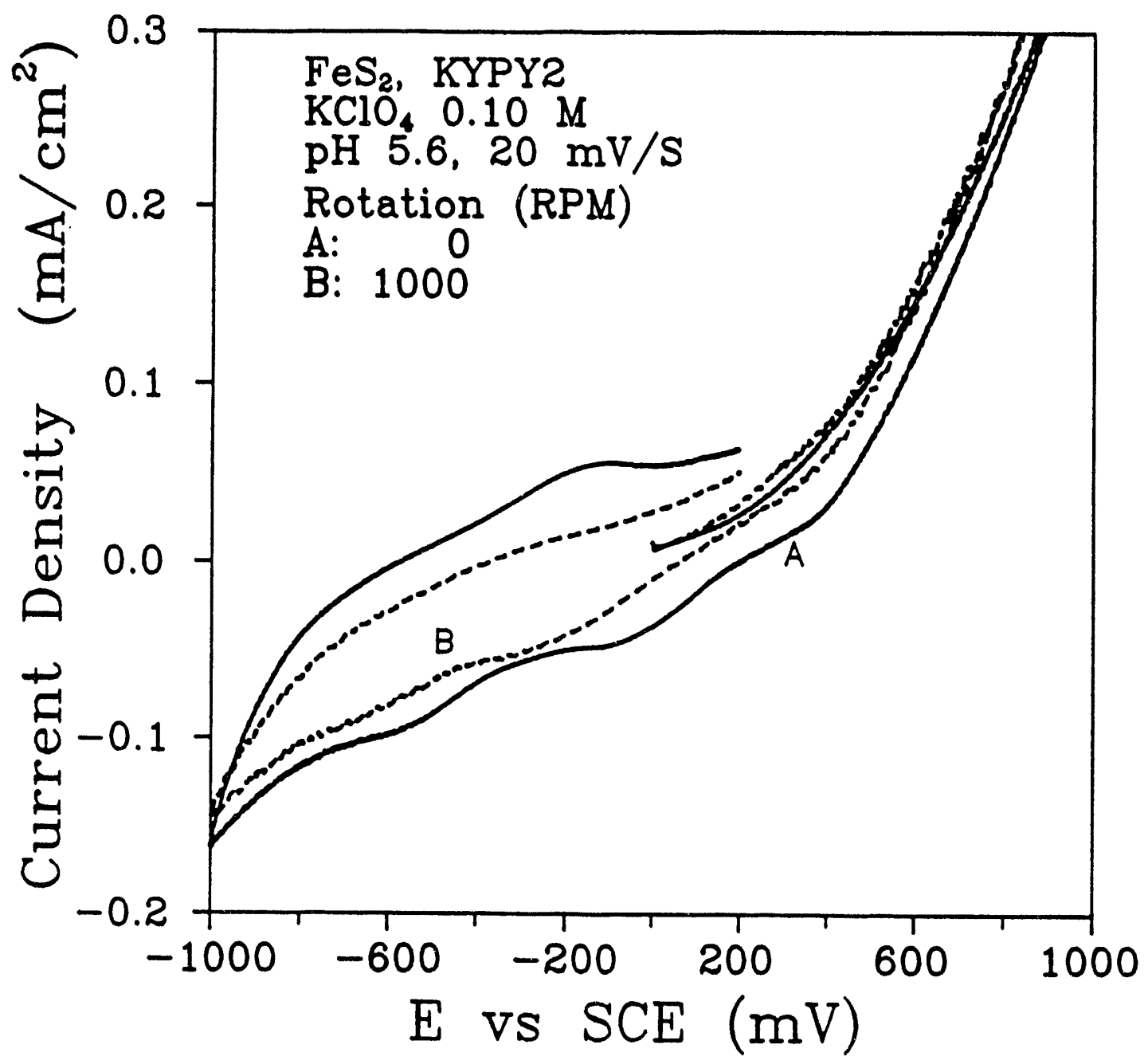

Figure 4.41 Cyclic voltammograms of the moderately coal/carboncontaminated coal-pyrite (KYPY2) electrode under stationary and rotation conditions at $\mathrm{pH}=5.6$. 


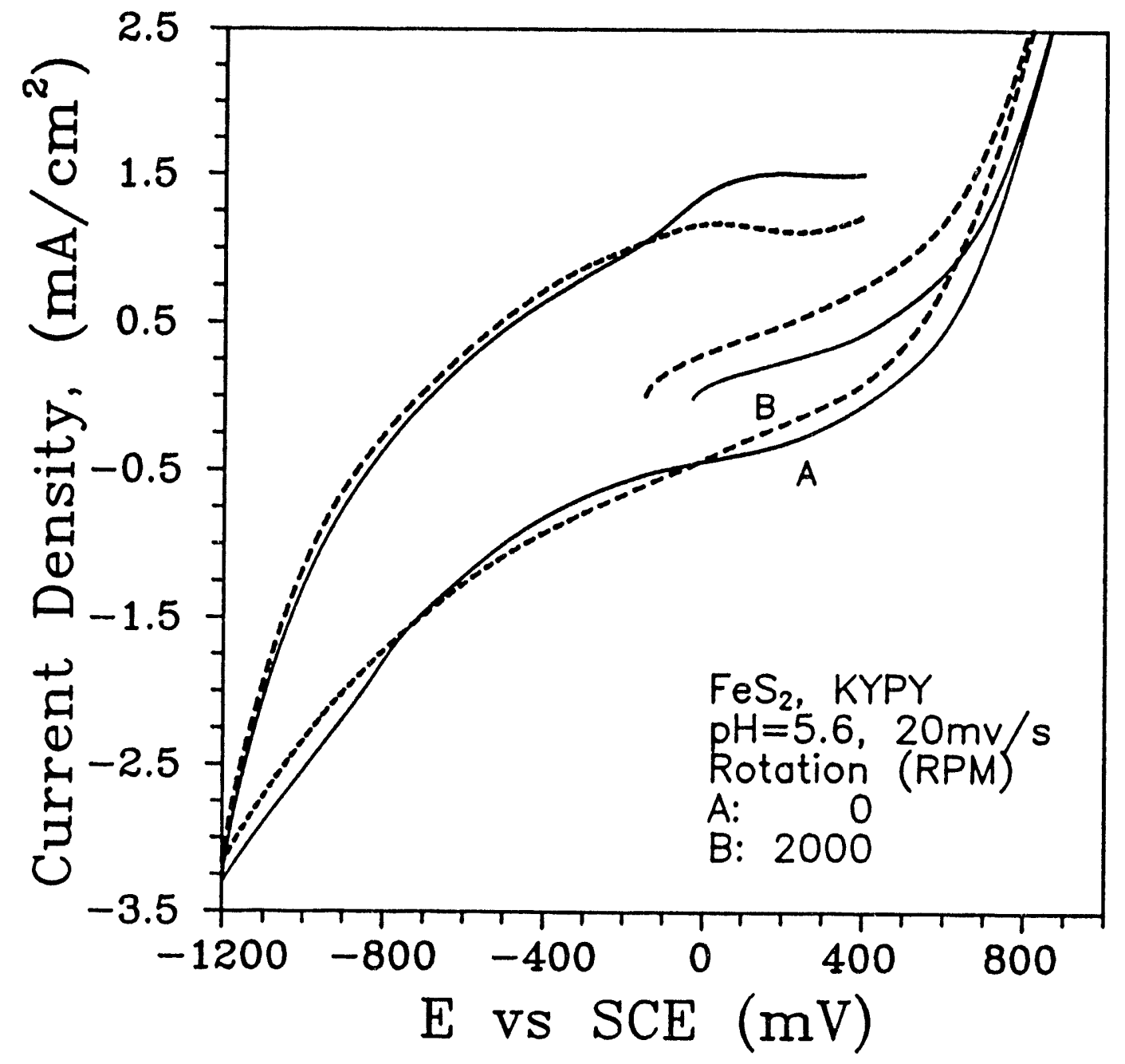

Figure 4.42 Cyclic voltammograms of the highly coal/carbon-contaminated coal-pyrite (KYPY) electrode under stationary and rotation conditions at $\mathrm{pH}=5.6$. 
is interesting to note that although KYPY1 and KYPY2 were prepared from the same crystal, their electrochemical reactivities was rather different. One is similar to orepyrite, the other is analogous to KYPY. Such a big difference was not anticipated for the same crystal. Furthermore, comparing the Figures $4 . j 9-4.42$, it is easily seen that the current density on the coal-pyrite electrode (KYPY) is 10 times higher than that of the ore-pyrite (PUPY). When compared at the same potential, the current density increases in the order of KYPY1 < KYPY2 < KYPY, following the same increase trend in carbon content. This indicates that the carbonaceous matter on the surface may be responsible for the differences. The high current density would be due to the highly electroactive organic compounds contained in the carbonaceous matter on coalpyrite surface. More importantly, the relative rotation independence of the voltammograms of the KYPY2 and KYPY electrodes suggests that the oxidation of coal-pyrite produces less soluble species than ore-pyrite, and the oxidation products are strongly adhered to the surface. In addition, the increased current density on coalpyrite may also be due to its large surface area resulting from the porous structure, with the reaction taking place deep within the surface. Therefore, a much thicker and stable oxidation layer is expected to be formed on the surfaces of coal-pyrites.

\subsubsection{Pyrite Oxidation in Alkaline Solutions}

Typical cyclic voltammograms for ore-pyrite (PUPY) electrodes in highly 
alkaline solution of $\mathrm{pH}=11$ are shown in Figure 4.43. At a stationary electrode, when the potential is initiated in the positive-going direction from the open-circuit potential, a sharp oxidation peak (I) is observed at potential around $300 \mathrm{mV}$ vs SCE. As the sweep potential is greater than $500 \mathrm{mV}$, an abrupt current increase (II) appears. The anodic peak (II) has been attributed to the oxidation of pyrite itself to form sulfate and ferric hydroxide precipitation (Hamilton and Woods, 1981; Ahlberg et al., 1990):

$$
\mathrm{FeS}_{2}+11 \mathrm{H}_{2} \mathrm{O} \rightarrow \mathrm{Fe}(\mathrm{OH})_{3}(\mathrm{~s})+2 \mathrm{SO}_{4}^{2-}+19 \mathrm{H}^{+}+15 e
$$

The elemental sulfur may also form by the oxidation of pyrite through the reaction (Wang, 1989; Wang and Forssberg, 1990):

$$
\mathrm{FeS}_{2}+3 \mathrm{OH}^{-}-\mathrm{Fe}(\mathrm{OH})_{3}(\mathrm{~s})+2 \mathrm{~S}^{\circ}+3 e
$$

Very interestingly, when the electrode is rotated, peak (I) becomes a plateau, while peak (II) shows no change. The rotation dependence of peak (I) is of great interest and has thus been further studied. Figure 4.44 shows the variation of the limiting current of peak (I) with rotation speed for the linear potential sweeps from -100 to $800 \mathrm{mV}$ on the PUPY electrode at $\mathrm{pH} 10$. The limiting current of peak (I) increases with increasing rotation speed. Moreover, a plot of limiting current against the square root of rotation speed results in two parallel straight lines as shown in Figure 4.45, with the back scan current passing through the origin. These results indicates that the peak (I) results from the oxidation of a soluble species at the pyrite surfaces and is diffusion-controlled. The further experiment shows that the current density of this 


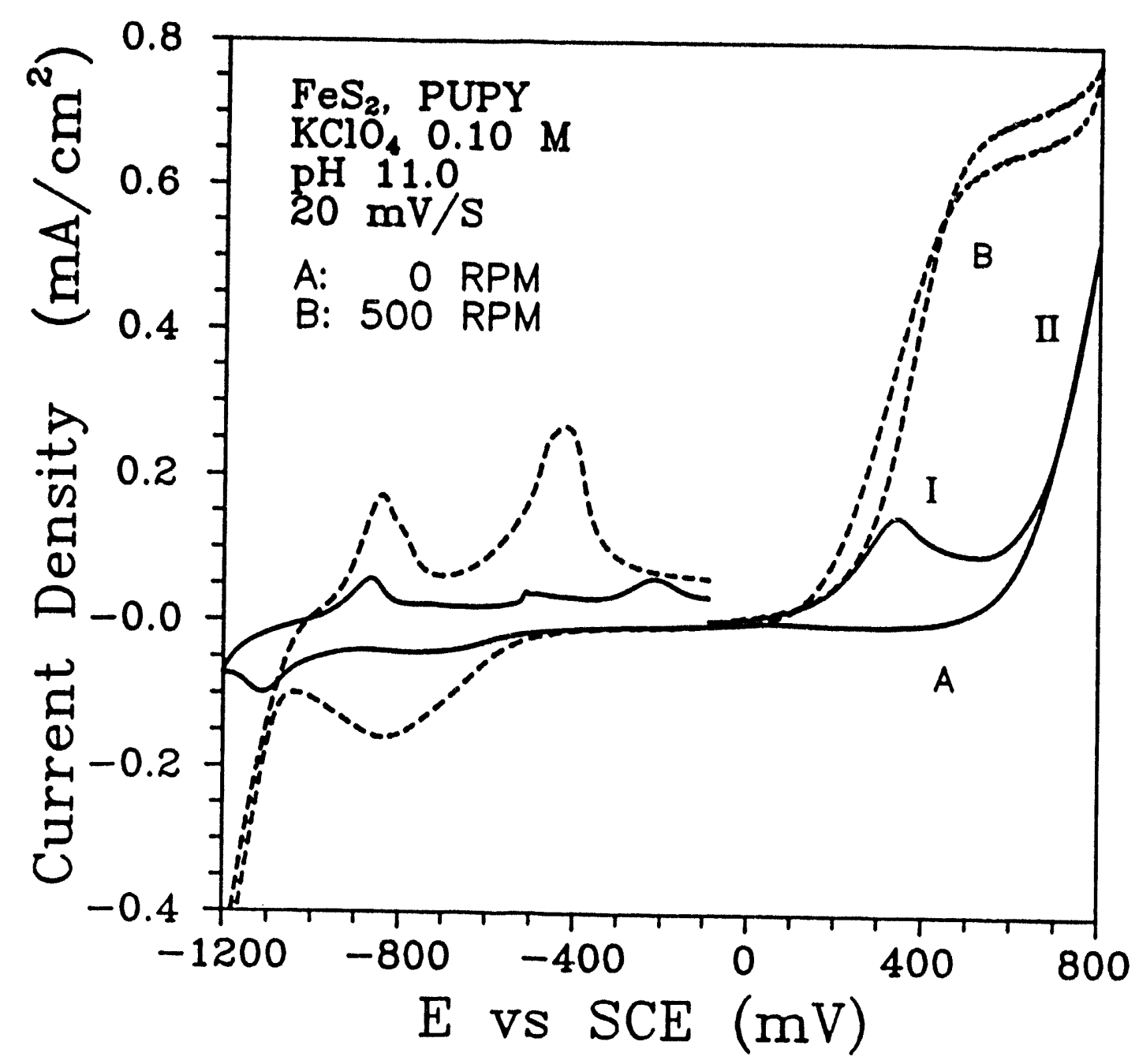

Figure 4.43 Cyclic voltammograms of the ore-pyrite (PUPY) electrode under stationary and rotation conditions at $\mathrm{pH}=11$. 


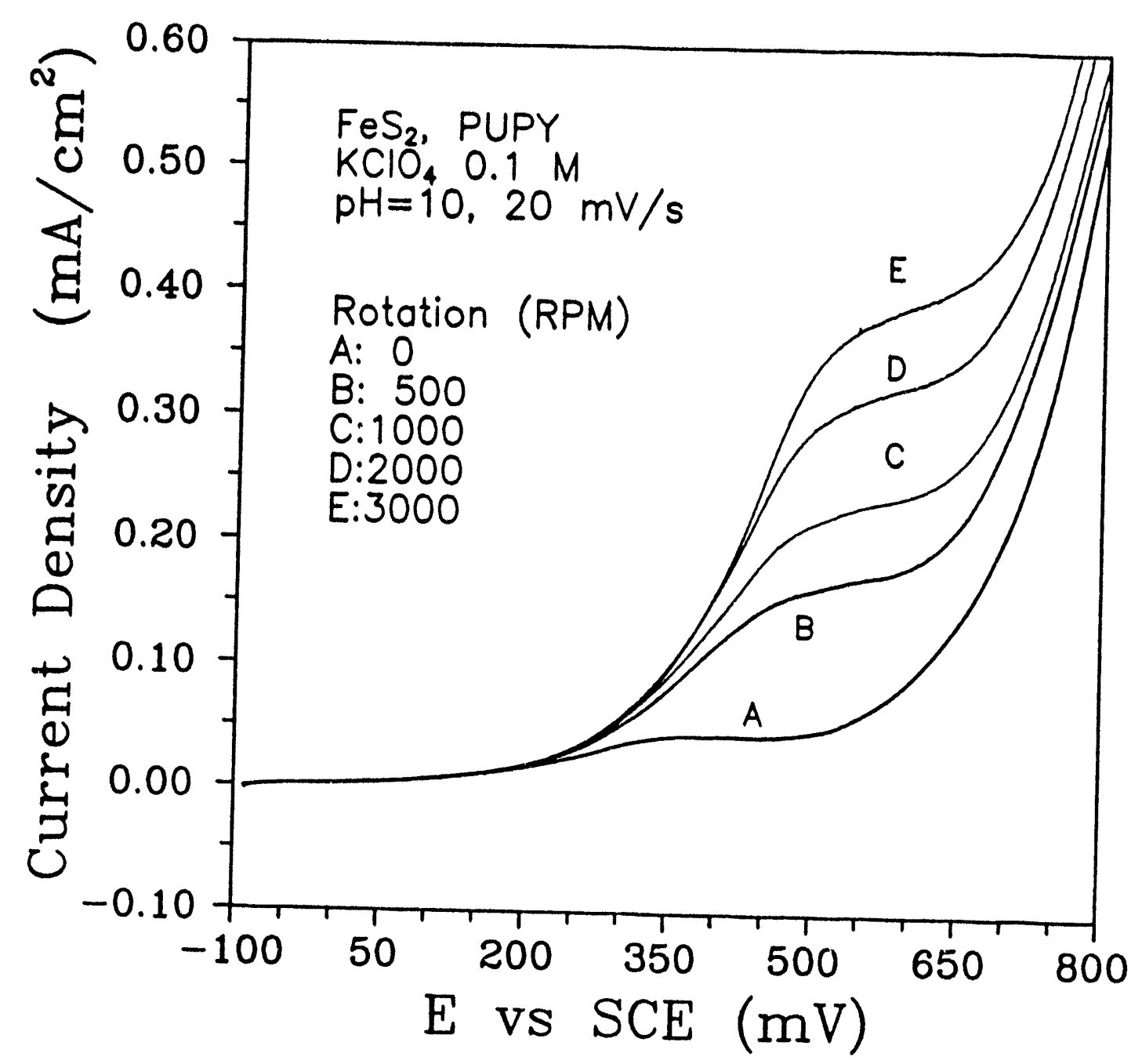

Figure 4.44 Linear sweep voltammograms of the ore-pyrite (PUPY) at different rotation speed at $\mathrm{pH}=10$. Sweep initiated from the open-circuit potential. 


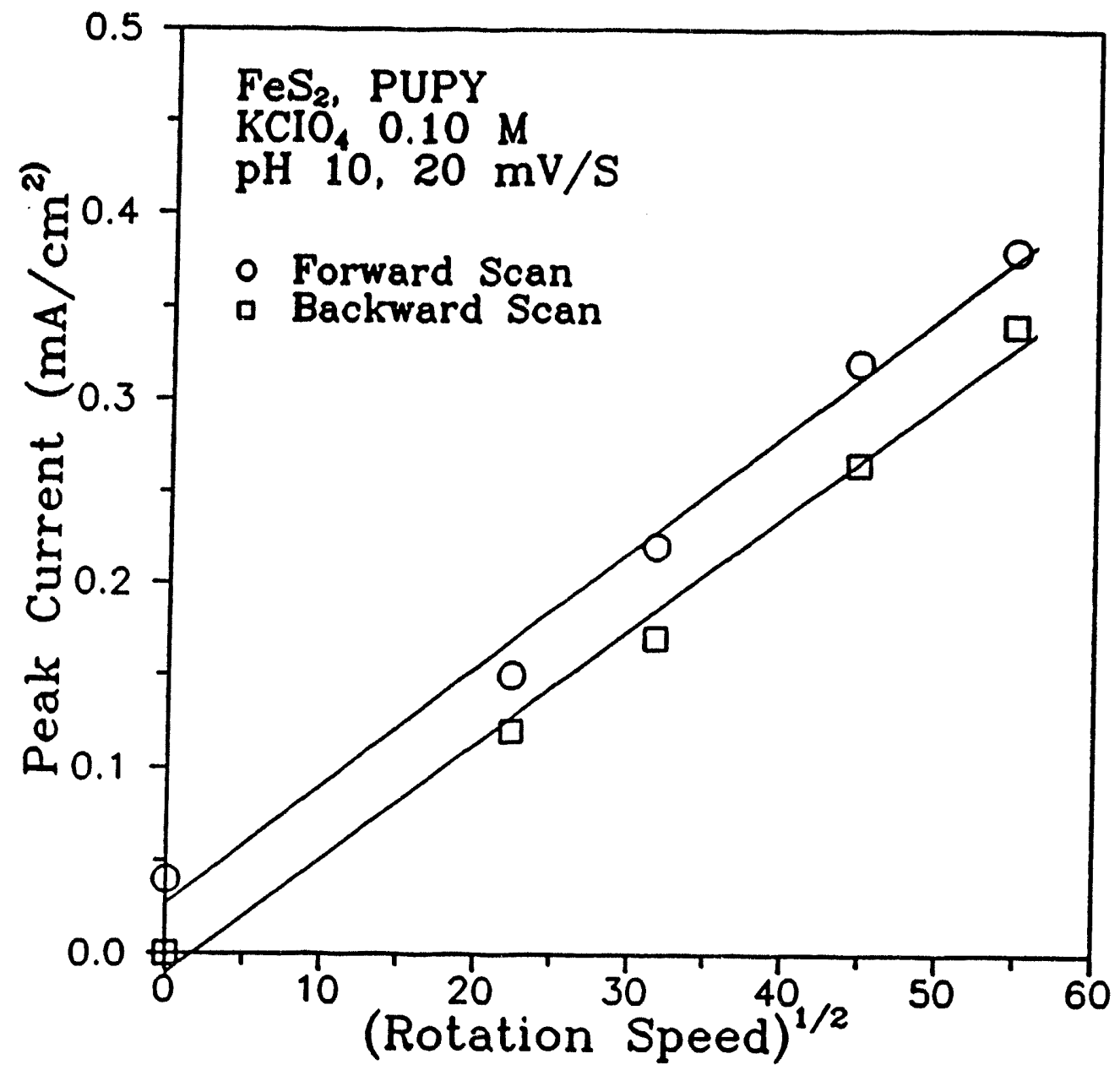

Figure 4.45 Limiting current density of peak $(I)$ as a function of the square root of rotation speed for ore-pyrite (PUPY) electrode at $\mathrm{pH}=10$. 
peak (I) increases significantly with increasing solution $\mathrm{pH}$ and the Tafel slope of the reaction is about $120 \mathrm{mV}$. These results demonstrate that the reaction is a oneelectron transfer reaction involving the adsorption of one hydroxide ion on the surface. The following reaction process is suggested for this peak (I) corresponding to the initial oxidation of pyrite surfaces (Ahlberg et al, 1990; Wang et al, 1992):

$$
\mathrm{FeS}_{2}+\mathrm{OH}^{-} \rightarrow \mathrm{FeS}_{2}[\mathrm{OH}]_{\mathrm{ads}}+e
$$

Figures 4.46-48 present the cyclic voltammograms of KYPY1, KYPY2 and KYPY at $\mathrm{pH}=11$, respectively. As can be seen, like in the acidic solutions of $\mathrm{ph}=5.6$, the voltammetric behavior of KYPY 1 is almost identical to that of ore-pyrite (PUPY) with strong rotation dependence, while KYPY2 occurs between the purer KYPY1 and high carbon-content KYPY electrodes. It should be noted that as in the acidic solution, the effect of the rotation speed on the voltammograms of the electrodes drastically decreases with increasing the carbon content of the coal-pyrites; however, the degrees of the rotation dependence for the corresponding electrodes at $\mathrm{pH}=11$ is apparently more prominent than at $\mathrm{pH}=5.6$. This shows that the coal-pyrite is more readily oxidized in alkaline solution than in acidic solution, which is due to the adsorption of hydroxide ions on the surface. In addition, the much higher current densities on coal-pyrite electrodes are again observed. These results demonstrate that the surface oxidation of coal-pyrite strongly depends on the individual sample. Accordingly, the oxidation mechanisms of coal-pyrite may be more complex than that 


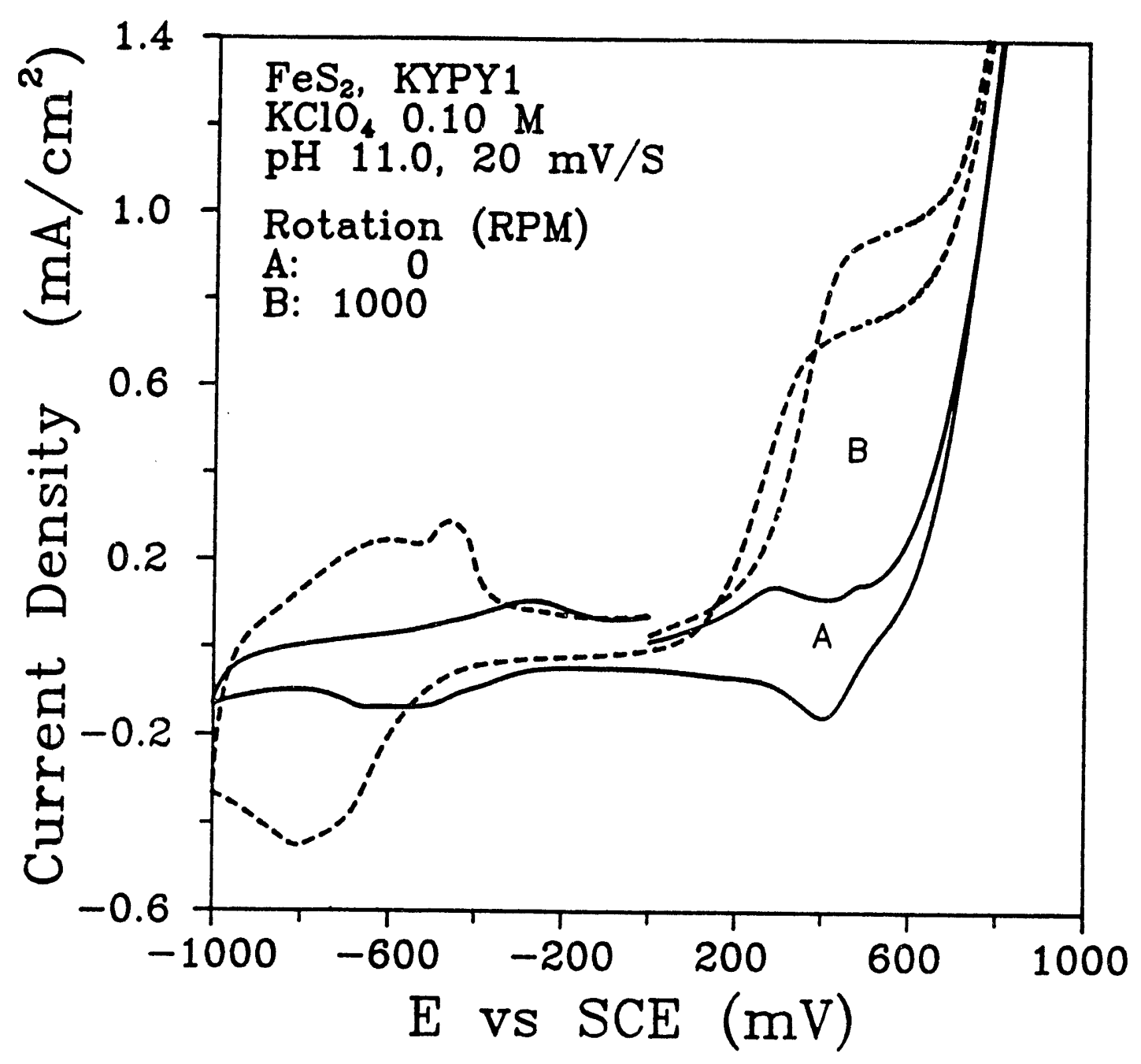

Figure 4.46 Cyclic voltammograms of the purer coal-pyrite (KYPY1) electrode under stationary and rotation conditions at $\mathrm{pH}=11$. 


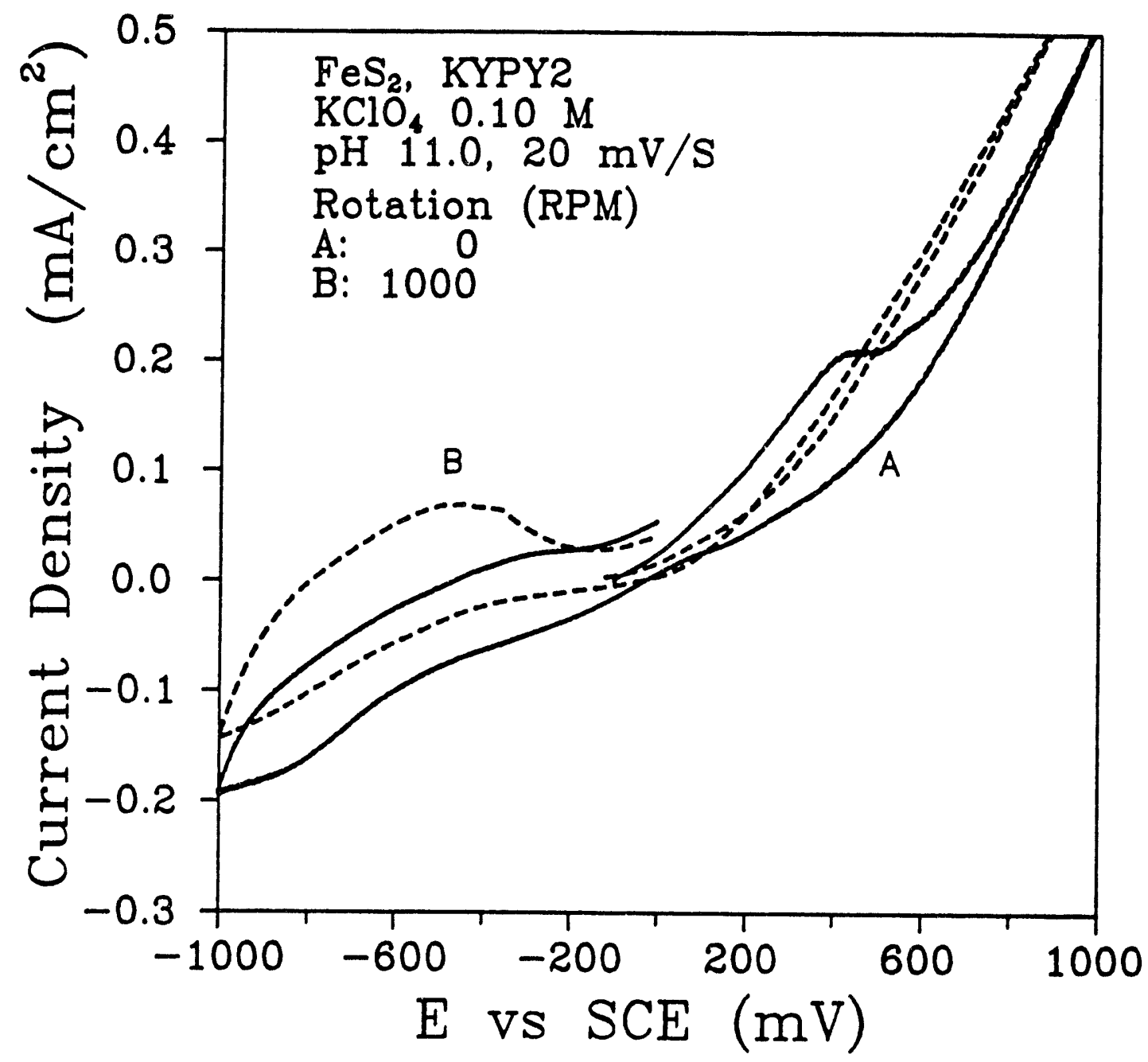

Figure 4.47 Cyclic voltammograms of the moderately coal/carboncontaminated coal-pyrite (KYPY2) electrode under stationary and rotation conditions at $\mathrm{pH}=11$. 


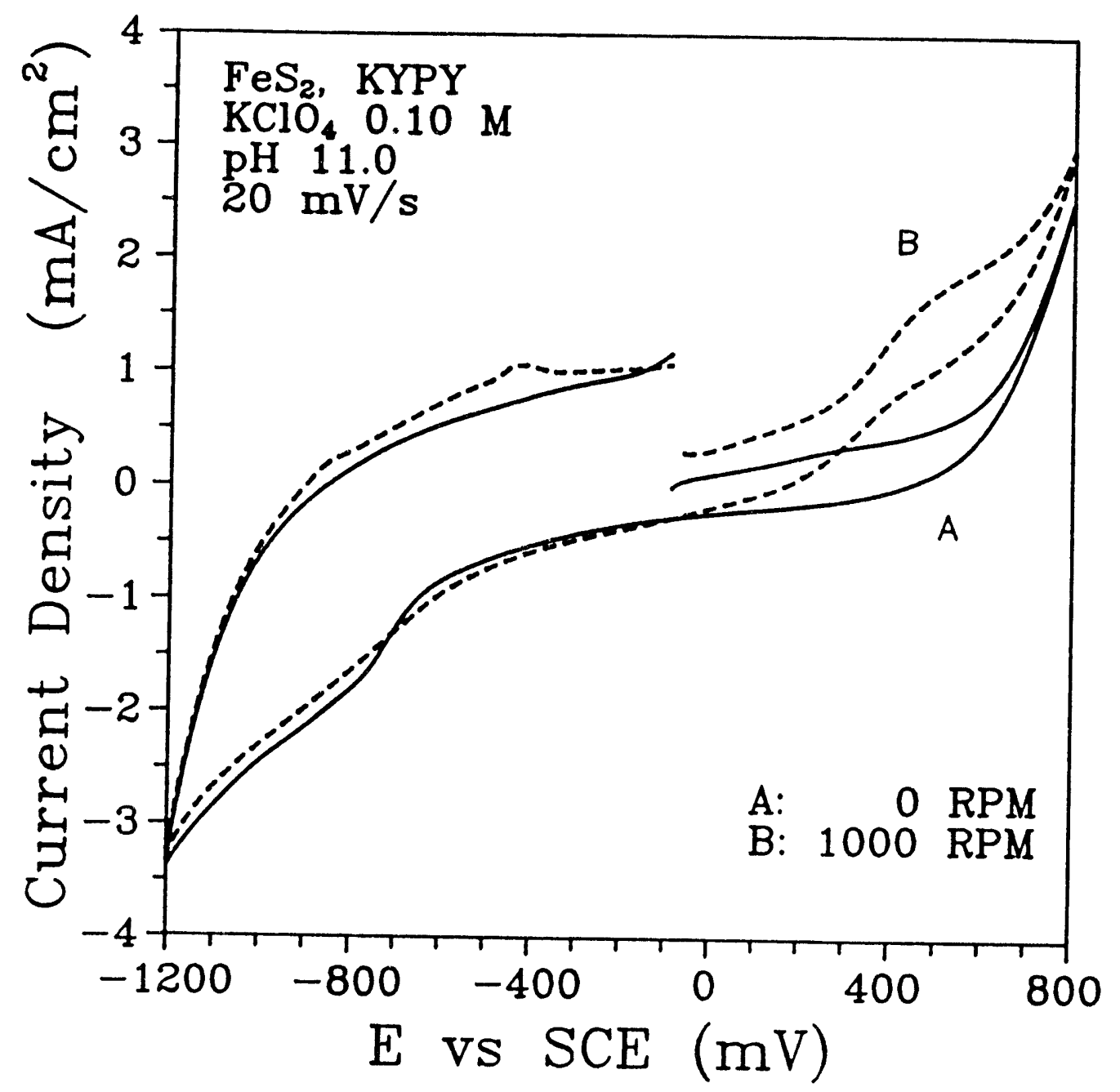

Figure 4.48 Cyclic voltammograms of the highly coal/carbon-contaminated coal-pyrite (KYPY) electrode under stationary and rotation conditions at $\mathrm{pH}=11$. 
of ore-pyrite. Nevertheless, coal-pyrite in general exhibits a higher degree of oxidation than ore-pyrite; and the surface oxidation product layers, especially for highly carbon-containing coal-pyrite, are thick and stable.

The results obtained from the electrochemical studies correspond well with the flotation and zeta potential studies described in Sections 4.1-4.4. The oxidation of pyrites can produce iron species on the surfaces. The surface properties of pyrites are to a large extent affected by the nature of these iron species. Flotation results showed that ore-pyrite and coal-pyrite have no self-induced floatability, which is due to the formation of hydrophilic iron hydroxide precipitation on the surface. Zeta potential studies indicated that the surface charge properties of ore-pyrite is determined by ferric ions formed by oxidation, while that of coal-pyrite is largely affected by ferrous ions. Cyclic voltammogram studies show that coal-pyrite possesses a higher degree of surface oxidation and much thicker oxidation products on the surface than orepyrite. As a result, when the ore-pyrite is subject to the ultrasonic treatment, the hydrophilic iron hydroxide layer is readily removed, exposing the hydrophobic sulfurrich layer, leading to greatly improved floatability both in the absence and presence of collectors. However, ultrasonic treatment and the addition of various hydrophobicizing reagents did not significantly improve the surface hydrophobicity of coal-pyrite. More interesting, the flotation behavior of coal-pyrite with xanthate is mainly determined by the reaction of ferrous and ferric ions with xanthate. 


\section{CHAPTER 5}

\section{CONCLUSIONS AND RECOMMENDATIONS}

\subsection{Conclusions}

From the results obtained in the present studies, the following conclusions are made:

1) The main difference in chemical composition between pyrites from coal and ore sources is that the coal-pyrite generally contains high carbon/coal content. This results in the distinct differences in their surface properties.

2) Electrochemical measurements and flotation tests showed that coal-pyrite exhibits a much greater oxidation rate than ore-pyrite. The oxidation products formed on coal-pyrite are also different from those on ore-pyrite.

3) The oxidation reaction of ore-pyrite depends on the oxidation potential and solution $\mathrm{pH}$ range. In the neutral to weakly alkaline solutions, ferrous and ferric ions are produced on surfaces with increasing oxidation potentials, respectively. In highly 
alkaline solutions, ferric hydroxide precipitation is the main oxidation product.

4) The oxidation of coal-pyrite strongly depends on the carbon/coal content. The relatively pure coal-pyrite shows similar oxidation properties to ore-pyrite. The oxidation of pyrites with moderate and high coal/carbon contamination are almost independent of solution $\mathrm{pH}$, and produce less soluble species than ore-pyrite. The oxidation products are strongly adhered to the surface.

5) Coal-pyrite and ore-pyrite have no floatability in the absence of a collector. The absence of floatability of pyrites is attributed to the presence of a hydrophilic iron hydroxide surface layer formed by the oxidation.

6) Zeta potential measurements showed that the surfaces of ore-pyrite and coal, prepared by dry grinding in air, are chiefly covered by ferric hydroxides, while coalpyrite surfaces are dominated by ferrous hydroxides. Surface cleaning using nitric acid washing can readily remove the surface iron hydroxide products.

7) Fuel oil, a commonly used collector in coal flotation, can also significantly increase the floatability of coal-pyrite. The hydrophobic interaction between fuel oil and the carbon/coal sites on surfaces is responsible for the oil-induced flotation of coal-pyrite. Fuel oil is not a good collector for ore-pyrite due to the lack of 
coal/carbon coatings on the surface.

8) Particle size plays an important role in the flotation of pyrites when using fuel oil as the collector. As the particle size decreases, the floatability of coal-pyrite increases. The increased flotation of finer coal-pyrite is due to the increased surface covered by the coal inclusions.

9) The flotation results in this study show that the entrainment of pyrite by coal froth is insignificant. The undesirable flotation of pyrite may result largely from the oil-induced floatability of the coal-pyrite itself.

10) The flotation of ore-pyrite with xanthate strongly depends on both solution $\mathrm{pH}$ and particle size. Coarse size ore-pyrite shows better flotation properties than the fine sizes. The flotation behavior of coal-pyrite and coal using xanthate is similar, it depends on the solution $\mathrm{pH}$ but not the particle size. Good flotation can be obtained only in acidic solutions for coal and coal-pyrite.

11) Ferric and ferrous ions have a strong depressing effect on ore-pyrite when using xanthate in the neutral to weak alkaline $\mathrm{pH}$ ranges. The lack of floatability of coal-pyrite and fine size ore-pyrite, in neutral to alkaline solutions of pH6-10, is due to the formation of poorly hydrophobic ferric dihydroxo xanthate on the surfaces. 
Depending on the degree of surface oxidation, ferric xanthate compounds are also responsible for the flotation of ore-pyrite in addition to dixanthogen.

12) A number of organic reagents having different functional groups, including sodium oxalate, tartaric acid, thiophene carboxylic acid, thiosalicyclic acid, and EDTA, have been examined to determine their effect for depressing coal-pyrite in coal flotation with fuel oil. The results show that only sodium oxalate improves the depression of coal-pyrite from coal, but the dosage required is high. Other reagents were either non-selective or had no effect on the separation of the coal-pyrite from coal. Commonly used inorganic compounds, including sodium silicate and sodium metaphosphate, were also found to be non-selective.

14) Sodium pyrophosphate was found to be an effective reagent for the selective depression of pyrite in coal flotation. Flotation results indicated that a very low dosage of pyrophosphate is sufficient for the complete depression of pyrite. The selective separation of coal-pyrite from coal can be readily realized over nearly the entire $\mathrm{pH}$ range. The primary mechanism responsible for the depression of pyrite by pyrophosphate results from the formation of hydrophilic ferric pyrophosphate complexes on the pyrite surfaces. 


\subsection{Recommendations}

On the basis of results obtained in this study, further research work in the following aspects are recommended:

1) The oxidation products of pyrite such as iron and sulfur species are important for determining the surface properties of coal and pyrite. Surface analysis techniques, XPS, AES and SEM should be applied for the direct determination of pyrite surface products.

2) Contact angle measurements should be conducted to study the natural hydrophobicity and the effects of nonpolar oil and other modification reagents. Such an investigation will contribute to the understanding of the differences between coal and pyrites during flotation.

3) Pyrophosphate has been shown to be a promising and efficient reagent in depressing pyrite in coal flotation. Extensive work is needed to examine the feasibility of using pyrophosphate as a depressant for other coal-pyrite samples.

4) A study of the kinetics of coal and pyrite flotation should be carried out to quantify the effects of particle size, flotation gas and other operating parameters. 


\section{REFERENCES}

Ahlberg, E., Forssberg, K.S.E., and Wang, X., 1990, "The surface oxidation of pyrite in alkaline solution," Journal of Applied Electrochemistry, Vol.20, pp.10331039.

Allison, S.A., Gold, L.A., Nicol, M. and Granvill, A., 1972, "A determination of the products of the reaction between various sulfide minerals and aqueous xanthate solution and a correlation of the projucts with electrode rest potentials, " Metallurgical Transactions, Vol.3, pp.2613-2618.

Aplan, F.F., 1976, "Coal flotation," Flotation-A.M. Gaudin Memorial Volume, M.C. Fuerstenau (ed.) AIME, New York, pp.1235-1264.

Aplan, F.F., 1977, "Use of the flotation process for desulfurization of coal," in Coal Desulfurization, Chemical and Physical Methods, T.D. Wheelock (ed.), ACS Symposium Series 64, AM.Inst. Chem. Soc., Washington, D.C., pp.70-82. pp.16-19.

Aplan, F.F. and Arnold, B.J., 1991, "Flotation," in Coal Preparation, 5th edition, J.W. Leonard (ed.), SME and Exploration, Inc., Littleton, Colorado, pp.450-485.

Arnold, B.J. and Aplan, F.F., 1986, "The effect of clay slimes on coal flotation, Part I: The nature of the clay," International Journal of Mineral Processing, Vol.17, pp.225-242.

Baker, A.F., Miller, K.J., 1971, "Hydrolyzed metal ions as a pyrite depression in coal flotation," US Bureau of Mines, Report of Investigations 7518, May, 21pp.

Baker, A.F., Miller, K.J. and Deurbrouck, A.W., 1973, "Two-stage flotation selectively floats pyrite from coal," Coal Mining and Processing, Vol.56, pp.44-46.

Ball, B. and Richard, R.S., 1976, "The chemistry of pyrite flotation and depression," In Flotation-A.M. Gaudin Memorial Volume, M.C. Fuerstenau (ed.) AIME, New York, pp.458-484.

Bard, A.J. and Faulkner, L.R., 1980, Electrochemical Methods. Fundamentals and Applications, John Wiley \& Sons, NY, 718pp. 
Biegler, T. and Swift, D.A., 1979, "Anodic behavior of pyrite in acidic solution," Electrochemica Acta, Vol.24, pp.415-420.

Briceno, A. and Chander, S., 1988, "An electrochemical characterization of pyrites from coal and ore sources," International Journal of Mineral Processing, Vol.24, pp.73-80.

Buckley, A.N., Hamilton, I.C., and Woods, R., 1985, "Investigation of the surface oxidation of sulfide minerals by linear potential sweep voltammetry and X-ray photoelectron spectroscopy," in Flotation of Sulfide Minerals, K.S.E. Forssberg (ed.), Elsevier, Amsterdam, pp.41-59.

Buckley, A.N., Hamilton, I.C., and Woods, R., 1988, "Studies of the surface oxidation of pyrite and pyrrhotite using X-ray photoelectron spectroscopy and linear potential sweep voltammetry," In Proceedings of the International Symposium on Electrochemistry in Mineral and Metal Processing II, P.E. Richardson and R. Woods (eds.), The Electrochemical Society, Inc., Pennington, N.J., pp.286-302.

Campbell, J.A.L. and Sun, S.C., 1970, "Bituminous coal electrokinetics," Transactions, AIME, Vol.247, pp.111-144.

Capes, C.E. and Germain, R.J., 1982, "Selective oil agglomeration in fine coal beneficiation," in Physical Cleaning of Coal: Present and Development Methods, Y.A. Liu (ed.), Marcel Dekker Inc., New York, pp.255-291.

Cases, J.M., Kongolo, M., de Donato, P., Michot, L. and Erre, R., 1990, "Interaction between finely ground galena and pyrite with potassium amylxanthate in relation to flotation, 2. Influence of grinding media at natural $\mathrm{pH}, "$ International Journal of Mineral Processing, Vol.30, pp.35-67.

Chander, S., 1987, "Inorganic depressants for sulfide minerals," Reagents in Mineral Technology, P. Somasundran and B.M. Moudgil (eds.) Marcel Dekker, New York, pp.429-469.

Chander, S., and Briceno, A., 1987, "Kinetics of pyrite oxidation," Minerals and Metallurgical Processing, No.8, pp.171-176.

Chander, S. and Fuerstenau, D.W., 1974, "The effect of potassium diethyldithiophosphate system," Transactions, AIME, Vol.256, pp.193-196.

Chapman, D.L., 1913, "A contribution to the theory of electrocapillarity," Philosophy: 
Magazine, Vol.25, pp.475-481.

Chen, Y.H. and Aplan, F.F., 1991, "Comparative flotation of coal-source and oresource pyrite," AIME Annual Meeting, Denver, Feb., pp.24-28.

Chernosky, F.J. and Lyon, F.M., 1972, "Comparison of the flotation and adsorption characteristics of ore and coal-pyrite with ethyl xanthate," Transactions, AIME, Vol.252, pp.11-14.

Choudhry, V. and Aplan, F.F., 1992, "Pyrite depression during coal flotation. Part I-inorganic ions," Minerals \& Metallurgical Processing, May, pp.51-56.

Conway, B.E., Ku, J.C. and Ho, F., 1980, "The electrochemical surface reactivity of iron sulfide $\mathrm{FeS}_{2}$," Journal of Colloid and Interface Science, Vol.75, pp.357-372.

Crawford, R. and Ralston, J., 1988, "The influence of particle size and contact angle in mineral processing," International Journal of Mineral Processing, Vol.23, p.1.

Eriksson, G., 1979, "An algorithm for the computation of aqueous multicomponent, multiphase equilibria," Analytica Chimica Acta, Vol.112, pp.375-383.

Finkelstein, N.P. and Poling, G.W., 1977, "The role of dithiolates in the flotation of sulfide minerals," Minerals Science and Engineering, Vol.9, pp.177-197.

Finkelstein, N.P., Allison, S.A., Lovell, V.M., and Stewart, B.V., 1975, in Advances in Interfacial Phenomena of Particle/Solution/Gas Systems, P. Somasundaran and R.B. Grieves (eds.), AIME, pp.165-175.

Firth, B.A. and Nicol, S.K., 1984, "The effect of oxidized pyritic sulfur on coal flotation," Coal Preparation, Vol.1, pp.53-70.

Fornasiero, D. and Ralston, J., 1992, "Interaction of ethyl xanthate with pyrite," in Proceedings of the Third International Symposium on Electrochemistry in Mineral and Metal Processing III, R. Woods and P.E. Richardson (eds.), The Electrochemical Society, Inc., Pennington, N.J., pp.191-220.

Forssberg, K.S.E., Antti, B.M. and Palsson, B.I., 1984, "Computer-assisted calculations of thermodynamic equilibria in the chalcopyrite-ethyl xanthate system," Reagents in the Mineral Industry, M.J. Jones and R. Oblatt (eds.), The Institution of Mining and Metallurgy, pp.251-264. 
Fuerstenau, D.W. and Mishra, B.K., 1981, "On the mechanism of pyrite flotation with xanthate," in Complex Sulfides, M.H. Jones (ed.), IMM, London, pp.271-278.

Fuerstenau, M.C., 1981, "Adsorption of sulphydryl collectors," in Principles of Flotation, R.P. King (ed.), pp.91-108.

Fuerstenau, M.C., Kuhn, M.C. and Elgillani, D.A., 1968, "The role of dixanthogen in xanthate flotation of pyrite, " Transactions, AIME, Vol.241, pp.148-156.

Fuerstenau, M.C., Lopez-Valdivieso, A., and Fuerstenau, D.W., 1988, International Journal of Mineral Processing, Vol.23, p.161.

Fuerstenau, M.C., Natalie, C.A., and Rowe, R.M., 1990, International Journal of Mineral Processing, Vol.29, p.89.

Fuerstenau, M.C. and Sabacky, B.J., 1981, " On the native floatability of sulfide minerals," International Journal of Mineral Processing, Vol.8, p.79.

Fuerstenau, M.C., Mishra, M. and Palmer, B.R., 1990, "Xanthate adsorption on selected sulfides in the virtual absence and presence of oxygen, Part 2," International Journal of Mineral Processing, Vol.29, pp.111-119.

Gaudin, A.M., 1932, Flotation, McGraw-Hill, New York, 552pp.

Gayle, J.B., and Eddy, W.H., 1962, "Effects of selected operating variables on continuous cell flotation of coal," US Bureau of Mines, Report of Investigations 5989.

Goldhaber, M.B., 1983, "Experimental study of metastable sulfur oxidation formation during pyrite oxidation at pH6-9 and 30 ," American Journal of Science, Vol.283, No.3, pp.193-217.

Guoy, G., 1910, "Constitution of the electric charge at the surface of an electrolyte," Journal of Physics, Vol.9, No.4, pp.457-467.

Guy, P.J. and Trahar, W.J., 1985, "The effects of oxidation and mineral interaction on sulfide flotation," in Flotation of Sulfide Minerals, K.S.E. Forssberg (ed.), Elsevier, Amsterdam, pp.91-110.

Hamilton, I.C. and Woods, R., 1981, "An investigation of surface oxidation of pyrite and pyrrhotite by linear potential sweep voltammetry," Journal of Electroanalytical Chemistry, Vol.118, p.327. 
Harris, P.J. and Richter, R., 1985, "The influence of surface defect properties on the activation and natural floatability of sphalerite," in Flotation of Sulfide Minerals K.S.E. Forssberg (ed.), Elsevier, Amsterdam, pp.141-158.

Hayes, R.A., Price, D.M., and Ralston, J., 1987, "Collectorless flotation of sulfide minerals," Mineral Processing and Extractive Metallurgy Review, Vol.2, pp.1-32.

Hayes, R.A. and Ralston, J., 1987, "The collectorless flotation and separation of sulfide minerals by Eh control, "International Journal of Mineral Processing, Vol.23, pp.55-84.

Helmholtz, H.L.F., 1879, Wiss. Abh. Phys. Tech. Reichsanst., Vol.1, p.925.

Hiskey, J.B. and Schilt, W.J., 1984, "Interfacial technology in solution mining," Proceedings of 2nd SME-SPE International Solution Mining Symposium, p.55.

Hogfeldt, E., 1982, Stability constants of metal-ion complexes. Part A: Inorganic ligands, Pergamon Press.

Hower, J.C., Trinkle, E.J., and Wild, G.D., 1986, "Maceral partitioning through beneficiation of Illinois basin coals," Coal Preparation, Vol.2, pp.149-164.

Kawatra, S.K. and Eisele, T.C., 1988, "Studies relating to removal of pyritic sulfur from coal by column flotation, " in Chapter 22, Column Flotation '88, K.V.S. Sastry (ed). SME, Littleton, Co, pp.213-222.

Kawatra, S.K. and Eisele, T.C., 1992, "Recovery of pyrite in coal flotation: Entrainment or hydrophobicity," Minerals \& Metallurgical Processing, May, pp.5761.

Khan, S.U.M., Farley, T.J., and Bultrus, J.P., 1992, "Electrochemical AC Impedance and X-ray Photoelectron Spectroscopic studies of interaction of phenylthiourea with coal pyrite surface," In Proceedings of the Third International Symposium on Electrochemistry in Mineral and Metal Processing, R. Woods and P.E. Richardson (eds.), The Electrochemical Society, Inc., Pennington, N.J., pp286-296.

Kissinger, P.T. and Heineman, W.R., 1984, Laboratory Techniques in Electrochemical Chemistry, Marcel Dekker, New York, pp.78-94.

Kydros, K., Matis, K., and Stalidis, G., 1993, "Cationic flotation of pyrites," Journal of Colloid and Interface Science, Vol.155, pp.409-414. 
Lai, R.W., Diehl, J.R., Hammack, R.W., and Khan, S.U.M., 1990, "Comparative study of the surface properties and the reactivity of coal pyrite and mineral pyrite," Minerals and Metallurgical Processing, February, pp.43-48.

Leja, J., 1982, Surface Chemistry of Froth Flotation, Plenum Publishing Corporation, New York.

Lowson, R.T., 1982, "Aqueous oxidation of pyrite by molecular oxygen," Chemistry Reviews, Vol.88, pp.482-497.

Luttrell, G.H. and Yoon, R.H., 1984, "The collectorless flotation of chalcopyrite ores using sodium sulfide," International Journal of Mineral Processing, Vol.13, pp.271283.

Majima, H. and Takeda, M., 1968, "Electrochemical studies of xanthate-dixanthogen systems of pyrite," Transactions, AIME, Vol.244, pp.431-436.

McCarron, J.J., Walker, G.W. and Buckley, A.N., 1990, "An X-ray photoelectron spectroscopic investigation of chalcopyrite and pyrite surfaces after conditioning in sodium sulfide solutions," International Journal of Mineral Processing, Vol.30, pp.116.

Meyer, R.E., 1979, "Electrochemistry of $\mathrm{FeS}_{2}, "$ Journal of Electroanalytical Chemistry, Vol.101, pp.59-71.

Miller, F.G., 1964, "Reduction of sulfur in minus 28 mesh bituminous coal," Transactions, AIME, Vol.229, pp.7-15.

Miller, K.J., 1975, "Coal-pyrite flotation," Transactions, AIME, Vol.258, pp.30-33.

Miller, K.J. and Deurbrouck, A.W., 1982, "Froth flotation to desulfurize coal," in Physical Cleaning of Coal: Present and Development Methods, Y.A. Liu (ed.), Marcel Dekker Inc., New York, pp.255-291.

Mishra, M. and Harris, R., 1988, "Column flotation of fine coal from waste coal refuse," Column Flotation'88, K.V.S. Sastry (ed.) Society of Mining Engineers, Inc., Colorado, pp.235-242.

Moxon, N.T., Bensley, C.N., Keast-Jones, R., and Nicol, S.K., 1987, "Insoluble oils in coal flotation: the effects of surface spreading and pore penetration, "International Journal of Mineral Processing, Vol.21, p.261-274. 
Oliver, J.F., Huh., C. and Mason, S.G., 1980, "An experimental study of some effects of solid surface on wetting," Colloids and Surfaces, Vol.1, pp.79-104.

Pang, J. and Chander, S., 1992, "The effect of EDTA on collectorless flotation of pyrite," in Proceedings of the Third International Symposium on Electrochemistry in Mineral and Metal Processing III, R. Woods and P.E. Richardson (eds.), The Electrochemical Society, Inc., Pennington, N.J., pp.221-234.

Parekh, B.K., Scotts, W.F., and Groppo, J., 1989, "Column flotation studies of ultrafine coals," Internal Technical Report, University of Kentucky, Center for Applied Energy Research. 13pp.

Parks, G.A., 1970, "The points of zero charge and isoelectric points of oxides, hydroxides, silicates and phosphates," Applied Surface and Colloid Chemistry Short Course, University of California, Berkeley.

Perry, R.W. an Aplan, F.F., 1985, "Polysaccharides and xanthated polysaccharides as pyrite depressant during coal flotation," Processing and Utilization of High Sulfur Coals, Y.A. Attia (ed.). Elsevier, New York, pp.215-238.

Peters, E, 1984, "Electrochemical mechanism for decomposing sulfide minerals," In Proceedings of International Symposium on Electrochemistry in Mineral and Metal Processing, P.E. Richardson, S.Srinvasan and R. Woods (eds.), The Electrochemical Society, Inc., Pennington, N.J., pp.343-361.

Plouf, T.M., 1980, "Froth flotation techniques reduce sulfur and ash," Mining Engineering, Vol.32, No.8, pp.1220-1223.

Raichur, A.M., 1992, "Comparative studies of the surface properties of pyrites from coal and ore sources," M.S. Thesis, University of Kentucky, 143pp.

Rao, T.C., 1988, "Recent advances in fine coal beneficiation," Minerals \& Metallurgical Processing, August, pp.124-132.

Ramprakash, Y. and Koch, D.F.A., 1991, "The interaction of iron species with pyrite surfaces," Joumal of Applied Electrochemistry, Vol.21, pp.531-536.

Ralston, J., 1991, "Eh and its consequences in sulphide mineral flotation," Minerals Engineering, Vol.4, Nos.7-11, pp.859-878.

Sato, M., 1960, "Oxidation of sulfide ore bodies. II: Oxidation mechanisms of sulfide 
minerals at $25^{\circ} \mathrm{C}, "$ Economy Geology, Vol.55, p.120.

Sheikh, N., 1972, "The chemical stability of the heavy metal xanthates," Ph.D. Thesis, University of British Columbia, Vancouver, BC, 154pp.

Sillen, L.G. and Martell, A.E., 1964, Stability constants of metal-ion complexes, The Chemical Society, Special publication No.17, London.

Sillen, L.G. and Martell, A.E., 1970, Stability constants of metal-ion complexes, The Chemical Society, Special publication No.25, London.

Smart, R.St.C., 1991, "Surface layers in base metal sulfide flotation," Minerals Engineering, Vol.4, No.7-11, pp.891-909.

Smith, R.M. and Martell, A.E., 1979, Critical stability constants, Vol.4, Inorganic ligands, New York, Plenum Press.

Smolunchowski, M., 1903, Krak. Anz., p.182.

Somasundaran, P. and Lin, I.J., 1972, "Effect of the nature of environment on the comminution process," Ind. Eng. Chem. Process. Des. Deve., Vol.11, pp.321-331.

Stern, O., 1924, "The theory of the electrolytic double layer," Z. Electrochem., Vol.30, p.508.

Stumm, W. and Morgan, J.J., 1982, Aquatic Chemistry, 2nd Edition, Wiley \& Sons, New York, 780pp.

Thirsk, H.R. and Harrison, J.A., 1972, A Guide to the Study of Electrode Kinetics, Academic Press, New York, 174pp.

Trahar, W.J., 1981, "A rational interpretation of the role of particle size in flotation," International Journal of Mineral Processing, Vol.8, pp.289-327.

Trahar, W.J., 1984, "The influence of pulp potential in sulphide flotation," in Principle of Mineral Flotation, M.H. Jones and J.T. Woodcock (eds), The Wark Symposium. Australia Inst. Min.Metall., Melbourne, pp.117-135.

Walker, G.W., Walters, C.P. and Richardson, P.E., 1986, "Hydrophobicity effects of sulfur and xanthate on metal and mineral surfaces," International Journal of Mineral Processing, Vol.18, pp.119-137. 
Wang, X.H., 1989, "The chemistry of flotation, activation and depression of ironcontaining sulfide minerals, " Ph.D. Thesis, Lulea University of Technology, Sweden, 540p.

Wang, X., Forssberg, K.S.E. and Bolin, N.J., 1989, "Thermodynamic calculations on iron-containing sulphide mineral flotation systems, I. The stability of ironxanthates," International Journal of Mineral Processing, Vol.27, pp.1-19.

Wang, X. and Forssberg, E., 1990, "EDTA-induced flotation of sulfide minerals," Journal of Colloid and Interface Science, Vol.140, No.1, pp.217-226.

Wang, X.H. and Forssberg, K.S.E., 1991, "Mechanisms of pyrite flotation with xanthates," International Journal of Mineral Processing, Vol.33, pp.275-290.

Wang, X.H., Jiang, C.L., Raichur, A.M., Parekh, B.K., and Leonard, J.W., 1992, "Comparative sudies of surface properties of pyrites from coal and ore sources," In Proceedings of the Third International Symposium on Electrochemistry in Mineral and Metal Processing III, R. Woods and P.E. Richardson (eds.), The Electrochemical Society, Inc., Pennington, N.J., pp.410-432.

Woods, R., 1971, "The oxidation of ethyl xanthate on platinum, gold, copper and galena electrodes," Journal of Physical Chemistry, Vol.75, pp.354-362.

Woods, R., 1976, "Electrochemistry of sulfide flotation," in Flotation-A.M. Gaudin Memorial Volume, M.C. Fuerstenau (ed.) AIME, New York, pp.298-333.

Woods, R., 1988, "Flotation of sulfide minerals," in Reagents in Mineral Technology, P. Somasundaran and B. Moudgil (eds.), Marcel Dekker, New York, pp.39-77.

Yancey, H.F. and Taylor, J.A., 1935, "Froth flotation of coal; sulfur and ash reduction," US Bureau of Mines, Report of Investigations 3263, pp.1-24.

Yoon, R.H., 1981, "Collectorless flotation of chalcopyrite and sphalerite ores by using sodium sulfide," International Journal of Mineral Processing, Vol.8, pp.31-48.

Yoon, R.H., 1991, "Advanced coal cleaning," in Coal Preparation, 5th edition, J.W. Leonard (ed.), SME, Littleton, Colorado, pp.966-1005.

Zimmerman, R.E., 1948, "Flotation of bituminous coal," Transactions, AIME, Vol.177, pp.338-356. 
APPENDIX 
Table A Stability constants, components and species in $\mathrm{Fe}-\mathrm{EX}-\mathrm{H}_{2} \mathrm{O}$ system

\begin{tabular}{|c|c|c|c|c|c|}
\hline \multirow[b]{2}{*}{ Components } & \multicolumn{2}{|l|}{$\log K f$} & \multicolumn{2}{|c|}{ Matrix } & \\
\hline & & & & & \\
\hline $\mathrm{H}^{+}$ & 0.00 & 1 & 0 & 0 & 0 \\
\hline$E^{-}$ & 0.00 & 0 & 1 & 0 & 0 \\
\hline $\mathrm{Fe}^{2+}$ & 0.00 & 0 & 0 & 1 & 0 \\
\hline $\mathrm{EX}$ & 0.00 & 0 & 0 & 0 & 1 \\
\hline Aqueous speci & & & & & \\
\hline HEX & 1.65 & 1 & 0 & 0 & 1 \\
\hline$(\mathrm{EX})_{2}(\mathrm{aq})$ & -2.57 & 0 & -2 & 0 & 2 \\
\hline $\mathrm{Fe}^{3+}$ & -13.00 & 0 & -1 & 0 & 0 \\
\hline $\mathrm{FeOH}^{2+}$ & -15.19 & -1 & -1 & 1 & 0 \\
\hline $\mathrm{Fe}(\mathrm{OH})_{2}^{+}$ & -18.67 & -2 & -1 & 1 & 0 \\
\hline $\mathrm{Fe}(\mathrm{OH})_{3}(\mathrm{aq})$ & -25.58 & -3 & -1 & 1 & 0 \\
\hline $\mathrm{Fe}(\mathrm{OH})_{4}$ & -34.60 & -4 & -1 & 1 & 0 \\
\hline $\mathrm{FeOH}^{+}$ & -9.50 & -1 & 0 & 1 & 0 \\
\hline $\mathrm{Fe}(\mathrm{OH})_{2}(\mathrm{aq})$ & -20.60 & -2 & 0 & 1 & 0 \\
\hline $\mathrm{Fe}(\mathrm{OH})_{3}^{-}$ & -32.00 & -3 & 0 & 1 & 0 \\
\hline $\mathrm{Fe}_{2}(\mathrm{OH})_{2}{ }^{4+}$ & -28.15 & 2 & -2 & 2 & 0 \\
\hline $\begin{array}{l}\mathrm{Fe}_{3}(\mathrm{OH})_{4}{ }^{5+} \\
\text { Solid species }\end{array}$ & -45.13 & -4 & -3 & 3 & 0 \\
\hline $\mathrm{Fe}(\mathrm{OH})_{3}(\mathrm{~s})$ & -19.00 & -3 & -1 & 1 & 0 \\
\hline $\mathrm{Fe}(\mathrm{OH})_{2}(\mathrm{~s})$ & -12.90 & -2 & 0 & 1 & 0 \\
\hline $\mathrm{Fe}(\mathrm{EX})_{3}(\mathrm{~s})$ & 11.80 & 0 & -1 & 1 & 3 \\
\hline $\mathrm{Fe}(\mathrm{EX})_{2}(\mathrm{~s})$ & 7.11 & 0 & 0 & 1 & 2 \\
\hline$(\mathrm{EX})_{2}(\mathrm{l})$ & 2.37 & 0 & -2 & 0 & 2 \\
\hline $\mathrm{Fe}(\mathrm{OH}) \mathrm{EX}(\mathrm{s})$ & -2.50 & -1 & 0 & 1 & 1 \\
\hline $\mathrm{FeOH}(\mathrm{EX})_{2}(\mathrm{~s})$ & 3.50 & -1 & -1 & 1 & 2 \\
\hline $\mathrm{Fe}(\mathrm{OH})_{2} \mathrm{EX}$ (s) & -5.80 & -2 & -1 & 1 & 1 \\
\hline
\end{tabular}

Note: EX: Ethyl Xanthate; E: Electron.

[See Forssberg et al (1984) for definition and calculation of Kf] 
Table B Stability constants, components and species in $\mathrm{Fe}(\mathrm{III})-\mathrm{H}_{2} \mathrm{O}$ system

\begin{tabular}{lccc}
\hline & $\operatorname{logKf}$ & \multicolumn{2}{c}{ Matrix } \\
Components & & 1 & 0 \\
$\mathrm{H}^{+}$ & 0.00 & 0 & 1 \\
$\mathrm{Fe}^{3+}$ & 0.00 & & \\
$\quad$ Aqueous species & & -1 & 1 \\
$\mathrm{FeOH}{ }^{+}$ & -2.19 & -2 & 1 \\
$\mathrm{Fe}(\mathrm{OH})_{2}{ }^{+}$ & -5.67 & -4 & 1 \\
$\mathrm{Fe}(\mathrm{OH})_{4}{ }^{+}$ & -21.60 & -2 & 2 \\
$\mathrm{Fe}(\mathrm{OH})_{2}{ }^{4+}$ & -2.15 & -3 & 1 \\
$\mathrm{Fe}(\mathrm{OH})_{3}(\mathrm{aq})$ & -19.60 & & \\
$\mathrm{Solid} \mathrm{species}$ & & -3 & 1 \\
$\mathrm{Fe}(\mathrm{OH})_{3}$ (s) & -4.00 &
\end{tabular}

Table C Stability constants, components and species in Pyrophosphate- $\mathrm{H}_{2} \mathrm{O}$ system

\begin{tabular}{lccc}
\hline & $\operatorname{logKf}$ & \multicolumn{2}{c}{ Matrix } \\
$\quad \mathrm{H}^{+}$ & & & \\
$\mathrm{P}_{2} \mathrm{O}_{7}{ }^{4}$ & 0.00 & 0 & 0 \\
Aqueous species & 0.00 & & 1 \\
$\mathrm{HP}_{2} \mathrm{O}_{7}{ }^{3-}$ & 9.40 & 1 & \\
$\mathrm{H}_{2} \mathrm{P}_{2} \mathrm{O}_{7}{ }^{-2}$ & 16.10 & 2 & 1 \\
$\mathrm{H}_{3} \mathrm{P}_{2} \mathrm{O}_{7}^{-}$ & 18.31 & 3 & 1 \\
$\mathrm{H}_{4} \mathrm{P}_{2} \mathrm{O}_{7}$ & 19.13 & 4 & 1 \\
\hline
\end{tabular}


Table D Stability constants, components and species in Phosphate- $\mathrm{H}_{2} \mathrm{O}$ system

\begin{tabular}{lccc}
\hline & $\operatorname{logKf}$ & \multicolumn{2}{c}{ Matrix } \\
\multicolumn{1}{c}{ Components } & & 1 & 0 \\
$\mathrm{H}^{+}$ & 0.00 & 0 & 1 \\
$\mathrm{PO}_{4}{ }^{3 .}$ & 0.00 & & \\
Aqueous species $_{\mathrm{HPO}_{4}{ }^{2}}$ & & 1 & 1 \\
$\mathrm{H}_{2} \mathrm{PO}_{4}{ }^{-}$ & 12.35 & 2 & 1 \\
$\mathrm{H}_{3} \mathrm{PO}_{4}$ & 19.54 & 3 & 1 \\
\hline
\end{tabular}

Table E Stability constants, components and species in Fe(III)-phosphate- $\mathrm{H}_{2} \mathrm{O}$ system

\begin{tabular}{|c|c|c|c|c|}
\hline & $\log K f$ & \multicolumn{3}{|c|}{ Matrix } \\
\hline \multicolumn{5}{|l|}{ Components } \\
\hline $\mathrm{H}^{+}$ & 0.00 & 1 & 0 & 0 \\
\hline $\mathrm{Fe}^{3+}$ & 0.00 & 0 & 1 & 0 \\
\hline $\mathrm{PO}_{4}{ }^{3 \cdot}$ & 0.00 & 0 & 0 & 1 \\
\hline \multicolumn{5}{|c|}{ Aqueous species } \\
\hline $\mathrm{FeOH}^{2+}$ & -2.19 & -1 & 1 & 0 \\
\hline $\mathrm{Fe}(\mathrm{OH})_{2}^{+}$ & -5.67 & -2 & 1 & 0 \\
\hline $\mathrm{Fe}(\mathrm{OH})_{4}$ & -21.60 & -4 & 1 & 0 \\
\hline $\mathrm{Fe}_{2}(\mathrm{OH})_{2}{ }^{4+}$ & -2.15 & -2 & 2 & 0 \\
\hline $\mathrm{Fe}(\mathrm{OH})_{3}(\mathrm{aq})$ & -19.60 & -3 & 1 & 0 \\
\hline $\mathrm{HPO}_{4}{ }^{2-}$ & 12.35 & 1 & 0 & 1 \\
\hline $\mathrm{H}_{2} \mathrm{PO}_{4}$ & 19.54 & 2 & 0 & 1 \\
\hline $\mathrm{H}_{3} \mathrm{PO}_{4}$ & 21.69 & 3 & 0 & 1 \\
\hline $\mathrm{FeHPO}_{4}^{+}$ & 20.65 & 1 & 1 & 1 \\
\hline $\mathrm{FeH}_{2} \mathrm{PO}_{4}{ }^{2+}$ & 23.03 & 2 & 1 & 1 \\
\hline \multicolumn{5}{|l|}{ Solid species } \\
\hline $\mathrm{Fe}(\mathrm{OH})_{3}(\mathrm{~s})$ & -4.00 & -3 & 1 & 0 \\
\hline $\mathrm{FePO}_{1}(\mathrm{~s})$ & 21.89 & 0 & 1 & 1 \\
\hline
\end{tabular}


Table F Stability constants, components and species in $\mathrm{Fe}(\mathrm{III})$-pyrophosphate- $\mathrm{H}_{2} \mathrm{O}$

\begin{tabular}{|c|c|c|c|c|}
\hline \multirow[b]{2}{*}{ Components } & \multicolumn{2}{|l|}{$\log K f$} & \multicolumn{2}{|c|}{ Matrix } \\
\hline & & & & \\
\hline $\mathrm{H}^{+}$ & 0.00 & 1 & 0 & 0 \\
\hline $\mathrm{Fe}^{3+}$ & 0.00 & 0 & 1 & 0 \\
\hline $\begin{array}{l}\mathrm{P}_{2} \mathrm{O}_{7}{ }^{4-} \\
\text { Aqueous spec }\end{array}$ & 0.00 & 0 & 0 & 1 \\
\hline $\mathrm{FeOH}^{2+}$ & -2.19 & -1 & 1 & 0 \\
\hline $\mathrm{Fe}(\mathrm{OH})_{2}{ }^{+}$ & -5.67 & -2 & 1 & 0 \\
\hline $\mathrm{Fe}(\mathrm{OH})_{4}$ & -21.60 & -4 & 1 & 0 \\
\hline $\mathrm{Fe}_{2}(\mathrm{OH})_{2}{ }^{4+}$ & -2.15 & -2 & 2 & 0 \\
\hline $\mathrm{Fe}(\mathrm{OH})_{3}(\mathrm{aq})$ & -19.60 & -3 & 1 & 0 \\
\hline $\mathrm{HP}_{2} \mathrm{O}_{7}{ }^{3-}$ & 9.40 & 1 & 0 & 1 \\
\hline $\mathrm{H}_{2} \mathrm{P}_{2} \mathrm{O}_{7}^{2-}$ & 16.10 & 2 & 0 & 1 \\
\hline $\mathrm{H}_{3} \mathrm{P}_{2} \mathrm{O}_{7}^{-}$ & 18.31 & 3 & 0 & 1 \\
\hline $\mathrm{H}_{4} \mathrm{P}_{2} \mathrm{O}_{7}$ & 19.13 & 4 & 0 & 1 \\
\hline $\mathrm{Fe}\left(\mathrm{P}_{2} \mathrm{O}_{7}\right)_{2}{ }^{5-}$ & 5.50 & 0 & 1 & 2 \\
\hline $\mathrm{Fe}\left(\mathrm{HP}_{2} \mathrm{O}_{7}\right)_{2}{ }^{3 \cdot}$ & 40.99 & 2 & 1 & 2 \\
\hline $\mathrm{Fe}(\mathrm{OH})_{2} \mathrm{P}_{2} \mathrm{O}_{7}{ }^{2-}$ & 3.00 & -2 & 1 & 0 \\
\hline $\mathrm{FeH}_{2} \mathrm{P}_{2} \mathrm{O}_{7}^{+}$ & 23.07 & 2 & 1 & 1 \\
\hline $\mathrm{FeH}_{3} \mathrm{P}_{2} \mathrm{O}_{7}{ }^{2+}$ & 24.74 & 3 & 1 & 1 \\
\hline $\begin{array}{l}\mathrm{Fe}_{2} \mathrm{P}_{2} \mathrm{O}_{7}{ }^{2+} \\
\text { Solid species }\end{array}$ & 23.50 & 0 & 2 & 1 \\
\hline $\mathrm{Fe}(\mathrm{OH})_{3}(\mathrm{~s})$ & -4.00 & -3 & 1 & 0 \\
\hline $\mathrm{Fe}_{4}\left(\mathrm{P}_{2} \mathrm{O}_{2}\right)_{3}(\mathrm{~s})$ & 22.55 & 0 & 4 & 3 \\
\hline
\end{tabular}




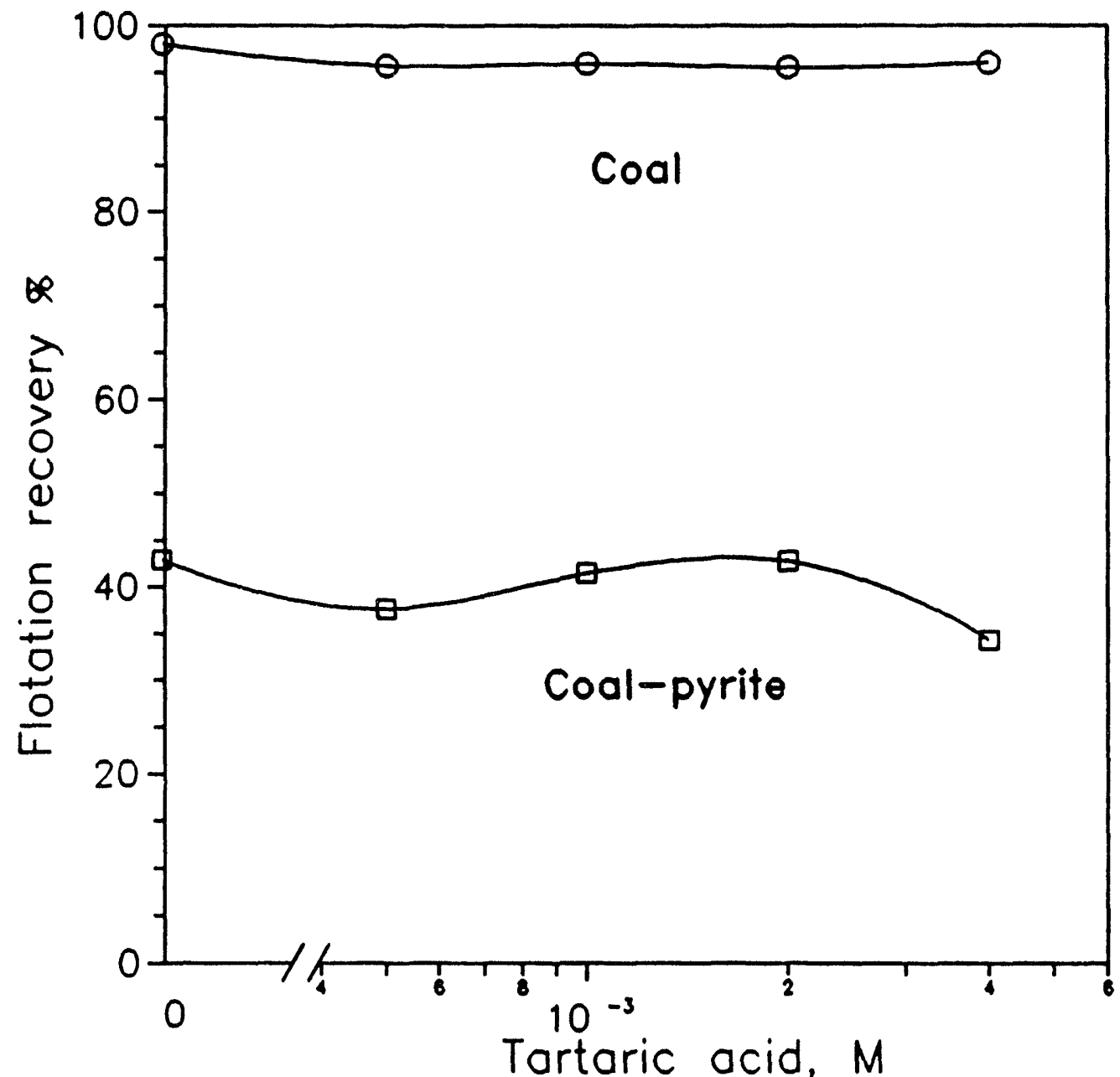

Figure A-1 Effect of tartaric acid on the flotation separation of coal and coal-pyrite in the presence of fuel oil. 


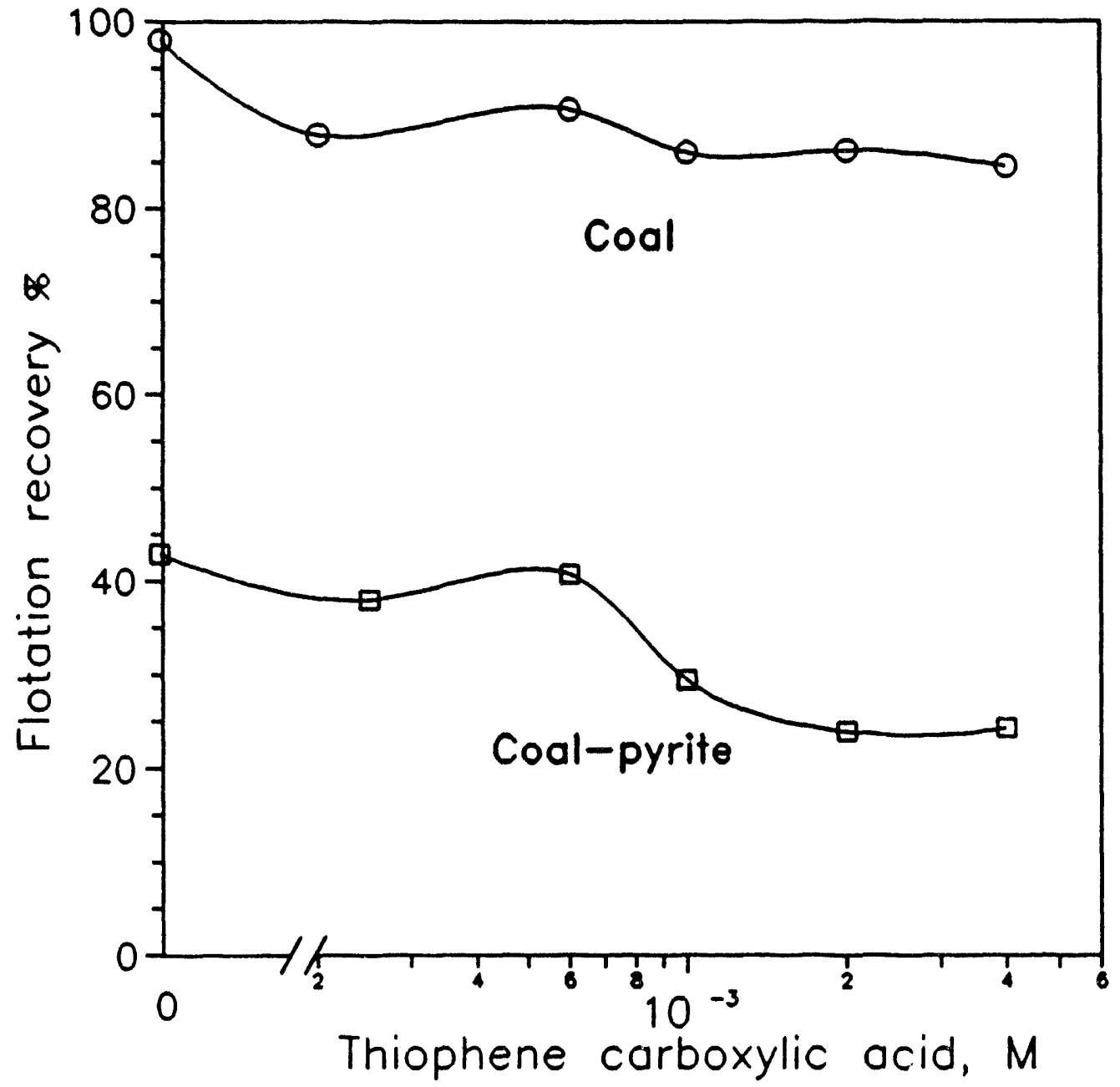

Figure A-2 Effect of thiophene carboxylic acid on the flotation separation of coal and coal-pyrite in the presence of fuel oil. 


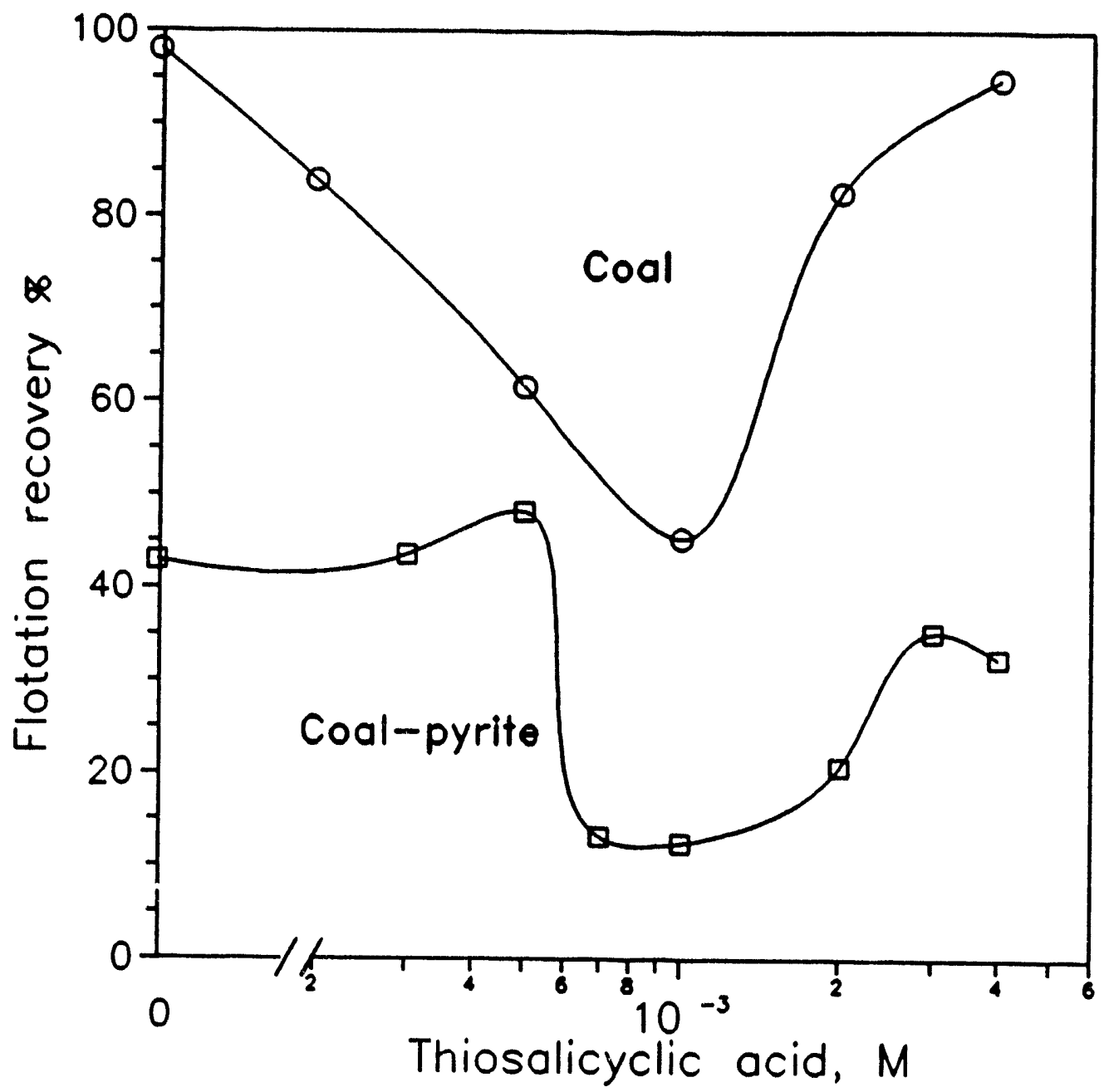

Figure A-3 Effect of thiosalicyclic acid on the flotation separation of coal and coal-pyrite in the presence of fuel oil. 


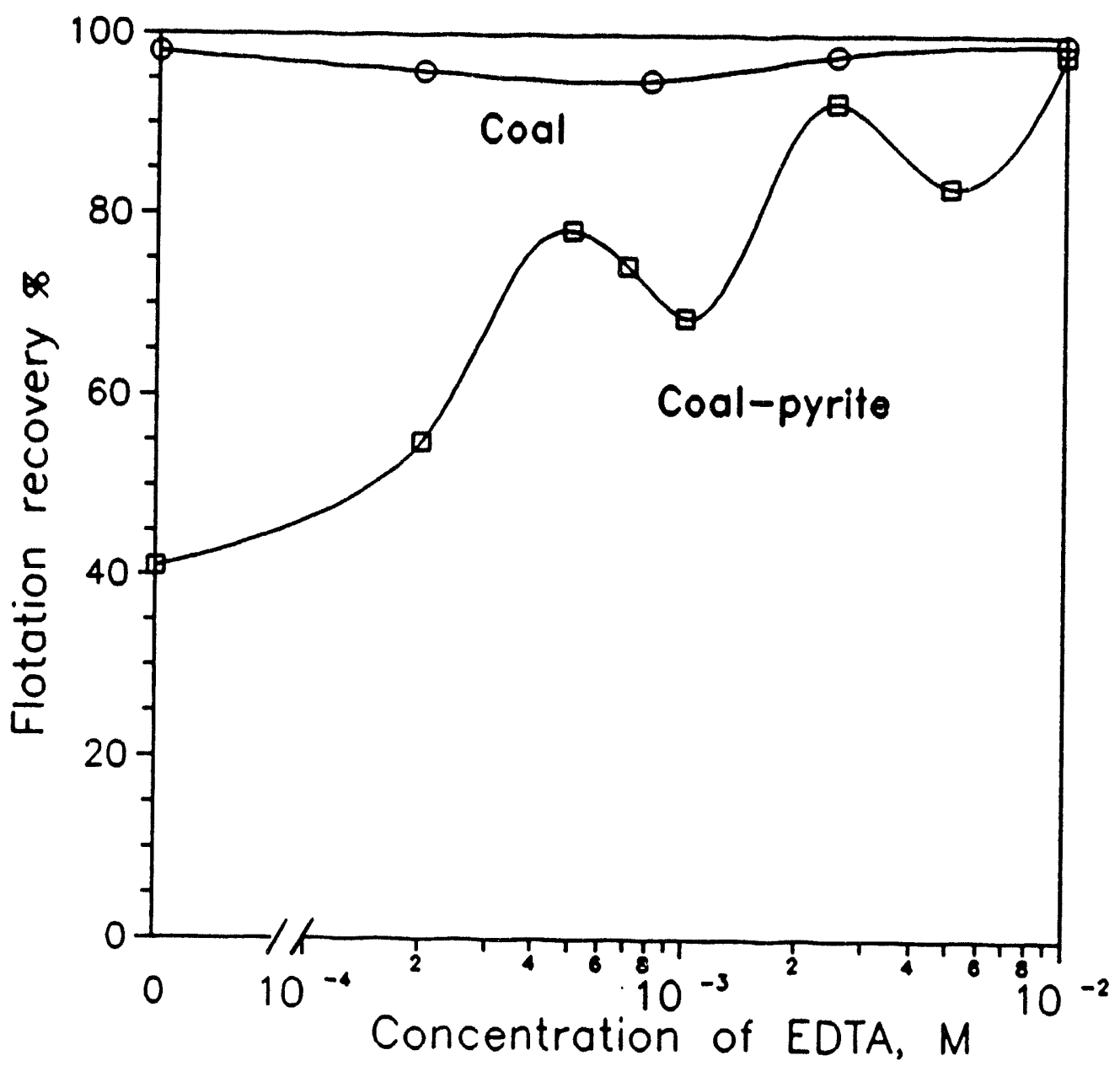

Figure A-4 Effect of EDTA on the flotation separation of coal and coal-pyrite in the presence of fuel oil. 


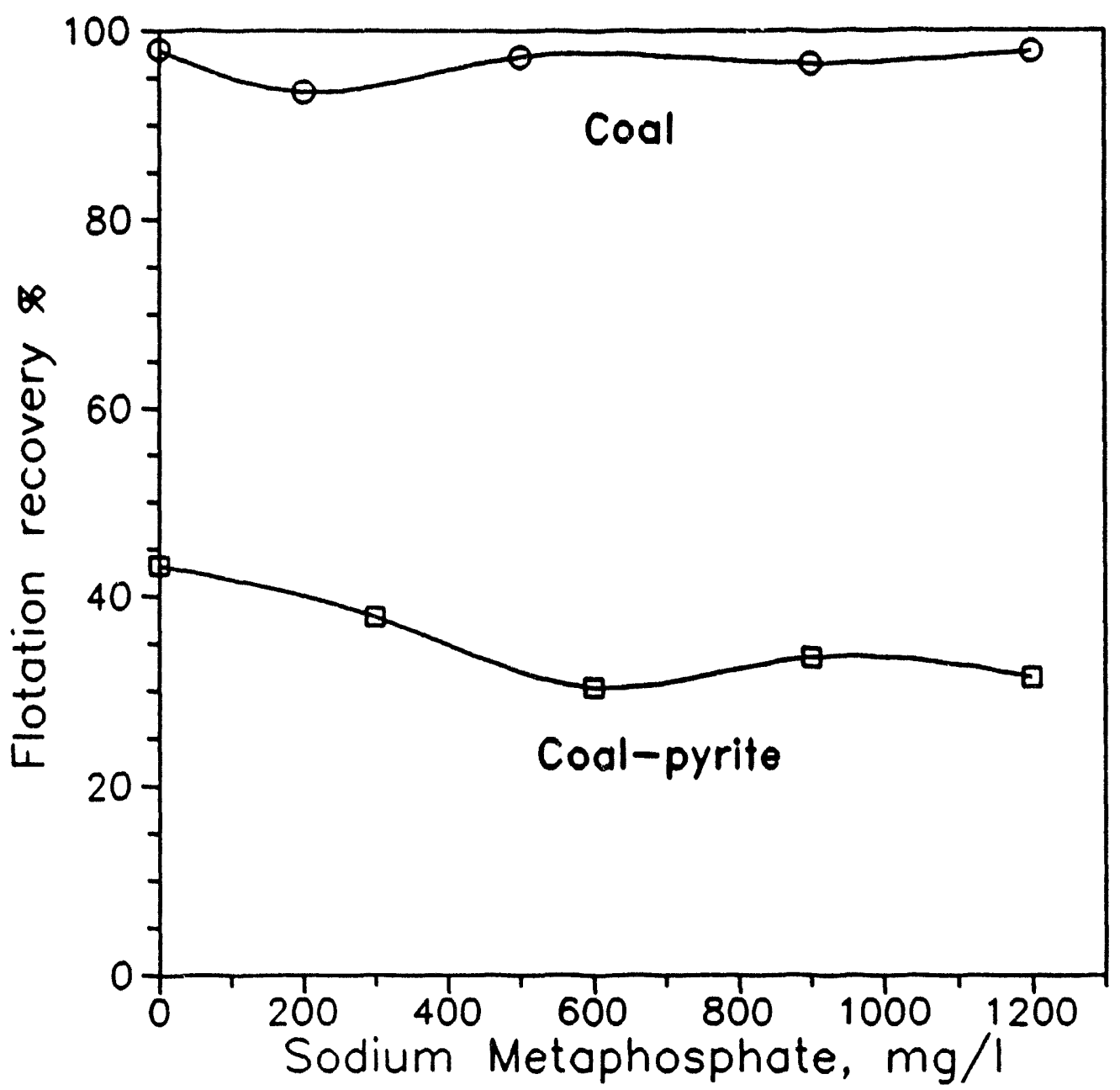

Figure A-5 Effect of sodium metaphosphate on the flotation separation of coal and coal-pyrite in the presence of fuel oil. 

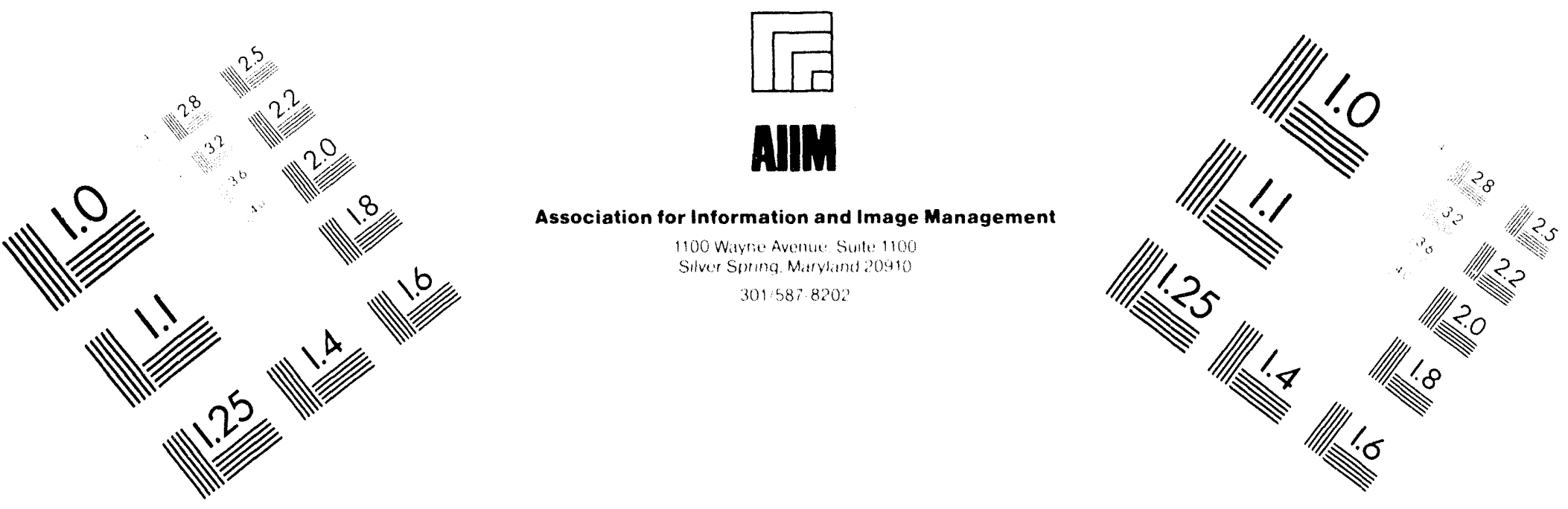

\section{Centimeter}

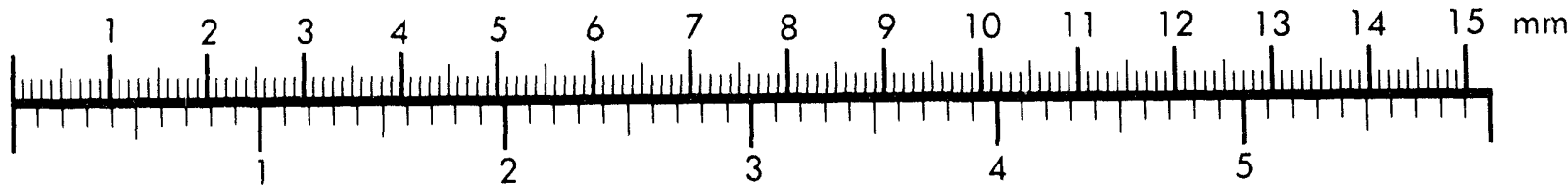

Inches
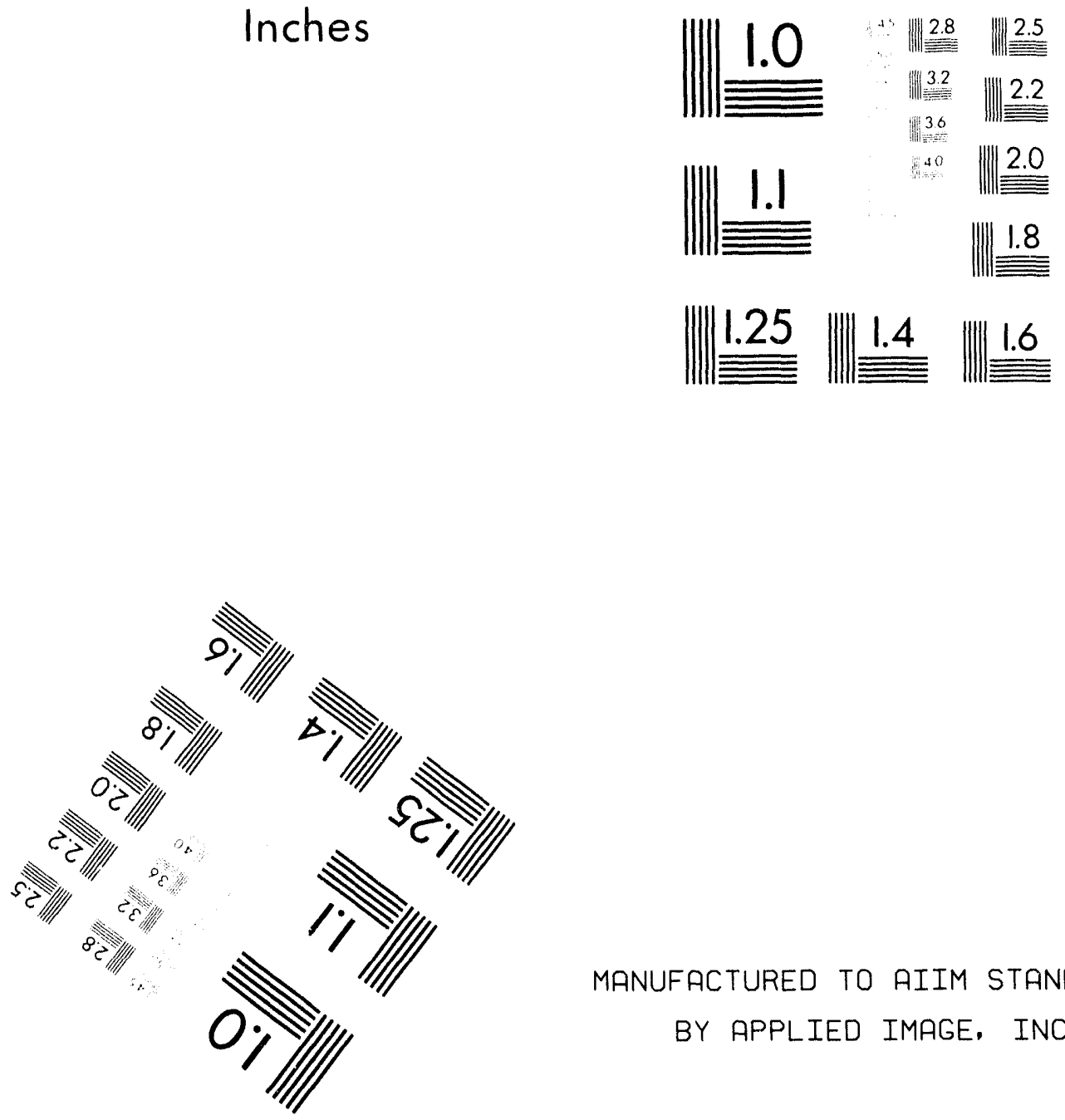

MANUFACTURED TO AIIM STANDARDS

BY APPLIED IMAGE. INC.

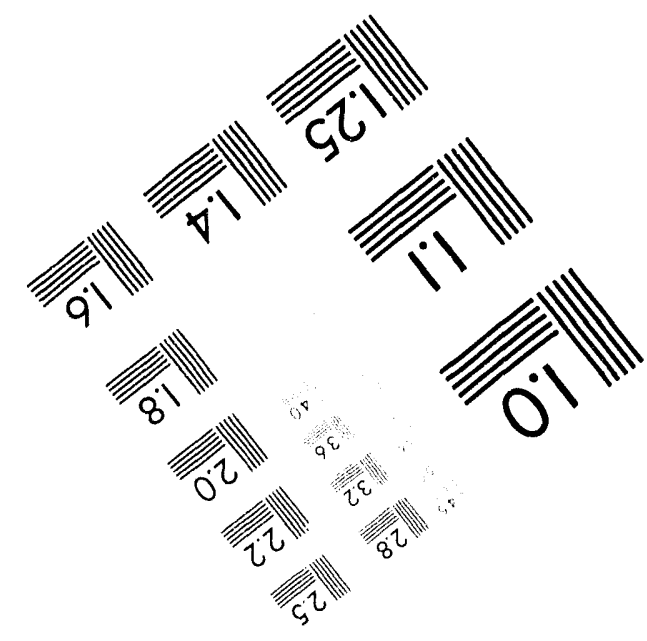



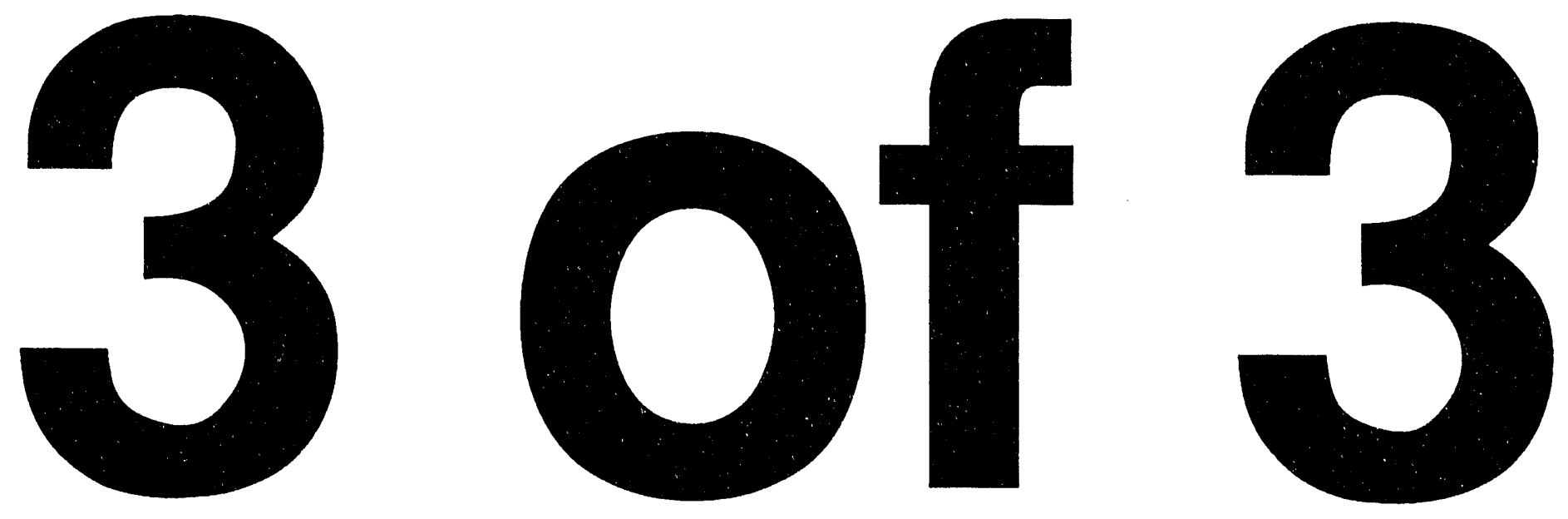


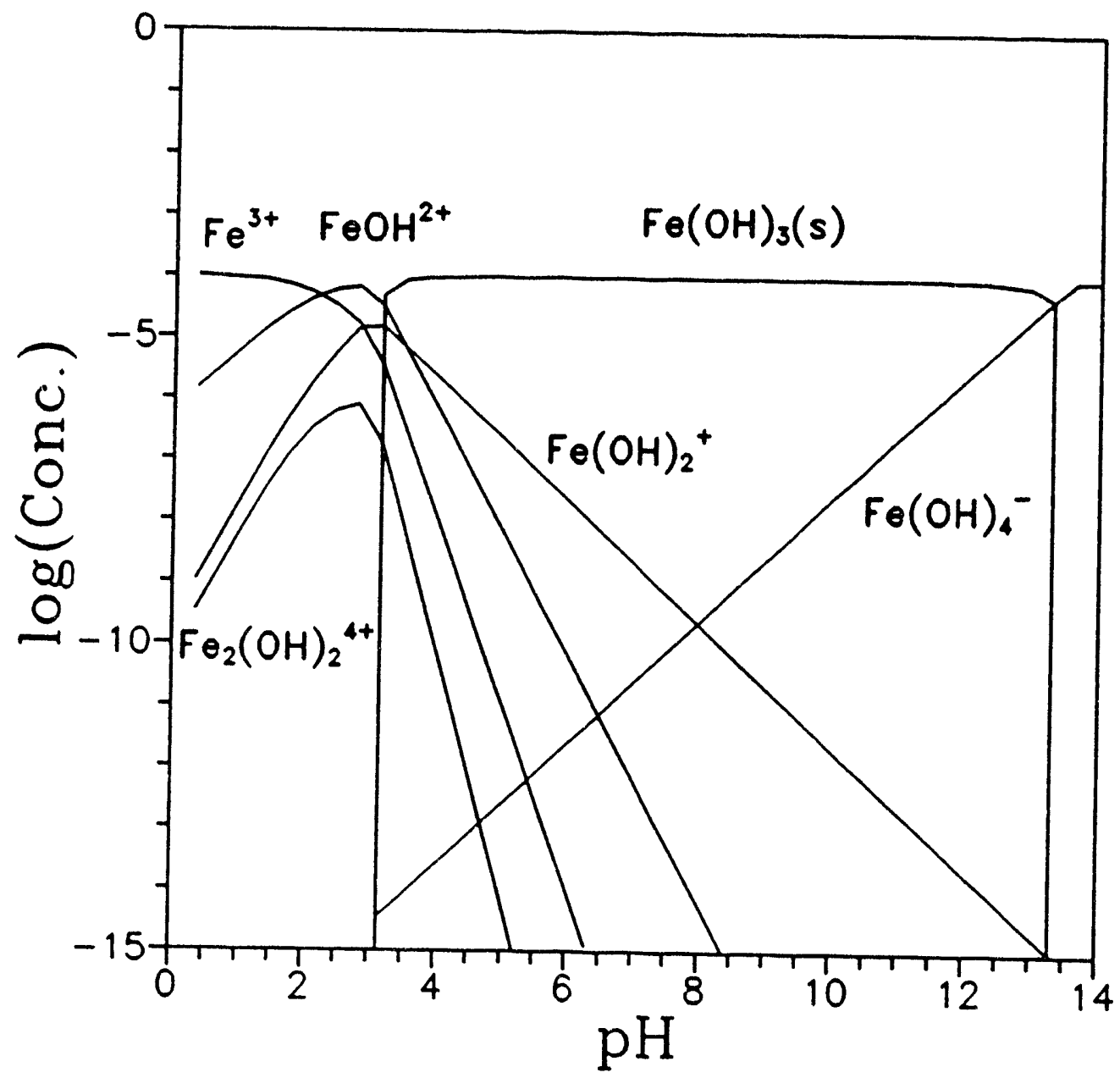

Figure A-6 $\log$ (Concentration)-pH distribution diagram of the $\mathrm{Fe}(\mathrm{III})$-water system at total concentration of $1 \times 10^{-4} \mathrm{M} \mathrm{Fe}$ (III). 


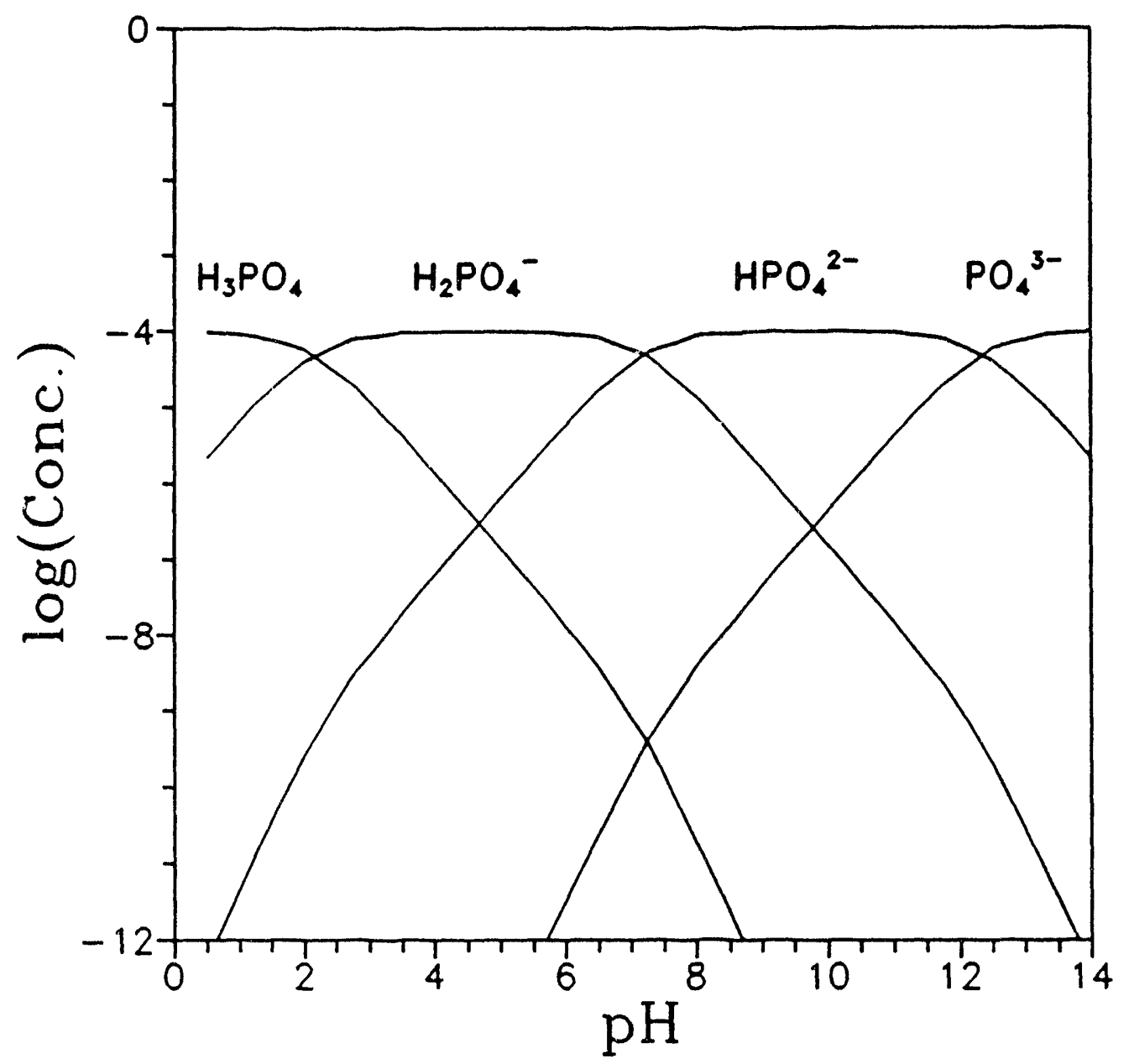

Figure A-7 $\log ($ Concentration)-pH distribution diagram for the phosphatewater system at total phosphate concentration of $1 \times 10^{-4} \mathrm{M}$. 


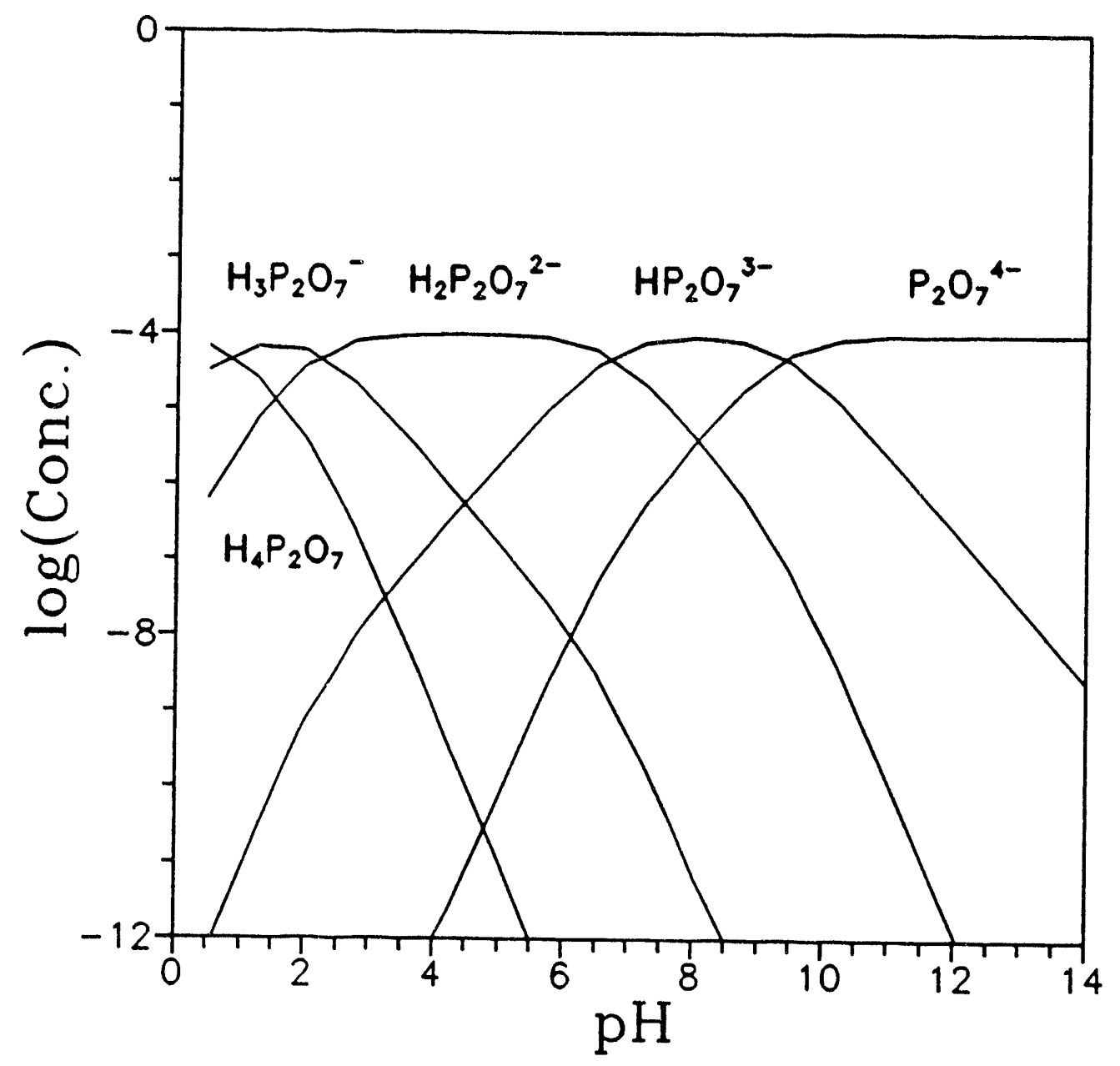

Figure A-8 Log(Concentration)-pH distribution diagram for the pyrophosphate-water system at total phosphate concentration of $1 \times 10^{-4} \mathrm{M}$. 


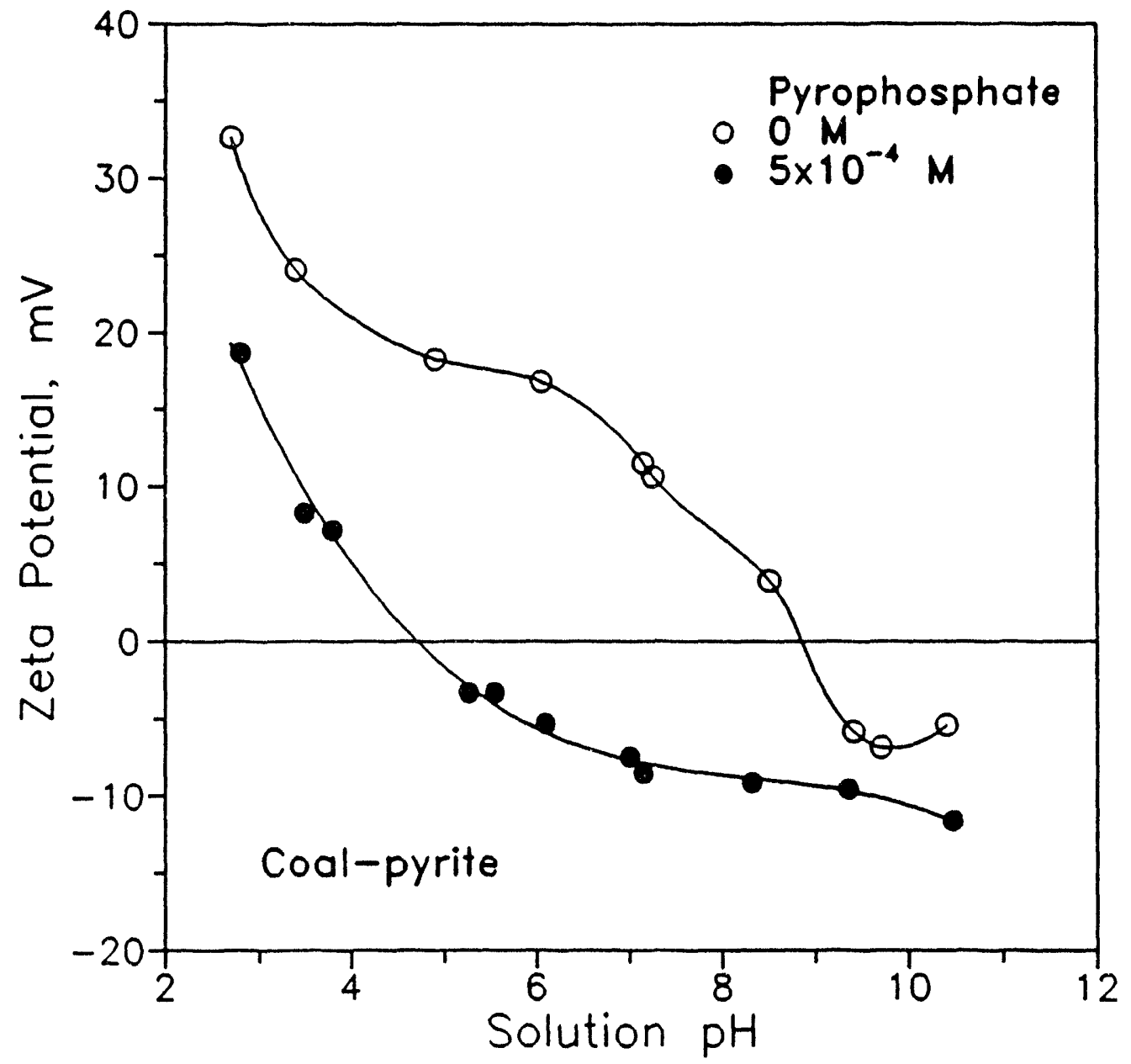

Figure A-9 The zeta potential of coal-pyrite in the absence and presence of pyrophosphate. 


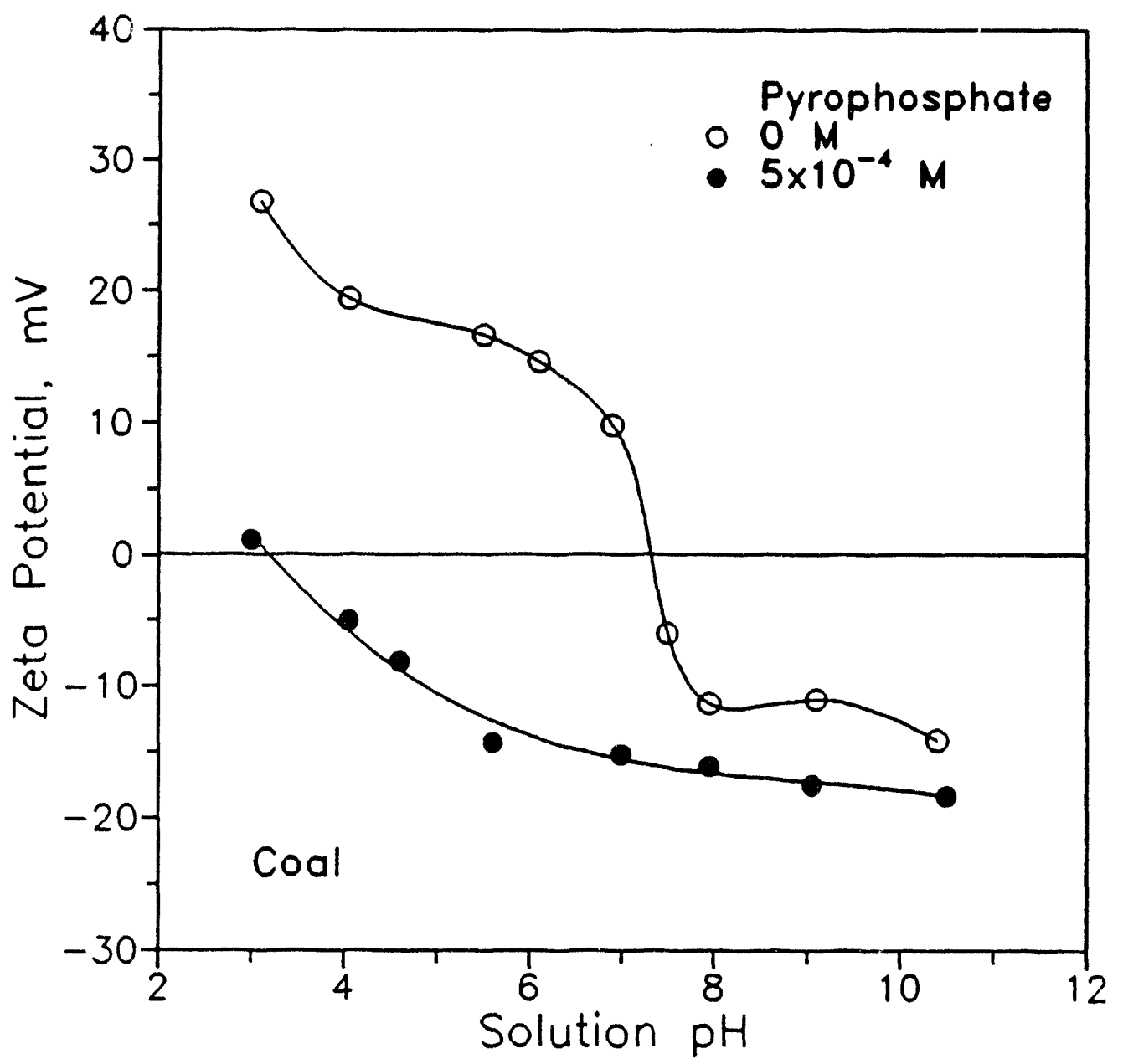

Figure A-10 The zeta potential of coal in the absence and presence of pyrophosphate. 


\section{ARTICLES/PRESENTATIONS}

1. Jiang, C.L., Wang, X.H., Parekh, B.K. and Leonard, J.W., "On the native and induced floatability of coal and pyrite," To be presented at 5th International Conference on High Sulfur Coals, Lexington. October 24-27, 1993. Full paper to be published in Proceedings of the Conference on Processing and Utilization of HighSulfur Coals V.

2. Wang, X.H., Jiang, C.L., Raichur, A.M., Parekh, B.K. and Leonard, J.W., 1992, "Comparative studies of surface properties of pyrites from coal and ore sources," In Proceedings of the Third International Symposium on Electrochemistry in Mineral and Metal Processing, R. Woods and P.E. Richardson (eds), The Electrochemical Society, Inc., Pennington, NJ, pp.410-432.

3. Wang, X.H., Jiang, C.L., Xuan, D. and Forssberg, E., 1992, "An electrochemical study of selective separation of $\mathrm{Cu}(\mathrm{II})$-activated pyrite and arsenopyrite," In Proceedings of the Third International Symposium on Electrochemistry in Mineral and Metal Processing, R. Woods and P.E. Richardson (eds), The Electrochemical Society, Inc., Pennington, NJ, pp.235-258.

4. Wang, X.H., Raichur, A.M., Jiang, C.L., Parekh, B.K. and Leonard, J.W., "Characterization of surface hydrophobicity of pyrites from coal and ore sources," Presented at the 1992 AIME/SME Annual Meeting, Phoenix, Arizona, Feb., 1992. 


\section{VITA}

Jiang, Chengliang was born on March 5, 1963 in Shandong Province, China. $\mathrm{He}$ obtained his Bachelor of Engineering degree in Minerals Processing from Xi'an Institute of Metallurgy and Architecture, Xi' an, China in July 1982 and was employed as a Mineral Processing Assistant Engineer at the Design and Research Institute for Chemical Mines in Lianyungang, Jiangsu Province, China. The following year, he enrolled in the Graduate Program at the Beijing Institute of Mining and Metallurgy, Beijing, China and received his Master of Engineering degree in Minerals Processing in 1986. He then began worked as a Mineral Processing Engineer in the same institute until July 1989. In August 1991, he joined the University of Kentucky to pursue his Master of Science degree in Mining Engineering. 

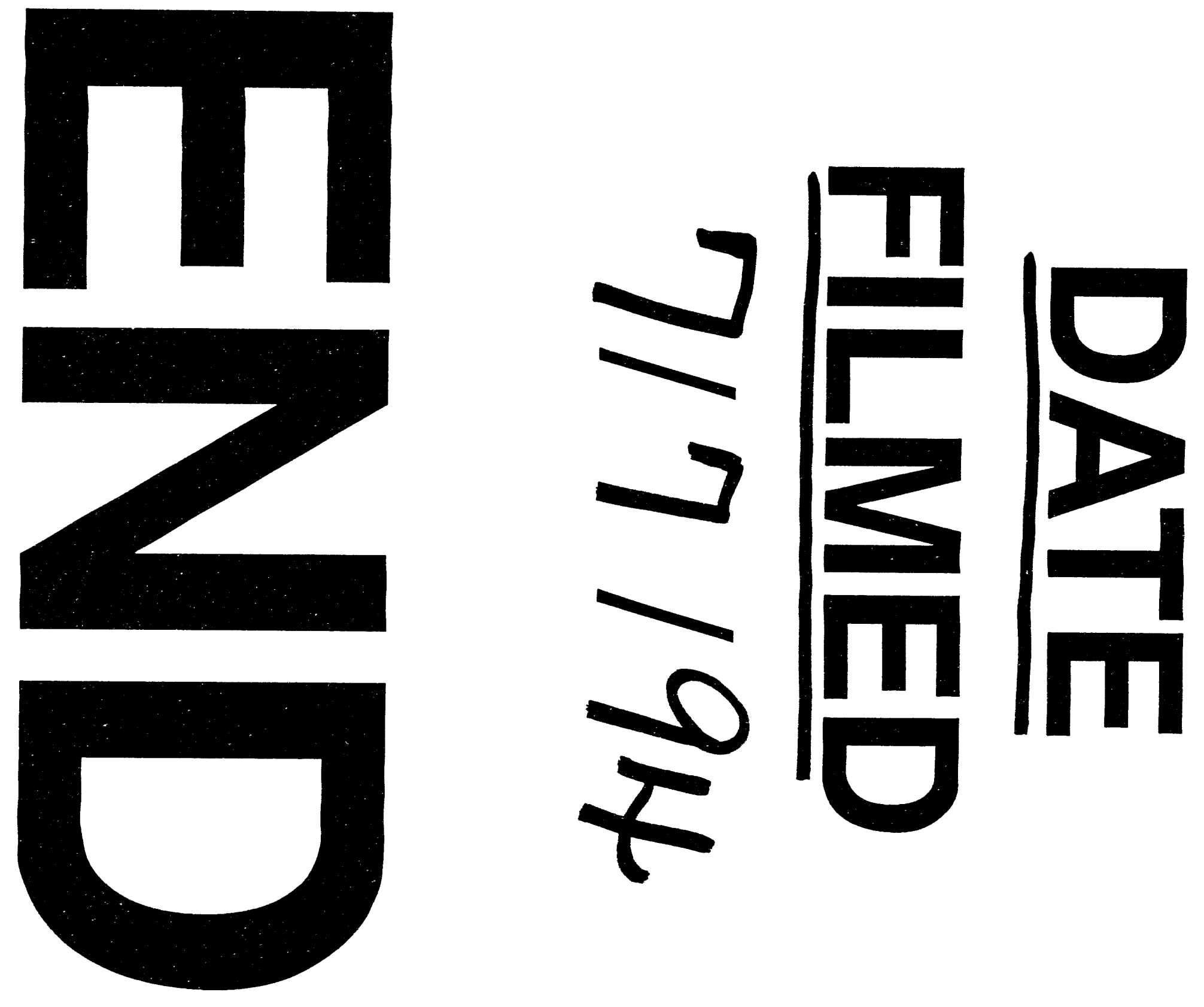


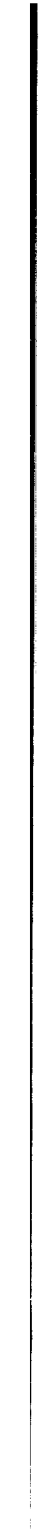

\begin{abstract}
.
\end{abstract}

